\title{
Humanity's Gone Viral
}

By

\author{
Claire Margaret Fitzpatrick
}

\begin{abstract}
A thesis
Submitted to Te Herenga Waka-Victoria University of Wellington

In fulfilment of the requirements of the degree of

Doctor of Philosophy
\end{abstract}

Te Herenga Waka - Victoria University of Wellington

2021

Doctoral Supervisors:

Dr Kate Schick

Dr Michael Daubs 


\section{Abstract}

This dissertation explores the role that hashtags play in maintaining political, social, and technological inequalities in modern society. It argues that the use of what I call 'collectivising hashtags', i.e., hashtags characterised by their use of pronouns to inclusively identify with Others, affords new opportunities for self-expression that may simultaneously empower and compromise certain individuals. It is written in response to experiences of racism shared via the \#TheyAreUs and \#ThisIsNotUs collectivising hashtags that trended following the terror attack on Muslim communities in Ōtautahi, Christchurch in March 2019, and questions commonly held assumptions by privileged users about the non-discriminatory nature of Aotearoa New Zealand politics and society. Using \#TheyAreUs and \#ThisIsNotUs as my first case study, I demonstrate how collectivising hashtags involve forms of appropriation on the part of privileged users, reinforcing unequal social hierarchies and silencing marginalised bodies. I consider the New Zealand Human Rights Commission's \#ThatsUs campaign in my second case study, assessing the vernacular affordances of social media that enable or restrict affected and affecting bodies' ability to respond to social and technological inequalities. I also explore the clever and imaginative ways that digital counterpublics subvert online interactions through strategic use of digital architecture, labour, visibility, and invisibility when addressing hashtags and social media platforms as racialised performances of self.

Users' everyday online encounters with collectivising hashtags present an opportunity to challenge dominant conceptions of self. Following the critical feminist traditions of Judith Butler, Erinn Gilson, and Kate Schick, my analysis incorporates an ethic of vulnerability in order to interrogate underlying power relations and people's location within them. My dissertation illustrates how hashtags are technologically created and structured in a way that affords certain bodies more political potential than others. I show that everyday performances of self via collectivising hashtag practices have the political potential to formatively shift who qualifies as 'human.'

To assess the affordances of collectivising hashtags, I used a multimodal analytic technique developed by André Brock called Critical Technocultural Discourse Analysis. I also conducted in-depth interviews with hashtag users and analysed the soft structures of digital networks, social media platforms and processes, and hashtag functionalities and their affects. Drawing on Melissa Harris-Perry's concept of the Crooked Room, I assert that collectivising hashtags operate within a 'crooked platform' which problematises the recognition of marginalised bodies. This analysis encourages users to think critically about the affecting nature of their online practices and privileges, or risk becoming complicit in the wider relations of power in which discrimination, oppression, and violence fester. As privileged users develop new practices of digital reconstitution in which an embodied online praxis is conceived in affective terms, I argue that they can instead embrace their own vulnerability, alterity, and precariousness, and move towards a fuller conception of what it means to be human. 


\section{Acknowledgements}

This dissertation could not have been completed without the love and support of the people in my life who helped me on my journey.

A special thank you to my supervisors, Dr Kate Schick and Dr Michael Daubs, whose insightful feedback and words of encouragement never failed to keep me going when inspiration flagged or the words just wouldn't come. Kate, I would never have begun my PhD had it not been for the honours paper you taught back in 2013. It was the first time I felt a personal connection with the International Relations discipline, and your curiosity and gentle persistence gave me an entirely new appreciation of what I could contribute to the field. I said back then that one day I would like to return to do my PhD, and here I am eight years later with you as my supervisor - a turn of events that I couldn't be happier with. At the outset of my research, I remember Kate saying, "we are going to need someone to help us out with the technical side of things," and so I went in search of a second supervisor with a background in Media Studies, asking Michael to join the team. Michael, I don't think we would ever have managed without the practical knowledge and experience you brought to the table; you grounded my thinking and helped shape my somewhat 'fluffy' ideas, challenging me to craft my words and get to the heart of what I was trying to say. I have learned so much from you and my research would not be where it is now without your input. I could not have asked for two better mentors. Thank you both for all the hours you put into reading my work, the many long philosophical conversations at VicBooks, your thoughtful feedback, and your gentle encouragement. In the difficult moments when I doubted my own capability - I trusted in your judgement.

I am also unreservedly grateful to the authors, artists, and activists whose ideas and contributions helped inspire this dissertation. In particular, to my interviewees, for their generosity in sharing their deeply personal stories and for the stimulating conversations, imagination, and accountability they brought to this work. To the New Zealand Human Rights Commission and the New Zealand United Nations Educational Trust institutions, that could not have been more accommodating and encouraging of my research. For the financial support I received from the Peace and Disarmament Educational Trust Scholarship, without which I would not have been able to complete this work. To the faculty of History, Philosophy, Political Science, and International Relations at Victoria University of Wellington, for providing me with work and income and the ability to travel for my research over the years. Your practical support made all of this possible.

Finally, a person does not complete a dissertation without the love and support of friends and family. When my family immigrated to Aotearoa New Zealand, all we had was each other, and the close bond we share has always helped me get through the difficult times. I want to thank my father, Mark Fitzpatrick, for teaching me quiet determination and patience; your longdistance running metaphors have served me well throughout this process. My sister, Megan Fitzpatrick, for always talking things over with me and reminding me to walk my dogs when things get too stressful. My long-time family friend, Helen Edwards, for having in-depth conversations about grammar over a pot of earl grey tea - I am not sure anyone else would have been willing to do that for me. Most of all, I want to thank my husband, Daniel Kebbell. I can't even begin to express how grateful I am for your love and support over the years, for always listening to me, debating with me, and reassuring me that I am on the right path. To say I couldn't have done this without you seems inadequate. You convinced me that I could do this - and you were right.

I would like to dedicate this work to my late mother Deborah Fitzpatrick.

She never had the opportunity to attend university herself - so ensured her daughters did. 


\section{Table of Contents}

Cover Page

Abstract

Acknowledgements

Introduction

Background

Research Topic

Thesis Outline

Chapter One: The Relevance of Vulnerability in International Relations Theory

1.1 Collectivising Hashtags: A Growing Phenomenon

1.2 Feminist Conceptual Framework

1.3 The Affordances of Collectivising Hashtags

1.4 Combining Feminist, Media Studies and International Relations Theory

Chapter Two: A Synergistic Approach To Research Design

2.1 Research Question

2.2 Methodological Approach

2.3 Collectivising Hashtags

2.4 Case Studies

a) \#TheyAreUs and \#ThisIsNotUs

b) \#ThatsUs

2.5 Method

2.6 Interviews

a) Interviews with Hashtag Users

b) Interviews with Hashtag Campaign Creators

2.7 Analysis

2.8 Limitations and Bias

2.9 Intellectual Property, Ethics, and Feminist Praxis

Chapter Three: Claiming Collectivity

3.1 The Power of Collectivity

3.2 Are They 'Us'? How Collectivising Hashtags Reinforce the Systemic Issues They Ostensibly Oppose

3.3 Is This 'Us'? Interrogating Underlying Power Relations and 'Our' Location Within Them 
3.4 Emancipating 'Us': Vulnerability and the Role of the Discursively Privileged Subject

Chapter Four: The Crooked Platform

4.1 Underlying Technological Inequalities
a) Folksonomy
b) Serendipity
c) Trending Topics

4.2 Capitalist Designs and Desires

4.3 Algorithms and Impulses: The Co-creation of Our Online Environment

4.4 The Crooked Platform
a) Deconstructing the Crooked Platform
b) The Transformative Potential of \#TheyAreUs and \#ThislsUs for the Crooked Platform
c) Collectivising Hashtags as Part of a Broader Conversation

Chapter Five: From Individual To Systemic

5.1 Networked Acts
a) A Collection of Individual Stories Speaks to Systemic Issues
b) Curated Communities

5.2 The Rise and Risks of User Participation
a) Comedy, Tragedy, and Performative Acts of Subversion
b) Playing to Game the System
c) State Regulation and Corporate Responsibility
d) The Limits of Agency and Counterpublic Advocacy

Conclusion

Processes of Digital Constitution and Potential for Future Research

Contribution

Significance 


\section{Introduction}

\section{Background}

What are we talking about when we talk about politics, why are certain spaces marked political, and how do we do politics? As boundaries between our offline and online lives have blurred, how people encounter politics is transforming. To understand the implications of this transformation requires new ways of thinking and analysing politics. Traditional approaches conceptualise how communities arrange themselves within broader political systems by replicating the methods of natural sciences. I have noticed that researchers seem to observe it in macro terms, formulating overarching lenses based primarily on legal, security, economic, and military structures. This epistemological approach has helped scholars better understand the origins of war and has provided frameworks for the maintenance of peace. ${ }^{1}$ It has also produced a rich body of literature examining the balance of powers, state systems, and modern democratic structures. ${ }^{2}$ However, what struck me about this conceptualisation of politics (and likely many other feminist scholars before me) is how far removed it is from my own experience. It is an elite form of politics to which I have no access, held at a distance and set apart for those who do the proper business of politics and International Relations. Politics is presented on a continuum, where certain things are shown to be 'more political' than others. Politics only belongs to certain bodies, in certain places and at particular moments in time. But these are not places that I frequent and they are not the kinds of spaces in which I have most commonly experienced or encountered politics.

Critical feminist theorists suggest people need to think not only big, but also small, and that "we have to do so simultaneously." 3 When I think about the moments in which I most keenly feel politics' edge, I find it is where I have experienced an emotion like humour, laughing at a witty tweet or satirical meme that someone has used to perfectly capture and communicate their feelings on an issue. International Relations becomes most evident to me in times of grief, when I see injustice or suffering and feel agitated by it in spite of the physical distance. These reactions lead me to believe that the political experience is quite ordinary, and that people cannot depart or separate themselves from it even if they want to. Ann Reynolds, Janet Staiger, and Ann Cvetkovich question the affecting relationship between politics and emotion asking:

How do we 'find' capitalism and neo-liberalism, or progressive and queer collectivity? Is it 'in' media, art, landscapes, cityscapes and bodies? Or is it better considered beneath, between, beyond or for only a moment, such as the lowering of a head or the vacant stare... the momentary recognition of possibility? Perhaps we truly encounter the political only when we feel. ${ }^{4}$

\footnotetext{
${ }^{1}$ Hendrik Bliddal, Casper Sylvest, and Peter Wilson, Classics of International Relations Essays in Criticism and Appreciation, (England, Oxfordshire: Routledge, 2013).

2 Bliddal, Sylvest, and Wilson, Classics of International Relations.

3 Cynthia Enloe, "The Mundane Matters," International Political Sociology 5, no.4 (2011): 449, doi: 10.1111/j.1749-

5687.2011.00145_2.x

${ }^{4}$ Ann Reynolds, Janet Staiger, and Ann Cvetkovich, Political Emotions, (London: Routledge, 2010): 4, doi: 10.4324/9780203849538.
} 
Critical feminists encourage us to consider the personal, embodied, and affecting aspects of political experience. However, there are few critical feminist contributions that call for greater attentiveness to lived experiences, feelings of commonality, and the power relations undergirding solidarity. Perhaps the most famous feminist pronouncement was the late 1960's rally cry 'The Personal is Political,' popularised in an essay by Carol Hanisch who argued that womens' personal experiences can be traced to their location within a system of power relationships. ${ }^{5}$ Cynthia Enloe recognised that "power was deeply at work where it was least apparent" and often resides in the mundane aspects of our everyday lives. ${ }^{6}$ Building on feminist traditions, my research asks: where do we find the mundane, the personal, and the assumed in the politics of modern encounter?7 For me, politics is not experienced in isolation; even my conceptualisation of self is realised in relation to others. Politics is encounter.

Encounter is defined as a moment in which people are confronted by another or others; it is based on a reactionary impulse, "a feeling that leaves one's dispositions affected."8 Politics happens in relation to others. Politics is about something that happens in the empty space between us. It is about what we bring into that space together, what I bring, what other people bring, the way that the space is architecturally structured and the affecting nature of that encounter where each of those elements acts upon the other. This is not a particularly new conception given that politics has its roots in the Greek polis - a central public space characterised by the structure of the city walls and those who resided within it. I argue that the spaces of political encounter are changing; modern modes of encounter are no longer constrained to physical spaces and the architecture that keeps certain people in and certain people out is becoming increasingly difficult to see.

To understand the political experience today requires broader epistemological and ontological approaches that embrace indigenous, critical race, and queer perspectives that challenge traditional conceptions of power and dominance. ${ }^{9}$ A broader conception of politics incorporates interdisciplinary research that considers the different aspects that make up the everyday lived experience, including environmental, social, and technological aspects that are often considered devoid of political value. ${ }^{10} \mathrm{~A}$ micropolitical approach recognises social spaces as sites of political significance in terms of meaning making through embodied practices. ${ }^{11}$ Judith Butler quips: "[I]t should come as no surprise that I propose to start, and to end, with the question of the human (as if there were any other way for us to start or end!)"12 It is in the same spirit that I propose a more 'human centric' micropolitical approach to International Relations, one that more accurately reflects the fluid, messy, and interdependent nature of

\footnotetext{
5 Carol Hanisch, “The Personal Is Political," 1970 in Notes From the Second Year: Women's Liberation, eds. Firestone and Koedt (US, New York: Published by Editors): 76-78.

6 Enloe,"The Mundane Matters," 447.

7 Enloe,"The Mundane Matters," 447.

8 Sara Ahmed, The Cultural Politics of Emotion, (Edinburgh: Edinburgh University Press, 2014): 8.

9 I follow Judith Butlers assertion that our political lives are epistemologically and ontologically grounded. On the one hand, this dissertation seeks to draw attention to the epistemological problem raised by the issue of online framing: the frames through which we apprehend or fail to apprehend the lives of others are politically saturated. On the other hand, the problem is ontological, since the 'being' of life is itself is a social reality constituted through selective means and as a result we cannot refer to this 'being' outside of the operation of power. See Judith Butler, Frames of War: When Is Life Grievable, (London: Verso Books, 2009) 1.

10 Enloe,"The Mundane Matters," 447.

11 Ty Solomon and Brent J. Steele, “Micro-moves in International Relations theory," European Journal of International Relations 23 no. 2 (2017): 277, doi: 10.1177/13540661166344442.

12 Judith Butler, Precarious Life: The Powers of Mourning and Violence, (London: Verso, 2006) 20.
} 
modern personal, political, and technological lives. I expand Butler's analysis to online spaces and renderings of self via hashtagging practices as a way of establishing whose lives can be marked as lives. ${ }^{13}$ It is in the lived experience that the political resides, as it is in the lived experience that all things reside.

Research Topic

My research examines how hashtags have changed modern modes of encounter and have the political potential to formatively shift 'who qualifies as human.' The primary question guiding my research is: to what extent do collectivising hashtags, as online renderings of self, act to create and maintain prevailing conceptions of Otherness and problematise recognition of precarious bodies who currently fall outside dominant conceptions of what it means to be human? Hashtags are 'me-now' status messages that emphasise the role of the self by expressing personal perspectives. ${ }^{14}$ However, hashtags can also be personal and collective at the same time and, as such, sustain social forms of networked individualism. ${ }^{15}$ Personally motivated expressions are infused with political potential as they attain public orientation through the architectural structures of what many consider to be our latest polis: social media platforms. ${ }^{16}$ The processes through which hashtags 'trend' or 'go viral' are reflective of sociocultural norms. Zizi Papacharissi argues, "Twitter engages that which is privately imagined and collectively aspirational, personally defined and politically directed, individually motivated and civically inclined, phatically presented but also reflective of a deeply personal ideology of a networked self." 17 She suggests that our online actions create micro-narratives about who individuals are and how they differ from or are similar to others, stating that "agency is semantically and affectively accessed, and claims to power performed." 18 Our online encounters accumulate to form not just digital imprints of social movements or current events, but also political performances of the self, "articulated one tweet at a time."19 Personal as political phenomena reveal the importance of everyday online encounters for locating personal renderings of the self and the 'Other'. ${ }^{20}$ It is through everyday use of hashtags that feelings towards Others are embodied, transferred and given meaning. To this end, I argue that hashtags are the modern iteration of the personal as political.

\footnotetext{
13 Butler, Precarious Life, xx-xxi.

${ }^{14}$ Mor Naaman, Jeffrey Boase, and Chih-Hui Lai, "Is It Really about Me?: Message Content in Social Awareness Streams," In Proceedings of the 2010 ACM Conference on Computer Supported Cooperative Work (2010): 189-192, doi: 10.1145/1718918.1718953.

15 Barry Wellman, "Computer Networks as Social Networks," American Association for the Advancemen of Science 293, no. 5537 (2001): 2031-34, doi:10.1126/science.1065547.

16 Zizi Papacharissi, Affective Publics: Sentiment, Technology, and Politics, (New York: Oxford University Press, 2014), 94.

17 Papacharissi, Affective Publics, 101.

18 Papacharissi, Affective Publics, 94.

19 Papacharissi, Affective Publics, 96.

${ }^{20}$ I use critical feminist constructs of 'Other' or 'Othering' to describe the act of marginalisation where certain individuals or groups are labelled as not fitting in within the norms of the dominant patriarchal society. Where Man is constructed as subject, Woman is constructed as Other. As such, the concept of Other tells us far more about patriarchal and dominant systems of marginalisation (see Davis, Embracing Alterity). More recently, intersectional studies have shown how generalized conceptions of subject and Other are present in specific intersecting forms that reflect dominant gender, race, ethnicity, religion, age, sexual orientation, and other structural positions. See Aili Tripp, "Retheorizing Human Security through a gender lens," in Gender Violence, and Human Security: Critical Feminist Perspectives, ed. Ali Tripp, Myra Marx Ferree, and Christina Ewig (New York: NYU Press, 2013).
} 
I focus on a specific category of hashtags that I call 'collectivising hashtags.' These are characterised by their use of pronouns to inclusively identify oneself with another or Others. These types of hashtags are popular for their paradoxically individualist and collectivist design, which allows users to insert themselves into the trending narrative. Used individually, collectivising hashtags express privately held feelings but, when grouped together, they produce a shared socio-political reality. For me, it is the individualist and collectivist paradox baked into collectivising hashtags that simultaneously creates their greatest political potential and their greatest weakness. The collectivising nature of hashtags, which relies on shared human precariousness, is needed to bring people together in solidarity. However, this precariousness obscures the particular problems of those who suffer from a disproportionate distribution of precarity. ${ }^{21}$ Collectivising hashtags 'say something' about who qualifies as human. Therefore, it is crucial that users better understand how collectivising hashtags move through online encounter, circulating between bodies, and "sticking to cement dominant conceptions." 22 This missing link between collectivising hashtags and corresponding conceptions of who qualifies as human goes to the heart of a founding concern of feminist and International Relations scholarship: the issue of power. ${ }^{23}$ I argue that collectivising hashtags are micro-expressions of power within which certain perspectives are articulated and prioritised and others marginalised. Collectivising hashtag practices are value-laden and socially and discursively produced. Hashtags reflect relations of power from which users derive their values and communicative practices. ${ }^{24}$ My research explores the extent to which collectivising hashtags, as online renderings of self, create and maintain status quo conceptions of Otherness. Throughout my dissertation, I explore how the use of collectivising hashtags can unwittingly downplay lived experiences and confuse important distinctions between corporeal vulnerabilities.

My research moves beyond the social discourse of collectivising hashtags by looking at how hashtags are technologically created and structured in a way that affords certain bodies more political potential than others. I undertake a Critical Technocultural Discourse Analysis ("CTDA") developed by André Brock. ${ }^{25}$ A CTDA analysis examines how the 'architectural' aspects of a hashtag problematise recognition of precarious bodies who currently fall outside dominant conceptions of what it means to be human. ${ }^{26}$ I use the term architecture to describe the functional aspects of a hashtag: the coded software processes, communicative platforms,

\footnotetext{
21 Butler, Frames of War, xxv.

22 The term 'stickiness' refers to the likelihood of a hashtag to spread based on person to person sharing. There are distinct mechanisms of information contagion for different kinds of hashtags based on their variation of stickiness and persistence. See Sanja Sharma, "Black Twitter? Radical Hashtags, Networks and Contagion," New Formations 78, no 78. (2013): 8, doi: 10.3898/NEWF.78.02.2013

23 Emma, Hutchison, Affective Communities in World Politics: Collective Emotions after Trauma, (New York:

Cambridge University Press, 2016), 19.

24 Hutchison, Affective Communities, 117.

25 André Brock, “Critical Technocultural Discourse Analysis," New Media and Society 20, no3 (2018): 1012, doi:10.1177/1461444816677532.

26 Throughout my dissertation I refer to the 'architecture' of hashtags as the soft structures of digital networks, social media platforms and processes, hashtag functionalities and their affects. The term 'architecture' is used in connection with the field of 'information architecture.' Information architecture addresses the design of information spaces as a process, in which platform owners, software engineers, and hashtag users all contribute to the creation of online spaces as its 'architects.' This opens up a conversation about the co-production of online spaces where the task of an information architect is analogous to those that an industrial architect faces when designing a building as both "design spaces for human beings to live, work, and play in." See Andrea Resmini and Luca Rosati, "A Brief History of Information Architecture," Journal of Information Architecture 3, no. 2 (2001): 43, doi:

10.1002/bult.2012.1720390104.
} 
informatic flows, networks and affects. Astrid Mager refers to computer engineers as the people who "architect the code" and are responsible for its construction. ${ }^{27}$ The purpose of architecture is not just to design walls; what is really being created are the spaces between walls, where people live their lives. What architects do is design the best ways to use a particular space by applying an understanding of how physical structures act upon us. The architecture of online spaces can serve to create shared, embodied, and political orientations that shape patterns of life and work to facilitate the production of boundaries between people. ${ }^{28}$ My premise is that hashtags present as architecture structured in code, and that the functionality of hashtags is designed in such a way that it guides normative usages of them. I use the theory of affordances from Media Studies to highlight the complex and interdependent relationship between user practices and technological developments of inequality. Ultimately, I am interested in how this architecture tilts online spaces in such a way that they favour particular usages, impacting the digital affordances of marginalised users (or acts to marginalise users). I rework Melissa Harris-Perry's concept of the 'crooked room' to explain how the structure of the architecture affects our conceptions of self and Other. ${ }^{29}$ I maintain that there is a need to acknowledge positionality in online spaces, examining how digital architecture informs people's use of them, and how privileged users' usages in turn affect conceptions of self and Other. I interrogate processes of 'digital reconstitution', suggesting that an embodied and vulnerable digital praxis can help users to re-align themselves within these crooked spaces. ${ }^{30}$ The technological, social, and economic underpinnings of trending hashtags are reflective of prevailing perceptions of "whose life counts as a life." ${ }^{1}$ I maintain that an awareness of the struggle over digital recognition is key to understanding modern experiences of power, precariousness, inequality and social justice.

\section{Thesis Outline}

I show how collectivising hashtag practices are productive of power by examining apprehensions of vulnerability, architectural structures and affordances of hashtags, and their affecting nature. This examination is presented across five chapters, with each chapter exploring a particular aspect of my research.

Chapter One, The Relevance of Vulnerability in International Relations Theory, lays the theoretical groundwork for the subsequent chapters. My research spans themes of vulnerability, precariousness and ignorance from feminist studies and International Relations and affordances theory from Media Studies. Hence, a key focus of the first chapter is demonstrating how I weave these two areas together. As the boundaries of the embodied self expand, new ways of thinking are required, and I argue that interdisciplinary work presents an opportunity to address this need. I marry together the rich body of literature from feminist and

\footnotetext{
27 Astrid Mager, "Algorithmic Ideology: How Capitalist Society Shapes Search Engines," Information, Communication and Society 15, no.5 (2012): 775, doi: 10.1080/1369118X.2012.676056.

28 Solomon and Steele, "Micro-moves in International Relations theory,"277.

${ }^{29}$ Melissa Harris-Perry's concept of the Crooked Room is discussed in depth in section 4.4 The Crooked Platform or see Melissa V. Harris-Perry, Sister Citizen: Shame, Stereotypes and Black Women in America, (New Haven: Yale University Press, 2011), 28-50.

30 Practices of digital reconstitution are conceived in affective terms (an embodied and relational online praxis), where the primary function of reflexivity is to remain open and responsive within online encounter.

31 Butler, Precarious Life, xv-xxi.
} 
critical race scholars on the problems of collectivity, solidarity and hospitality in the theory of precariousness. I put this critical feminist theory in conversation with the theory of affordances from Media Studies which can be seen as a bringing together of the technological aspects of collectivising hashtags' design, platforms, and processes in combination with user behaviours.

The second chapter, A Synergistic Approach To Research Design, provides the forms and the backbone of my thesis and outlines in detail my research question, my choice of case studies, the data collection processes and analysis stages, ethical considerations and methodological limitations. In this chapter, I emphasise the connections between epistemology, methodology, and methods in a way that is consistent with critical feminist praxis, and how my own positionality is reproduced throughout my dissertation.

The third chapter, Claiming Collectivity, centres on my case studies: the \#TheyAreUs and \#ThisIsNotUs hashtags that were used in response to the White supremacist terrorist attack that took place at Al Noor Mosque and Linward Islamic Centre in Ōtautahi Christchurch on Friday 15 March, 2019. I use my case study to demonstrate how the appropriating nature of collectivising hashtags can confuse corporeal vulnerabilities, resulting in willful ignorance that actively maintains status quo conceptions of Otherness. This chapter encourages hashtag users to think critically about assuming the identity of vulnerable Others and conflating shared human precariousness with individual experiences of precarity.

The fourth chapter, The Crooked Platform, focuses on how technological inequalities are sustained through the architecture of hashtags and their folksonomic, serendipitous, and trending functions. I take a vernacular approach to hashtag affordances that emphasises users' own accounts of technology, where affordances become a part of a user's experience and perception of technology. ${ }^{32}$ The purpose of this chapter is to move beyond social constructivism and provide a CTDA analysis of collectivising hashtags that explores how the architectural structures built into a hashtag problematises recognition of precarious bodies.

Chapter Five, From Individual to Systemic, investigates the New Zealand Human Rights Commission's ("NZHRC") \#ThatsUs campaign, and discusses how "counterpublics" make strategic use of the discursive, architectural and affective affordances of hashtags in order to challenge the dominant knowledge and in online spaces. ${ }^{33}$ I draw on my interview findings and explore the humorous, imaginative, and community-based approaches that subvert collectivising hashtags in order to bring attention to ways that the platform is crooked (inequitably structured in such a way that it problematises recognition of marginalised bodies). I argue that critical feminist praxis is adapting and transforming itself in online spaces, as boundaries between people's online and offline lives blur conceptions of 'doing' feminism and 'being' a feminist.

\footnotetext{
32 The term 'vernacular affordances' was coined by Joshua McVeigh-Schultz and Nancy Baym to emphasise "how people themselves understand affordances in their encounters with technology." See Joshua Mcveigh-Schultz and Nancy Baym, "Thinking of You: Vernacular Affordance in the Context of the Microsocial Relationship App, Couple," Social Media and Society 1 no.2 (2015): 2, doi: 10.2277/2056305115604649..

33 Jackson and Foucault Welles use the term 'counterpublics' to describe the unique sites and methods used by marginalised groups to produce nondominant forms of knowledge. See Sarah Jackson and Brooke Foucault Welles, "Hijacking \#myNYPD: Social Media Dissent and Networked Counterpublics," Journal of Communication 65 n0.6 (2015): 933, doi: 10.1111/jcom.12185.
} 
Throughout these chapters, my dissertation investigates the transformative potential of collectivising hashtags. The racism and extremism shared via \#ThatsUs, \#TheyAreUs and \#ThisIsNotUs collectivising hashtags forced New Zealanders to look inward and question themselves about who is included and what 'we' represent as a society. The immediacy and popular nature of collectivising hashtags is uniquely revealing; which hashtags trend or go viral is indicative of popular concern and the politics of any given moment (meaningful or banal). They are not only expressions of our present affinities, but they can also evoke feelings and affect, which in turn shape how one perceives self and Other. Online platforms and practices have had an incredible affect on the way people encounter each other and participate in politics. Andrew Chen argues we "exist in a complex, messy context of a society that has become inseparably intertwined with technology to the point where there is no clear cause and effect-our technology and our values drive and affect each other." 34 Collectivising hashtags are socially constituted and constitutive in that they can change the way that individuals perceive themselves and Others. Hashtags are social and cultural phenomena that are both shaped by and also perpetually shaping practices of encounter, recognition, and human precariousness. I advocate for a broader consideration of the embodied, affecting and relational aspects of technology, especially those that result in inequalities that may be invisible to most users. The overarching purpose of critical feminist praxis is to look at how power structures develop in everyday lived experiences of marginalised bodies, providing insight into underlying systems of inequality that are often assumed and unquestioned. I want to begin with what is often missing from 'the proper business' of International Relations research and start a micropolitical conversation drawing on the feminist knowledge of the emotional, embodied and effectual workings of vulnerability, ignorance and precariousness in digital atmospheres. I start by conducting an interdisciplinary inquiry drawing on International Relations, feminist studies and Media Studies that lays the foundation for a deeper understanding of modern relations of power and inequality.

${ }^{34}$ Andrew Chen, Shouting Zeros and Ones: Digital Technology Ethics and Policy in New Zealand, (Wellington: Brigit Williams Books, 2002), 14. 


\section{Chapter One \\ The Relevance of Vulnerability in International Relations Theory}

The purpose of critical feminist research is, in part, to look at how power relations develop through our everyday practices. While traditional Eurocentric versions of International Relations theory examine overarching governing bodies, feminists suggest looking at the everyday lived experiences of people to understand how politics works - asserting that our corporeal bodies are the actual sites of politics. I maintain that this is a more exciting and empowering way to look at politics. Rather than some distant political institution with which we have no real connection, if we can take ownership of our own bodies and practices, we can take ownership of politics ourselves. In this thesis, I examine what ordinary everyday encounters with other bodies via social media can tell us about power relations. I look to collectivising hashtags as evidence of online renderings of self and bring together discussions on individual hashtag movements to illustrate how the collectivising intent is becoming a growing phenomenon. There is a rich body of literature from feminist and critical race scholars on the problems of collectivity, solidarity and hospitality grounded in the theory of vulnerability. I explore how literature on the creation of Otherness can be applied to collectivising hashtags as a practice. The theory of affordances from social media literature helps me to consider the asymmetries of power, both technological and social. ${ }^{35}$ In this way, affordances provide a way to move beyond strict social constructivism and technological determinism. ${ }^{36}$ This vernacular understanding of affordance turns our attention inward, calling us to question how our online performances of self problematise the recognition of vulnerable bodies who currently fall outside dominant conceptions of what it means to be human. This shift in perspective prompts an alternative approach and method, beyond the mantra of hashtags as social construction. ${ }^{37}$ My literature review brings together literature from the cutting edge of International Relations, feminist and Media Studies research and sets the groundwork for a more complex understanding of the modern relations of power.

This chapter provides a theoretical overview of online renderings of self as they pertain to feminist, Media Studies, and International Relations literature. I situate my research in relation to existing critical feminist knowledge on online narratives of self. This chapter is presented in four parts. The first section explores the interdisciplinary feminist research of Jenna Brager, Helen Berents, Elizabeth Groeneveld, and Meredith Loken, whose case studies on individual hashtag movements bring to light broader epistemic problems. ${ }^{38}$ I argue that the dualistic

\footnotetext{
35 Refer to section 1.3 The Affordances of Collectivising Hashtags for in-depth discussion on affordance theory or see Taina Butcher and Anne Helmond, "The Affordance of Social Media Platforms," in The Sage Handbook of Social Media, ed. Jean Burgess, Alice Marwick, and Thomas Poell (Sage Publications Ltd, 2018), 233-253.

36 Butcher and Helmond, "The Affordance of Social Media Platforms," 238.

37 See, for example Helen Berents, "Hashtagging Girlhood: \#IAmMalala, \#BringBackOurGirls and Gendering Representations of Global Politics,"International Feminist Journal of Politics 18, no.4 (2016): 513-27, doi: 10.1080/14616742.2016.1207463; Elizabeth Groeneveld, "Are We All Pussy Riot? On Narratives of Feminist Return and the Limits of Transnational Solidarity," Feminist Theory 16, no3. (2015): 289-307, doi:

10.1177/1464700115604134; Michelle Rodino-Colocino,"\#MeToo: Countering Cruelty with Empathy," Communication and Critical Cultural Studies 15, no.1 (2018): 96-100, doi: 10.1080/1479142.2018.1435083. 38 See for example: Meredith Loken, "\#BringBackOurGirls and the Invisability of Imperialism," Feminist Media studies 14, no.6 (2014): 1100, doi: 10.1080/14680777.2014.975442; Jenna Brager, "The Selfie and the Other: Consuming Viral Tragedy and Social Media (after)Lives," International Journal of Communication 9, no1 (2015): 1660-71; Berents, "Hashtagging Girlhood"; Groeneveld, "Are We All Pussy Riot?"
} 
construction of hashtags as both personal and collective speaks to a broader trend, where recognition of minority bodies is dependent on a problematic relationship with privileged onlookers. The second section draws on the feminist themes of vulnerability, ignorance, and precariousness that provide a helpful theoretical framework for beginning the work of critically examining the epistemological grounds upon which online claims to solidarity are made. ${ }^{39}$ The impact of epistemologies of ignorance, vulnerability, and precariousness demonstrate how everyday performances of self, via collectivising hashtag practices, create and maintain status quo conceptions of humanity. The third section explores the concept of affordances from Media Studies, which brings together the architectural aspects of collectivising hashtags design, platforms, and processes in combination with user behaviours and their affective responses. ${ }^{40}$ The theory of affordances highlights the complex and interdependent relationship between user practices and technological developments as tools of inequality. The fourth section addresses strands of feminist scholarship at the cutting edge of contemporary International Relations theory, which draw on micropolitics and the everyday lived experiences of self, emotion, and affect. This section demonstrates how my dissertation contributes to burgeoning interdisciplinary approaches, including feminist, Media Studies, and International Relations methodological approaches. I argue that the study of social media will benefit from critical feminist scholarship on the embodied and affectual workings of vulnerability, ignorance, and precariousness in digital atmospheres. By presenting a critical feminist methodological approach to the role of affective-encounter via social media, my thesis finds connections "between form, function and belief" in relation to collectivising hashtags. ${ }^{41}$ This chapter lays the ground work for the critical feminist conceptual framework that I will use in combination with a CTDA methodological approach in the subsequent chapters.

\subsection{Collectivising Hashtags: A Growing Phenomenon}

Over the past few years, the use of social media and the number of online person-to-person connections has grown exponentially. ${ }^{42}$ Internet-based communication fosters participatory sharing of information. We live in a world where advancements in technology transform the way we encounter and communicate with one another. Increasingly widespread access to social media is the newest iteration of this technological evolution. While technological sharing of information is not new, the amount of data, the speed at which it travels and the networked nature through which it moves has advanced significantly with the introduction of the smartphone. ${ }^{43}$ The public now expects to participate in the crisis as they happen via social media platforms. Philip Seib remarks that "even intelligence agencies cannot match the speed of Twitter." 44 People now have the ability to record their suffering and repression and, through

\footnotetext{
39 Erin Gilson, “Vulnerability, Ignorance, and Oppression," Hypatia 26, no.2 (2011), doi:10.1111/j.15272001.01158.x; Nancy Tuana, "The Speculum of Ignorance: The Women's Health Movement and Epistemologies of Ignorance," Hyptia 21, no3 (2006) doi:10.1111/j.1527-2001.2006.tb01110.x; Butler, Precarious Life.

40 Butcher and Helmond, "The Affordance of Social Media Platforms."

${ }^{41}$ André Brock, "Critical Technocultural Discourse Analysis," New Media and Society 20, no3 (2018): 1012, doi:10.1177/1461444816677532.

42 International Telecommunications Union, "ITU Facts and Figures 2020." ITU, 31 July, 2020,

https://www.itu.int/en/ITU-D/Statistics/Documents/facts/FactsFigures2020.pdf

43 Philip Seib, The Future of \#Diplomacy, (Cambridge: Polity, 2016), 280.

44 Seib, The Future of \#Diplomacy, 280.
} 
the internet, are able to confront audiences with their own experiences. ${ }^{45}$ People share news from a first-person perspective, changing our frame of reference and the way we participate in its circulation. As more stories circulate, widespread recognition and commonality become the primary drivers of popular news and competition for recognition increases. Easily understandable and digestible stories are more likely to reach viral status; complex events that are not as easily sharable, likable, or worthy of retweeting can fail to get the attention of mainstream audiences. ${ }^{46}$ Stories of the dispossessed are more likely to trend if they are suitably relatable, particularly if people can see themselves as part of the story. ${ }^{47}$ This has led to the growing trend of personalisation in online statements of solidarity, in which social media users invoke the concept of self when addressing issues of injustice, violence or crisis.

Consequently, hashtags are fast becoming a commonplace response to a tragedy. It is now common practice to voice feelings of solidarity by subsuming the identity of the victim via hashtagging practices. During a crisis, hashtags bring people together, offering a discursive framing process that gathers peoples' observations of events, experiences and responses. ${ }^{48}$ James McVey and Heather Woods explain that hashtags function as networks organised around nodes of connectivity which forge "individuals into a collective." 49 Hashtags coordinate or signal the commonality of a subject: "It is through the hashtag that strangers are organised as latent participants in public conversations with the possibility of activation and transformation by and through the circulating text that follows after the hashtag (\#) sign."50 Hashtags are concise and clever in their construction. McVey and Woods observe that hashtags must be "catchy, repeatable, and abstract enough to invite a huge number of tweets, while simultaneously being clear enough about their referent to ensure the conversation remains focused on the topic." 51 Hashtags are used in everyday speech both online and offline often sarcastically, or ironically. However, hashtags are not as trivial or arbitrary as they might at first appear. Often, hashtags are perceptive, and those that trend provide sharp insight into the thinking of the online public.

Hashtags are reactionary; they articulate an immediate emotional response to human tragedy. Originating with \#WeAreTrayvonMartin (following the racially motivated shooting of Black American teenager Trayvon Martin in 2012), this construct has been reproduced to fit multiple purposes. ${ }^{52}$ Echoes include the \#MeToo movement challenging sexual harassment, \#IAmMalala in response to the attempted assassination of Pakistani education activist Malala Yousafazi,

\footnotetext{
45 Kari Andén-Papadopoulos, "Citizen Camera-Witnessing: Embodied Political Dissent in the Age of 'Mediated Mass Self-Communication,"” New Media and Society 16, no.5 (2014): 753, doi: 10.1177/1461444813489863.

46 Brager, "The Selfie and the Other," 1667.

47 Personalisation has a long history in media, particularly in journalism (e.g., a reporter 'personalising' a story by asking a local resident for a reaction). In terms of programmability and platforms, personalisation has its roots in Web 2.0. See Neil Thurman, "Making 'The Daily Me': Technology, Economics and Habit in the Mainstream Assimilation of Personalized News," Journalism 12, no.4 (2011) 195-415, doi: 10.1177/1464884910388228. 48 Rachel Kuo, "Racial justice activist hashtags: Counterpublics and discourse circulation," New Media and Society 20, no.2 (2018): 497, doi: 10.1177/1461444816663485.

${ }^{49}$ James Alexander McVey and Heather Suzanne Woods, "Anti-Racist Activism and the Transformational Principles of Hashtag Publics: From \#HandsUpDontShoot to \#PantsUpDontLoot," Present Tense, 2 March 2016, https://www.presenttensejournal.org/volume-5/anti-racist-activism-and-the-transformational-principles-ofhashtag-publics-from-handsupdontshoot-to-pantsupdontloot/

50 McVey and Woods, "Transformational Principles of Hashtag Publics "

51 McVey and Woods, "Transformational Principles of Hashtag Publics."

52 Yarimar Bonilla and Jonathan Rosa, "\#Ferguson: Digital Protest, Hashtag Ethnography, and the Racial Politics of Social Media in the United States," American Ethnologist 42, no.1 (2015): 14, doi: 10.1111/amet.12112.
} 
and \#BringBackOurGirls for the kidnapping of Nigerian school girls labelled 'our'.53 I use the term collectivising hashtags to describe this new phenomenon. Here 'collectivising' connotates the amalgamation, affiliative or appropriating nature of seemingly personal statements. Collectivising hashtags are generally associated with 'bad news' and codified via social media platforms such as Twitter, Facebook, and YouTube. For many social media users, collectivising hashtag practices are genuine attempts at expressing support and condolence following tragedy. Well-meaning onlookers claim to share in victims' grief and 'stand with them' by assuming their identity in an expression of solidarity. Groeneveld acknowledges the political force of 'we are all...' solidarity statements which 'can serve as powerful ways of linking violence and/or injustice towards individuals to larger structural inequalities and/or histories of oppression." 54 Collectivising hashtags are paradoxically individualist and collectivist by design. Taken individually, collectivising hashtags are 'me now' declarations expressing privately held feelings. ${ }^{55}$ When grouped together they produce shared socio-political statements regarding recognition, agency, and belonging. The proliferation of numerous collective 'wes' makes claims of recognition and identification. ${ }^{56}$ Jodi Dean refers to the Occupy Movement, saying that the slogan '“we are the 99\%' asserts a collectivity; it voices a shared desire for equality and justice." 57 The \#WeAreThe99\% was often used as a signoff at the end of very individual and personal stories to encourage others to add to the narrative and share their own stories and economic struggles. Hashtags are a cultural and political phenomenon that is shaped by and perpetually shaping practices of encounter. They say something about how we see ourselves in relation to others, those we identify with and those we overlook.

Proponents of social media argue that our online interactions can result in greater emotional identification with Others, bringing stories of suffering directly into the lives of privileged onlookers and arousing compassion and greater understanding across difference. ${ }^{58}$ Michelle Rodino-Colocino maintains that certain hashtags such as the \#MeToo campaign have the potential to advance "transformative empathy" and become an agent for exposing systems of oppression and injustice. ${ }^{59}$ Rodinio-Colocinio refers to the collective power of the \#MeToo movement, stating, "[T] here is nothing as powerful as knowing that you are not alone. The sooner young women understand that they are not an anomaly, the sooner they can begin their healing process." 60 The power of the collectivising hashtag \#MeToo was its ability to counter victims feelings of isolation by facilitating broad discussion on the internet and shedding light on the shocking extent of sexual harassment. Rodinio-Colocinio emphasises the importance of \#MeToo's origin as a collective conversation about power and privilege as the key to understanding the hashtag's popularity. ${ }^{61}$

\footnotetext{
53 Loken, “The Invisability of Imperialism," 1100.

54 Groeneveld, "Are We All Pussy Riot?" 303.

55 Zizi Papacharissi, Affective Publics, 100.

56 Paolo Gerbaudo and Emiliano Treré, "In Search of the 'We' of Social Media Activism: Introduction to the Special Issue on Social Media and Protest Identities,"Information, Communication \& Society 18, no.8 (2015): 870, doi: 10.1080/1369118X.2015.1043319.

57 Jodi Dean, “Claiming Division, Naming a Wrong," Theory and Event 14, no.4 (2011): 11-14.

58 Andrew Linklater, “Distant Suffering and Cosmopolitan Obligations," International Politics 44, no.1 (2007): 19-36, doi: 10.1057/palgrave.ip.8800156.

59 Rodino-Colocino, "Countering Cruelty with Empathy," 97.

60 Rodino-Colocino, "Countering Cruelty with Empathy," 97.

61 Rodino-Colocino, "Countering Cruelty with Empathy," 97.
} 
Collectivising hashtags can bring together individual lived experiences and link them to broader systemic issues within society. According to Tarana Burke, founder of the \#MeToo movement, the aim was to expose systems of oppression and privilege of which sexual harassment and assault are both cause and effect. ${ }^{62}$ The Me Too campaign's incarnation as a hashtag simultaneously "imperilled and reinforced" Burkes' concern for inequalities and the need to consider underlying positions of power and privilege. ${ }^{63}$ As the hashtag \#MeToo gained popularity, it increasingly centred around women in Hollywood and became aligned with the Time's Up movement (which is primarily concerned with workplace pay equality issues). While pay equality and the safety of actresses within the film industry are still important to the \#MeToo movement, this development overshadowed Burkes' fundamental goal which is to help those most vulnerable to sexual harassment, specifically women of colour who are victimsurvivors and have no support systems. ${ }^{64} \mathrm{~A}$ lack of self-awareness and differences among lived experience of hashtaggers can lead to "unintentionally imitating the problems it ostensibly opposes." 65 Herein lies the fundamental flaw of collectivising hashtags: their universality, which is needed to bring people together in solidarity and shed light on social injustices and victims, simultaneously obscures the particular problems of those bodies by virtue of that very generality and universality.

Throughout my dissertation, I explore how the use of collectivising hashtags can unwittingly downplay lived experiences and confuse important distinctions between corporeal vulnerabilities. Critics of social media suggest that we are seeing privileged audiences engage in a kind of "fascinated cannibalism," a consumption of vulnerable bodies who are labelled Other.66 Groeneveld, in her analysis of hashtag \#WeAreAllPussyRiot (which trended in response to the incarceration of Pussy Riot members following a protest at a Russian Orthodox church), asserts that the suggestion that anyone could be Pussy Riot acts to decontextualise the protest itself. ${ }^{67}$ To illustrate this argument, Groeneveld points to the use of colourful balaclavas to invoke "illusions of sameness" and demonstrate solidarity by identifying oneself as a 'fellow' Pussy Riot Member. ${ }^{68}$ The use of balaclavas and the assertion that we are all Pussy Riot provides a feeling of inclusivity for Western media audiences, allowing them to feel that they themselves represent the interests of the band. ${ }^{69}$ In reality, there are fundemental differences between Pussy Riot activists like Nadezda Tolokonnikova, Maria Alyokhina, and Yekaterina Samutsevich wearing balaclavas in order to avoid identification and arrest and privileged audiences choosing to wear balaclavas as a fun or interesting act of personal identification. The key difference here is that Tolokonnikova, Alyokhina, and Samutsevich put their corporeal bodies on the line when protesting; their protest at the Orthodox Church risked the threat of physical violence from the State, and they were eventually incarcerated for their acts where they took part in a hunger strike. Collectivising hashtags like \#WeAreAllPussyRiot thus elide the specificities of corporeal risk and differences in lived experiences. ${ }^{70}$ Feminist theorists remain wary of the latent particularity of universalisms, arguing instead for "embracing, not

\footnotetext{
62 Rodino-Colocino, "Countering Cruelty with Empathy," 97.

63 Rodino-Colocino, "Countering Cruelty with Empathy," 97.

64 Rodino-Colocino, "Countering Cruelty with Empathy," 97.

65 Loken, "The Invisability of Imperialism," 1101.

66 Brager, "The Selfie and the Other," 14.

67 Groeneveld, "Are We All Pussy Riot?" 298.

68 Groeneveld, "Are We All Pussy Riot?" 298.

${ }^{69}$ Groeneveld, "Are We All Pussy Riot?" 298.

70 Groeneveld, "Are We All Pussy Riot?" 298
} 
through obscuring or denying or eliding particularity."71 Tuana maintains that alterity is not something we should attempt to remove; our differences in lived experience are not something we can collectivise and we need to recognise that there are "modalities of being that exceed our own and cannot be fully comprehended."72 Accordingly, we must pay greater attentiveness to context and to the grounds upon which claims to solidarity are made because, as Groeneveld elegantly concludes, "we are not all Pussy Riot - nor should we be."73

Collectivising hashtag practices become increasingly problematic when privileged onlookers assume the identity of vulnerable subjects as was the case with the \#ICantBreathe (police brutality towards African-American communities), \#IAmRefugee (following the bombing of Syrian civilians in Aleppo), and \#IAmJewish (following a series of attacks against Jewish Communities in France in 2015) hashtags. Claiming to be one of these vulnerable groups willfully ignores the fact that these marginalised groups face real persecution, oppression and dispossession, the likes of which privileged audiences have not encountered. Papacharissi reminds us that "we imagine what it might feel like for them, but our experience of their reality is precisely that: imagined. It lacks the gravitas of actuality." 74 Privileged onlookers cannot claim to understand the experience of the vulnerable Other or 'be' them. Catlin Dewey remarks, "you simply can't claim an identity so inextricably tied to pain and persecution when you have suffered none of that history." 75 Nevertheless, under the constant pressure of shareability and virality, hashtags are subject to "disjunctures of meaning, to misrepresentation and appropriation." 76 The relative affordability of smart phones with advanced recording capabilities and internet access has allowed more and more people to share their own experiences online. "Citizen camera-witnessing" facilitates connectivity with distant suffering precisely by its distinct claim to truth in the name of 'vulnerable subjects' who are sharing their vulnerabilities. ${ }^{77}$ Here 'vulnerable subjects' refers specifically to bodies who suffer the corporeal consequences of vulnerability, as opposed to our universal capacity for vulnerability, as a means to highlight the inequalities in lived experiences of vulnerability.78 Sara Ahmed suggests that "passive empathy" is prone to developing on Twitter; because Western audiences view marginalised people as atypical, exotic, and interesting, their stories risk appropriation. ${ }^{79}$ Rodino-Colocino explains, "passive empathy is the feeling of being in another's shoes without the risk of actually doing so." 80 When privileged bodies appropriate the story of distant Others, they disregard alterity and the very real inequalities and corporeal differences that exist in lived experiences. In her discussion on affective solidarity, Claire Hemmings writes "empathy may lead to sentimental attachment to the Other, rather than

\footnotetext{
71 Simone de Beauvoir, The Second Sex, trans. C Borde and S. Malovany-Chevallier (New York: Random House, 1949) cited in Alyson Cole, "All of Us Are Vulnerable, But Some Are More Vulnerable than Others: The Political Ambiguity of Vulnerability Studies, an Ambivalent Critique," Critical Horizons 17, no.2 (2016): 273 doi: 10.1080/14409917.2016.1153896.

72 Tuana, "The Speculum of Ignorance," 15-16.

73 Groeneveld, "Are We All Pussy Riot?" 303.

74 Papacharissi, Affective Publics, 5.

75 Caitlin Dewey, “\#JeSuisNarcissique: Why Do ‘solidarity’ Hashtags Only Go Viral When They're Actually about Us?” The Washington Post, 13 January, 2015, https://www.washingtonpost.com/news/theintersect/wp/2015/01/12/jesuisnarcissique-why-do-solidarity-hashtags-only-go-viral-when-theyre-actuallyabout-us/?noredirect=on\&utm_term $=$. ce890a7fa855

76 Brager, "The Selfie and the Other," 1669.

77 Andén-Papadopoulos, "Citizen camera-witnessing," 753.

78 Cole, "All of Us Are Vulnerable," 263.

${ }^{79}$ Ahmed, The Cultural Politics of Emotion, 30.

80 Rodino-Colocino, "Countering Cruelty with Empathy," 96
} 
genuine attachment with her concerns, or worse, it may signal cannibalisation of the other masquerading as care." 81 The risk here is that privileged bodies superficially identify with tragedy that befalls vulnerable Others without reflecting critically on the circumstances that led to that suffering. ${ }^{82}$

Collectivising hashtag practices can act to reproduce settler-colonial power relations between privlidged audiences and marginalised communities. Berents, in her assessment of the hashtag \#IAmMalala, claims that telling the story of another's suffering is highly problematic. There is a loss of agency as young people like Malala Yousafzai are tokenised, and "the specificity of their suffering erased through claiming of space through first-person campaigns 'I am Malala."'83 Participants in the social media campaign not only empathise with Yousafzai's distress but also appropriate it as their own through hashtag campaigns. ${ }^{84}$ Collectivising hashtags like \#IAmMalala lay claim to the experience of vulnerability, which in turn (re)produces problematic and limited ideas about girlhood.85 Berents argues that gendered representations of 'girls' in hashtags such as \#IAmMalala and \#BringBackOurGirls presents these individuals as "helpless third world women." 86 The inscription of settler-colonial power relations through these hashtags not only relies on the reading of marginalised people as incapable of addressing these situations but also foregrounds the dangerous Other to which these 'helpless' girls are vulnerable. ${ }^{87}$ Berents writes, "Dichotomised narrative of girlhoods is inextricably bound with, dependent on and reproduced by political and social economies of power privilege and presence of transnational scale." 88 Collectivising hashtags can reinforce and maintain settlercolonial power relations and imply that, if Others are at risk, this necessitates 'more capable' Western audiences must 'step in' and intervene on their behalf. ${ }^{89}$ It is essential to understand the broader political context and histories behind the narratives of Others that privileged onlookers attempt to insert themselves into.

The use of collectivising hashtags illustrates a complicated tension between wanting to provide a voice to the voiceless Other and speaking on their behalf. For example, the 'Our' in the \#BringBackOurGirls campaign speaks to a troubling discourse through which the value of the distant Other is placed in relationship to the more privileged Western agent. ${ }^{90}$ This is to say, the subject who "bestows solidarity upon others" is coded as having agency and value, whereas the figures with whom solidarity is claimed have none except their association with the privileged subject.91 Mary Maxfield, in her critical reflection on the \#BringBackOurGirls campaign, writes:

81 Claire Hemmings, "Affective Solidarity: Feminist Reflexivity and Political Transformation," Feminist Theory 13, no.2 (2012):152, doi: 10.1177/1464700112442643.

82 Kate Schick, “Unsettling Pedagogy: Recognition, Vulnerability, and the International," in Recognition and Global Politics: Critical Encounters Between State and World, ed. Patrick Hayden and Kate Schick (Manchester: Manchester University Press, 2016) 31.

83 Berents, "Hashtagging Girlhood," 518.

${ }^{84}$ Berents, "Hashtagging Girlhood,"519.

85 Berents, "Hashtagging Girlhood," 514.

86 Berents, "Hashtagging Girlhood," 513.

87 Berents, "Hashtagging Girlhood,"523.

88 Berents, "Hashtagging Girlhood," 517.

89 Berents, "Hashtagging Girlhood," 517.

90 Groeneveld, “Are We All Pussy Riot?" 299.

91 Groeneveld, “Are We All Pussy Riot?” 303. 
Supporters may very well have felt a human connection to the Chibok community; as they endured such egregious violence, and desired somehow to protect these girls, as they would any youth, against further harm. Unfortunately, such intentions cannot transcend the legacy of colonialism, which continues to operate in transnational interactions, at both the psychic and social levels. The presumptions of colonialism, and the racism embedded in it, remain active in the 'common sense' practices of the Global North, including the seemingly altruistic desire to act on behalf of African girls. ${ }^{92}$

In the same vein, Loken suggests that the \#BringBackOurGirls campaign presents a problematic narrative of women as deserving only through their capacity to be claimed by Western media audiences, saying, "she becomes our girl, contextually indistinguishable and thus deserving of our protection from her communal struggle-in-kind."93 Loken notes that the campaign frequently used unsourced images of African women who were not related to the kidnapping.94 The assertion that they are 'our girls' acts paradoxically to ignore the intersections of race, class, and colonialism..$^{95}$ The \#BringBackOurGirls campaign relies on the homogenising of the colonial gaze. ${ }^{96}$ Loken suggests that the dualistic construction of women as worthy of political recognition because of their relationship with a more privileged agent acts to reproduce settler-colonial power relations. ${ }^{97}$ Social inequalities are sustained by what Stuart Hall calls "the spectacle of the Other," where one dominant community is normalised and all other communities are positioned in its periphery. ${ }^{98}$ Western onlookers should be wary of collectivising hashtag practices that primarily work to improve the altruistic image by centring the activist. 99

Social media is affecting a kind of 'looped gaze', where recognition of the Other is determined by their relevance to Western media audiences. The looped gaze occurs when a privileged person encounters a minority body and only recognises the known and familiar aspects of themselves within the Other body. To illustrate this dynamic, Brager draws on the news story of a Lebanese teenager Mohammad al-Chaar who died in a Beirut bombing minutes after taking a selfie with his friends. ${ }^{100}$ After examining the ways in which al-Chaar's selfie was circulated and presented to Western media audeiences, Brager concludes that it is the practice of selfie-taking, not al-Chaar's death, that makes this "third world selfie taker" recognisable as a grievable subject for Western media spectators: "The selfie of al Chaar becomes a liminal space in which Western social media consumers access the familiar and grievable, and their own sense of unbridgeable distance." 101 Brager argues that by considering social networks as a site of confrontation and context that engenders different modes of vacated looking and ethical seeing, "another portrait begins to emerge, of self-representation and representation in the

\footnotetext{
92 Mary Maxfield, "History Retweeting Itself: Imperial Feminist Appropriations of 'Bring Back Our Girls,'” Feminist Media Studies 16 no.5 (2016): 896 doi: 10.108/1480777.2015.1116018.

93 Loken, "The Invisability of Imperialism," 1101.

94 Groeneveld, “Are We All Pussy Riot?” 299.

95 Loken, "The Invisability of Imperialism," 1101.

96 Loken, "The Invisability of Imperialism," 1101.

97 Loken, "The Invisability of Imperialism," 1101.

98 Stuart Hall, Representation: Cultural Representations and Signifying Practices, (London, Thousand Oaks: Sage in association with the Open University, 1997), 223-90.

99 Maxfield, "History Retweeting Itself," 896.

100 Brager, "The Selfie and the Other," 1665.

101 Brager, "The Selfie and the Other," 1665.
} 
media landscape."102 Accordingly, our recognition of the Other is determined by their relevance to ourselves. What we are seeing is not really the Other but rather the familiar and known elements of ourselves within them. bell hooks, in her appraisal of White feminism, writes "They could not see that their generosity was directed at themselves, that it was self-centred and motivated by their own opportunistic desires." 103 Bringing the lives of the distant Other into the view of privileged onlookers has not resulted in any true form of recognition. Instead, it has left us with an "impoverished form of recognition" that only allows us to see the Other insofar as the plight of the Other moves our Western sensibilities. ${ }^{104}$

The case of '\#JeSuis' hashtag following the 2015 terrorist attack on the Paris office of satirical newspaper Charlie Hebdo also exemplifies this looped gaze. Washington Post reporter Dewey noted our tendency to respond to the tragedy in a self-referential manner, writing:

Activist hashtags only seem to catch on if we phrase them to be about ourselves. In the five days since two men gunned down 12 people in the offices of the French satirical paper Charlie Hebdo, that's become particularly clear. We could have stood with Charlie, or mourned Charlie, or performed a number of other verbs in French or English; we could have held pens in the air or said 'not afraid' as chanters in Paris' Place de la republique did...and yet the only thing to go viral - was one predictable construction \#JeSuisCharlie. \#JeSuisAhmed. Je Suis, Je Suis, Je Suis. ${ }^{105}$

The use of \#JeSuis hashtags enabled audiences to raise awareness of a cause and, at the same time, display their views through public affiliation, "possibly to reinforce one's own public view as someone who is aware and committed." 106 Amanda Hess calls into question the motivations behind the \#JeSusis hashtags stating:

The \#Iam construction functions like a politicised selfie, drawing attention to both the speaker and the subject...so while \#IAm often begins as a way to grant a voice to the voiceless - it typically arises in death, as it did for Trayvon Martin, Eric Garner, and the staffers of Charlie Hebdo - it's designed to grant a platform to another silenced demographic: ourselves. ${ }^{107}$

The concern here is that the life of the vulnerable subject becomes subsidiary; they become martyrs fuelling another's political narrative. Dewey asks: "is that about 12 murdered people at Charlie Hebdo, or is that about you, actually?"108 Anti-racism activist and author Nova Reid cautions privileged users against online activism that fosters 'White saviour narratives' or 'performative activism.' Reid explains that performative acts of hashtag activism are self-

102 Brager, "The Selfie and the Other," 1669.

103 bell hooks, Ain't I a Woman: Black Women and Feminism, (New York: Routledge, 2014), 144-145, doi,

10.4324/9781315743264.

${ }^{104}$ Schick, "Unsettling Pedagogy," 30.

105 Dewey, “\#JeSuisNarcissique."

106 Barbara De Cock and Andrea Pizarro Pedraza, "From Expressing Solidarity to Mocking on Twitter: Pragmatic

Functions of Hashtags Starting with \#Jesuis across Languages," Language in Society 47, no.2 (2018): 200 doi: 10.1017/S00474045180000052.

107 Amanda Hess, “\#IAm: The default mode of showing solidarity in the hashtag era," Slate, 9 January, 2015,

http://www.slate.com/articles/news_and_politics/politics/2015/01/_jesuischarlie_the_default_mode_of_showing_s olidarity_in_the_hashtag_age.html.

108 Dewey, "\#JeSuisNarcissique." 
serving, stating, "this was a stage performance. A way to manage their perception, so their ego could feel better about all that's wrong in the world."109 The term 'White Saviour' was originally coined on Twitter by Teju Cole who referred to the 'White Saviour Industrial Complex' in situations where White people did good work only to validate privilege that allows them to 'feel good' about charitable acts without engaging in anti-racist work. ${ }^{110}$ The White Saviour is fuelled by an impulsive desire to fix bad things, to be the hero of the story, to swoop in and rescue marginalised bodies. ${ }^{111}$ Cole warns that for some White people, their drive towards saviourism comes from a place of guilt, a desire to be forgiven or to maintain superiority and invulnerability. ${ }^{112}$ Reid suggests if a person is unclear on the intention of helping Others they should ask themselves, "am I acting because it's the right thing to do, to centre the needs of others, or am I doing this for myself, to feel better and make myself look good?"113 Jackson, Bailey and Foucault Welles found that hashtags that claim to move privileged users towards solidarity or kinship with people from marginalised communities ought to be regarded with scepticism as a kind of 'faux allyship' that ultimately recentres privileged groups. ${ }^{114}$ There is a rich literature from intersectional feminists that highlight the shortfalls of White allyship. Existing scholarship covers a range of topics including, identity politics, representation, experiences of violence, performative activism, poverty porn and volunteer tourism. ${ }^{115}$ Privileged users are becoming increasingly aware of the cumulative effects of discrimination at the intersections of racism, sexism and classism as marginalised bodies share their lived experiences online and yet they have become more uncertain about what to do with that newfound awareness. ${ }^{116}$ This pattern results in White allyship being relatively superficial with collectivising hashtags being potentially "appropriative of the attention garnered by the marginalised group with which their allies hope to be in solidarity."117 Jackson, Bailey and Foucault Welles found that ultimately allyship hashtags that rely on the viral circulation of an incident of racial or gendered violence have the potential to shift attention away from the incident and "engender a level of self-centred reflection that does not contend with the systemic nature of the problem." 118 A student of Reid's anti-racism programme was able to identify the initial motivations fuelling her participation in online activism stating,

\footnotetext{
109 Nova Reid, "No More White Saviours Thanks: how to be a true anti-racist ally." The Guardian. 19 September, 2021. https://www.theguardian.com/world/2021/sep/19/no-more-white-saviours-thanks-how-to-be-a-true-antiracist-ally

110 Teju Cole, “The White-Saviour Industrial Complex." The Atlantic, 22 March, 2012.

https://www.theatlantic.com/international/archive/2012/03/the-white-savior-industrial-complex/254843/

111 Reid, "No More White Saviours Thanks."

112 Reid, "No More White Saviours Thanks."

113 Reid, "No More White Saviours Thanks."

114 Jackson, Bailey, and Foucault Welles, \#Hashtag Activism, 156.

115 Influential literature from critical race and gender theorists on the limitations of allyship include: bell hooks. Feminism Is for Everybody: Passionate Politics. Taylor and Francis, 2014: doi: 10.4324/9781315743189; Cole, Teju. "The White Saviour Industrial Complex". Known and Strange Things: Essays. Random House (2016): 340349. Judith Butler. Gender Trouble Feminism and the Subversion of Identity. New York: Routledge (1999). More recent intersectional interdisciplinary research on performative activism on social media includes: Jessamy Gleeson and Breanan Turner. "Online Feminist Activism as Performative Consciousness-Raising: A \#MeToo Case Study." In MeToo and the Politics of Social Change 2019: 53-69

Ranjan Bandyopadhyay and Patil Vrushali. "'The white woman's burden' - the racialized, gendered politics of volunteer tourism". Tourism Geographies. 19 no. 4 (2017): 644-657, doi:10.1080/14616688.2017.1298150.

116 Jackson, Bailey, and Foucault Welles, \#Hashtag Activism, 181.

117 Jackson, Bailey, and Foucault Welles, \#Hashtag Activism, 181.

118 Jackson, Bailey, and Foucault Welles, \#Hashtag Activism, 181.
} 
My performative allyship and saviourism is somewhere between perfectionism, people pleasing, and wanting to make everything OK in the world, so I don't have to feel the pain, discomfort, hurt and anger of others. I want utopia so I don't have to deal with big emotions. I wanted the answers quickly in anti-racism work, so I could do my bit and move on. I realised I can't make a difference if I can't face the thought of not being liked or upsetting people. 119

So while these activist hashtags can be linked to performative acts of White SSaviourism, they also have transformative potential to draw privileged audiences into critical conversations about their power and privilege and motivations behind their activism. Jackson, Bailey and Foucault Welles conclude that, "the consciousness raising and navel-gazing in the hashtag reveal the messy realities of online activism, in which ordinary users can take up hashtags and particular political narratives to be either/or self-serving or reparative but both, in greater of lesser degrees." 120 Collectivising hashtag practices are still in their infancy and White allyship is experiencing growing pains that demand further critical analysis. ${ }^{121}$ Throughout this dissertation I will explore who collectivising hashtags are for, and what political change, if any, they forward.

Hashtags navigate the intersections of our own identities and that of Others. ${ }^{122}$ Offering new discursive framing processes for articulating agency and circulating our own interpretations and observations of Others' experiences and identities. ${ }^{123}$ The phenomenon of the collectivising hashtags exemplifies the digital collapse of "public and private boundaries thus affording opportunities for expression that may simultaneously empower and compromise individuals." 124 It is crucial that we critically examine the growing phenomenon of collectivising hashtags. We need to ask ourselves, why do we respond to tragedy in a selfreferential way, and what are the implications of assuming the identity of vulnerable Others through hashtagging practices? In what follows I suggest that a feminist conceptual framework encourages us to think critically about the effects of our online interactions with Others, and to interrogate underlying power relations and our location within them.

\subsection{Feminist Conceptual Framework}

In order to analyse collectivising hashtagging practices, my dissertation incorporates a feminist conceptual framework of vulnerability, precariousness, and ignorance. Critical theorists Butler, Gilson, and Tuana provide a helpful framework for beginning the work of developing epistemologies of ignorance and vulnerability. ${ }^{125}$ I suggest that vulnerability and the associated epistemologies of ignorance and precariousness can help us better understand why people are increasingly responding to crisis via collectivising hashtags. Vulnerability through collectivising hashtags incorporate shared experiences of humanness. For example,

\footnotetext{
119 Reid, "No More White Saviours Thanks."

120 Jackson, Bailey, and Foucault Welles, \#Hashtag Activism, 180.

121 The key dilemmas of the politics of solidarity and limits of White allyship will be discussed further in Chapter

Five Performances of Self c) The Limits of Agency and Counterpublic Advocacy.

122 Kuo, "Racial Justice Activist Hashtags," 497.

123 Kuo, "Racial Justice Activist Hashtags," 497.

124 Papacharissi, Affective Publics, 94-95.

125 Butler, Precarious Life; Gilson, "Vulnerability, Ignorance, and Oppression”; Tuana, "The Speculum of Ignorance."
} 
the collectivising hashtag \#ICantBreathe was created in response to the death of Eric Garner after police officers threw him to the ground and put him in a chokehold. Garner's last words, as recorded on a cellphone video, were: 'I can't breathe.' He repeated the phrase 11 times before he died.126 The collectivising hashtag \#ICantBreathe speaks to the basic human need to draw breath and the precariousness of life that is lost without it. Precariousness is a universally shared experience that enables people to understand and share in feelings of grief and demonstrate solidarity by hashtagging \#ICantBreathe. However, the hashtag \#ICantBreathe was grounded in a particular context indispensable to its creation, namely the severe injustice Black Americans face at the hands of police. The experience of state persecution inequitably distributed based on race is not an experience that can be shared by all; it is specific to Black Americans and people of colour. So, while there are many experiences we share as humans such as vulnerability, precariousness and ignorance, these experiences are not equally experienced and felt. This tension between universalism and alterity in vulnerability is one I expose through my examination of collectivising hashtags. I look at critical feminist literature on vulnerability, precariousness, and ignorance to provide a framework for beginning the work of understanding the practice of collectivising hashtags.

Throughout my dissertation, I consider how our understanding of online encounters can be recast by considering Butler's concepts of precariousness, precarity, and hierarchies of grievability in light of new collectivising hashtag practices.127 Butler claims that the apprehension of human precariousness has the potential to make grief itself into a collective moral resource.128 The experience of grief is a universal one: "Despite our differences in location and history, my guess is it is possible to appeal to a 'we' for all of us have some notion of what it is to have lost somebody." 129 Butler also claims that "there is something to be gained in the political domain" by maintaining vulnerability as part of an International Relations framework. $^{130}$ The experience of loss and precarity, when distributed globally, has the potential to remind us of our shared human vulnerability and "our collective responsibility for the physical lives of each other." 131 Gilson maintains that vulnerability should be considered a primary human condition. ${ }^{132}$ Rather than being conceived in a purely negative way as "susceptible, exposed, at risk, in danger", Gilson conceives vulnerability as an "ambivalent state of potentiality." 133 On this account, Gilson writes "Vulnerability is a basic kind of openness to being affected and affecting in both positive and negative ways, which can take diverse forms in different social situations." 134 Vulnerability is a "pervasive feature of the human condition" that encompasses "conceptions of passivity, affectivity, openness to change, dispossession and exposure" to harm and precariousness. ${ }^{135}$ Gilson further describes vulnerability's ambivalent potential as follows:

\footnotetext{
126 Terry Gross, “'I Can’t Breathe' Examines Modern Policing And The Life and Death of Eric Garner,” Fresh Air, 23 October, 2017, https://search-proquest-com.helicon.vuw.ac.nz/other-sources/i-cant-breathe-examines-modernpolicing-life/docview/1954001696/se-2?accountid=14782

127 Butler, Precarious Life.

128 Butler, Precarious Life, 30.

129 Butler, Precarious Life, 20.

130 Butler, Precarious Life, 30.

131 Butler, Precarious Life, 30.

132 Gilson, "Vulnerability, Ignorance, and Oppression," 309.

133 Gilson, "Vulnerability, Ignorance, and Oppression," 309.

134 Gilson, "Vulnerability, Ignorance, and Oppression," 310.

135 Gilson, "Vulnerability, Ignorance, and Oppression," 309-310.
} 
Being vulnerable makes it possible for us to suffer, to fall prey to violence and be harmed, but also to fall in love, to learn to take pleasure and find comfort in the presence of other, and to experience the simultaneity of these things. ${ }^{136}$

Gilson redefines vulnerability as a "condition of potential" that makes possible other conditions, such as feeling and affect. ${ }^{137}$ Vulnerability is a shared human condition that can both enable and limit us as people who are both "affected and affecting in turn."138

This "apprehension of a common human vulnerability" highlights the affecting nature of our actions and encounters with other bodies. ${ }^{139}$ As socially constituted bodies, we are all vulnerable to one another: "attached to others, at risk of losing those attachments, exposed to others, at risk of violence by virtue of that exposure." 140 Butler claims that one insight this vulnerability affords is that there are other people whom we may never meet, on whom our lives depend. ${ }^{141}$ She writes:

To be injured means that one has the chance to reflect upon injury, to find out the mechanisms of its distribution, to find out who else suffers from permeable borders, unexpected violence, dispossession, and fear, and in what ways. ${ }^{142}$

This fundamental co-dependency on anonymous others offers an alternative way of structuring our International Relations. ${ }^{143}$ Shared vulnerability offers a chance to imagine a world in which inescapable interdependency is acknowledged as the basis for the global political community. ${ }^{144}$ However, if we take a look at our current international system, it becomes clear that no such transformation of grief has taken place and Butler concludes that "loss has failed to make a we of us all."145

Human lives are supported and recognised differently around the world because vulnerability is differentiated and allocated differently amongst people. ${ }^{146}$ There are radically different ways in which human vulnerability, specifically corporeal vulnerability, are distributed in the international system. ${ }^{147}$ In her review of Butler's biopolitics, Janell Watson clearly differentiates between Butler's conception of precariousness and precarity explaining:

Corporeal fragility both equalises and differentiates: all bodies are menaced by suffering, injury, and death (precariousness), but some bodies are more protected and others more exposed (precarity). Precariousness is shared by all; precarity is 'distributed unequally.'148

136 Gilson, "Vulnerability, Ignorance, and Oppression," 310.

137 Gilson, "Vulnerability, Ignorance, and Oppression," 310.

138 Gilson, "Vulnerability, Ignorance, and Oppression," 310.

139 Butler, Precarious Life, 20.

140 Butler, Precarious Life, 20.

141 Butler, Precarious Life, xii.

142 Butler, Precarious Life, xii.

143 Butler, Precarious Life, xii.

144 Butler, Precarious Life, xii-xiii.

145 Butler, Precarious Life, 20.

146 Butler, Precarious Life, 31-32.

147 Butler, Precarious Life, 32.

148 Janell Watson, “Butler's Biopolitics: Precarious Community," Theory and Event 15 no.2 (2012): 1. 
For Butler, precariousness and precarity are intersecting and paradoxical concepts. ${ }^{149}$ While all lives are by definition precarious (in that life's persistence is not guaranteed and can be ended at any moment), there are certain bodies such as racial minorities, LGBTQI+ communities, people with a disability and other minority groups whose risk of mortality, dispossession, or marginalisation is more significant than others. What is key here is that precarity is not distributed equally. Butler explains that strategies to implement that unequal distribution are precisely at work during times of crisis and in differential treatment to human tragedy and inequalities. ${ }^{150}$ Butler claims that, at its core, precarity is a "politically induced condition in which certain populations suffer from failing social and economic networks of support and become differentially exposed to injury, violence and death."151 I explore how collectivising hashtags paradoxically speak to shared precariousness while denying the particular precarity of Other bodies. In the forthcoming chapters, I suggest that appropriating the experience of precarity not only omits more deep-rooted structural inequalities, but it also acts to hinder privileged bodies' ability to locate and work through their participation within this technological cycle of vulnerability, ignorance, and violence.

Butler believes it is crucial to better understand the visual, discursive, and technological frames and political conditions in which the avoidance of precariousness seeks to deny the condition of precarity to Other vulnerable bodies.152 I argue that collectivising hashtags are architecturally structured in such a way that they become productive of power. For example, trending hashtags are circulated by privileged users to establish their hegemony, and as a consequence these frames which maintain precariousness and ignore precarity, decide which bodies are recognised, and given value or agency. When individual vulnerable bodies become collectivised within ordinary discourse, "the frame solicits our complicity" and establishes the normalisation of appropriating precarity. 153 Butler explains "this circulation brings out or, rather, is the iterable structure of the frame."154 As part of the very mechanism of their circulation, it becomes possible to apprehend something about how inequalities are established and maintained both on and offline. ${ }^{155}$ News is presented in such a way that it is palatable to Western audiences; the context of the event is generally ignored in favour of dominant Western narratives such as good versus evil, freedom versus extremism, us versus them. ${ }^{156}$ Butler claims the frames through which we apprehend or fail to apprehend precarious lives are "politically saturated." 157 The creation of Otherness has embedded itself within the modern framework of mourning. Butler states, "certain lives will be highly protected, and the abrogation of their claims to sanctity will be sufficient to mobilise the forces of war. Other lives will not find such fast and furious support and will not even qualify as grievable." 158 She suggests that the modern framework in which we apprehend human life is hierarchical and that certain forms of grief, particularly those relating to the West's lost sense of security

149 Butler, Frames of War, 25.

150 Butler, Frames of War, 25.

151 Butler, Frames of War, 25.

152 Butler, Frames of War, 25.

153 Butler, Frames of War, xvii.

154 Butler, Frames of War, 12.

155 Butler, Frames of War, 12.

156 Butler, Frames of War.

157 Butler, Frames of War, 1.

158 Butler, Precarious Life, 32. 
(events such as 9/11, the November Paris attacks, or the Manchester Arena bombing), are globally recognised and amplified.159 In contrast, other losses become "unthinkable and ungrievable." 160 This 'differential allocation of grievability', which acts to decide which lives we mourn and which lives we do not, produces certain exclusionary conceptions about who qualifies as normatively human, reinforcing the divide between 'us' and the vulnerable Other. ${ }^{161}$ Recognising this divide, I explore how the online circulation of collectivising hashtags reinforces this differential allocation of grievability and sheds light on how people respond to their own vulnerability and that of Others.

The vulnerability that binds us together in our humanness simultaneously stands to separate us from outsiders who are "objects of fear, suspicion, hatred, envy, contempt, or disgust."162 When we see distant Others suffering, we confront the precariousness of human life, which calls attention to our insecurity and vulnerability to harm. ${ }^{163}$ Susan Wendell discusses the affective nature of vulnerability in her discourse on disabled bodies, saying, "If somebody tells me that she is in pain, she reminds me of the existence of pain, the imperfection and fragility of the body, the possibility of my own pain, the inevitability of it." 164 Being open to one's own vulnerability and that of others can be acutely unsettling, as it confronts us with difficult aspects of our existence that we might prefer to leave unchallenged. ${ }^{165}$ Disturbed by the negative aspects of vulnerability, we may instead choose to seek what we perceive to be "invulnerability", and in doing so become ignorant of our own humanity. ${ }^{166}$ In order to secure our own invulnerability, we disavow our openness to harm, choosing instead to project it onto the vulnerable Other. ${ }^{167}$ Wendell continues,

If I cannot avoid it [pain] in her presence, I will avoid her. I may even blame her for it. I may tell myself that she could have avoided it, in order to go on believing that I can avoid it. I want to believe that I am not like her; I cling to the differences. Gradually, I make her 'other' because I don't want to confront my real body, which I fear I cannot accept. 168

When confronted with our universal human capacity for vulnerability, we have a tendency to distance ourselves by creating distinctions between our own and Other bodies. Privileged bodies conceive the corporeal consequence of vulnerability as an unfortunate reality for Others - inconceivable for privileged Western bodies like 'us'.

Gilson claims that ignorance of vulnerability is produced through the pursuit of an ideal of invulnerability that involves "ethical and epistemological closure." 169 The primary concern for

\footnotetext{
159 Butler, Frames of War, 26-27.

160 Butler, Frames of War, 26-27.

161 Butler, Frames of War, 26-27.

162 Andrew Linklater, “Grand Narratives and International Relations,”Global Change Peace \& Security 21, no1 (2009)

9-10, doi: 10.1080/14781150802659234.

163 Susan Wendell, "Toward a Feminist Theory of Disability," Hypatia 4, no2 (1989): 113, doi: 10.1111/j.1527-

2001.1989.tb00576.x.

164 Wendell, "Toward a Feminist Theory of Disability," 113.

165 Gilson, "Vulnerability, Ignorance, and Oppression," 313.

166 Gilson, "Vulnerability, Ignorance, and Oppression,” 312-319.

167 Gilson, "Vulnerability, Ignorance, and Oppression," 312.

168 Wendell, "Toward a Feminist Theory of Disability," 113.

169 Gilson, "Vulnerability, Ignorance, and Oppression," 308.
} 
Gilson is that this drive for invulnerability undergirds a more persuasive form of ignorance that "paves the way for oppressive types of ignorance."170 In other words, invulnerability (understood as a willful denial of vulnerability) is an attempt by privileged bodies to close themselves off to being affected and impacted by others. One of the effects of a negative understanding of vulnerability as susceptibility to harm is what Gilson calls "willful ignorance", generated through a desire to become invulnerable and impervious to harm. ${ }^{171}$ In an attempt to create a masterful self-identity, privileged bodies reject vulnerability and project it onto Others with whom they disidentify. ${ }^{172}$

The denial of vulnerability can be understood to be motivated by the desire-conscious or not-to maintain a certain kind of subjectivity privileged in capitalist socioeconomic systems, namely, that of the prototypical, arrogantly self-sufficient, independent, invulnerable master subject. ${ }^{173}$

Invulnerability is understood as a form of ignorance that denies both the shared human capacity for vulnerability and the differential effects of precarity. ${ }^{174}$ Western audiences perceive it to be in their best interest to remain willfully ignorant and not look too closely at the distant Other. ${ }^{175}$ Willful ignorance is more than "'not caring to know' but is a deeper form of ignorance, closer to a disavowal than a dismissal", that is actively cultivated and must be continually maintained because it appears to be in privileged bodies' best interest to remain ignorant. ${ }^{176}$ In Tuana's words:

Willful ignorance is a deception that we impose upon ourselves, but it is not an isolated lie that we consciously tell ourselves, a belief we know to be false but insist on repeating. Rather, willful ignorance is a systematic process of self-deception, a willful embrace of ignorance that infects those who are in positions of privilege, an active ignoring of the oppression of other and one's role in that exploitation. ${ }^{177}$

Ignorance thus becomes a structural problem that serves to maintain status-quo systems of inequality which foster oppression based on race, class, gender, ethnicity, sexuality, nationality, age, and ability. Kate Schick suggests that invulnerability is founded on the binary of self and Other which enables privileged bodies to position themselves as observer and judge without requiring them to associate themselves with the oppressor. ${ }^{178}$ Privileged bodies are able to distance themselves from the idea that they might identify with the oppressor, a practice which "fails to attend to our own implication in oppressive structures." ${ }^{779}$ Elizabeth Spelman argues that privileged bodies strive to maintain their own perceived invulnerability because the reality of histories of oppression are seen as "too difficult and upsetting" to

170 Gilson, "Vulnerability, Ignorance, and Oppression,” 319-320.

171 Gilson, "Vulnerability, Ignorance, and Oppression," 312.

172 Gilson, "Vulnerability, Ignorance, and Oppression," 312.

173 Gilson, "Vulnerability, Ignorance, and Oppression," 312.

174 Gilson, "Vulnerability, Ignorance, and Oppression," 312.

175 Tuana, "The Speculum of Ignorance," 11.

176 Gilson, "Vulnerability, Ignorance, and Oppression," 313-14.

177 Tuana, "The Speculum of Ignorance," 11.

178 Schick, "Unsettling Pedagogy," 30.

179 Schick, "Unsettling Pedagogy," 30. 
process. ${ }^{180}$ To become vulnerable would require rethinking privileged conceptions of self, for example, "as someone who is basically a good person, hardworking and diligent, as someone who has achieved what she has achieved fairly and justly rather than due to White privilege."181 Bringing the lives of the distant Other into the view of privileged onlookers has not resulted in any true form of recognition. Ultimately, privileged bodies cannot see the Other because they are blinded by willful ignorance and their own unattainable visions of an invulnerable self. Given that collectivising hashtags can shape our conceptions of Otherness, it is important to understand how these hashtags are architecturally constitutive; that is, to conceptualise the functional as well as relational processes whereby collectivising hashtags become productive of power and inequality. Through examining my first case studies \#TheyAreUs and \#ThisIsNotUs, I explore how willful ignorance and a desire for invulnerability interplay with privileged performances of self via collectivising hashtag practices.

\subsection{The Affordances of Collectivising Hashtags}

Social constructs of self are created in complex online environments in which discourse, hashtags, algorithms, and platform architectures interplay with how users encounter Other bodies. The theory of affordances has been adopted by Media Studies theorists as a 'middle term' that brings together the architectural aspects of social media platforms and processes in combination with user behaviours and affective responses. ${ }^{182}$ In its original meaning, the theory of affordances helped researchers to establish how particular environments encourage or constrain particular usages for their inhabitants. The theory of affordances was initially powerful because of its relationality, "the way that it connects a perceiving subject and a set of materially embedded action capacities."183 The concept of affordances was originally developed by James Gibson in 1979 in the field of ecological psychology as a way to understand how environments are both architecturally enabling and constraining, and socially constructed and situated. ${ }^{184}$ Affordances are both functional and relational, "functional in the sense that it enables as well as constrains actions, and relational in that affordances are not experienced in isolation, but rather in relation to a complex ecology of other people and other affordances."185 Affordances do not limit social behaviour to user customs and practices; instead, they challenge researchers to locate both architectural and social factors that shape our online interactions. Bucher and Helmond discuss the conceptualisation of affordances as a term that navigates how technology and society are interconnected, suggesting:

The term 'affordance' provides a way to move beyond naïve technological determinism and strict social constructivism...affordance provides a middle term that both takes into account the ways in which technologies are socially constructed and situated on the one hand, and materially constraining and enabling on the other hand."186

\footnotetext{
180 Elizabeth V. Spelman, “Managing Ignorance," in Race and Epistemologies of Ignorance, ed. Shannon Sullivan and Nancy Tuana (Ithaca: State University of New York Press, 2007), 119-131.

181 Spelman, "Managing Ignorance," 123.

182 Bucher and Helmond "The Affordances of Social Media Platforms," 237.

183 Mcveigh-Schultz and Baym, "Thinking of You," 2.

184 Bucher and Helmond "The Affordances of Social Media Platforms," 235.

185 Bucher and Helmond "The Affordances of Social Media Platforms, " 237.

186 Bucher and Helmond "The Affordances of Social Media Platforms, " 238.
} 
In the humanities and social sciences, the term 'affordances' has been used to account for "the ways that technological artifacts or platforms privilege, open up or constrain particular actions and social practices." 187 In this dissertation, affordances provide a lens for examining the possibilities and limitations that collectivising hashtags provide users within an encounter. The theory of affordances' is key to my research because it provides a framework for assessing how architectural aspects of collectivising hashtags, in combination with user behaviour and affective responses, act to maintain or challenge prevailing conceptions of humanity.

Affordances as a concept is used in social media research to capture the relationship between the architecture of media and human agency. ${ }^{188}$ Social media platforms are designed to serve a particular purpose channelling data flow from users back to commercial databases in order to "fit the underlying economic business models of the platform."189 In the context of collectivising hashtags, this programmability is facilitated by a coded interface which enables the applications of hashtags on online platforms like Twitter, Instagram and Facebook. It is important to note that algorithms (as curated sequencing of code) are not agnostic; programmers design them with their own motivations and outcomes in mind, "outcomes influenced by commercial or other interests and agendas." 190 José van Dijck pointedly claims that the "the devil is in the default" when it comes to the workings of online systems. ${ }^{191}$ She argues that social media platforms are transitioning from systems that promote human connectedness to systems that are "all about automated connectivity and data flows nudging them into commercial attention zones." 192 We should be particularly wary of claims that these platforms are impartial and equitable. Time magazine called Facebook's mission to share the internet to developing countries "an act of self-serving techno-colonialism", pointedly commenting:

Hooking up the remaining 5.1 billion people who have currently no access to the Internet is not like hooking them up to a piped water and irrigation system; it is like proposing to import a single brand of bottled water into remote areas of the world's developing countries. ${ }^{193}$

Commercially driven social media platforms and their algorithmic processes are ultimately designed to facilitate corporate goals. In a series of interviews conducted on how capitalist societies shape search engines, Mager found that one third of interviews described engineers as the "central driving force" behind algorithms. ${ }^{194}$ Similarly, Emad Khazraee and Alison Novak seek out hidden capitalist ideologies in everyday digital applications such as search engines processes in order to illustrate how broader power structures might find their ways into

\footnotetext{
187 Peter Nagy and Gina Neff, "Imagined Affordance: Reconstructing a Keyword for Communication Theory," Social Media \& Society 1 no.2 (2015): 2, doi:10.117/2056305115603385.

188 Bucher and Helmond "The Affordances of Social Media Platforms," 238.

189 Bucher and Helmond "The Affordances of Social Media Platforms," 241.

190 David Beer, “The Social Power of Algorithms," Information, Communication \& Society 20, no1 (2017): 4, doi: 10.1080/1369118X.2016.1216147.

191 José van Dijck, The Culture of Connectivity: A Critical History of Social Media, (Oxford: Oxford University Press, 2013), 46.

192 José van Dijck, "After Connectivity: The Era of Connectication," Social Media \& Society 1, no.1 (2015): 1, doi: $10.1177 / 2056305115578873$.

193 Dijck, "After Connectivity," 1.

194 Mager, "Algorithmic Ideology," 755.
} 
algorithmic processes and designs. ${ }^{195}$ Both researchers conclude that the internet is a product of a neoliberal agenda; it is a databased vehicle automated through algorithms, data flows, interfaces and business circles.196 Affordances of social media are characterised by programmable infrastructures and capitalist objectives, as well as user behaviours. ${ }^{197}$ The power of hashtags is not just in their code, but in the way that they become part of a discursive understanding of desirability or 'code of normalisation' that recognises and amplifies certain narratives. ${ }^{198}$ Megan Boler and Elizabeth Davis argue that the "algorithmic is deeply entangled in racialised, classed and gendered logics of the political present." ${ }^{199}$ Underlying social media platforms such as Facebook, Twitter and YouTube are proprietary algorithms which filter data produced by users and shape them into calculated streams specific to each user. ${ }^{200}$ Algorithms are the decision making parts of code; they have the ability to make choices, "to classify, to sort, to order, and to rank."201 For David Beer, the power of algorithms here is in their ability to decide what matters and to decide what should be most visible.202 My research examines how performances of self via collectivising hashtags play into and are influenced by the corporate, for profit nature of online platforms.

While the affordances of social media are heavily influenced by their design, structure and capitalist foundations, users also contribute to their architecture. Mager contends that the capitalist ideology that gets inscribed in algorithms are negotiated by a network of actors and interests including website providers, designers and, importantly, users. ${ }^{203}$ She stipulates that "our technologies mirror our societies. They reproduce and embody the complex interplay of professional, technical, economic, and political factors." 204 Mager quotes a graduate student in human-centred design and engineering who explained,

The reason they're pushing this information at us is because we're gobbling it up. I mean, we're consumers, and we're also producers. I think the driving force behind this information economy is our, kind of, probably, possibly a little bit unhealthy desire to just keep consuming, and communicating, and producing at such a frenzied rate. ${ }^{205}$

It is important to note that the affordances of social media platforms are not fixed by designers and programmers; users have agency and are involved in the co-creation of digital environments. Both website providers and users stabilise the algorithmic capitalist ideology by entering alliances with technology used to reach their own goals - reinforced by the clever architectural construction of algorithmic "punishments and rewards." ${ }^{206}$ Mager explains that users who try to opt-out or work against capitalist algorithmic processes are disadvantaged. In

\footnotetext{
195 Emad Khazraee and Alison N. Novak, "Digitally Mediated Protest: Social Media Affordances for Collective Identity Construction," Social Media \& Society 4 no.1 (2018), 3 doi: 10.1177/2056305118765740.

196 Dijck, "After Connectivity,” 1.

197 Tarleton Gillespie, “The Politics of 'Platforms,"” New Media \& Society 12, no.3 (2010): 347, doi:

10.1177/14614444809342738.

198 Beer, "The Social Power of Algorithms," 9.

199 Megan Boler and Elizabeth Davis, "The Affective Politics of the 'Post-Truth' Era: Feeling Rules and Networked Subjectivity," Emotion, Space \& Society 27 (2018): 83, doi: 10.1016/j.empspa.2018.03.002.

200 Dijck, The Culture of Connectivity, 54.

201 Beer, "The Social Power of Algorithms," 5.

202 Beer, "The Social Power of Algorithms," 6.

203 Mager, "Algorithmic Ideology," 773

204 Mager, "Algorithmic Ideology," 773.

205 Mager, "Algorithmic Ideology," 778.

206 Mager, "Algorithmic Ideology," 782.
} 
an interview with a search engine scholar, she relays, "We're caught up in a physical exchange, yeah (...) you're giving that information in exchange for that service, and you're punished if you don't say yes. Not punished in a negative way, but punished with less than other people have."207 According to Mager, the affordances of platforms make activities that support capitalistic goals seem more attainable, and those that go against "the new spirit of capitalism" prohibitive. ${ }^{208}$ Users feel that it is in their best interests to enact and maintain contemporary digital practices and solidify the new spirit of capitalism online. Machine learning algorithms are increasingly adapting to users' interests, locations and desires as identified by their histories of interactions. Mager remarks that users should not merely conceive themselves as 'victims' of algorithms and their new modes of data-collecting exploitation, "Rather, they should be conceptualised as actively stabilizing the technology with their marketing, search and consumer practices - partly consciously, partly unconsciously." 209 This interdependence suggests shifting the focus of attention from impacts that algorithms have on users and society towards social practices and power relations involved in the construction of online spaces..$^{210}$ Mager claims it is essential to understand that privately-owned media platforms benefit from our "marketing strategies, consumer desires, ignorance, compliance, innovation, fetish, politics of privatisation and, most of all, globalised capitalism that increasingly escapes local sociopolitical cultures and frameworks." ${ }^{211}$ In this dissertation, I focus specifically on how platforms benefit from user practices through the application of feminist research on precariousness, ignorance, and invulnerability.

I explore how affordances of collectivising hashtags are produced and stabilised by users and by status quo power relations. Joshua McVeigh-Schultz and Nancy Baym emphasise the theory of affordances as an encounter between bodies and artifacts. ${ }^{212}$ They explain, "affordances as a concept was initially powerful because of its relationality - the way that it connects a perceiving subject to a set of architecturally embedded action-capacities." ${ }^{213}$ I extend this argument further to suggest that positionality, where we stand in relation to those we encounter, is a key aspect of hashtag affordances. Technological privileges and digital literacy are indicative of the ways that people employ and make sense of affordances. ${ }^{214}$ Affordances are specific to each user whose experience is grounded in a complex ecology of other users. ${ }^{215}$ Bucher and Helmond argue that the ways in which users imagine or expect particular algorithmic affordances affect how they approach these platforms. ${ }^{216}$ Affordances emerge between users' perceptions, attitudes, and expectations; between the architecture and functionality of technologies. ${ }^{217}$ Accordingly, ways of knowing or analysing affordances require an emphasis on users' own accounts of technology, "where affordances becomes as much part of the users' experiences and perceptions of technologies as of the technologies themselves." 218 Imagined affordances may not just affect how users approach social media platforms, but more

\footnotetext{
207 Mager, "Algorithmic Ideology," 778.

208 Mager, "Algorithmic Ideology," 773.

209 Mager, "Algorithmic Ideology," 779.

210 Mager, "Algorithmic Ideology," 782.

211 Mager, "Algorithmic Ideology," 783.

212 Mcveigh-Schultz and Baym, "Thinking of You," 2.

213 Mcveigh-Schultz and Baym, "Thinking of You," 2.

214 Mcveigh-Schultz and Baym, "Thinking of You," 2.

215 Bucher and Helmond, "The Affordances of Social Media Platforms," 239.

216 Bucher and Helmond, "The Affordances of Social Media Platforms," 239.

217 Bucher and Helmond, "The Affordances of Social Media Platforms," 239.

218 Bucher and Helmond, "The Affordances of Social Media Platforms,"239-240.
} 
importantly they may performatively shape digital affordances themselves. ${ }^{219}$ People's expectations and perceptions of a technology's application, like a hashtag, may affect behaviour as much as its architectural properties do.

Multiple beliefs exist around what a hashtag is for, and what the prospects of an algorithmically strategic approach would do to the possibilities and constraints of its use. Omid Aziz and Manohar Paluri consider the ways Facebook's algorithms respond to user input in adaptive ways:

Facebook uses machine learning techniques for ranking search results, serving the most relevant ads, identifying faces and predicting which memories people would like to see. The platform feature 'On This Day' employs a machine learning model which learns in real-time and continuously from people about which memories they would like to see on their News Feeds. 220

Algorithms make predictions about what content users would like to see, shaping and guiding our online interactions with others in accordance with perceived preferences. Algorithms can reinforce dominant power dynamics by creating systems that circulate dominant truths and discursively reinforce norms, particularly in regards to who is seen and unseen. Beer challenges us to think about algorithms beyond affordances of software, asking "should we treat them as lines of code, as objects or should we see them as social processes in which the social world is embodied in the substrate of the code?"221 Zygmunt Bauman contends that the algorithmic characteristics of the internet work against extensions of human solidarity, stating, "paradoxically, the widening of the range of opportunities to promptly find ready-made 'likeminds' for every and any interest pursued narrows and impoverishes, instead of augmenting and enriching, the 'social skills' of the seekers after the 'virtual community of minds.'”222 Algorithms increasingly define the spaces and boundaries of our online encounters with Others, promoting a standardised conception of what it means to be human in digitally mediated contexts. How users employ these seemingly insignificant and 'neutral' combinations of $1 \mathrm{~s}$ and 0 s effectively decides who we encounter online and, perhaps more importantly, who we do not.

Pure technological determinism fails to adequately consider the asymmetries of power through which deliberation and consensus are achieved. ${ }^{223}$ Critical Media Studies scholars use the concept of social affordances to examine what technology affords its users, i.e., how technological properties enable or constrain social relations and social structures in specific ways. ${ }^{224}$ Gibson suggests that how people behave, move, or simply exist in an environment

\footnotetext{
219 Bucher and Helmond, "The Affordances of Social Media Platforms," 239.

220 Omid Aziz and Manohar Paluri, "Engineering for Nostalgia: Building a Personalized 'On This Day' Experience," Facebook Engineering, 17 March, 2021, https://code.facebook.com/posts/1748968875380127/engineering-fornostalgia- building-a-personalized-on-this-day-experience/

221 Beer, "The Social Power of Algorithms," 4.

222 Zygmunt Bauman, Living on Borrowed Time: Conversations with Citlali Rovirosa-Madrazo, (UK, Cambridge: Polity, 2013), 166.

223 Lincoln Dahlberg, "Rethinking the Fragmentation of the Cyberpublic: From Consensus to Contestation," New Media \& Society 9 no.5 (2007): 827-47, doi: 10.1177/14614444807081228. See also Petros Iosifidis and Mark Wheeler, Public Spheres and Mediated Social Networks in the Western Context and Beyond, (UK, London: Palgrave, 2016), 141.

224 Bucher and Helmond, "The Affordances of Social Media Platforms," 235.
} 
affords important cues as to how others should behave, move or co-exist. ${ }^{225}$ Gibson illustrates this with the example of the pedestrian sidewalk; people constantly adjust their own movements to other people in their pathway. 226 While the environment may give structure to an organism's existence, Gibson suggests that "behaviour affords behaviour."227 Importantly for Gibson, "what the other animal affords the observer is not only behaviour but also social interaction." 228 In the context of email technologies, William Gaver explains that "the properties of email systems may not determine the communities that eventually form around them... but they do strongly constrain the cultures that might develop." 229 The theory of affordances establishes the architectural qualities of hashtags as (partly) constitutive of sociality and communicative actions. ${ }^{230}$ Although hashtags technically afford identical actions, when taking into account what users say, believe and expect, what these features are able to accomplish varies greatly.231 How people interact, move or simply exist in online atmospheres reveals important clues about what they believe to be the potentialities and limits of social media platforms and processes. ${ }^{232}$ This is to say, users' perceptions, beliefs and expectations of what technology does or how it performs actively shape how users engage with them. ${ }^{233}$ Aristea Fotopoulou recognises this trend in her research regarding marginalised voices, stating:

My empirical research shows, women's and queer groups reorganise according to what they see as demands of network conditions in the digital era and, for many, the struggle for representational space in networked environments can be seen as merely a quest of popularity. 234

Facebook users compete with one another for Likes because they believe that more Likes will result in greater visibility in a digital ecology characterised by popularity. ${ }^{235}$ Thus, posts are organised around various popularity and affinity metrics, including user interaction and their engagement with posts through activities such as liking, sharing and commenting. ${ }^{236}$

Social media is designed in such a way that it reflects the majority perspective, which is concerning for critical race and feminist scholars. The intersubjective basis of meaning-making and the dominant role of 'like-minded' Western deliberative groups means we are only engaging with the status quo perspective.237 Pallavi Guha notes that while social media mechanisms such as hashtags are celebrated for generating public debate, the focus has been almost exclusively on examples derived from Western democracies. ${ }^{238}$ Racial, gendered, and

\footnotetext{
225 James J. Gibson, The Ecological Approach to Visual Perception, (UK, London: Routledge, 2015), 36.

226 Gibson, The Ecological Approach to Visual Perception, 36.

227 Bucher and Helmond, "The Affordances of Social Media Platforms," 234-235.

228 Gibson, The Ecological Approach to Visual Perception, 36.

229 William W. Gaver, "Situating Action II: Affordances for Interaction: The Social Is Material for Design," Ecological Psychology 8, no.2 (1996): 120, doi: 10.1207/s15326969eco0802_2.

230 Gaver, "Affordances for Interaction, " 120.

231 Bucher and Helmond "The Affordances of Social Media Platforms," 242.

232 Bucher and Helmond "The Affordances of Social Media Platforms," 242.

233 Nagy and Neff, "Imagined Affordance," 4-7.

234 Aristea Fotopoulou, "Feminist Activism and Digital Networks Between Empowerment and Vulnerability," (UK, London: Palgrave Macmillan, 2016), 14

235 Fotopoulou, "Feminist Activism and Digital Networks," 14.

236 Bucher and Helmond, "The Affordances of Social Media Platforms," 242.

237 Iosifidis and Wheeler, Public Spheres and Mediated Social Networks, 141.

238 Pallavi Guha, "Hash Tagging But Not Trending: The Success and Failure of The News Media to Engage with Online Feminist Activism in India," Feminist Media Studies 15, no.1 (2014): 155, doi: 10.1080/14680777.2015.987424.
} 
class bias are 'baked into' algorithmic technologies and social media platforms. ${ }^{239}$ Algorithmic logic is subject to the same biases in creating the online world as exist in the offline world. ${ }^{240}$ Differences in identity do not disappear online; divisions such as race, class, and gender carry over into and affect social interactions online. Algorithms encoded with bias can reaffirm or even exacerbate inequalities and discrimination. Our online actions inform how algorithms structure the online environment in which we operate. Rachel Kuo claims that "not all participants are - or feel - equally welcome in online forums." ${ }^{241}$ For Kuo, divisions of identity are performed and reproduced online, and these technologically mediated divisions of identity affect public discourse. ${ }^{242}$ She argues that as a "racially unmarked space, Twitter is rarely understood as constitutive of White identity. ${ }^{243}$ In an interview at the Hairpin she explains, "Race is about being tokenized in spaces that are coded white but attempt to offer a veneer of inclusivity while pushing ideologies that perpetuate the very same white supremacy that leaves us [people of colour] out of the resource distribution."244 My research reaffirms that the underlying social and cultural identities shaping Twitter's design, expectations, and use, privileges the usage of White users 'as the norm.'245

Social media platforms like Facebook, Twitter and YouTube encourage the creation of cumulative advantage, where users are more likely to follow other users with an already extensive network reach, creating a rich-gets-richer visibility loop. Zeynep Tufekci suggests that algorithms have unintended discriminatory consequences for marginalised bodies. ${ }^{246}$ To illustrate this argument, Tufekci uses the example of algorithmic filtering on Twitter and the hashtag campaign \#Ferguson which trended locally (following the shooting of Michael Brown, a Black American teenager in Ferguson, Missouri) yet failed to trend nationally. ${ }^{247}$ Tufekci asked:

Why? Almost certainly because there was already national, simmering discussion for many days and Twitter's trending algorithm (said to be based on a method called 'term frequency inverse document frequency') rewards spikes...So, as people in localities who had not been talking a lot about Ferguson started to mention it, it trended there through the national build-up in the last five days penalized Ferguson. ${ }^{248}$

That is to say, the relatively slow and consistent build up of tweets from Black American communities in Missouri meant that while enough people were using \#Ferguson for it to trend locally, its slow and steady spread meant that even as numbers reached the thousands, it

239 Lauren Kirchner, "When Discrimination Is Baked Into Algorithms," The Atlantic, 7 September, 2015 https://www.theatlantic.com/business/archive/2015/09/discrimination-algorithms-disparate-impact/403969/ 240 Heather Woods and James A. McVey, "\#BlackLivesMatter as A Case Study in the Politics of Digital Media: Algorithms, Hashtag Publics, and Organizing Protest Online,” Teaching Media Quarterly 4, no. 1 (2016), http://pubs.lib.umn.edu/tmq/vol4/iss1/5

241 Kuo, "Racial Justice Activist Hashtags," 449.

242 Woods and James McVey, "The Politics of Digital Media: Algorithms."

${ }^{243}$ Kuo, "Racial Justice Activist Hashtags," 449.

244 Kuo, "Racial Justice Activist Hashtags," 505.

245 Brock, "Critical Technocultural Discourse Analysis," 1014.

246 Zeynep Tufekci, "What Happens to \#Ferguson Affects Ferguson: Net Neutrality, Algorithmic Filtering and Ferguson," The Message, 15 August, 2014, https://medium.com/message/ferguson-is-also-a-net-neutrality-issue6d2f3db51eb0\#.rj1vniwdq

247 Tufekci, "What Happens to \#Ferguson Affects Ferguson."

248 Tufekci, "What Happens to \#Ferguson Affects Ferguson." 
ultimately failed to trend nationally. ${ }^{249}$ Social media platforms typically do not do very well covering inequitable problems of marginalised populations (which are considered even less interesting at a national level), meaning stories of Black Americans often go unheard. ${ }^{250}$ In this way, minority communities are at a disadvantage when it comes to getting visibility on Twitter. The substantial Black presence on Twitter is referred to by some as "Black Twitter" in which millions of diverse Black Twitter users network, connect, and engage with other Black users who have similar concerns, experiences, tastes and cultural practices. ${ }^{251}$ Despite Black users having high representation on Twitter in relation their population size, Twitter users are "generally presumed to be White." 252 Black users' significant contribution of digital labour is overlooked and their content is often limited and marginalised by constricting digital architectures. Sarah Florini looks at hashtags as indexing tools used to distinguish Black cultural identities on Twitter. Florini found that Black users often perform their identities through the linguistic practice of "signifyin"' which deploys figurative language, humour and wordplay to display cultural competence and knowledge. ${ }^{253}$ Florini explains that signifyin' on Twitter "allows Black users not only to reject colour blindness by actively performing their racial identities, but also to connect with other Black users to create and reify a social space for their 'Blackness.'”254 What is powerful about these hashtags is that they provide a network in which Black cultural identity is openly performed and maintained. In Chapter Five I will discuss how these networked acts and the performing of identity online are an important mode of resistance to marginalisation and erasure. ${ }^{255}$ The flip side of in-group network assemblages is that they can result in limiting functionalities with the formulation of filter bubbles that can act to limit minority community voices. For example, Facebook's algorithm selectively chooses what information a user would like to receive based on information about the user, such as location, past click-behaviour and search history. ${ }^{256}$ Tufekci is particularly wary of the impact of Facebook's filter bubbles on visibility, saying "what if Ferguson had started to bubble...Would it ever make it through the algorithmic filtering on Facebook? Maybe, but with no transparency to the decisions, I cannot be sure. Would Ferguson be buried in algorithmic censorship?"257 Tufekci concludes "It's an algorithmic filtering issue. How the internet is run, governed and filtered is a human rights issue. Don't let anyone tell you otherwise. What happens to \#Ferguson affects what happens to Ferguson." 258

My research investigates not just why collectivising hashtags have become popular, but how collectivising hashtags' technological architecture problematises recognition of precarious bodies and sustains existing inequalities. Through my case studies, I explore how digital counterpublics navigate the architectural limitations of collectivising hashtags by creating specific networks, and by adapting the linguistic structure of hashtags. Barry Wellman et al.

249 Tufekci, "What Happens to \#Ferguson Affects Ferguson."

250 Tufekci, "What Happens to \#Ferguson Affects Ferguson."

251 Theorists who discuss Black Twitter include, Brock, "From the Blackhand Side: Twitter as cultural conversation," Journal of Broadcasting \& Electronic Media 56 no.4 (2012): 529-49, doi: 10.1080/08838151.2012.732147; Mikki Kendall, Hoodfeminism: Notes from the women that a movement forgot (New York: Penguin Books, 2020); Sarah Florinin, “Tweets, Tweeps, and Signifyin': Communication and Cultural Performance on 'Black Twitter,'” Television \& New Media 15 no.3 (2014): 223-237, doi: 10.1177/1527476413480247.

252 Florinin, "Tweets, Tweeps, and Signifyin,"” 225.

253 Florinin, "Tweets, Tweeps, and Signifyin,"” 223.

254 Florinin, "Tweets, Tweeps, and Signifyin,"” 235.

255 Florinin, "Tweets, Tweeps, and Signifyin,"” 225-226.

256 Tufekci, "What Happens to \#Ferguson Affects Ferguson."

257 Tufekci, "What Happens to \#Ferguson Affects Ferguson."

258 Tufekci, "What Happens to \#Ferguson Affects Ferguson." 
argue that internet use is reinforcing pre-existing structures in the developed world that are organised around networked individualism rather than group or local solidarities.259 The limitations of localised hashtags like \#Ferguson and the widespread trending of \#BlackLivesMatter and \#ICantBreathe (all of which are a part of the same movement against racially motivated violence towards Black people) suggest that the affordances of a hashtag results from a combination of algorithmic structures as well as the social and discursive power of collectivity, universality and personalisation. ${ }^{260}$ The discursive flexibility of the hashtag, as both personal and collective, allows it to narrow the scope of online discourse to a particular topic and person while simultaneously opening up that discourse to widespread viral circulation amongst networks. ${ }^{261}$ McVey and Woods explain,

The intelligence of the hashtag as a rhetorical tool of online organising lies in its ability to invite individual signifying practices while also abstracting those acts of signification for the purposes of public addressivity among strangers. ${ }^{262}$

Collectivising hashtags are discursively designed to allow strangers to join together in what would otherwise be a personal dialogue. The algorithmic makeup of the hashtag functions to organise discourse while concomitantly opening that discourse to "the chaos of online circulation." 263 Hashtags are both valuable to and dangerous for marginalised groups because, by their very nature, they call into being publics whose ideologies are not predictable, consistent or homogeneous. The interactive nature of the hashtag means that they are open to adaptation, combination and transformation beyond their original intent as they circulate.

Trending hashtags often ignore the expansiveness of the lived experience and the alterity both within and amongst marginalised communities by choosing to promote a monolithic narrative. Even subversive racial justice and feminist hashtags are limited by the homogenous corporate logics and algorithmic functionalities of social media platforms. McVey and Woods point out that this transformative functionality of a hashtag can be highly problematic for marginalised communities online, stating "the very lack of surety that gives hashtags their capacity for the rapid circulation and viral uptake by diverse audiences also introduces the conditions for the formation of publics beyond what was originally intended."264 To illustrate this argument, they discuss the 'hashtag hijacking' of \#HandsUpDontShoot campaign which was publicly connected with the aforementioned \#ICantBreathe, \#Ferguson, and \#BlackLivesMatter hashtag movements. The \#HandsUpDontShoot hashtag was conceived in response to the shooting of Michael Brown because, prior to his death, sixteen eyewitnesses recall Brown raising both open hands in the air in a gesture for police officers not to shoot. ${ }^{265}$ As a result, 'Hands Up Don't

259 Barry Wellman et al., "The Social Affordances of the Internet for Networked Individualism," Journal of ComputerMediated Communication 8 no.3 (2003): 1, doi: 10.1111/j.1083-6101.2003.tb00216.x..

260 It is important to keep in mind that \#Ferguson was a pivotal moment for the BLM movement and that these hashtags are interconnected. \#Ferguson played a formative role in ongoing formation of the BLM movement, its networks, and subsequent related hashtags (including \#BlackLivesMatter, \#ICantBreathe, \#SayHerName, \#SayHisName and \#FalconHeights). See Sarah J. Jackson, Moya Bailey and Brooke Foucualt Welles, \#Hashtag Activism: Networks of Race and Gender Justice, (Cambridge, MA: The MIT Press, 2020), 123.

261 McVey and Woods, "Transformational Principles of Hashtag Publics."

262 McVey and Woods, "Transformational Principles of Hashtag Publics."

263 McVey and Woods, "Transformational Principles of Hashtag Publics."

264 McVey and Woods, "Transformational Principles of Hashtag Publics."

265 Laura Santhanam, Vanessa Dennis, and Travis Daub, "What Do the Newly Released Witness Statements Tell Us about the Michael Brown Shooting," PBS, 16 March, 2021, https://www.pbs.org/newshour/nation/newly-releasedwitness-testimony-tell-us-michael-brown-shooting 
Shoot' became a slogan and now iconic gesture to symbolise the injustice of racialised state violence towards Black American communities. ${ }^{266}$ Unfortunately, the popularity of the hashtag \#HandsUpDontShoot led to its discriminatory mutation by right-wing groups who began sharing the hashtag \#PantsUpDontLoot in an attempt to counter the narrative of state racism that emerged in the wake of Brown's killing. ${ }^{267}$ The racist slogan \#PantsUpDontLoot spread by The National Review condensed "easily repeatable and overly simplified tropes about Black life into a single hashtag allowing racist publics to gloss over complexities of deeply entrenched historical racism by focusing on a media spectacle of Black dereliction." 268 The universality, adaptability and replicability of circulating hashtags offers a stage for activists who desire to imagine the world otherwise. It also presents the opportunity of co-option for those who oppose these activist interventions. ${ }^{269}$ It is a common digital practice to use multiple hashtags together in a single post or tweet, meaning that hashtags like \#PantsUpDontLoot can be used with the original trending hashtag \#HandsUpDontShoot to 'hijack' its popularity and gain greater visibility with the interested audience. McVey and Woods conclude that there is a close relationship between technological affordances of hashtags and the unique possibilities as well as "perils of the digital sphere" as a site for the rhetorical labour of anti-racist organising. ${ }^{270}$ This complex relationship between hashtag collectivity and functions of algorithms will be explored in greater depth in Chapter Four of my dissertation. The affordance lens can help to form a better understanding of the relationship between the social and technical context of collective identity and contentious politics. ${ }^{271}$

I suggest we might better understand digital platforms and processes as specific kinds of 'atmospheres', where affordances reflect the complex co-evolution of users' perceptions, attitudes, affect and the current media ecology.272 My research investigates social, political and technological constructs. In the theory of affordances, the question of who affords what and to whom in digital contexts has become increasingly complex. ${ }^{273}$ Nagy and Neff suggest that older notions of affordances fail to address the complexity of relational as well as emotional and affecting affordances of technology. ${ }^{274}$ Rather, they suggest thinking about the affordances of social media as one-way relationships whereby technology affords something to users, we need to think about it as a reciprocal relationship where users afford something to technologies in return. ${ }^{275}$ Such a perspective infers affordances a more vernacular account, emphasising how users themselves promote different aspects and action possibilities of social media. ${ }^{276}$ Bucher and Helmond argue that users' understandings and perceptions of algorithms influence the architectural construction of social platforms; "characteristics of machine

\footnotetext{
266 It is important to note that hashtags surrounding the BLM movement were networked and built upon one another. See Jackson, Bailey, and Foucault Welles, \#HashtagActivism: Networks of Race and Gender Justice, 123. 267 McVey and Woods, "Transformational Principles of Hashtag Publics."

268 McVey and Woods, "Transformational Principles of Hashtag Publics."

${ }^{269}$ McVey and Woods, "Transformational Principles of Hashtag Publics."

270 McVey and Woods, "Transformational Principles of Hashtag Publics."

271 Khazraee and Novak, "Digitally Mediated Protest," 3.

272 I have specifically chosen to use the word 'atmosphere' to capture the idea of an affecting environment. People often speak about how a person's mood can affect the atmosphere in a room, and conversely how one person's emotional state can affect others. Atmosphere describes the interdependent and affecting relationship between technological functions and algorithms, users, designers, architectures, user beliefs, capitalistic structures and ideologies as they act upon one another.

273 Bucher and Helmond "The Affordances of Social Media Platforms," 239.

274 Nagy and Neff, "Imagined Affordance," 2-3.

275 Nagy and Neff, "Imagined Affordance," 2-3.

276 McVeigh-Schultz and Baym, "Thinking of You," 1.
} 
learning systems like Facebook make user beliefs an important component in shaping the overall system behaviour, as end-users activity is generative of the system itself."277 Users' experiences, perceptions and use of technologies become as much part of the technologies development as the technologies themselves. ${ }^{278}$ Users actively participate in the ongoing coproduction of their digital environments and their technological functionalities, shifting the focus and responsibility for change on to our digital practices and privileges that shape who and what we hear on social media. There is potential here for change: "This shift in perspective enables us to understand that search technology, as every technology, could be otherwise."279 The social practices and architectural structures that shape our technologies go right to the heart of how we live and organise our societies. Understanding them "allows us to see that our technologies do not necessarily have to be the way they actually are."280 This vernacular understanding of affordances turns our attention inward, calling us to question how our online performances of self problematise the recognition Others. Accordingly, my inquiry into the affordances of collectivising hashtags focuses not merely on their ability to provide a platform for marginalised voices, but also on recognition of their underlying networks of discursive privilege, power and our own location within them. Privileged users have a responsibility to recognise how our online performances of self-affect corporeal realities of vulnerable subjects.

In order to capture the multi-relational dynamics of collectivising hashtag practises and the social encounters that various algorithmic features facilitate, I employ Harris-Perry's concept of the crooked room, which she uses to explore the particular epistemology Black women face in White spaces. ${ }^{281}$ In Sister Citizen, Harris-Perry claims that in their confrontation with race and gender stereotypes, Black women are standing in a crooked room and have to navigate which way is up. ${ }^{282}$ The concept of the crooked room is based on a hypothesis in cognitive psychology research on field dependence which, much like the theory of affordances, explores the influence of environmental and visual cues on ones perception of self in relationship to environmental reality. ${ }^{283}$ Harris-Perry summarised the sociological experiment of the crooked room in the following description:

Field dependence studies show how individuals locate the upright in a space. In one study, subjects were placed in a crooked chair in a crooked room and then asked to align themselves vertically. Some perceived themselves as straight only in relation to their surroundings. To the researchers' surprise, some people could be tilted by as much as 35 degrees and report that they were perfectly straight, simply because they were aligned with images that were equally tilted. But not everyone did this: some managed to get themselves more or less upright regardless of how crooked the surrounding images were. 284

\footnotetext{
277 Bucher and Helmond "The Affordances of Social Media Platforms," 239.

278 Bucher and Helmond "The Affordances of Social Media Platforms," 239-240.

279 Mager, "Algorithmic Ideology," 782.

280 Mager, "Algorithmic Ideology," 770.

281 Harris-Perry, Sister Citizen.

282 Harris-Perry, Sister Citizen, 29.

283 Kelly Harris-DeBerry, Denese Shervington, and Rashida Govan, “Crooked Room: Stories from New Orleans," Institute of Women and Ethnic Studies, 13 April, 2021,

https://static1.squarespace.com/static/59f78bfbf43b558afe23e48a/t/5a84ac1be4966b15dd8840b8/1518644264

742/crooked-room_final_web.pdf

${ }^{284}$ Harris-Perry, Sister Citizen, 29 -36.
} 
In order to understand why Black women's public actions and political strategies sometimes seem tilted in ways that accommodate dominant groups and negative stereotyping of Black women, Harris-Perry argues that it is important to first recognise the structural constraints that influence their behaviour. ${ }^{285}$ Harris-Perry maintains that the crooked room is designed in such a way that it makes you believe that the room is straight, normal, and nothing to be opposed to but rather to embrace. ${ }^{286}$ Harris-Perry urges Black communities not to accept the imbalance of the crooked room and to push back against its normalisation "no matter how many times they say, 'It's NOT a crooked room!"'287

Harris-Perry characterises Black women's struggle with the slanted images of the crooked room as a problem of self-recognition, an important theme for political philosophers interested in issues of identity, divergence, and citizenship. ${ }^{288}$ Harris-Perry references Ralph Ellison's novel Invisible Man for its treatment of the recognition crisis faced by Black Americans opening with a declaration of misrecognition: "I am invisible, understand, simply because people refuse to see me." 289 Ellison's protagonist struggles with multiple forms of misrecognition, finding that he is sometimes hyper visible, "exposed to the aggressive and unwanted gaze of tormentors" and at other times transparent, as though the people he encounters can simply see through him. ${ }^{290}$ Harris-Perry concludes that racism and the stereotypes projected within the crooked room keep others from seeing the figure of the Invisible Man accurately. ${ }^{291}$ Feminist scholar bell hooks asserts that recognition is a political act in her book Black Looks. ${ }^{292}$ hooks argues that the very act of looking at or encountering individuals from marginal groups is infused with power because power is developed in relation to one another; to be a person of relative power and privilege viewing another person of less power and privilege is inherently a political act. ${ }^{293}$ For hooks the gaze of the powerful can never be "neutral nor benign"; misrecognition of marginalised bodies hinders their political autonomy. ${ }^{294}$ Building on hooks conception of misrecognition, Harris-Perry asserts that "challenging White people's assumptions about what they see when they view Black people is a critical step toward liberation and equality." 295 The misrecognition experienced by Black women who attempt to engage in the public sphere is what Harris-Perry conceptualises in the crooked room. ${ }^{296}$

I argue that social media platforms are the modern, digital equivalent of the crooked room. Building on Harris-Perry's and hooks' arguments of misrecognition, I assert that the affordances of collectivising hashtags allow privileged bodies to create a 'crooked platform' in which they encounter and Other non-dominant bodies. The crooked platform creates digital spaces that are architecturally and ideologically structured to prioritise the experience of privileged users. The privileges associated with Whiteness and the disadvantages projected

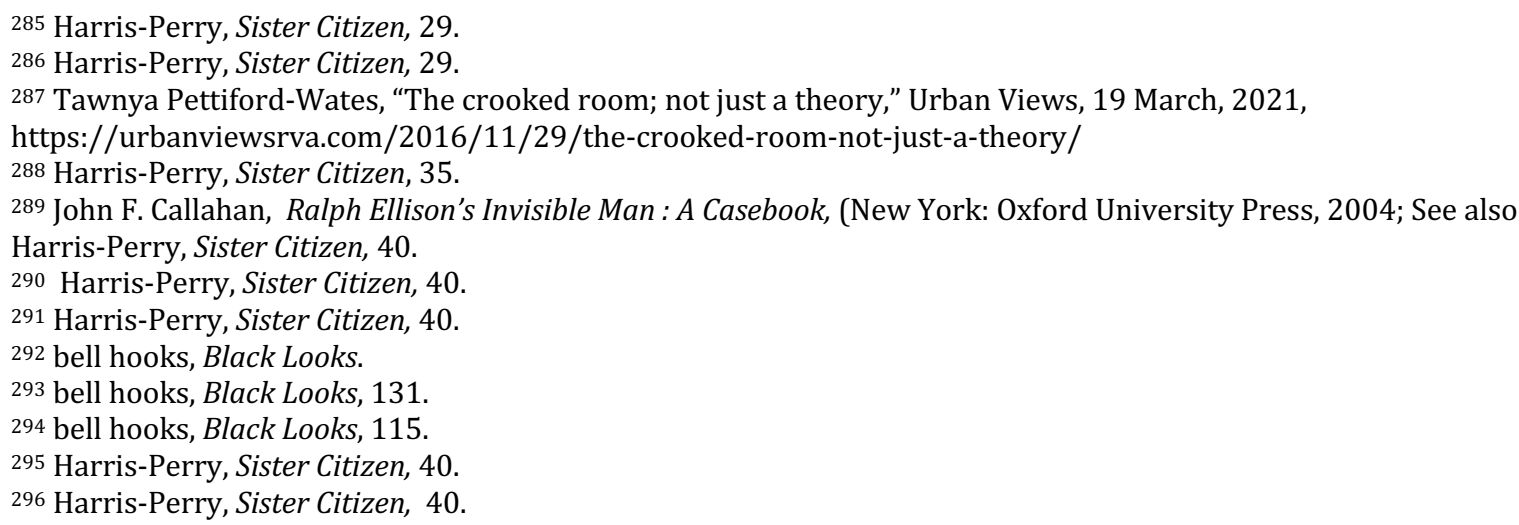


upon marginalised bodies have become an invisible structural feature of the social, economic, and political backdrop of the online environment that we inhabit. It is no surprise, then, that when marginalised users seek to engage with these platforms, they experience similar challenges to those they face in the physical world and quickly identify that the supposed neutrality of these platforms is a dream that has not been realised. The room is still crooked, we simply can no longer see the walls.

\subsection{Combining Feminist, Media Studies and International Relations Theory}

International Relations scholars are increasingly looking to micropolitical and interdisciplinary perspectives to better understand the complex and pluralistic state of world politics. An important part of my interdisciplinary research is the weaving together of literature from different disciplines and recognising how seemingly unrelated areas of study can offer unique insights when brought together. A critical feminist conceptualisation of emotion or vulnerability can provide the basis for us to perceive the ideology behind why people are drawn to collectivising hashtag practices and how they promote a certain conception of self and Other. The theory of affordances from Media Studies brings the technological architecture of hashtags to the forefront, which is essential to understand how hashtags function practically to reinforce inequalities, an aspect often ignored by International Relations studies. An exciting aspect of my research process has been seeing how these usually distinct areas of study speak to each other. A central contribution of this thesis is my observing correlations between different literatures and how they interact to provide new insight into a problem area that is both social and technological, bridging the gap between the two to highlight the interconnectedness of the human experience.

In an article on 'micro-moves', Solomon and Steele argue that shifts to the micropolitical offer compelling reconfigurations of International Relations, where varied sites of global politics are located and the role of 'ordinary' people centralized within it.297 They suggest there is a growing dissatisfaction with grand or structural theory's value as evidenced by trends in the International Relations field towards the study of practices, emotions and the everyday experience of politics. ${ }^{298}$ Grand and structural theories of International Relations are classified by Solomon and Steele (as well as by certain constructivist studies) as Liberal, Realist, and English schools of thought. ${ }^{299}$ Over the past three decades International Relations has focused on these grand theories, providing analysis at the international and global structural levels. These schools maintain that International Relations ought to be understood by observing particular theoretical assumptions and patterns from a distance, and in doing so they often ignore the rich subsystem and sub-state phenomena. ${ }^{300}$ The concern is that grand and structural theories may have directed scholarly attention away from the 'humanity of politics' by viewing humans as part of a broader movement towards some abstract world state. ${ }^{301}$ Solomon and Steele suggest that rather than peering down on the world from the third imageheights of systemic pressures, contemporary International Relations scholars now explore the

297 Solomon and Steele, "Micro-moves in International Relations theory," 271.

298 Solomon and Steele, "Micro-moves in International Relations theory," 267.

${ }^{299}$ Solomon and Steele, "Micro-moves in International Relations theory," 269.

300 Solomon and Steele, "Micro-moves in International Relations theory," 268-9.

301 Solomon and Steele, "Micro-moves in International Relations theory," 272. 
significance of the micro, the everyday and the ordinary of global politics, stating, "although grand theory neglected most of the life of global politics, life continued with or without it." 302 Instead of focusing on the roles and practices of lofty institutions, my dissertation focuses on the micro-political and further develops our engagement with the everyday life of citizens, the bodies who suffer the corporeal consequences of terrorism, racism, inequality and poverty.

Micropolitical perspectives on International Relations hold within them the promise to advance our understanding of power, identity, and security. ${ }^{303}$ Micropolitical studies consider underlying features that form our experimental constitution of larger structural categories like nation, state, economy, and security. ${ }^{304}$ The fluid and unspoken features of our socio-political lives such as sensation, resonance, and movement often slip through the binaries of structural frame works. ${ }^{305}$ Recently, academic attention has shifted away from inter-state conflict, which is becoming increasingly infrequent, towards violence which remains pervasive in international politics. ${ }^{306}$ Accordingly, International Relations scholars are increasingly departing from extant 'grand' frameworks and moving towards approaches that consider the lived, embodied and experiential everyday processes. ${ }^{307}$ This recent turn to the micropolitical is in large part indebted to feminists' efforts to include gender in the study of International Relations. ${ }^{308}$ Feminist studies have long engaged in everyday spaces and practices, emphasizing the role of the body, performances and emotions of ordinary people. ${ }^{309}$ Solomon and Steele have found that with increasing shifts to the micro, academic International Relations is beginning to (re)discover the lives and people of global politics, and that it has "breathed life back into a field that grand theory has mostly neglected." 310 There is burgeoning literature on the affective and emotional aspects of International Relations that seeks to understand how individual emotions become collective and force political change. ${ }^{311}$ There have been rich International Relations studies examining the body, trauma, and memory that contended that war is more comprehensively viewed, not only as a game played by states and militaries, but also as a "disruptive, lived phenomena that is forced upon bodies." 312 Studies on power and justice now include an embodied sensibility, one that focuses on the interrelationships among laws, bodies, discourse and space.313 There is growing interest in how politics is constituted in and through our performances of self, suggesting that they are intwined in significant and consequential ways. ${ }^{314}$ Thus, there is a need to recognize and unpack the affective, spatial and temporal processes at the everyday levels of International

\footnotetext{
302 Solomon and Steele, "Micro-moves in International Relations theory," 268.

303 Solomon and Steele, "Micro-moves in International Relations theory," 267.

304 Solomon and Steele, "Micro-moves in International Relations theory," 270.

305 Solomon and Steele, "Micro-moves in International Relations theory," 270.

306 Solomon and Steele, "Micro-moves in International Relations theory," 271.

307 Solomon and Steele, "Micro-moves in International Relations theory," 275.

308 Solomon and Steele, "Micro-moves in International Relations theory," 274.

${ }^{309}$ For feminist perspectives on the personal as political in International Relations see: Carol Hanisch's "The

Personal is Political”; Cynthia Enloe's "Mundane Matters"; and Christine Sylvester's Feminist Theory and

International Relations in a Postmodern Era.

310 Solomon and Steele, "Micro-moves in International Relations theory," 268.

311 Recent studies on the emotional and affecting nature of International Relations include: Emma Hutchison and Roland Bleiker's Fear No More: Emotions and World Politics; Judith Butler's Precarious Life; and Sara Ahmed's The Cultural Politics of Emotion.

312 Recent studies along these lines include: Patrick Hayden and Kate Schicks' Recognition and Global Politics: Critical Encounters Between State and World; Maja Zehfuss' Wounds of Memory, Clara Eroukmanof "responding to terrorism with peace, love and solidarity"; and Linda Åhäll and Thomas Gregory's "Security, Emotions, Affect".

${ }^{313}$ Solomon and Steele, "Micro-moves in International Relations theory," 271.

314 Milija Gluhovic, Silvija Jestrovic, Shirin Rai, and Michael Saward, The Oxford handbook of Politics and Performance, Oxford University Press (2018): doi: 10.1093/oxfordhb/9780190863456.013.100
} 
Relations where the dynamics of power, identity and progress often lie. If researchers only study International Relations from a macro-lens they might just miss something important about the bodies who constitute it.

A micropolitical perspective promises to reshape how we view politics and our place in it. There is a lot of politics in everyday politics. There is nothing intrinsically powerful or fundamentally political about these spaces and institutions of government. Rather, it is through micro-processes that power takes hold at everyday levels and grows from spatial assemblages of affect, bodies and rhythms. ${ }^{315}$ In light of this I believe that everything can be considered as political. This has called me to re-consider those casual spaces I encounter, the conversations that take place in break rooms before class begins, the posters students pin up in University hallways, the memes and hashtags people use. This is the politics of the ordinary where "habits, dispositions, feelings, the body, emotions and thinking can all be considered to be potential sites of domination and resistance." 316 Micropolitics can serve to foster further interdisciplinary collaboration in an International Relations field "careening towards fragmentation." 317 An important role of micro-analysis in International Relations emerges precisely because it cuts across different paradigms, perspectives and approaches. A micropolitical approach lends itself to my interdisciplinary framework that incorporates Media Studies, feminist and International Relations perspectives. I believe that this micro-political research is still in its infancy, and we are going to see its uptake by more young International Relations scholars. It is a politics that lives and breathes - it is ordinary and accessible and radical.

The shift to the micropolitical also calls for a reconceptualisation of existing interdisciplinary studies from Media Studies and International Relations which traditionally only consider online actions as as precursor to some broader movement or 'real world' political action. The majority of inter-disciplinary work in the areas of International Relations and Media Studies is pre-occupied with the 'slacktivism debate' concerned with the value of social media campaigns as a pre-political instrument, qualified by its ability to bring about change through civic engagement. 318 Tufekci claims that slacktivism is a false debate, suggesting that we are asking the wrong questions:

Was it social media or was it people? Was it social media or was it labour movements? Was it social media or was it anti-imperialist movements? Was it social media or was it youth? These questions are wrong, and the answer is yes. The correct question is how. 319

\footnotetext{
315 Solomon and Steele, "Micro-moves in International Relations theory," 280.

316 Solomon and Steele, "Micro-moves in International Relations theory," 279-280.

317 Solomon and Steele, "Micro-moves in International Relations theory," 273.

318 See Evgeny Morozov, The Net Delusion: The Dark Side Of Internet Freedom, (US, New York: Public Affairs, 2011);

See also Henrik Serup Christensen, "Political Activities On The Internet: Slacktivism or Political Participation by Other Means," First Monday 16 no. 2 (2011), doi: 10.5210/fm.v16i2.3336. One notable counter argument to the slacktivism debate is presented in Zizi Papacharissi's book: Affective Publics which looks at emotion and affect in digital and political communications.

319 Zeynep Tufekci, "New Media and the People-Powered Uprisings," MIT Technology Review, 30 August 2011, https://www.technologyreview.com/2011/08/30/191614/new-media-and-the-people-powered-uprisings/
} 
In a review of Tufekci's book Twitter and Tear Gas, Jane Hu explained that social movements and digital activism have changed significantly. ${ }^{320}$ Social media has since seen the Arab Spring 2.0, Frances' 'yellow vest' movement, the 2019 Iranian protests, the Hong Kong protests and the 2020 BLM uprisings. These movements have demonstrated the scale, creativity, and endurance necessary to challenge even those most skeptical of the internet's activism capacity. ${ }^{321} \mathrm{Hu}$ suggests that social media activism has reached a "second act" explaining,

As Tufekci notes in her book, the real world effects of Occupy, the Women's March, and even Ferguson-era B.L.M. were often underwhelming. By contrast, since George Floyds' death, cities have cut billions of dollars from police budgets; school districts have severed ties with police; multiple police-reform-and-accountability bill have been introduced into congress; and cities like Minneapolis have vowed to defund policing. Plenty of work remains, but the link between activism, the Internet and material action seems to have deepened. What's changed?322

Sarah Jackson, Moya Bailey and Brooke Foucault Welles suggest that activist groups are now better at using the internet to frame, formalise and advance their agenda. ${ }^{323}$ They suggest that social media provides a digital counterpublic in which voices excluded from traditional media spaces now engage in "alternative networks of debate."324 Digital counterpublics have developed tactics, through strategic use of hashtags and messaging, to maximise their reach. What is most striking about this strategic approach is that it demonstrates a deeper understanding of social media affordances, and the potential and limitations of hashtags. I emphasise throughout my dissertation that modern conceptions of activism and being a feminist are changing and that subversive use of collectivising hashtags is a political act.

As more people join digital counterpublics and participate in collectivising performances of self, it becomes increasingly clear that the boundaries between the individual and the collective and affect and effect, in both online and offline lives, are blurring. Social media and hashtag activism can no longer be split into this duality where our online lives are researched separately to our offline lives, where their only value is what effects they produce in 'the real world'. Hu concludes, "As more and more of us join those conversations, prompted by the words and images we see on our screens, it's clear that the revolution will not be tweeted - at least, not entirely." 325 I argue that our online and offline lives are both part of the modern human experience. Online communities and communications, and the affecting nature of our online encounters, suggest an altogether unique interdisciplinary approach that changes the way we conceive of self and Other.

I argue that what is missing from this conversation about online encounters is feminist knowledge on the embodied and affectual workings of vulnerability, ignorance, and precariousness of digital atmospheres. The self-centred and tongue-in-cheek nature of hashtags means that their public and political powers are often overlooked. However, hashtags

\footnotetext{
320 Jane Hu, "The Second Act of Social-Media Activism," The New Yorker, 3 August 2020,

https://www.newyorker.com/culture/cultural-comment/the-second-act-of-social-media-activism

${ }^{321} \mathrm{Hu}$, "The Second Act of Social-Media Activism."

$322 \mathrm{Hu}$, "The Second Act of Social-Media Activism."

323 Jackson, Bailey, and Foucault Welles, \#HashtagActivism.

324 Jackson, Bailey, and Foucault Welles, \#HashtagActivism, xxv, xxxiii.

$325 \mathrm{Hu}$, "The Second Act of Social-Media Activism."
} 
are not merely expressions of our present affinities, but can also evoke feelings of affect, which in turn shape how one perceives self and Other. For International Relations theorists, social media is generally valued in terms of bringing about political action rather than political expressions of affect, feeling, and being. ${ }^{326}$ Natalie Fenton argues that the "'Politics of being' are characterised by emotions of passion, anger and hope, which need to be accounted for when studying digital media and radical politics." 327 Social media is vital because it is capable of transforming and transmitting affect, cultivating "subsequent feelings, emotions, thoughts, attitudes and behaviours." 328 Online comments abundantly refer to and re-enact viscerally felt, embodied emotions, such as shuddering, fuming, and weeping. ${ }^{329}$ Papacharissi observes:

We respond affectively, we invest our emotion in these stories, and we contribute to developing narratives that emerge through our own affectively charged and digitally expressed endorsement, rejection, or views. Technologies network us, but it is narratives that connect us, making us feel close to some and distant from others. ${ }^{330}$

It is through casual online interactions that people seek a sense of participation that Stephen Coleman has called a feeling of being counted; "the affective character of an experience that renders it fulfilling for individuals." 331 The circulation of embodied energies is generative of an atmosphere that creates a shared sense of belonging. ${ }^{332}$ So, while online engagement on social media does not necessarily result in the formation of community, it can affect feelings of community and solidarity. ${ }^{333}$ Conversely, an online encounter can result in feelings of exclusion, distance, and Otherness. Collectivising hashtags afford affective gestures and present a first step in framing our attitudes towards self and Others. Boler and Davis remark that "social media could benefit from (feminist) scholarship that emphasises the social and relational nature of emotions." 334 By presenting a feminist methodological approach to the role of affective-encounter via social media, this paper aims to add to scholarship in the politics of online collectivising movements.

A critical feminist approach considers the relational and multi-layered aspect of affordances, emphasising the embodied and affecting nature of our online performances. Penelope Papailias advocates online "witnessing" as an embodied practice. ${ }^{335}$ The shift from the passive language of 'observing' to the active language of witnessing more accurately reflects the contemporary emergence of affective publics. 336 Papailias explains,

While the term spectator assumes an a priori distinction between bodies and images (which have a 'good' or 'bad' effect on viewers), witnessing underlies the act of relating

\footnotetext{
326 Iosifidis and Wheeler, Public Spheres and Mediated Social Networks.

327 Natalie Fenton, “Digital, Political, Radical” Journal of Communication Inquiry 42, no.3 (2018): 275-277, doi:

10.11770196859918757528.

328 Papacharissi, Affective Publics, 22.

329 Penelope Papailias, "Witnessing in the Age of the Database: Viral Memorials, Affective Publics, and the

Assemblage of Mourning," Memory Studies 9, no 4. (2016): 444 doi: 01.1177/170698015622058.

330 Papacharissi, Affective Publics, 5-6.

331 Stephen Coleman. How Voters Feel. (Cambridge, New York: Cambridge University Press, 2013), 126.

332 Papailias, "Witnessing in the Age of the Database," 444.

333 Coleman, How Voters Feel, 126.

${ }^{334}$ Boler and Davis, "The Affective Politics of the 'Post-Truth' Era," 81.

335 Papailias, "Witnessing in the Age of the Database," 438.

336 Papailias, "Witnessing in the Age of the Database," 438.
} 
(to) images and bodies as integral to shaping the ethical discourse of political community and of locating oneself in the world situation. ${ }^{337}$

According to Papailias, testifying can take the form of nothing more than a few words, e.g., "an emoticon, a click to forward an image." 338 Witnessing promotes a sense of affinity with the event and its victims; our testimony fuses seeing the suffering of a vulnerable subject and the response to that sight. ${ }^{339}$ From Papailias' perspective, images of distant suffering are not simply observed by a global audience but are produced by, and productive of, a dispersed corporeal network. ${ }^{340}$ Whereas traditional perspectives confine emotion to a "pre or antipolitical status" and recognise only certain forms of political action such as protest, Papailias deconstructs this 'Cartesian duality,' demonstrating the embodiment of mindfulness and the possibility of self-reflectivity. ${ }^{341}$ Social media has blurred the boundaries between being informed about tragedy and testifying to it.

Affordances are not limited to the visible senses; they are also affecting in that they can be heard and felt. ${ }^{342}$ Adi Kuntsman argues that it is only by addressing the emotionality of conflict as documented in mundane online interactions that people are able to fully grasp the affective and ethical fabric of war and politics, and not just the 'grand' events such as demonstrations and political speeches. ${ }^{343}$ When discussing political engagement online, Papacharissi says,

Affective attunement demonstrated through liking a post on Facebook, endorsing an item in a news aggregator, uploading and sharing a YouTube video, or using a meme generator to create and share a simple message via a photograph is indicative of civic intensity and thus affords a form of engagement. ${ }^{344}$

Online social networks are a transnational arena of witnessing distant suffering and a space for expressing political feelings. ${ }^{345}$ Opinions and affective positions such as hatred, joy, militancy, disgust, rage, sadness and compassion can all be considered a kind of witnessing. ${ }^{346}$ If we understand social media as an 'archive structured by feelings', it can carry with it the potential of feeling differently, "because it so powerfully animates the affective logic through which political cruelty is sustained." 347 Kuntsman argues that digital archives act not only as records of political feelings, but also as "cyberspaces of memory and commemoration as virtual traumascapes", that is, mediators for remembering. 348 Kuntsman calls this blurring "ghosting of the present"; by denying victims their pain and their humanness and instead envisioning their deaths as inevitable and ungrievable, "turning them into ghosts while alive." ${ }^{449}$ According

\footnotetext{
337 Penelope Papailias, “(Un)Seeing Dead Refugee Bodies: Mourning Memes, Spectropolitics, and the Haunting of Europe,"Media, Culture and Society 14, no. 8 (2019): 11, doi: 10.1177/063443718756178.

338 Papailias, "Witnessing in the Age of the Database," 11.

${ }^{339}$ Luc Boltanski, Distant Suffering: Morality, Media and Politics, (UK Cambridge: Cambridge Press 1999), 114.

340 Papailias, "Witnessing in the Age of the Database," 11.

341 Papailias, "Witnessing in the Age of the Database," 11.

342 Bucher and Helmond, "The Affordances of Social Media Platforms," 236.

343 Adi Kuntsman, "Digital Archives of Feelings and Their Haunted Futures," Borderlands 10, no. 6 (2001): 5.

344 Papacharissi, "Affective Publics," 24.

345 Kuntsman, "Digital Archives of Feelings," 5.

346 Papailias, "Witnessing in the Age of the Database," 11.

${ }^{347}$ Kuntsman, "Digital Archives of Feelings," 11.

348 Kuntsman, "Digital Archives of Feelings," 16.

349 Kuntsman, "Digital Archives of Feelings," 11, 16.
} 
to Kuntsman, these ghosts remain with us even if they become temporarily forgotten. ${ }^{350}$ They are always there and, "in their refusal to disappear, they come to disturb the future, calling for post-mortem justice which is denied them in the present." 351 Ghosting can be viewed not only as an ongoing form of 'political erasure', but also as a form of presence which calls vulnerable selves to 'haunt' our social media feeds and demand future justice.352 \#SolidarityIsForWhiteWomen, \#NotYourNarrative, and \#NotYourAsianSidekick are examples of collectivising hashtags that call into question dominant narratives and highlight Western appropriation and marginalisation of minority voices. By making subversive use of both visibility and invisibility, "members of a racialised digital counterpublic who have been perceived as 'invisible' within the dominant public utilise hashtags to make their presence and message more visible to publics dominated by Whiteness." 353 I suggest that privileged onlookers need to think critically about the role they play in constructing digital atmospheres that foster ignorance, dispossession, and power inequalities. Following in the footsteps of these critical feminist and Media Studies theorists, I draw on collectivising hashtag case studies to explore how we enact ourselves as embodied, social and political subjects through social media practices and technologies linked to online performances of self. Changing dominant practices will not be easy, it will require difficult and ongoing work on the part of privileged users who will undoubtedly fail, fall short, and must persist in this iterative and uncertain process. The hashtags we use online matter, our online performances of self affect which bodies are afforded full recognition of their humanity and which are marginalised and left unseen.

The purpose of critical feminist research is to look at how power structures develop in the everyday practices of people. Micro-political acts, like the use of hashtagging, while seemingly ordinary and banal, provide unique insight into underlying systems of digital inequality that we often overlook. Unlike existing theorisations of emotions and encounter in world politics, my conceptualisation brings collectivising hashtags to the forefront. Few, if any, insights connect collectivising hashtags with normative conceptions of who counts as a recognisable human subject. To this end, what my research contributes to existing literature is twofold: First, a way to identify the political in the affective practices of everyday performances of self and Other via collectivising hashtags. Digital media and its influence on the precariousness of life is key to understanding the prevailing political, economic, and social underpinnings of inequality in modern society. The messages people like and share via social media promote a particular understanding of the value of human life. An inquiry into affectual encounter helps users to understand how online practices act to reinforce prevailing conceptions of humanity, which recognises the lives of men above women, the lives of citizens over foreigners, and the lives of White people over people of colour. Second, my research focuses on digital affordances that are formed in and through collectivising hashtag practices. This vernacular approach to online performances of self suggests that structural inequality need not exist only in material structures. Rather it can develop in invisible spaces in between people: that is, inequality in the modern age may at least in part be caused and sustained by digital interactions, potentially resulting in a shift in power relations. Following feminist tradition, my research does not seek to objectively reveal 'the truth' or prescribe remedies but rather to uncover unseen, silenced or

\footnotetext{
350 Kuntsman, "Digital Archives of Feelings," 16.

${ }^{351}$ Kuntsman, "Digital Archives of Feelings," 16.

352 Kuntsman, "Digital Archives of Feelings," 11-17.

353 Kuo, "Racial Justice Activist Hashtags," 500.
} 
ignored truths. ${ }^{354}$ I argue that we can better understand underlying inequalities by perceiving ourselves as embodied and relational subjects through social media practices. Critical Media Studies scholars are quick to problematise online practices but often stop short of investigating potential opportunities. My dissertation looks at the architectural and relational aspects of collectivising hashtags in order to explore their potential and limitations for affective transformation to emancipate the prevailing politics of humanism. Given the rapid expansion of collectivising hashtags and the profound influence they have on the way we perceive one another, the need to understand the affective conditions of online encounter is more significant than ever before. Appreciating the emotional resonance of collectivising hashtags is an important step towards understanding the new fluid and pluralistic state of world politics.

354 Linda Åhäll, "Affect as methodology: Feminism and the Politics of Emotion," International Political Sociology 12, no. 1 (2018):41, doi: 10.1093/ips/olx024. 


\section{Chapter Two \\ A Synergistic Approach To Research Design}

Critical feminist theories pay particular attention to issues of dominance and powerlessness and how these issues affect our understanding of International Relations. Given that my research focuses on the creation of Otherness, the primary concern for me as a critical feminist researcher when addressing methodology is ensuring that my research design does not replicate systems of dominance. Prioritising marginalised voices, understanding my own positionality and that of the people who contribute to my research are of utmost importance to my methodological approach. The primary purpose of my inquiry is to "connect the everyday troubles individuals face to public issues of power, justice and democracy." 355 As a critical feminist scholar, I pay particular attention to the praxis of my research. That is, I ask myself: How does my methodological approach influence my research and its application?356 I do not to intend to 'solve' the structural inequalities, prejudice, or bias inherent in collectivising hashtag practices, but rather, through my research, aim to decentre normative theories of International Relations. I do this by focusing on the personal, emotional, situated and micropolitical encounters of marginalised people whose lived experience embodies International Relations theory. According to Herbert Rubin and Irene Rubin, critical analysis is action-based research. ${ }^{357}$ Rather than advocating empirical neutrality and impartial observation, critical researchers argue that "research should redress past oppression, bring problems to light, and help minorities, the poor, the side-lined, and the silenced." 358 Following critical feminist praxis, I emphasise the interconnections between epistemology, methodology and methods. ${ }^{359}$ I acknowledge that my own positionality and research practices cannot be de-linked and that this openness and understanding presents an opportunity for me to become vulnerable, which is in itself characteristic of how critical feminist research works. ${ }^{360}$ The "synergistic relationship" between epistemology, methodology and methods work together in my dissertation to produce a situated and holistic research design process that challenges status quo approaches to International Relations. ${ }^{361}$

The purpose of this chapter is to explain and justify how my methodological approach allows me to answer my research question both in practical terms and in such a way that it is consistent with critical feminist praxis. This research design chapter is divided into six parts. The chapter begins with my research question, which acts to guide my methodological approach (and subsequent data collection and analysis). The second section provides an overview of current methodological debates within critical theory on the analysis of emotion and affect. In the third section, I explain how collectivising hashtags provide a real-world application and starting point for my research into the affecting nature of our encounter with

\footnotetext{
355 Joe L. Kincheloe and Peter McLaren "Reflecting on Critical Theory and Qualitative Research," in The Landscape of Qualitative Research, eds. N. Denzin and Y Lincoln (CA, California: Sage, 2003): 449.

356 Brock, "Critical Technocultural Discourse Analysis," 1027.

357 Herbet Rubin and Irene Rubin, Qualitative Interviewing: the Art of Hearing Data, (Thousand Oaks, Calif: Sage Publications, 2005), 19-38, doi: 10.4135/9781452226651.n2.

358 Rubin and Rubin, Qualitiative Interviewing, 25.

359 Sharlene Nagy Hesse-Biber, Handbook of Feminist Research: Theory and Praxis, (Thousand Oaks, California: SAGE publications, 2012).

360 Sharlene Nagy Hesse-Biber and Deborah Piatelli, "The Synergistic Practice of Theory and Method" in Handbook of Feminist Research: Theory and Praxis, ed. Nagy Hesse-Biber (Thousand Oaks, California: SAGE publications, 2012), 176-185.

${ }^{361}$ Hesse-Biber and Piatelli, "The Synergistic Practice of Theory and Method," 176.
} 
others. In the fourth section, I outline my choice of case studies. The \#TheyAreUs and \#ThisIsNotUs case study looks at the collectivising hashtags that were used in response to the shooting at Al Noor Mosque and Linward Islamic Centre in Ōtautahi Christchurch on Friday $15^{\text {th }}$ March, 2019. The \#ThatsUs case study is a digital storytelling campaign launched in 2016 by the NZHRC to combat racism in New Zealand. ${ }^{362}$ In the fourth section, I introduce Critical Technocultural Discourse Analysis ("CTDA") as the technique I use to examine the affordances of collectivising hashtag case studies. Following this, in the fifth section, I lay out my processes of data collection and analysis, including in-depth interviews, collection of tweets and discourse analysis. In the sixth section, I highlight the methodological limitations and complexities associated with a research project that bridges feminist, media and International Relations studies. In this final section, I provide an ethical consideration of data collection methods.

\subsection{Research question}

My personal and professional experience led me to interdisciplinary research bridging feminist, media and International Relations studies. Through my own experience in online spaces I noticed the phenomenon of collectivising hashtags taking different forms - how online friends enthusiastically took part in collectivising hashtags, moved by particular traumatic incidents, but without much understanding of the histories that led to the events themselves. As a public and digital diplomacy officer at a foreign embassy I looked at the more technical sides of the online spaces, focusing on algorithmic functions, reach and networks, which are the often unseen elements of online spaces. Through my own experiences, I started to see connections between different aspects of my personal and professional life and, following the traditions of feminist researchers, I decided to embark on a research project that would enable me to draw those ideas together into something that is more than the sum of its parts. To that end, the object of my research is to contribute to burgeoning feminist conversations on the embodied and affectual workings of vulnerability, ignorance, and precariousness in digital atmospheres. The question guiding my research project is:

To what extent do collectivising hashtags, as online renderings of self, act to create and maintain prevailing conceptions of Otherness and problematise recognition of precarious bodies who currently fall outside dominant conceptions of what it means to be human?

To answer this question, I address strands of feminist scholarship at the cutting edge of contemporary International Relations theory and Media Studies, drawing on micropolitics and the everyday lived experiences of self, emotion, and affect. The personal as political phenomenon reveals the importance of collectivising hashtags in locating personal renderings of self and Other. It is through our everyday online encounters with others and performances of self via collectivising hashtags that our feelings towards Others are embodied, transferred and given meaning. It is the day-in-day-out 'below the radar' casual reinforcements that bring to light underlying racist, sexist or xenophobic dispositions. ${ }^{363}$ I ask, whether the messages

\footnotetext{
362 New Zealand Human Rights Commission, “About the Campaign: That's Us is a campaign by the Human Rights Commission to combat racism," 18 March 2021, https://www.thatsus.co.nz/about

363 Enloe, "The Mundane Matters," 449.
} 
shared via collectivising hashtags, along with their unseen algorithmic functionalities, act to enable or marginalise those voices that they aim to stand in solidarity with. Furthermore, I ask to what extent users' encounters in online spaces are reflective of offline inequalities and how hashtagging practices act to foster or counter those inequalities. As the phenomenon of collectivising hashtags proliferates it becomes increasingly important to ask questions centred around whether modern hashtagging practices afford more inclusionary or exclusionary practices. Collectivising hashtags and our associated encounters on online platforms combine to create a rich site for exploring conceptions of self and Other. Therefore, it is crucial that we better understand the affecting nature of collectivising hashtags, what they afford certain bodies, and how this acts to maintain or challenge our status quo conceptions of humanity.

\subsection{Methodological Approach}

Critical feminists bring a unique epistemological and methodological approach to research that allows for questions to be answered in such a way that centres women and Othered groups and reframes their marginalisation. ${ }^{364}$ The challenge of understanding Othering is linked to conceptualising the political nature of emotion and affect. Quantifying attitudes towards other people is an impossible endeavour, fraught with methodological complications. Conceptions of self and Other cannot be easily measured, nor can they be quantified, even in qualitative terms. ${ }^{365}$ Political scholars have long expressed apprehension regarding the complex nature of examining internal political dispositions. For example, Maja Zehfuss states: "we seem unsure how to deal with it [emotion], even how to analyse it, and therefore it seems safer to exclude it from the proper business of understanding war and politics." ${ }^{366}$ However, if we hope to create less exclusionary communities and more human centred local and international relations, we must endeavour to learn more about how our shared identities, dispositions, and connections formulate within digital atmospheres. ${ }^{367}$ Critical theory disciplines offer insight into how best to conceptualise and methodically evaluate our user behaviour and affective responses. ${ }^{368}$ Inquiries in critical feminist theory are among some of the most promising places to start. As I discussed in the previous chapter, feminists have long expressed the value of the personal as political, the importance of the micro-political: the mundane and ordinary and emotional aspects of politics that are traditionally excluded from the "science as usual" methods of assessing politics and International Relations. ${ }^{369}$ Conceptions of self and Other are decidedly personal; how we respond to other bodies within an encounter is emotional, embodied and relational. ${ }^{370}$ I assert that in order to understand how certain bodies fall outside dominant

\footnotetext{
364 Hesse-Biber, Handbook of Feminist Research.

365 Roland Bleiker and Emma Hutchison, "Fear No More: Emotions and World Politics," Review of International Studies 34 (2008): 125, doi: 10.1017/S0260210508007821.

366 Maja Zehfuss, Wounds of Memory: The Politics of War in Germany, (UK, Cambridge: Cambridge University Press, 2009): 240 doi: 10.1017/CB09780511551109.

367 Emma Hutchison and Roland Bleiker, "Theorizing Emotions in World Politics," International Theory 6, no.3 (2014): 491-514, doi: 10.1017/S1752914000232

368 Maéva Clément and Eric Sangar, Researching Emotions in International Relations: Methodological Perspectives on the Emotional Turn, (Cham: Springer International Publishing AG, 2017).

${ }^{369}$ Feminists have challenged the scientific model of research that subscribes to the tenets of verification, generalization, objectivity, and value neutrality. See Hess-Bieber and Piatelli, "The Synergistic Practice of Theory and Method," 176-177.

370 The concept of Otherness derives from the prominent feminist Simone de Beauvoir who explains how identity of women is constructed in relation to men, positioning women as secondary and Other. Otherness is also a key
} 
conceptions of what it means to be human, we must look to those expressions and performances of self and Other.

In establishing a methodological approach to analysing the politics of emotion, Ahmed states, "[I]f I can never truly know another person's emotion, I would at least like to know the visible causes or manifestations of this emotion." 371 While the inner experience of Othering bodies might be impossible to pinpoint, the emotional attitude of distancing can be readily observed by analysing performances of self, thereby providing some indirect evidence of bodily experience. ${ }^{372}$ Emma Hutchison begins her conceptual analysis by looking at representations, which she argues are outward expressions of our most internal feelings. ${ }^{373}$

Representations are as close as one can get to conceiving of emotions. This is because the internal, ephemeral nature of emotions precludes the possibility of understanding them through any other means than their instrumental display. Consider, for instance, the difficulty of explaining one's feelings to another. One person can never truly know how another person feels. They can only assume to know, provided those feelings are outwardly expressed-represented, that is in a language or communicative system able to be understood by them. In this way, as both constitutive, discursive approaches to emotion and the studies of representation imply, representations inevitably stand for or embody particular contextually bound forms of feeling. ${ }^{374}$

Discourse analysis is a particularly useful lens for examining the production of power because discourses structure "how we feel about others and how we are affected by them." 375 Crucially for feminist theorists, discourse is about the "gaps and silences" involved in how we make sense of the world. ${ }^{376}$ Hutchison finds that representations reveal which lives are put on display and which are hidden. ${ }^{377}$ Our words and the feelings shared within them are both politically and socially significant because of the discursive potentials they possess. Discourses work to define and enable and also to silence and exclude bodies by endorsing certain voices and making Others "meaningless, inadequate or otherwise disqualified." 378 Discourse provides a starting point for methods enabling investigations into how our attitudes constitute and are constitutive of social hierarchies and political realities.

I maintain the most promising location to study late modern conceptions of self and Other is via the manner in which they are communicated and represented online. Where Hutchinson turns to representations through speech and images, I turn instead to online renderings of self, specifically online expressions of human connection via collectivising hashtag practices, focusing on the ways that hashtag users perceive, articulate, and ultimately define the

concept for intersectional feminists and critical race scholars who examine how majority and minority identities are constructed in relation to White dominance and privilege.

371 Ahmed, The Cultural Politics of Emotion, 130.

372 Hutchison, Affective Communities in World Politics, 18

373 Hutchison, Affective Communities in World Politics, 18.

374 Hutchison, Affective Communities in World Politics, 18.

375 Mel Stanfill, "The Interface as Discourse: The Production of Norms through Web Design," New Media \& Society 17, no7 (2015): 1061, doi: 10.1177/1461444814520873.

376 Åhäll, "Affect as Methodology," 43.

377 Hutchison, Affective Communities in World Politics, 120.

378 Hutchison, Affective Communities in World Politics, 120. 
technocultural space in which they operate and exist. ${ }^{379}$ I bridge International Relations and Media Studies scholarly traditions in order to provide a window into our understanding of what it means to be human in a context in which social media technologies increasingly mediate our encounters with others. Through collectivising hashtags, our feelings associated with connection become intertwined with the socially situated relational structures and technological architecture that act to produce status-quo understandings of who counts as a recognisable human subject. My research sheds light on the pivotal but largly neglected role that collectivising hashtags play in creating dominant conceptions of humanity.

\subsection{Collectivising Hashtags}

Collectivising hashtags represent a missing link between the discursively constructed identities of marginalised bodies and underlying social, economic, and political inequalities shaping the design and use of social media platforms. Hashtags are by no means the only way in which we can explore online renderings of self. Interdisciplinary inquiries explore a wide variety of communication technologies such as virtual reality games, artificial intelligence and emojis. ${ }^{380}$ However, I argue that collectivising hashtags are particularly well suited to exploring ideas of, self, affect, and Other. There are four key reasons for choosing to analyse collectivising hashtags:

1. Collectivising hashtags are fast becoming a common response to a tragedy. Twitter far outpaces traditional modes of communication in terms of accessibility, speed, and personal network spread. ${ }^{381}$ Trending hashtags confront us long before comprehensive details of crisis reach us. Hashtags are reactionary; they articulate our immediate emotional response to human tragedy. The immediacy and popular nature of hashtags is uniquely revealing; which hashtags trend or go viral is indicative of popular concern or interest on Twitter at any given moment.

2. Collectivising hashtags are personal and collective at the same time. The hashtag centralises discourse by offering one access point for an individual to lend support to another's voice and also results in message amplification. ${ }^{382}$ They say something about how we see ourselves in relation to Others, those whom we identify with and those whom we overlook. Collectivising hashtags are everyday renderings of self which gain public orientation and political relevance by way of trending tags. 383 To this end, collectivising hashtags are the modern iteration of the personal as political.

3. Hashtags are social and cultural phenomena that are shaped by and perpetually shaping practices of encounter, recognition, and human precariousness. They are not

\footnotetext{
379 Brock, “Critical Technocultural Discourse Analysis,” 1016.

380 See, André Brock, Miriam Sweeney, “Critical Informatics: New Methods and Practices," Proceedings of the American Society for Information Science and Technology 51, no1 (2014): 1-8, doi: 10.1002/meet.2014.1450510132; Jean Burgess, Alice Marwick, and Thomas Poel, The SAGE Handbook of Social Media, (UK, London: SAGE Publications Ltd, 2018), doi:10.4135/9781473984066

381 Twitter has lowered the financial and technological barriers to entry allowing for greater user access to communication. Using relatively inexpensive equipment and with limited technical knowledge, people can now engage in public speech and share information without mediation by mainstream media. Moreover, hashtags allow an individual users to coalesce into a larger collective network. See Jackson, Bailey, and Foucault Welles, \#Hashtag Activism: Networks of Race and Gender Justice.

382 Kuo, "Racial Justice Activist Hashtags,"502.

383 Papacharissi, Affective Publics, 101.
} 
only expressions of our present affinities, but they can also evoke feelings and affect, which in turn shape how one perceives self and Other. Collectivising hashtags are socially constituted and constitutive in that they can change the way that individuals perceive themselves and Others.

4. The link between collectivising hashtags and corresponding conceptions of who qualifies as human goes to the heart of a key concern in International Relations: the issue of power. ${ }^{384}$ Collectivising hashtags are value-laden and socially and discursively produced. They reflect relations of power from which such values and forms of communication derive.385 The technological, social, and economic underpinnings of collectivising hashtags are reflective of status quo perceptions of whose life counts as a life. ${ }^{386}$ Collectivising hashtags are sites of power within which certain perspectives are articulated and prioritised, and Others marginalised. The struggle over digital recognition is key to understanding modern experiences of power, precariousness, inequality, and social injustice.

For these reasons, collectivising hashtags are an effective starting place to examine how online renderings of self act to create and maintain status quo conceptions of Otherness. Rachel Kuo maintains, "the question is no longer whether hashtag activism is or is not effective... Analysing the connection of actors, websites, and clusters in different networks provide insight into how hashtags are effective." 387 My dissertation examines how collectivising hashtags afford different results for different users in order to better understand the ways hashtags affect online renderings of self, reinforcing dominant and unequal social hierarchies both on and offline. 388

\subsection{Case Studies}

I employed the case study method to limit the scope of my research and provide a more indepth, personal and purposeful inquiry into collectivising hashtag practices. The aim of case study research should be to produce "a holistic - that is, a richly or thickly contextualised and embedded-understanding of the phenomenon or system under investigation." 389 David Snow and Danny Trom provide a clear and practical three part definition of a case study as:

(a) an investigation and analysis of an instance or variant of some bounded social phenomenon that

(b) seeks to generate a richly detailed and "thick" elaboration of the phenomenon studied through

\footnotetext{
384 Hutchison, Affective Communities in World Politics, 19.

385 Hutchison, Affective Communities in World Politics, 117.

386 Butler, Precarious Life, $\mathrm{xv}$-xxi.

387 Kuo, "Racial Justice Activist Hashtags," 512.

388 Kuo, "Racial Justice Activist Hashtags," 512.

389 David Snow and Danny Trom, "The case study and the study of social movements." in Methods of social movement research, ed, B. Klandermans and S. Staggenborg (Minneapolis: University of Minnesota Press, 2002), 150.
} 
(c) the use and triangulation of multiple methods or procedures that include but are not limited to qualitative techniques. ${ }^{390}$

The case study method allowed me to build a suitable holistic and thick understanding of collectivising hashtags as a social phenomenon. I chose to limit the scope and focus to case studies primarily located in Aotearoa New Zealand for contextual consistency. ${ }^{391}$ Local case studies had the benefit of being more accessible (particularly when contacting hashtag campaign creators).

The case study method addresses the absence of women and marginalised groups in traditional modes of research. Case study research is particularly popular when researching contemporary critical feminist activism and social movements because it enables researchers to document marginalised bodies' perspectives, experiences and achievements. ${ }^{392}$ The goal is to give counterpublics a greater voice in their own "conceptualising, theorising, and organising." 393 This centring of the subject is of great importance to my research and to critical feminist praxis that challenges the invisibility of marginalised bodies.

\section{a) \#TheyAreUs and \#ThisIsNotUs}

The dangers of online hate and the corporeal consequences of the Othering of bodies is made painfully evident in the many tragic instances of technology enhanced violence across the globe. Social media platforms and their livestreaming capacities afford new opportunities for free expression that have been proven to put marginalised bodies at risk in an unexpectedly embodied and violent way. This tension was tragically highlighted by the terrorist attack on the Muslim community of Ōtautahi, Christchurch. On Friday 15th March 2019, a gunman walked into Al Noor Mosque and Linward Islamic Centre killing fifty-one people and leaving a further fifty people wounded; the live-streamed mass shooting was purposefully designed to go viral. ${ }^{394}$ The attack shattered Aotearoa New Zealand's sense of security, and any previously held assumptions about the sanctity of Aotearoa New Zealand's unprejudiced politics and society were overturned. Terrorism had reached this 'little corner of the world', and an unthinkable vulnerability was exposed. The horrific toll on human life rightly gave rise to fear, mourning, and anger. It has also led some in Aotearoa New Zealand to question how such a thing could have happened, generating vital debates about who is included, who belongs, and who is protected within Aotearoa New Zealand society. My inquiry into this case study

\footnotetext{
390 Snow and Trom, "The case study and the study of social movements," 147; See also Sarah Maddison and Frances Shaw, "Feminist Perspectives on Social Movement Research" in Handbook of Feminist Research: theory and praxis, ed, Sharlene Nagy Hesse-Biber (Thousand Oaks, California: SAGE publications, 2012), 420, doi: $10.4135 / 978148333847$

391 The hashtags \#ThatsUs, \#TheyAreUs, and \#ThisIsNotUs were primarily circulated in Aotearoa, New Zealand. However, due to the global nature of Twitter the hashtags were used internationally. In particular, the \#TheyAreUs hashtag was used in Australia, the United Kingdom, and France (amongst other countries) immediately following the Mosque Shootings on 15 March 2019.

392 Shulamit Reinharz and Lynn Davidman, Feminist Methods in Social Research, (New York: Oxford University Press, 1992), 171.

393 Maddison and Shaw, "Feminist Perspectives on Social Movement Research," 429.

394 Rt Hon. Jacinda Ardern, “Ministerial Statements - Mosque Terror Attacks-Christchurch," Official Website of the New Zealand Government, 19 March, 2019,

https://www.parliament.nz/en/pb/hansarddebates/rhr/combined/HansDeb_20190319_20190319_08
} 
unpacks Aotearoa New Zealand's reaction to this horrific act of terrorism, specifically by exploring the use of the \#TheyAreUs and \#ThisIsNotUs hashtags.

Figure 1.

At a time when people feel most isolated in their grief, collectivising hashtags offer a way to connect them with others who are feeling the same. The hashtags \#ThisIsNotUs and \#TheyAreUs captured the public and media's attention and were shared hundreds of times, receiving thousands of impressions within the first few days of their creation. ${ }^{395}$ The collectivising hashtags \#TheyAreUs and \#ThisIsNotUs offer unique insight because of their reactionary nature. These hashtags were created within minutes of the shooting and spread rapidly, presenting a unique insight into people's immediate response to crisis and insecurity. The collectivising hashtag \#TheyAreUs trended following Prime Minister Jacinda Ardern's first public speech after the Mosque attack, in which she stated:

It is clear that this is one of New Zealand's darkest days. Clearly, what has happened here is an extraordinary and unprecedented act of violence. Many of those who will have been directly affected by this shooting may be migrants to New Zealand, they may even be refugees here. They have chosen to make New Zealand their home, and it is their home. They are us. The person who has perpetuated this violence against us is not. They have no place in New Zealand. There is no place in New Zealand for such acts of extreme and unprecedented violence, which it is clear this act was. ${ }^{396}$

Here, Ardern's 'They' refers to Muslim victims, particularly migrants and refugees who have chosen to immigrate to Aotearoa New Zealand. The 'us' is understood to mean Aotearoa New Zealand as a nation. The message 'They are us' asserts a collectivity, a sentiment intended to reassure Muslim communities that they are welcome and belong within Aotearoa New Zealand society, that Muslim bodies are in fact one of 'us'. Prime Minister Ardern was quick to assure the world that the attack was "an extraordinary and unprecedented" event that goes against everything Aotearoa New Zealand holds dear as a nation. ${ }^{397}$ She was unequivocal in her rejection of the perpetrator, saying that the person who carried out the massacre was 'not us.' Marianne Elliot suggests that many New Zealanders were ready to believe Ardern and to identify with her representation of a compassionate, empathetic and inclusive nation. ${ }^{398} \mathrm{~A}$ number of New Zealanders took to Twitter maintaining that hate, extremism, and violence do not define Aotearoa New Zealand by claiming \#ThisIsNotUs. The hashtag \#ThisIsNotUs can be read as both a rejection of racism and intolerance and an aspirational declaration of national values of diversity, kindness, and compassion. For many New Zealanders, the \#TheyAreUs and \#ThisIsNotUs hashtags are genuine attempts at expressing support and condolence following the Ōtautahi Mosque attacks and declare that they share in victims' grief and 'stand with them' in an online expression of solidarity. My inquiry into \#TheyAreUs and \#ThisIsNotUs (in Chapter Three) explores collectivising hashtags as performances of self, paying specific

\footnotetext{
395 I used Twitter Archivist to collate tweets that used \#TheyAreUs and \#ThisIsNotUs hashtags.

396 Rt Hon. Jacinda Ardern, "Further update from Jacinda Arden on Christchurch mass shooting," Official Website of the New Zealand Government, 15 March, 2019, https://www.beehive.govt.nz/release/further-update-jacindaardern-christchurch-mass-shooting

397 Marianne Elliott, "After Christchurch: A Tale of Two New Zealands," The Conersationalist, 29 March, 2019, https://conversationalist.org/2019/03/29/a-tale-of-two-new-zealands-and-the-journey-toward-reconciliation/ 398 Elliott, "After Christchurch."
} 
attention to feminist concepts of precariousness and precarity. Using \#TheyAreUs and \#ThisIsNotUs as brief case studies, I demonstrate how collectivising hashtags can involve forms of projection and appropriation on the part of Pākehā and Tauiwi subjects which can enable people to claim to know the experience of Muslim communities.

Online discourse moves beyond online spaces and the affecting nature of our words and actions in online spaces have corporeal consequences. The proliferation of collective identifications - us, we, our-makes claims of recognition and identification. They also express exclusion, discrimination and racism. ${ }^{399}$ My case study is important because it shows us the very real and sometimes dangerous group rhetoric we participate in, and what happens when those more reductive beliefs are allowed to fester. The Mosque shooting put a spotlight on the connection between online and offline hate, drawing an unsettling new connection for many. Chief Human Rights Commissioner Paul Hunt suggests online hate and racism led to extremism in Aotearoa New Zealand, stating:

I argued that casual racism can lead to stereotyping; and stereotyping can lead to 'othering' - that is, seeing other humans as somehow alien; and 'othering' can lead to demonising; and demonising can lead to genocide. Today, I wish to revise that. Casual racism can lead to stereotyping; then 'othering'; then demonising; and then 15th March, Christchurch. Casual racism offends, disempowers, constrains. 400

It is important to better understand how conceptions of Otherness are performed and reinforced in online spaces and spill over into offline spaces. In Chapter Three, I employ \#TheyAreUs and \#ThisIsNotUs as case studies in order to explore how these hashtags afford new opportunities for self-expression that may act to marginalise those bodies it claims explicitly to include. I examine the \#ThisIsNotUs and \#TheyAreUs hashtags together with feminist conceptions of ignorance and invulnerability in order to better understand how collectivising hashtags involve forms of appropriation on the part of privileged subjects, reinforcing unequal social hierarchies and silencing marginalised subjects.

\section{b) \#Thatsus}

\section{Figure 2.}

\#ThatsUs is a digital storytelling campaign launched in 2016 by the New Zealand Human Rights Commission ("NZHRC") to combat racism in Aotearoa New Zealand.401 The hashtag campaign \#ThatsUs is an initiative designed to support the New Zealand Migrant Settlement and Integration Strategy and partially funded by the New Zealand National Commission for United Nations Educational, Scientific and Cultural Organisation ("UNESCO"). The campaign invites the public to use the collectivising hashtag \#ThatsUs to articulate and share personal experiences of racism and ignorance and, in doing so, challenge conceptions of what kind of a

399 Gerbaudo and Treré "In Search of the 'We' of Social Media Activism," 870.

400 Paul Hunt, "Tackling racism, islamophobia and hate in New Zealand." Human Rights Commission, 18 March,

2021, https://www.hrc.co.nz/news/tackling-racism-islamophobia-and-hate-new-zealand/

401 New Zealand Human Rights Commission, "About the Campaign." 
person a New Zealander is. ${ }^{402}$ The \#ThatsUs website outlines the purpose of the campaign, explaining:

We live in one of the most ethnically diverse as well as one of the most peaceful places on earth: whether it stays that way is up to us. Overseas and closer to home, racial intolerance is on the rise. 1 in 3 complaints to the Human Rights Commission are about racial discrimination but we know most people never complain. This website gives New Zealanders a safe place to share their personal stories of racism and prejudice. Since we launched last September we've reached 3 million people. By sharing the stories of real people we enable people who haven't experienced racial prejudice to know what prejudice sounds like and feels like. How we treat other people will define what kind of country we become and what kind of person a New Zealander is. Give Nothing To Racism: That's Us. ${ }^{403}$

The campaign emphasises casual or micro-racist encounters which feed into the subject of the everyday political. Issues of racism, intolerance, and ignorance addressed by the \#ThatsUs campaign directly relate to exclusionary practices of discourse I explore throughout my dissertation. Using the \#ThatsUs campaign as a case study allows me to supplement macrotheoretical analysis with a concrete micro-level inquiry. Additionally, the campaign utilises digital storytelling mechanisms in order to elevate marginalised voices. The original \#ThatsUs campaign run by the NZHRC has transformed over the years, from That's Us in 2016, to That's Us: Give Nothing To Racism in 2017, and more recently entering phase two Give No Voice To Racism in 2020.404 The common thread through the development of this campaign is its foundation in the real-life experiences of racism in Aotearoa New Zealand. The campaign aims to raise awareness of racist behaviour both on and offline and demonstrate the real harm caused to those on the receiving end.

The \#ThatsUs campaign seeks actionable change through openness and vulnerability, which are themes featuring prominently within critical feminist studies. Unlike the majority of collectivising hashtags, \#ThatsUs it is not limited to statements of victim affiliation. Rather, it invites the perspectives of bystanders and perpetrators. \#ThatsUs is an enriching case study for generating new self-reflexive practices and new paths towards emancipation, such as through the online practices of listening and counterpublics' subversive use of hashtags that I discuss in Chapter Five.405 It is also useful in uncovering the possibilities and limitations of collectivising hashtags, particularly in regards to online truth-telling and reconciliation processes. \#ThatsUs incorporates the architectural, the mediated, and the emotional affordances of collectivising hashtags. The \#ThatUs hashtag and website offer personal stories for analysis, helping me to assess the affecting nature of Collectivising hashtags. Examining the development of \#ThatsUs campaign by NZHCR and UNESCO helped shed light on affordances as they emerged between the architecture and functionality of technologies and between perceptions of hashtag designers and users. The collectivising hashtag campaign \#ThatsUs

\footnotetext{
402 New Zealand Human Rights Commission, "About the Campaign."

403 New Zealand Human Rights Commission, "That Us," 18 March, 2021, http://www.thatsus.co.nz/

404 New Zealand Human Rights Commission, "New Campaign says 'Give No Voice To Racism," 18 March, 2021, https://www.hrc.co.nz/news/new-campaign-says-give-no-voice-racism/

405 Jeffrey Longhofer, Jerry Floersch, and Eric Hartmann, "A Case for the Case Study: How and Why They Matter,"

Clinical Social Work Journal 45, no. 3 (2017): 189-200, doi: 10.1007/s10615-017-0631-8
} 
brings to light a number of concerns including digital affordances, inclusion, and status quo conceptions of being a 'New Zealander.'

The \#ThatsUs, \#TheyAreUs and \#ThisIsNotUs case studies allow me to explore themes of precarity, ignorance and vulnerability and ask important questions around how and why conceptions of self and Other arise. There is a clear link between my case studies, which share the themes of racism, collectivism, and New Zealand nationalism. \#ThatsUs was an attempt to bring to light minority narratives of self and highlight the racist encounters experienced both on and offline. The purpose of the campaign was to highlight underlying issues of inequality, racism, and White supremacy - issues that became glaringly evident to mainstream New Zealand following the Mosque shootings and were responded to with the use of the \#TheyAreUs and \#ThisIsNotUs hashtags. My collectivising hashtag case studies advance understandings of who is included, belongs, and counts within Aotearoa New Zealand society. In other words, they make a cumulative statement about who 'us' is.

\subsection{Method}

I use CTDA to examine users' discursive behaviour and affective responses in a way that connects collectivising hashtags users, creators, and technological aspects with underlying ideologies. ${ }^{406}$ CTDA is a multimodal analytic technique developed by André Brock for the investigation of internet and digital phenomena, artefacts and culture. ${ }^{407}$ The CTDA approach incorporates Ian Hutchby's concept of affordances which brings together architectural aspects of social media platforms and processes in combination with user behaviours and affective responses. ${ }^{408}$ CTDA incorporates critical race, feminism, queer, or disability theory to start from the epistemological standpoint of marginalised social media users and avoid deficit-based models of underrepresentation populations' technology use. ${ }^{409}$ Brock argues:

Examining egregious online racism while ignoring more subtle, structural forms of online discrimination is problematic; equally as problematic is social science and communication research that attempts to preserve colour-blind perspectives on online endeavours by normalising Whiteness and othering everyone else. ${ }^{410}$

It is Brock's view that such elisions of power as integral components of social analysis constitute a "willful depoliticisation of social informatics" that further underscores the entrenchment of normative, analytic and consequently inequitable orientations towards technology. ${ }^{411}$ This traditional perspective of technologies as "value-neutral" preserves existing social hierarchies through technology dissemination, design and use. ${ }^{412}$ Miriam Sweeney

\footnotetext{
406 Brock, "Critical Technocultural Discourse Analysis."

407 Brock, "Critical Technocultural Discourse Analysis," 1012.

408 Ian Hutchby, "Technologies, Texts and Affordances," Sociology 35, no.2 (2001): 449, doi:

$10.1177 /$ S0038038501000219.

${ }^{409}$ Brock, "Critical Technocultural Discourse Analysis," 1012.

410 Brock, "From the Blackhand Side," 546.

411 Sweeney and Brock, "Critical Informatics," 1-8.

412 Stanley Reiser, "The Culture of Technology," Social Science and Medicine 21, no.5 (1985): 597, doi:

10.1016/0277-9536(85)90048-6.
} 
advances Brock's argument, suggesting that methods which emphasise the idea of a valueneutral internet fail to "map meaning." 413 That is to say, social media platforms are developed and used by people with particular and partisan end-goals in mind. These end goals often have a deeper meaning and are reflective of socio-political drivers. ${ }^{414}$ Internet users, content providers, and designers all filter their internet experiences through racial frames when distributing online resources such as visibility, cultural capital, and political capital along preexisting cultural lines.415 The purpose of CTDA is to analyse opaque as well as transparent structural relationships of dominance, discrimination, power, and control as manifested in our encounters with technology. 416 A CTDA is critical of the content that people tweet, and how people use collectivising hashtags to "write themselves into being." 417 More specifically, it is conscious of "the ways that the medium 'hails' them into being as 'users'". 418 This analysis reveals the extent to which hashtag users are responding to external mediations of self afforded to them by communication technologies as architectural artefacts, rhetorically creating conceptions of Otherness and problematising recognition of precarious bodies.

The CTDA approach is unique because it applies critical technocultural theories to information and communication technologies as architectural artefacts, and pairs this exploration of technological hardware and software with the relational aspects of technologies, such as online texts, to analyse information technologies' structural, discursive, and relational construction. 419 CTDA diverges from traditional discourse analysis by moving beyond normative social constructivism and it enables me to implement an affordances-based approach which frames collectivising hashtags as discourse located within social media. Brock argues that discourse analysis (when used alone) reduces inequalities to the social aspect and privileges usages of elites as the norm, "leaving unspoken the environmental, social or cultural ideologies shaping social design, expectations, or use." 420 CTDA purposefully incorporates the architectural aspects of media construction, theorised as a "set of rules and resources built into the technology by designers during its development which are then appropriated by users as they interact with the technology." 421 CTDA is an essential tool for critical Media Studies scholars that contributes to building an understanding of "technology as culture" grounded in user perspectives and real-world practices as well as their architectural construction. ${ }^{422}$ Brock argues that even an individual act of engaging with social media is "in and of itself a discursive construction of self in dialogue with an 'other."'423 CTDA is particularly well suited to my methodological approach because it examines technologies as culture or, as I propose, as expressions of self or as an embodied and relational approach to online encounter. Brock recalls his reason for developing the CTDA technique, saying, "it is this precise moment where users interpolate themselves through their interactions with digital technologies - that CTDA was designed to examine." The benefit of CDTA is that it exposes how ideologies of

\footnotetext{
413 Sweeney and Brock, "Critical Informatics," 2.

414 Sweeney and Brock, "Critical Informatics," 2.

415 Brock, "From the Blackhand Side," 532.

416 Blommaert and Bulcaen, "Critical Discourse Analysis," 448.

417 Brock, "Critical Technocultural Discourse Analysis," 1025.

418 Brock, "Critical Technocultural Discourse Analysis," 1025.

419 Sweeney and Brock, "Critical Informatics," 1-8.

420 Brock, "Critical Technocultural Discourse Analysis," 1014.

421 Brock, "Critical Technocultural Discourse Analysis," 1016.

422 Sweeney and Brock, "Critical Informatics," 1.

423 Brock, "Critical Technocultural Discourse Analysis," 1026.
} 
gender and race are inherent in the conditions of modernity, capitalism and technoscience.424 The CTDA technique enables me to think about discursive, architectural, and ideological affordances of collectivising hashtags simultaneously, while using a feminist conceptual framework to interrogate underlying power relations and our location within them. Brock and Sweeney maintain that "this integration is crucial for forging ideological linkages between seemingly disparate phenomena, technologies, social actors, and institutions as a precursor for movements towards social justice." 425 In my dissertation, I use CTDA to understand linkages between collectivising hashtagging practices and socio-political inequalities.

Centring marginalised voices is key to the CTDA method. Sweeney and Brock explain, "CTDA, influenced by critical cultural epistemologies, flips the standard mode of inquiry by explicitly privileging the perspectives of people of colour and women and other socially marginalised groups." 426 Other critical scholars have successfully infused CTDA with critical feminist, intersectional, race and labour, and other conceptual frameworks to examine avatars, weblogs, podcast, Twitter and gaming. ${ }^{427}$ Kuo, in her assessment of \#SolidarityIsForWhiteWomen and \#NotYourAsianSidekick, uses CTDA and network analysis together to examine not only the conversation's context and content, but also how conversations circulate through different publics. ${ }^{428}$ Kuo outlines the cultural contours developed by each hashtag and examines the content of the tweets as well as the hashtags used in order to determine the overarching narrative. ${ }^{429}$ For Kuo, CTDA acts as a technique to examine the hashtag's discursivity in a way that connects Twitter's form, users, and interface with underlying ideologies. ${ }^{430}$ Raven Maragh uses a variation of CTDA to demonstrate the role of the digital in constructing racial authenticity.431 Maragh's version of CTDA draws on critical race theory and focuses on Twitter users' articulations of "acting White" to foster broader conversation about the complex nuances of Black communities online. ${ }^{432}$ Maragh couples in-depth interviews with an analysis of interviewees' tweets in order to contextualise racial authenticity and practices of "acting White" online. ${ }^{433}$ Maragh notes, "CTDA allowed me to analyse the practice, belief and artefact of the digital alongside my interviews to centre the roles of online communication regarding racial authenticity." 434 Maragh gained contextual knowledge from Twitter users about their experiences online and used CTDA to integrate the symbolic with the digital artefact in ways that speak to the digital culture. ${ }^{435}$ I use CTDA to discuss the importance of understanding our own positionality in online spaces, and how our performance of self via collectivising hashtags combined with the architectural structures of hashtags can act to confuse precarity and precariousness.

I chose CTDA as my method because of its flexibility as well as its ability to draw connections between the form, function, belief and meaning of technological artefacts and associated

\footnotetext{
424 Sweeney and Brock, "Critical Informatics," 2.

425 Sweeney and Brock, "Critical Informatics," 3.

426 Sweeney and Brock, "Critical Informatics," 5.

427 Brock, "Critical Technocultural Discourse Analysis,” 1025.

428 Kuo, "Racial Justice Activist Hashtags," 500.

429 Kuo, "Racial Justice Activist Hashtags," 500.

430 Kuo, "Racial Justice Activist Hashtags," 500.

431 Raven Maragh, “Authenticity on 'Black Twitter': Reading Racial Performance and Social Networking,” Television \& New Media 19, no.7 (2018): doi: 10.1177/1527476417738569.

432 Maragh, "Authenticity on 'Black Twitter,'” 595.

433 Maragh, "Authenticity on 'Black Twitter,'” 596.

434 Maragh, "Authenticity on 'Black Twitter,'” 598.

435 Maragh, "Authenticity on 'Black Twitter,'” 597.
} 
practices. ${ }^{436}$ Brock, Sweeney, Kuo and Maragh all take a unique approach to CTDA, and this necessitates a slightly different application, while still "keeping within the spirit of CTDA."437 Brock writes,

Though the techniques of interface analysis may differ according to the specificities of the interface in question, the foundations of CTDA as an approach (i.e. the combination of interface analysis with user discourse analysis and critical cultural frameworks) remain intact. 438

Brock presents CTDA as a flexible methodological approach that integrates "critical cultural analytic frameworks in service of critical informatics objectives." ${ }^{39}$ In Brock's analysis of Black Twitter, he employs critical race and technocultural theory to understand how mainstream online authors and Black online authors articulate Twitter as a racial artefact employing technocultural practices. ${ }^{440}$ According to Brock, CTDA's "uptake by young scholars shows that it has promise for feminist, queer, disability, and other critical scholars." Sweeney uses CTDA to provide critical analysis of Microsoft's Ms Dewey Artificial Intelligence search engine, with an emphasis on the feminist theory of performativity and affordance theory for the interface. ${ }^{441}$ Sweeney's unique application of CTDA has two parts. The first is a semiotic analysis of the interface (including the aesthetic aspects of Ms Dewey as interface). ${ }^{442}$ The second examines the architectural aspects of the interface, by compiling search terms and search responses and exploring them through critical discourse analysis techniques. ${ }^{443}$ Building on the CTDA methodologies of Brock, Maragh, Kuo, and Sweeney, I study collectivising hashtags as internet phenomena in a way that integrates interface analysis with user discourse analysis. ${ }^{444}$ This allows me to consider the ways that inequality is built into the architectural structures of collectivising hashtags as well as the digital culture and ideology that facilitates their use. I take advantage of CTDA's flexible approach to incorporate a critical feminist framework and emphasise the connection between collectivising hashtags and the nature of vulnerability, precariousness, and ignorance. For me, CTDA is more than a method for data collection and analysis, it has become a guiding philosophy for answering my research question in a way that considers both underlying architectural systems of inequality and performances of self in online spaces.

Through the application of CDTA, I am able to address the following lines of inquiry that are central to my research:

1. How collectivising hashtags \#TheyAreUs and \#ThisIsNotUs are discursively constructed.

2. Affordances of collectivising hashtags using \#ThatsUs as a case study.

\footnotetext{
436 Sweeney and Brock, "Critical Informatics," 3.

437 Sweeney and Brock, "Critical Informatics," 4.

438 Sweeney and Brock, "Critical Informatics," 5.

${ }^{439}$ Sweeney and Brock, "Critical Informatics," 2.

440 Brock, "From the Blackhand Side," 529.

441 Miriam Sweeney, “Not Just a Pretty (Inter)Face: A Critical Analysis of Microsoft's 'Ms. Dewey,"' PhD Dissertation, University of Illinois, 2013.

442 Sweeney, "Not Just a Pretty (Inter)Face," 55.

${ }^{443}$ Sweeney, "Not Just a Pretty (Inter)Face," 55.

${ }^{444}$ Brock, "Critical Technocultural Discourse Analysis,”; Sweeney, "Not Just a Pretty (Inter)Face,”; Maragh,

"Authenticity on 'Black Twitter,'; Kuo, "Racial Justice Activist Hashtags."
} 
3. How collectivising hashtags act to enable or constrain affected and affecting bodies' ability to challenge the prevailing political, social and technical underpinnings of inequality in modern society.

My object of study is collectivising hashtags: specifically, vernacular affordances analysed alongside selected tweets that speak to feminist themes of precariousness and precarity. My analysis conceptualises collectivising hashtags as an interplay of technological architecture, social practice, and dominant belief systems. ${ }^{445}$ The complexities of CTDA as a technique required that I narrow the scope of my inquiry in order to manage the amount of data that would be collected whilst still gathering enough information to conduct an in-depth analysis. Brock outlines the complexities of multimodal data collection, stating:

For those interested in using a CTDA approach, be warned: Its interpretive and critical approach is complex, unwieldy, and often necessitates verbosity. Neither interface analysis nor critical discourse analysis can be done succinctly. The former demands interpretive analysis based on deep description, while the latter requires extensive socio-cultural context for validity and intelligibility...the goal is to sustain a subtle analysis of both the domestic context of use and the semiotic richness of the online world people engage in. CTDA analyses strive to maintain a balance between studying context and studying text - but it is not an easy task. ${ }^{446}$

I collected data for \#TheyAreUs, \#ThisIsNotUs and \#ThatsUs via Twitter and the NZHRC online storytelling website. I supplemented this with in-depth interviews and analysis of existing literature to establish the social, political and technological context. I focused on collectivising hashtags case studies and limited my data collection to 100 tweets (for each hashtag) and 7 interviews from \#ThatsUs, \#TheyAreUs and \#ThisIsNotUs hashtags. I collected data on those case studies via in-depth interviews and an internet-based search of their corresponding hashtags using Twitter Archivist. ${ }^{447}$ The first phase of data collection looked at collectivising hashtags as practice; here, data was collected through in-depth interviews with \#TheyAreUs and \#ThisIsNotUs hashtag users, where information on meaning and construction of "ideology-in-practice" was considered. ${ }^{448}$ The second phase of data collection looked at collectivising hashtags as artifacts; here, data was collected through interviews with \#ThatsUs digital campaign designers at the NZHRC and UNESCO to contextualise the affordances of collectivising hashtags. I examined this information alongside existing technical literature on Twitter's modes of production and hashtag constructions, in addition to my own observation of hashtags architecture (e.g. hashtag use and Twitter as a platform). ${ }^{449}$ In the third phase of data collection (collectivising hashtags as discourse), I analysed the content of tweets that employed the collectivising hashtags \#ThatsUs, \#TheyAreUs and \#ThisIsNotUs through a critical feminist lens. This approach to data collection ensured that I had an in-depth but not

\footnotetext{
445 Brock, "Critical Technocultural Discourse Analysis," 1023.

446 Brock, "Critical Technocultural Discourse Analysis," 1023.

447 Twitter archivist is an analytics tool for collecting Twitter data. I used Twitter Archivist to track and archive my case study hashtags \#TheyAreUs \#ThisIsNotUs and \#ThatsUs. 448 Brock, "Critical Technocultural Discourse Analysis," 1024.

${ }^{449} \mathrm{~A}$ number of researchers incorporate affordance theory in their assessments of digital engagements including: Kuo, "Racial Justice Activist Hashtags"; Brock, "Critical Technocultural Discourse Analysis"; and Maragh,

"Authenticity on 'Black Twitter."'
} 
overwhelming data-set that included the contextual, technological and cultural factors that lead to the design and use of collectivising hashtags.

\subsection{Interviews}

CTDA requires an in-depth knowledge of campaign development and use, which I obtained through interviews and close observation of campaign participants and creators. I employed the critical feminist approach to interviews called responsive interviewing. ${ }^{450}$ The goal of responsive interviewing is to obtain a thorough understanding of what is being studied.451 Depth was achieved by going after context; dealing with the complexity of multiple overlapping and occasionally conflicting themes (such as vulnerability and ignorance) and paying attention to specific meanings, situations and history. ${ }^{452}$ The responsive interviewing model, characterised by Rubin and Rubin, relies heavily on the interpretive constructivist philosophy, mixed with a bit of critical feminist theory and then shaped by the practicalities of doing in-depth interviews. 453 The responsive interviewing model emphasises that the interviewer and interviewee are both human beings who move in response to one another, and that they form a relationship during the interview that affects both the interviewer and interviewee that translates to data collection. ${ }^{454}$ Critical feminist researchers do not try to remove the relational aspects of interviews, arguing instead that the interviewer and interviewee should try to build a relationship in which they share responsibility for finding the words and concepts in which ideas are expressed and lived experiences described.455 Rubin and Rubin maintain that the interviewer has to be aware that their own biases and expectations might influence the interviewee. ${ }^{456}$ Rather than pretend that interviewers come into the situation with no biases and can listen to answers without sifting them through their own experiences and cultural lenses, the responsive interviewing model argues that researchers need to continually examine their own understandings and reactions. Critical feminist researchers have found that this self-reflective approach brings both the researcher and interviewee into a more equitable position that humanises both the researcher and the interviewee. 457 Rubin and Rubin challenge the traditional power distribution within an interview by saying, "If positivists disempower interviewees, feminists intentionally empower them." 458

My research method decentres normative discourses by starting from the position of silenced or ignored truths and exploring inequalities embodied in online renderings of self. Accordingly, I conducted interviews that challenge dominant usage of \#ThatUs \#TheyAreUs and \#ThisIsNotUs hashtags. This included a broad range of perspectives including people from the Muslim communities in Aotearoa New Zealand, representation from Mana Whenua, the

\footnotetext{
450 Rubin and Rubin, Qualitative Interviewing.

451 Rubin and Rubin, Qualitative Interviewing.

452 Rubin and Rubin, Qualitative Interviewing, 30.

453 Rubin and Rubin, Qualitative Interviewing, 30-31.

454 Rubin and Rubin, Qualitative Interviewing, 30-31.

455 Rubin and Rubin, Qualitative Interviewing, 26.

456 Rubin and Rubin, Qualitative Interviewing, 30.

457 Maddison and Shaw, "Feminist Perspectives on Social Movement Research," 423.

458 Rubin and Rubin, Qualitative Interviewing, 26.
} 
Pacifikas community, immigrants and refugees. ${ }^{459}$ It is important to note that I do not claim to speak for the 'subjects' of this study. My research explores a number of sensitive issues, including personal stories of racial prejudice and persecution that I (as Tauiwi) have never experienced first-hand and can never truly comprehend. ${ }^{460}$ Therefore, my role as a researcher is to work with, and never in place of, marginalised people. One of the primary reasons that I chose a CTDA approach is because it recognises and amplifies the voices of marginalised groups and presents person-centric investigations of International Relations. ${ }^{461}$ By taking this approach, my research allows for more equitable and diffusive power relationships by reconfiguring the relationship of "researcher and subject" to that of "researcher and collaborator." 462

Using a critical feminist conceptual framework and CTDA as my methodological technique, I conducted seven in-depth interviews with collectivising hashtag users and campaign creators. I further coupled these in-depth interviews with an analysis of interviewees' tweets to contextualise performances of self online. ${ }^{463}$ My interviews aimed to replicate an ordinary conversation. Where possible, I chose to conduct interviews in person to better allow for clear commutation and the subtle emotional cues that can be lost over digital interview platforms. ${ }^{464}$ Rubin and Rubin maintain,

An interview should not involve applying a sterile instrument to a passive object, but should resemble normal conversation in which the interviewee influences the exchanges. 465

Central to a responsive interviewing model is the understanding that the interviewer and interviewee are in a relationship in which there is mutual influence, yet in which individuality needs to be accounted for. 466 To get depth of understanding, the interview design needed to be flexible. My initial questions were prompts that could be rethought and altered when necessary. I also invited interviewees to take the questions in their own direction and collaborate as conversational partners. My analysis began during the interviewing process; as I completed each interview, I examined its content to see what I had learned and what I still needed to find out. During data collection, I read every interview carefully before preparing the next one. As a result, I had a working idea of what important concepts, themes and events were present.467 I modified my interview questions on an ongoing basis, prepared follow up questions and pursued emerging ideas. ${ }^{468}$ Ideas brought to light in interviews with hashtag creators and hashtag users helped me to better understand the social and relational affordances at play. In addition to voice recording the interviews on a Dictaphone (in person)

\footnotetext{
${ }^{459}$ Mana Whenua are indigenous Māori people of Aotearoa New Zealand who have territorial rights, power and authority over the land.

460 Tauiwi means a foreigner or non-Māori immigrant to Aotearoa New Zealand. This can refer to people of European, or other colonial origins.

461 Donna Hancox, "From Subject to Collaborator: Transmedia Storytelling and Social Research," Convergence 23, no1 (2017): 59, doi: 10.1177/1354856516675252.

462 Hancox, "From Subject to Collaborator: Transmedia Storytelling and Social Research," 59.

463 Maragh, "Authenticity on 'Black Twitter,"” 596.

464 Due to the Covid19 outbreak in Aotearoa and the border lockdown that began in March of 2020, I completed my

final two interviews via Zoom conference call.

465 Rubin and Rubin, Qualitative Interviewing, 26.

466 Rubin and Rubin, Qualitative Interviewing, 33.

467 Rubin and Rubin, Qualitative Interviewing, 206.

468 Rubin and Rubin, Qualitative Interviewing, 202.
} 
and via Zoom (when interviews were conducted via web) so that I could then transcribe exactly what was said, I made written notes during the interviews to consider feeling and emotion. Indicators of mood often looked like laughter, silence, pauses or hesitation, changes in focus, profanity or the way words were pronounced. During the interviews, I made a memo of "notable quotes" that I felt strongly spoke to my research question or prompted further thought that could be translated into a theme that needed to be looked into further.469 Whenever a good quote caught my ear, I included it in my memos to follow up its meaning later and then used this to help me look for relationships between themes during the final analysis of the data. 470 Transcribing the interviews myself encouraged me to practice listening and pay particular attention to what my interviewees said and helped me to better prepare for my next interview. In the following paragraphs, I break down the format of these interviews.

\section{Interviewee Table.}

\section{a) Interviews with Hashtag Users and Analysis of their Tweets}

Interviews with hashtag users included individuals who responded to the Mosque attacks via the \#TheyAreUs and \#ThisIsNotUs hashtags. As specified by the CTDA method, my interviews aimed to centre marginalised voices, highlighting digital inequalities and developing positive strategies and counter-narratives. I recruited hashtag users who offered to share their own positionality and expressed concern for the appropriating nature of collectivising hashtags or self-identified as marginalised bodies. I used semi-structured and unstructured interviews to acquire a deeper understanding of the use and affordances of the \#ThatsUs, \#TheyAreUs and \#ThisIsNotUs collectivising hashtags for marginalised users. I prioritised the voices of those who had experienced precariousness in online spaces to speak to broader questions about appropriation and Othering in politics. ${ }^{471}$

Interviews with collectivising hashtag users, specifically those interviewees who have had their voice appropriated by collectivising hashtags, called for greater flexibility and openness in interviews. I sent questions to users in advance of meeting and invited feedback and additions to the framework of interviews. I expressed initial questions broadly to give interviewees the opportunity to answer from their own lived experience. Interviews with hashtag users ranged from one to two hours. I took notes during the interviews, again highlighting the emotional aspects and pauses that are less obvious in recordings, as well as orally recording them for transcription after. I asked follow up questions when necessary. I coupled my interview data with tweets derived from interviewee Twitter posts that I analysed with their permission. I interviewed participants before analysing tweets as a way to provide a rich multi-layered account of their online motivations and behaviours. ${ }^{472}$ By discussing the individual tweets with hashtags users, I allowed them to 'speak to' the meaning of their own tweets rather than 'reading into' and imposing my own understanding of their tweets. I was

\footnotetext{
469 Rubin and Rubin, Qualitative Interviewing, 205.

470 Rubin and Rubin, Qualitative Interviewing, 205.

${ }^{471}$ Raven Maragh, in her inquiry into online practices of 'acting White', conducted fourteen interviews with Black Americans about their experience of online performativity. She explains: "I privilege these voices as they employ performance and identity management strategies that speak to broader questions in the fields of communication and race studies." See Maragh, "Authenticity on 'Black Twitter,"” 596-597.

472 Maragh, "Authenticity on 'Black Twitter,'” 598.
} 
interested in analysing interviewees' experiences with performances of self via collectivising hashtag practices as "ongoing, processual, and strategically performed probing that [locates the] underpinnings of their tweets in their own words." 473 This approach ensured and evolved to enable marginalised users to maintain ownership of their own tweets and voice while providing me with a better understanding of their use and purpose. This structure also helped me to establish a number of distinct personal narratives before looking at the larger data set of collectivising hashtags retrieved from Twitter. After participants described performances of self via collectivising hashtags in their interviews, I created subcategories such as, vulnerability, appropriation, feeling, and grief that surfaced from the interviews and looked for these themes more broadly in collectivising hashtags.

Responsive interviewing allowed for the main areas of my inquiry to be driven from the study's theoretical foundations and research question.474 Consequently, I structured collectivising hashtags user questions around the themes of vulnerability, ignorance and precariousness and touched on the research question in terms of the interviewees' online rendering of self. During interviews, my research question was broken down into three key areas:

1. Performances of self via collectivising hashtags

2. Perceived architectural and relational affordances

3. How Twitter feels as a space

Because my research question is articulated in a particularly narrow and academic manner, I needed to translate these three areas into questions that allowed interviewees to more easily understand complex ideas. For example, the idea of "vernacular affordances" would be phrased as "What do you use hashtags for?", "What do you think everyone else uses Twitter for?", and "How does social media feel to you as a space? Is it inclusive or exclusive or somewhere in between?" In this way, I was able to centre critical feminist themes by asking about participants' experiences not only with collectivising hashtags, but also with the real world implications of these practices. In keeping with my desire to address critical feminist themes of vulnerability, ignorance, and online encounters as embodied practice, I invoked particular terminology during interviews including appropriation, emotion, feeling, self and atmosphere. I prompted interviewees with questions such as:

- Personal experiences of online encounter, performances of self and Other, e.g., Drawing on your personal experience as a performer and theatre-maker, how would you say Twitter enables or constrains your performances of self?

- Feelings towards online storytelling, voice, and recognition, e.g., Could you tell me about how Twitter feels to you as a space? Do you feel Twitter is an "even" space? Or is it reflective of dominant (Pākehā/White) narratives?

- Perceived affordances of collectivising hashtags, user practices, and appropriate uses, e.g., What purpose/use do trending hashtags serve for you?

473 Maragh, “Authenticity on 'Black Twitter,'” 598.

474 Maragh, "Authenticity on 'Black Twitter,'” 598. 
Importantly, I was not interested simply in how users utilise collectivising hashtags online. Rather, I focused on how participants understand conceptions of self via collectivising hashtags and how these come to create, maintain and/or contradict a dominant conception of self and corresponding inequalities.

\section{b) Interviews with Hashtag Campaign Creators}

The \#ThatsUs case study focuses on the technological features of the campaign, delving deeply into its construction, execution, and representation as conceived within a critical feminist framework. Brock stipulates that "technocultural discourses must be framed from the cultural perspectives of the user AND of the designer [emphasis in original]." 475 Accordingly, I used one-to-one interviews to elicit the opinions and perspectives of both in relation to the \#ThatsUs campaign. Interviews with campaign designers will also reveal how design ideologies are "written into technologies" for legibility by \#ThatsUs users. ${ }^{476}$ Interviews with campaign creators included interviews with a Digital Campaign Manager at the NZHRC, the UNESCO Social Media Coordinator and UNESCO Online Content Coordinator, and the Campaign Manager at UNESCO headquarters in Paris. I recruited interviewees in New Zealand by contacting the NZHRC directly. I contacted the Secretariat at the New Zealand National Commission for UNESCO who connected me with the Communications Departments at UNESCO headquarters in Paris. While in Paris I was also able to conduct an interview with the Office of Ambassadeur pour le Numérique (the French Ministry of Digital Affairs). The Office of Ambassadeur pour le Numérique was involved in the organisation of the Christchurch Call to Action Summit (held in Paris 15 May 2019) initiated by Prime Minister Ardern following the Mosque shootings. Interviews with hashtag campaign creators were conducted in person, ranged from 1-2 hours, and were orally recorded and transcribed following the interview.

Interviews with campaign users and interviews with NZHRC and UNESCO representatives shed light on the perceived affordances of the campaign in broadening user conceptions of who counts as a New Zealander and canvased a range of topics including:

- Choice of collectivising hashtags

- Perceived affordances of hashtags, platforms, and architectural applications

- Perceived impact of hashtag campaigns

- The relationship between social media platforms providers, designers and users

The purpose of interviews with campaign creators was to get a better grasp on the context of these hashtags and delve deeply into their creation and their perceived architectural affordances. Questions focused on how the group decided on the hashtag, alternatives considered, and the planning that went into the deployment of the hashtag. In line with a CTDA approach, the interviews established the structural and relational affordances of the \#ThatsUs hashtag campaign. This knowledge is necessary to understand the atmosphere in which hashtag designers create and negotiate with hashtag users. These interviews helped to create a contextual understanding of the hashtag campaigns and brought to light a number of themes

475 Brock, "Critical Technocultural Discourse Analysis,” 1020.

476 Brock, "Critical Technocultural Discourse Analysis," 1026. 
(such as pace, design, or usages) that I incorporated into the more personalised and in-depth interviews with hashtags users.

\subsection{Analysis}

My qualitative analysis of interviews and tweets establishes an understanding of collectivising hashtags that builds on what was learned from the interviews and then speaks to present literature in order to provide a more holistic understanding of the collectivising phenomenon. Qualitative data analysis "is not about mere counting or providing numeric summaries. Instead, the objective is to discover variation, portray shades of meaning, and examine complexity." 477 While Big Data approaches have become increasingly popular for algorithmic explorations as a way to learn about what discourse patterns exist online, ${ }^{478}$ they often fail to explain why these patterns exist and, by focusing on dominant trends, fail to address or centre minority perspectives. My analysis aims to interpret the data in a way that aligns with critical feminist research, beginning from the epistemological standpoint of underrepresented collectivising hashtag users. My CTDA pays particular attention to emotion in interviews and feminist themes within tweets that speak to power imbalances, vulnerability, ignorance and precarity online. An affordances lens is used to operationalise the technical and cultural features of technological interfaces, which are often the only point of contact where many users encounter information and communication technologies. ${ }^{479}$ Accordingly, I seek to expose connections between online encounters, inequality, power, our ideology and how they manifest. Ultimately, I am interested in structures of feeling supported by the "soft and networked architectures of online media" that influence who appears as a recognisable human subject. 480 This examination requires a particularly 'close reading' that examines all areas of discursivity (including emotional, architectural and relational elements) that contribute to producing possible interpretations of collectivising hashtags.

A key part of my analysis involved combining data units on the same topic, both within single tweets and interviews and across the hashtag user and designer interviews. ${ }^{481}$ I systematically examined each interview transcript and tweet to identify recurring concepts and themes. This first stage of analysis was recognition, in which I found the themes, concepts, events and topical markers in my data set. I used a combination of established critical feminist themes such as vulnerability, ignorance and precarity, but did not limit my analysis to these themes in order to make room for original insights in my own data. I prioritised the creation of themes from the in-depth interviews as they provided the most "contextually 'thick' conceptions." 482 After I refined, elaborated upon and interrogated concepts and themes, I coded them. I allocated each theme a data unit with its own codes. For example,

Tweet 1: "Wearing a headscarf to uni as a show of support and solidarity with the many Muslim Women who routinely harassed for the act of following their faith. I will work

\footnotetext{
477 Rubin and Rubin, Qualitative Interviewing, 202.

478 Brock, "Critical Technocultural Discourse Analysis," 1025.

479 Sweeney and Brock, "Critical Informatics."

480 Papacharissi, Affective Publics, 27.

481 Rubin and Rubin, Qualitative Interviewing, 203.

482 Maragh, “Authenticity on 'Black Twitter,'” 598.
} 
hard to raise up your voices in any way I can \#HeadscarvesForHumanity \#ScarvesInSolidarity \#TheyAreUs"

Quote 1: "A part of me felt like I needed to be in solidarity with them as well because for them as Muslims they were like 'this is our daily life and we were [paused]... It's horrible but we were expecting this, and this could happen and it did' so I think it was that desire to open up a conversation that would align strongly in solidarity with them."

I converted individual data points such as Tweet 1 and Quote 1 into shared coded groups. Tweet 1 was allocated four codes 'solidarity,' 'precarity,' 'self,' and 'collectivity.' Quote 1 was allocated two of the same codes 'solidarity,' and 'precarity' so that these individual data points shared the searchable units 'solidarity,' and 'precarity.'

For the second stage I split my coded data findings into two key sections. Section One looked at performances of self and Other and Section Two focused on the architectures of collectivising hashtags, their affordances, algorithms, and usages. While the data ranged over a wide variety of themes, and there was some variation in these themes across data points, the following themes were almost always present:

Section One: Performances of Self and Other

- Collectivity, belonging, solidarity

- Centring of self or appropriating experience

- Vulnerability

- Nationalistic conceptions of self

- Ignorance and White defensiveness

- Lived experiences and storytelling

- Calling out

Section Two: Architectures and Affordances

- News and immediacy

- Spheres and networked communities

- Collective ownership

- Encountering difference

- Personal performance and strategies

- Humour or satire

- Openness, transparency, equality in use

- Vulnerability, privacy and risk

- Emotion and affect

- Fluidity and uncertainty

Rubin and Rubin's hybrid model argues that coding, recognising concepts and themes, and theory development are part of one integrated progress. Rubin and Rubin set out the parameters of coding in qualitative inquiries, stating:

You cannot code for everything that is in your data, nor would you want to. Instead you look for those items that are most important for understanding your research topic by 
looking for those that you have already noted in our memo file or those that are suggested by published literature and speak to your research concerns. ${ }^{483}$

In Rubin's hybrid model, which sits part-way between the responsive interviewing formal coding schema and grounded theory models, you need not code every passage or term but only those concepts and themes that are most closely related to your research questions. ${ }^{484}$ Many qualitative researchers prefer to use the grounded theory model that minimises the influence of previous studies and literature, asserting that coded concepts and themes must emerge from the data without use of the literature. 485 However, the open coding process is better attuned to the responsive interviewing model I employed, where the recognition, coding, and theory development processes learned in earlier phases are used to greater advantage in later stages. Accordingly, I used an open coding framework using some, but not all, assumptions of grounded theory, coding as I went rather than preparing a fixed list of concepts. The open coding process approach enabled me to incorporate critical feminist theory and build upon valuable themes established by other CTDA researchers. This form of open coding works particularly well in projects like mine in which the researcher is familiar with the concepts they are looking for. In my case, I kept in mind existing feminist theoretical frameworks of Butler, Gilson and Tuana and paid particular attention to any themes that went unsaid or lay beneath the surface of my research process.

My analysis of the interviews paid special attention to concepts and themes of vulnerability, precariousness and ignorance that were often expressed by reference to the emotional and affecting nature of tweets. At the final stage of analysis, I thought about how the insights gained from my interviews came together to form a coherent theory that works towards understanding a broader part of collectivising hashtag practices and offers an explanation of why this occurs, as well as the implications for those precarious bodies whose voice has been appropriated through collectivising hashtags. When I conducted a deep reading of interviews, I asked myself why this phenomenon of collectivising hashtags is occurring, how conceptions of self and Other are important and how certain themes like vulnerability, ignorance and precarity might be related - all parts of my particular version of theory development and CTDA. This analytical approach allowed me to examine concepts, themes and events across different interviews and combine them into a coherent whole that portrays a culture of hashtag use and the collectivising nature of their practice and how this could potentially be problematic. 486

\subsection{Limitations and Bias}

Unpacking the contours of \#TheyAreUs, \#ThisIsNotUs and \#ThatUs discourse and their relational and functional affordances is a complex endeavour that requires in-depth knowledge and access to campaign participants and creators. CTDA is not a straightforward approach.

\footnotetext{
483 Rubin and Rubin, Qualitative Interviewing, 209.

484 Rubin and Rubin, Qualitative Interviewing, 223.

485 Richard E. Boyatzis, Transforming Qualitative Information: Thematic Analysis and Code Development, (CA, Thousand Oaks: Sage Publications, 1998); See also Kathy Charmaz, "Teaching Theory Construction With Initial Grounded Theory Tools: A Reflection on Lessons and Learning," Qualitative Health Research 25, no.12 (2015): 16101622, doi: $10.1177 / 1049732315613982$

486 Rubin and Rubin, Qualitative Interviewing, 207.
} 
This is because evaluating the interdependent and affecting relationship between hashtag users, the affordances of collectivising hashtags, and the motives behind technological architecture and platform providers all need to be considered simultaneously. A common criticism of CTDA inquiries comes from positivist schools of thought concerned with the measurability, replaceability and empirical validity of interpretative studies. 487 Empirical researchers within the social sciences have drawn upon positivist concepts to legitimise particular methodological techniques. ${ }^{488}$ Positivists advocate for a strict dichotomy between fact or value and a deductive model of scientific inquiry. ${ }^{489}$ According to positivist models, the scientific method begins with carefully controlled, neutral observation of empirical events to enable the regularities or patterns of relationships to be observed. ${ }^{490}$ While big data approaches still have value and are particularly useful in helping establish patterns of behaviour, I am more interested in asking questions about the implications of these patterns of behaviour, specifically for those who fall outside the norm, rather than 'proving' their existence. Moreover, feminist critiques of positivism suggest that scientific observation is itself based on a particular understanding of knowledge,

It begins not from 'nothing,' nor from the 'neutral' perception of given relations, but rather from immersion in a scientific tradition that provides frames of reference or conceptual schemes that organize reality and shape the problems for further investigation. ${ }^{491}$

Critical theorists argue that instrumental and quantitative analyses incorporate (without acknowledgement) rationalist normative ideologies centring Western, White, middle class, heterosexual, men as 'human.' 492 Brock maintains that CTDA was formulated precisely to "expose that validity and replicability are false constructs of positivism, that each researcher brings their disciplinary, cultural and social perspectives to the research they conduct." 493 Empiricists and quantitative scholars may be concerned with the replicability of a CTDA approach because other researchers when presented with the same data are likely to come to different conclusions. However, Brock argues, and so do I, that this criticism only acts to reaffirm the role of positionality in research; it seeps into even the most clinical experiments. Bias cannot be dispensed with but it can be considered more openly. ${ }^{494}$ The task for critical feminist researchers is to challenge the assumption of methods as neutral techniques and rethink 'common sense' practices.

Critical feminist methodologies do not claim to objectively reveal the 'truth' in the same way that my research does not aim to 'prove' that collectivising hashtags 'Other' bodies. Rather, feminist inquiries are centred on "challenging norms, the normative, and the normal often

\footnotetext{
487 See Mary Hawkesworth "Truth and Truths in Feminist Knowledge Production: Positivist and Feminist Conceptions of Objectivity" in Handbook of Feminist Research: theory and praxis, ed, Sharlene Nagy Hesse-Biber (Thousand Oaks, California: SAGE publications, 2012), 94-96. See also Mary Hawkesworth, "Knowers, Knowing, Known: Feminist Theory and Claims of Truth," Journal of Women in Culture and Society 14, no.3 (1989): 533-557, doi: $10.86 / 49523$

488 Hawkesworth "Truth and Truths in Feminist Knowledge Production," 95.

489 Bliddal, Sylvest, and Wilson, Classics of International Relations.

490 Bliddal, Sylvest, and Wilson, Classics of International Relations.

491 Hawkesworth "Truth and Truths in Feminist Knowledge Production," 97.

492 Brock, "Critical Technocultural Discourse Analysis," 1017.

493 Brock, "Critical Technocultural Discourse Analysis," 1027.

494 Brock, "Critical Technocultural Discourse Analysis," 1027.
} 
through lived experiences." ${ }^{495}$ My methodological approach aimed to decentre normative discourses by starting from the position of silenced or ignored truths and exploring inequalities embodied in online renderings of self. My research used interviews and participant observation to uncover lived experiences of Otherness, drawing on the personal as political and other feminist themes of emotion, vulnerability, and ignorance in order to reimagine research on the politics of online encounter. Following critical feminist methodologies, I analyse the unique ways and mechanisms through which performances of self and Other become socially and politically significant.

\subsection{Intellectual Property, Ethics, and Feminist Praxis}

Legal, privacy, and publication issues are key considerations for research involving social media data. One of the biggest concerns with digital ethnography is the extent to which data should be considered public or private. The ethics of using public tweets (or other social media) is an ongoing debate. In a study of ethical practices and beliefs among online data researchers, Vitak, Proferes, Shilton, and Ashtorab point out that there are no agreed norms or best practices in this space. ${ }^{496}$ One side of the digital debate suggests that as long as you are quoting from a publicly available Twitter account, confidentiality should not be an issue because the tweet is already not confidential. Key to this argument is the standpoint that social media users have all agreed to a set of terms and conditions for the social media platform they use and that within these terms are clauses on how data may be accessed by third parties, including researchers. Twitter's Privacy Policy now mentions that academics may use tweets as part of research. The counter argument is that, even if a tweet is publicly accessible, its use in a research project may not be what the author intended, particularly if you use it without their knowledge. Fiesler and Proferes found that participant perceptions of Twitter research ethics are highly contextual, differing based on factors such as how the research is conducted or disseminated, who the researchers are, and what the study is about. ${ }^{497}$ There are different ethical risks attached to social media methodologies; accordingly, digital ethnography has to be evaluated on a case-by-case basis. ${ }^{498}$

A key ethical consideration for social media researchers is users' expectations. Matthew Williams et al. suggest that it is good practice for social media researchers to consider the unique nature of the online context of the tweet. ${ }^{499}$ In my case, the Twitter handles of @NZhumanrights and @UNESCO do not raise any confidentiality issues because public tweets are already not confidential due to their government and institutional affiliations. The confidentiality of individual NZHRC and UNESCO representatives is maintained by referring to participants by their role rather than their name. Williams et al. point out that "providing total

\footnotetext{
495 Åhäll, "Affect as Methodology," 41.

${ }^{496}$ Jessica Vitak et al., "Ethics Regulation in Social Computing Research Examining the Role of Institutional Review Boards," Journal of Empirical Research on Human Ethics 12, no.5 (2017): 327-382, doi: $10.1177 / 1556264617725200$.

497 Casey Fiesler and Nicholas Proferes, “'Participant' Perceptions of Twitter Research Ethics," Social Media \& Society 4, no.1 (2018): 2, doi: 10.1177/2056305118763366.

${ }^{498}$ Kath Hennell, Mark Limmer, and Maria Piacentini, "Ethical Dilemmas Using Social Media in Qualitative Social Research: A Case Study of Online Participant Observation,” Sociological Research Online 25, no.3 (2012): 473-489, doi: $10.1177 / 1360780419888933$

499 Mathew L. Williams, Pete Burnap, and Luke Sloan, "Towards an Ethical Framework for Publishing Twitter Data in Social Research: Taking into Account User' Views, Online Context and Algorithmic Estimation," Sociology 51, no.6 (2017): 1149-1168, doi: 10.1177/0038038517708140.
} 
anonymity to directly quoted users is not practical in this form of research, due to Twitter guidelines and the issue of online search...[T]herefore, users must be made aware of this limitation during consent negotiations"500 Townsend and Wallace argue that "an open discussion on Twitter in which people broadcast their opinions using a hashtag (in order to associate their thoughts on a subject with others' thoughts on the same subject) can be considered public." 501 The most practicable method for my research was to continue to collect Twitter data without consent, but seek informed consent from interviewees for the use of their Twitter data when it was to be directly quoted. As an example, Papailias, Brager, Bucher and Helmond use direct quotes relating to political hashtag campaigns. ${ }^{502}$ Accordingly, the option of can/cannot use Tweets was sought from all interview subjects and their co-operation was key to the success of this study.

I sought ethics approval before collecting hashtag data and undertaking interviews. My research followed Te Herenga Waka, Victoria University of Wellington guidelines on ethical practice and paid particular attention to the emerging area of digital research and online ethical practice. Permission was sought to access information from administrative bodies including NZHRC and New Zealand National Commission for UNESCO, since participation from campaign managers was an important part of assessing the vernacular affordances of hashtags. When publishing, I gave special consideration to anonymisation of social media users in research outputs. I also paid particular attention to principles of reciprocity, equivalence and manaakitanga mediated by whakapapa, mana and relationships guided by Te Tiriti o Waitangi. ${ }^{503}$ According to Sidney Moko Mead, koha acts as a personal expression of gratitude; accordingly I budgeted for a gift as koha for each of my interviewees.504 Ultimately, my research aims to centre and value minority bodies who have offered to share their lived experiences - not as speaking voices appropriated, but as voices that are valued and heard, using this research to highlight existing online inequalities to challenge the historical structures of privilege and inequality within which we all live.

The Association of Internet Researchers suggest that a researcher's responsibility towards participants increases with the involvement of vulnerable individuals or groups online.505 The vulnerability associated with stories of racism and xenophobia shared via the \#ThatsUs, \#TheyAreUs and \#ThisIsNotUs hashtags raised ethical concerns for my data collection. The discussion of case studies in Chapter Three required additional attention to privacy protections, as some topics and individuals revealed personal information. ${ }^{506}$ For example, the \#TheyAreUs and \#ThisIsNotUs hashtags were shared by private accounts during a particularly difficult and emotionally taxing time. In contrast, \#ThatsUs was a public campaign run by the

\footnotetext{
500 Williams, Burnap, and Sloan, "Towards an Ethical Framework for Publishing Twitter Data in Social Research,"1161.

501 Leanne Townsend and Clare Wallace, “The Ethics of Using Social Media in Research: A New Framework," The Ethics of Online Research 2 (2017): 189-207, doi: 10.1108/S2398-601820180000002008.

502 See Papailias, “(Un)Seeing Dead Refugee Bodies”; Brager, "The Selfie and the Other"; Bucher and Helmond "The Affordances of Social Media Platforms."

503 Sidney Moko Mead, Tikanga Māori: Living by Māori Values, (Aotearoa New Zealand, Wellington: Huia Publishers, 2016), 146.

504 The funding for Koha came from my Peace and Disarmament Scholarship from the Ministry of Internal Affairs and the Ministry of Foreign Affairs and Trade.

505 British Psychological Association, "Ethics Guidelines for Internet-Mediated Research," April 2017, www.bps.org.uk/publications/policy-and-guidelines/ research-guidelines-policy-documents/research- guidelinespoli

506 Jackson, Bailey, and Foucault Welles, \#HashtagActivism, 205.
} 
NZHRC where participants were given the opportunity to publish anonymously and chose to participate knowing their words would be published as part of an online campaign. I always considered the context of the tweets and the value of marginalised voices and made my best effort to respect any signals that tweets were intended to be private (such as tweets from private accounts).507 Jackson, Bailey and Foucault Welles outline the difficult balance that must be struck when looking at online data, stating,

The threats to privacy and security that are introduced through unwanted use of social media data are real, but so too are the threats to social scientific insight if we are unable to create pathways for researchers to access data within and across social platforms. ${ }^{508}$

I suggest that this balance is especially important because of the vested interest of this project in online forms of racism and harm. The livestreaming of the Mosque shooting shows that our online actions intersect with our corporeal lives and more needs to be understood about how dangerous racist and extremist narratives are cultivated in online spaces. Jackson, Bailey, and Foucault Welles conclude that it is imperative that content creators, social media companies and scholars work together to find ethical and equitable solutions that enable access to data that underwrites research on behavioral questions and social justice. ${ }^{509}$ Given that these online platforms can act to foster online inequality and lead to offline harm it is increasingly important that researchers look to online encounters as a new public and political forum. As I have argued throughout this dissertation our online performances of self are both personal and political and therefore should be treated as such. I maintain that it is important that we balance the need for privacy with valuable research into online narratives and platformed inequality.

Critical feminist scholars have long recognised the messiness of everyday life and how politics and personal dispositions infiltrate our research. ${ }^{510}$ Social science researchers are part of the world they study and are inextricably involved in the processes and product of their own research. Fotopoulou notes:

By moving through both online and offline spaces as a researcher in each of the cases examined in the chapters of this book, I was also a user, a producer and a consumer of digital media. This book should thus be seen as a production of embodied knowledge, reflective of my own position as someone with intersecting identities. 511

A method used by critical feminist scholars to create awareness of positionality is that of selfdisclosure and reflexivity, where the researcher discloses her position in the world, her identity, and intellectual and political beliefs. ${ }^{512}$ I acknowledge my own intersectionality; experiencing the devastating consequences of racial intolerance in my birthplace of South

\footnotetext{
507 Jackson, Bailey, and Foucault Welles, \#HashtagActivism, 205.

508 Jackson, Bailey, and Foucault Welles, \#HashtagActivism, 206.

509 Jackson, Bailey, and Foucault Welles, \#HashtagActivism, 206.

510 Roland Bleiker and Emma Hutchison, "Fear No More: Emotions in World Politics," Review of International Studies

34, no.1 (2008): 128, doi: 10.1017/S026021020508007821

511 Fotopoulou, Feminist Activism and Digital Networks, 23.

512 Kathryn G. Herr and Gary L. Anderson, Action Research Dissertation: A Guide for Students and Faculty, (US, Los

Angeles: SAGE Publications, 2005), doi: 10.4135/9781452226644.
} 
Africa and my identity as Tauiwi, an immigrant to Aotearoa New Zealand, have undoubtedly played a key role in my research. Experiences of social inequality have played a formative role in my life, which is what makes collectivising campaigns both familiar and concerning to me. Acknowledging my positionality is an important part of negotiating my own identity and role as an academic moving forward. I want to affirm Fotopoulou's pronouncement that as a researcher moving between online and offline spaces, I am also a user, producer, and consumer of digital media. ${ }^{513}$ My decision to use collectivising hashtags \#ThatUs \#TheyAreUs and \#ThisIsNotUs as case studies is motivated as much by my desire to add to feminist conversations on the embodied and affectual workings of vulnerability, ignorance and precariousness in digital atmospheres as it is by the need to examine and work through underlying networks of discursive privilege and power, and my own location within them. Therefore, this research should be seen as a production of embodied knowledge reflective of my own position as a cisgendered Tauiwi immigrant to Aotearoa New Zealand learning how to move in response to my own precariousness and the corporeal precarity of those around me. Rather than advocating neutrality, I aim to acknowledge how my own lived experience, my position in the world, identity, intellectual and political beliefs, and cultural lens has come to influence my research.

Critical feminist studies emphasise the importance of standpoint, arguing that research should aim to redress oppression, bring problems to light, and prioritise the voice of marginalised bodies (those who are often silenced or underrepresented). While it is important that minority voices are centred and listened to within my research, this need for cross-cultural dialogue is held in tension with the added emotional labour my research asks of marginalised bodies. Marginalised bodies are often placed in the position of having to 'teach' Pākehā and Tauiwi about the experience of being Othered. This well-meaning desire to know and learn from diversity inevitably expresses aspects of the colonialising tendencies that intersectional feminists actively oppose. Through my methodological approach I want to stress that antiracist work should not fall to marginalised bodies within my research; it is of utmost importance that I (and those I address who are located at a similar proximity to Whiteness and privilege) engage in my own race work throughout the project. Accordingly, I aim to embrace discomfort and engage in the work of learning about my own Tauiwi histories and social privileges in relation to those around me and embrace positively what Alison Jones calls the "productive acceptance of ignorance of the Other." 514 Throughout my research process I aimed to practice what Tuana calls "loving ignorance", realising that while much of human experience can be shared, there are certain modalities of being that exceed my own, such as experiences of vulnerability, marginalisation or grief that one person could never truly comprehend of another. ${ }^{515}$ I aim to approach differences in lived experiences with a sense of humility and a sense of wonder, listening and learning from interviewees as a self-reflexive research praxis. I openly admit that this is a messy and difficult balance (that I will likely get wrong as I continue to learn about how my positionality influences my research) and I remain open to negotiating with the help of interviewees as my conversational partners. As a Tauiwi researcher in Aotearoa New Zealand, I strive to uphold Te Tiriti o Waitangi and the principles of reciprocity,

513 Fotopoulou, Feminist Activism and Digital Networks, 402.

514 Alison Jones, "The Limits of Cross-Cultural Dialogue: Pedagogy, Desire, and Absolution in the Classroom,"

Educational Theory 49, no. 3 (1999): 315-316 doi: 10.1111/j.1741-5446.1999.00299.x.

515 Tuana, "The Speculum of Ignorance," 15-16. 
and recognise how my own whakapapa, genealogy, lineage, and traditions formulate how I perceive the world and influence my research. 516

Part of navigating my way as a critical feminist scholar has been understanding how methodology is linked to overarching narrative and findings within my research. Methodology is often perceived to be the more 'scientific' part of the research process and is managed in a clinical way that focuses on justifying variables and negating bias. However, as I dive deeper into the epistemological standpoint of critical feminist researchers who aim to work outside normative frameworks and challenge their assumed 'rationality', I have begun to realise that there is no such thing as a perfect or unbiased methodological approach. My positionality as a researcher within International Relations, my cultural background and the nature of it will inevitably influence the way I approach my research, not only in the overarching theories of vulnerability and ignorance or CTDA technique but also in my statistical, or 'rational' choices, such as the number of interviewees and tweets I choose.

Rather than following Western centric ideas of 'proper scientific research' that manages variables, considers replicability and 'proves' dominant patterns, I started with the outliers, recognising that in their separation they have more to share about the norm than those in centre positions do. By prioritising in-depth personal interviews, I made room for understanding emotionality, personal histories and lived experiences, all of which provide a better understanding of context. A critical feminist approach to research goes 'all the way down' as much methodologically as it does theoretically. Its underlying beliefs influenced how I approached every detail of my data collection and analysis, such as who I chose to interview (centring marginalised bodies), the way in which I approached interviews with them (as collaborative partners and not as subjects to study) and how I chose to analyse not only their words but the technological affordances of the technologies they engage with (to highlight underlying technological and systemic inequalities). hooks, in her discussion on the conduct of interviews, says that allowing people to 'talk back' during interviews gives voice to interviewees who are often silenced and, in doing this, talking back becomes a political act.517 I would like to build upon this principle, arguing that the way we conduct research and the methods we choose become in and of themselves a political act. Accordingly, my methodological approach should be seen as a political statement, one that values and listens to the voices of the marginalised, one that acknowledges my own positionality, privilege and limitations as a Tauiwi academic. It is my aim to engage in a self-reflexive research methodology that works towards new and more equitable approaches to research within the International Relations and Media Studies disciplines.

516 Mead, Tikanga Māori, 164.

517 bell hooks, Talking Back: Thinking Feminist, Thinking Black, (MS, Boston: South End Press, 1989). 


\section{Chapter Three}

Claiming Collectivity

This chapter explores how online renderings of self create and maintain status quo conceptions of Otherness and can problematise the recognition of precarity. ${ }^{518}$ I argue that the use of collectivising hashtags affords new opportunities for self-expression that may simultaneously empower and compromise certain individuals. Following the feminist traditions of Butler, Gilson, and Schick, my analysis incorporates an ethic of vulnerability in order to interrogate underlying power relations and our location within them. ${ }^{519}$ This analysis encourages people to think critically about assuming the identity of vulnerable Others and conflating shared human precariousness with individual experiences of precarity. The first section explores the power of collectivity. I suggest that collectivising hashtags are used performatively to give expression to our grief and shared precariousness. The second section looks at the damaging effects of collectivising hashtags and how they can undermine the inclusivity that they ostensibly support. This section draws on the \#TheyAreUs collectivising hashtag that followed the terrorist attack on 15 March 2019 in Ōtautahi Christchurch, Aotearoa New Zealand. In this section, I argue that the appropriating nature of collectivising hashtags creates an 'impoverished form of solidarity' by confusing important distinctions between corporeal vulnerabilities that downplay the lived experiences of marginalised communities. $^{520}$ The appropriating nature of collectivising hashtags often acts to re-centre the self, maintain agency, and facilitate the dominance of privileged narratives. The third section examines the underlying power relations of \#ThisIsNotUs and our own location within them. It explores how the negative aspects of vulnerability can drive privileged bodies to stubbornly maintain their preferred version of self through willful ignorance and invulnerability. In this way, collectivising hashtags act to obscure complicity and allow dominant groups to distance themselves from the realities of racism and violent extremism. In order to work towards emancipation, I advocate for a gradual shift towards vulnerability and reflexivity that turns people's attention inward, calling them to become more vulnerable and aware of the affecting nature of digital practices.

\subsection{The Power of Collectivity}

Figures 3, 4, 5, and 6.

I think the beauty of Twitter (and fuck I am not saying that it's me) is how people are able to communicate so clearly and with such poetry in 140 characters (or whatever it is). I find it remarkable-it is a kind of poetry-it is a kind of magic when someone is able to do it. It's the same with meme culture that someone is able to communicate a really complex human need through a picture with some comic sans. It is

\footnotetext{
${ }^{518}$ A variation of this chapter has been accepted for publication. See forthcoming, Fitzpatrick, Claire, "Claiming Collectivity: The Socio-Political Affects of Hashtagging 'Us,'” International Feminist Journal of Politics, Manuscript in preparation July, 2021.

519 Butler, Precarious Life; Gilson, "Vulnerability, Ignorance, and Oppression"; Schick, "Unsettling Pedagogy."

520 I derived 'impoverished form of solidarity' from Kate Schick's 'impoverished form of recognition.' See Schick,

"Unsettling Pedagogy," 30.
} 
extraordinary, it's like a triumph of our time and Twitter is that too. And that's why I like and retweet stuff, if someone says something, likes something, expresses something and it just like-it's me-and it's like that is me and I think maybe that sparks something. 521

Critical feminist theorists highlight the socio-political constraints inherent to the internet, suggesting that communications networks act to reinforce rather than challenge dominant power structures. The popularity of collectivising hashtags illustrates the appeal and marketability of the collective. ${ }^{522}$ Collectivising hashtags have a unique power to connect us. Trending hashtags succinctly capture an emotion, a feeling or concern at a particular moment in time. They spread with remarkable speed because something within that snapshot speaks to the individual and the collective. The hashtag must speak to something of our own experience. Which hashtags go viral is often unpredictable and surprising. They need to trigger or 'spark' something, a resonance, an understanding in the mind of an often overwhelmed and apathetic audience. Successful hashtags manage to capture something important, a message that thousands of people connect with. The emotional drive for solidarity, camaraderie and understanding is heightened during times of crisis. Hashtags speak to a shared human experience of vulnerability and give voice to the collective feelings of grief, anger, and precariousness that hang in the air following tragedy. In reference to the \#WeAreAllPussyRiot hashtag and associated digital campaign following the incarceration of members of the feminist collective Pussy Riot for their staging of a musical protest in a Russian Orthodox church, Groeneveld says pointedly "they are both 'just like us' and just different enough" and thus present an opportunity for privileged bodies to include themselves in the trending narrative. ${ }^{523}$ This strategy works powerfully in an age of hashtag activism because of its ability to trigger emotional response and impassioned reaction from a self-interested population.524 It is the act of asserting solidarity via collectivising hashtagging practices that enables people to insert themselves in the trending discourse.

Collectivising hashtags are paradoxically individualist and collectivist by design. They are performances of self that express privately held and publicly delineated conceptions of self. Paolo Gerbaudo, in his assessment of the Occupy Movement online, claims that modern online practices are identity claims, whereby an identification of the individual in the collective is constructed through a fusion of the individual into a formless and enigmatic collective entity. ${ }^{525}$ Gerbaudo asks, "are they also claiming participation in 'we'", as an entity that is not simply a network of connected individuals, but a collective creature that is more than the sum of its parts?526 Gerbaudo explains this collectivising momentum saying:

What we are witnessing in fact, in this time of economic and political crisis and instability, is a new desire for collectivity, in which individualised social media communications are often perceived simply as a springboard for a process of social and physical re-compositions...They are ad hoc and are characterised by evanescence and a

\footnotetext{
521 Interview conducted Thursday 11 June 2020 via Zoom conference call.

522 Groeneveld, "Are We All Pussy Riot?" 297.

523 Groeneveld, “Are We All Pussy Riot?" 298.

524 Loken, "The Invisability of Imperialism," 1100.

525 Paolo Gerbaudo, "The Persistence of Collectivity in Digital Protest," Information, Communication \& Society 17, no.

2 (2014): 268, doi: 10.1080/1369118X.2013.868504.

526 Gerbaudo, "The Persistence of Collectivity," 268.
} 
certain enigmatic character. Yet, they are forms of collectivity in which individual users through the internet and beyond come to develop a sense of belonging to something bigger than themselves, and in which 'the small and fitful contributions of the crowd', such as choosing a certain profile picture, posting certain hashtags or retweeting certain messages appear in the guise of identity subscriptions, acts through individual internet users assert: I belong. ${ }^{2} 27$

People find belonging and meaning in online spaces, feelings of community, support and solidarity. This drive to belong to a collective, to find solidarity and solace, to help make sense of the difficult events is heightened by instability. Collectivising hashtags often trend online during times of crisis. Examples include \#WeAreAllTrayvon following the shooting of Black American teenager Trayvon Martin; \#JeSusisCharlie, following a shooting at the French satirical newspaper Charlie Hebo; \#IAmMalala, in response to the attempted assassination of Pakistan education activist Malala Yousafzai; and my case studies, \#TheyAreUs and \#ThisIsNotUs, following the 2019 terrorist attack in Ōtautahi Christchurch. ${ }^{528}$ Collectivising hashtags highlight the collective power of grief and vulnerability, and the contingent and affecting nature of our lives on the lives of others. Collectivising hashtags can be seen as an emotional response to a human tragedy that allows us to take part in a collective grieving process.

I suggest that Butler's analysis in Precarious Life can be expanded to include online spaces in order to better understand how a differential distribution of precarity influences our online renderings of self and Other. Butler claims that all people have a notion of what it is to have lost someone or of the risk of losing them. ${ }^{529}$ It is, in fact, a key commonality of the human experience. Precariousness is what defines us as humans; our lives are by definition transitory and can end at any moment. Butler explains how precariousness connects us, saying,

This means that each of us is constituted politically in part by virtue of the social vulnerability of our bodies, as a site of desire and physical vulnerability, as a site of a publicity at once assertive and exposed. Loss and vulnerability seem to follow from our being socially constituted bodies, attached to others, at risk of losing those attachments, exposed to others, at risk of violence by virtue of that exposure. .530

When people witness the loss of human life or the corporeal vulnerability of others they are reminded of their own precariousness. Butler argues that we all live with this particular vulnerability, a vulnerability to other bodies that is unpredictable in nature, calling it a "a vulnerability to a sudden address from elsewhere that we cannot preempt." 531 Shared feelings of vulnerability often resurface during times of tragedy and resonate deeply with many of us.

It is during times of social and political uncertainty that an apprehension of human precariousness and vulnerability becomes undeniable. Linda Åhäll and Thomas Gregory, focusing on our responses to traumatic events such as terrorism and war, argue that collective

527 Gerbaudo, "The Persistence of Collectivity," 268.

528 Bonilla and Rosa, "\#Ferguson Digital Protest," 4-17; Berents, "Hashtagging Girlhood," 513-27.

529 Butler, Precarious Life, 20.

530 Butler, Precarious Life, 20.

531 Butler, Precarious Life, 29. 
expressions of fear, anger, and loss can provide the "emotional glue' that binds the collective together and provides the appearance of an essence or stable identity." 532 The performative power of emotion can help to secure a shared sense of identity and constitute political communities that are comforting during turbulent times. ${ }^{533}$ Butler explains that while many people think that grief is privatising (that it returns us to a solitary situation) it is in a sense the opposite, having both a collective and political function:

I think it furnishes a sense of political community of a complex order, and it does this first of all by bringing to the fore the relational ties that have implications for theorising fundamental dependency and ethical responsibility. If my fate is not originally or finally separable from yours, then 'we' is traversed by a relationality we cannot easily argue against; or rather, we could argue against it, but we would be denying something fundamental about social conditions of our very formation. ${ }^{534}$

Collectivising hashtags allow people to include themselves in communal expressions of grief, express solidarity and acknowledge our shared precariousness. The inclusion of personal pronouns in collectivising hashtags facilitates the expression of personally felt emotions - I feel hurt, broken and helpless and $\mathbf{I}$ understand the way you are feeling in this moment and $\mathbf{I}$ want to express solidarity with everyone else. Hashtagging is also a political performance; hashtags allow users to extend their private messages to the broader public and invite others to add to the conversation. Collectivising hashtags have a unique political power in that they enable people to express something as individuals and link this to broader trending debates within online platforms.

Hashtags are politically loaded and communally orientated. When you post a message without a hashtag, it is limited to your immediate online following (those people that follow you and those that follow you in return). However, when you use a hashtag on Twitter, that post becomes more accessible to those beyond your chosen circle. Hashtags act as an indexing system to compile certain topics thus allowing people to encounter different perspectives and people interested in the same topic - people with perspectives that they otherwise might not encounter. If you would like to know what people on Twitter (in your country or around the globe) are concerned with at any particular moment, look at what is trending. In this way, trending hashtags fulfill an important political function by highlighting the issues that are of the greatest interest and importance to particular online communities at any one time. Hashtags are declarative; they are affective expressions aimed at presenting an aggregate of conversations of people in online societies. Collectivising hashtags situate and affirm a sense of self held in relation to the collective. Zizi Papacharissi argues that Twitter affords rich and variable public and private performances of self.535 For Papacharissi, hashtagging "both categorises the performance and makes it accessible to wider audiences. It affords performative statements of self greater visibility, effectively eponymizing them." 536 According

532 Linda Åhäll and Thomas Gregory, "Security, Emotions, Affect,” Critical Studies on Security 1, no.1 (2013): 118 doi: 10.1093/ips/olx024.

533 Åhäll and Gregory, "Security, Emotions, Affect," 118.

534 Butler, Precarious Life, 22-23.

535 Papacharissi, “Affective Publics : Sentiment, Technology, and Politics,” 96.

536 Zizi Papacharissi, "Without You, I'm Nothing: Performances of the Self on Twitter," International Journal of

Communication [accessed online 13 April 2021] (2012):

https://link.gale.com/apps/doc/A298057184/AONE?u=vuw\&sid=AONE\&xid=eca099d9. 
to Papachrissi, privately motivated actions attain a public orientation on Twitter as personal style is meshed with political potential. ${ }^{537}$ Public and private performances of the self are expressed through condensed statements on Twitter that frequently manifest a converged response to current sociocultural and political issues. ${ }^{538}$ Papacharissi explains this convergence, stating:

Tweets varied and adapted to the topic nature of the hashtag, which afforded some situational definition. The thematic orientation of the tag provided the context for statements of self, suggesting how these statements might be encoded by the self and then further decoded by audiences actual and imagined. 539

Collectivising hashtags conflate personal, political and technological performances of self. While we might traditionally think of social media as serving a primarily personal function in which we share things about our lives with chosen friends and family, collectivising hashtags situate those personal performances within a broader collective. Our personal and political performances and debates are unfolding in online spaces and the collectivising hashtag invites the public to make the personal something political. Collectivising hashtags like \#MeToo ask: what is your experience with sexual harassment? \#ICantBreathe asks: what is your personal experience with racially motivated violence? These are intrinsically political questions. Online performances enable individuals to traverse from private to public but also, potentially from, "the personal to the political or from the individual to the collective and back." 540 Groeneveld does not dismiss 'the political force of 'we are all...' solidarity statements, which can serve as powerful ways of linking violence and/or injustice towards individuals to larger structural inequalities and/or histories of oppression." ${ }^{41}$ This collectivity is perhaps one of the most innovative and influential social movement practices of the $21^{\text {st }}$ century.

The phenomenon of collectivising hashtags exemplifies the digital collapse of public and private boundaries affording opportunities for expression that may simultaneously empower and compromise individuals. ${ }^{52}$ The use of collectivising hashtags can unwittingly downplay the lived experiences of marginalised bodies and confuse important distinctions between corporeal vulnerabilities. Collectivising hashtag practices become increasingly problematic when privileged onlookers assume the identity of vulnerable subjects, as was the case with the \#ICantBreathe (police brutality towards African-American communities), \#IAmRefugee (following the bombing of Syrian civilians in Alleppo), and \#IAmJewish (following several attacks on Jewish communities in France) hashtags. Andén-Papadopoulos observed that online movements shared by those who themselves risk bodily injury have proven to facilitate connectivity with suffering precisely by their distinct claim to truth in the name of vulnerable subjects who are sharing their own vulnerabilities. ${ }^{543}$ As discussed earlier, 'vulnerable subjects' refers specifically to bodies who suffer the corporeal consequences of vulnerability, as opposed to our universal capacity for vulnerability, in order to highlight the inequality that inherently

\footnotetext{
537 Papacharissi, "Affective Publics," 94-95.

538 Papacharissi, "Affective Publics," 96.

539 Papacharissi, "Without You, I'm Nothing," 1999-2000.

540 Papacharissi, "Affective Publics," 95.

541 Groeneveld, "Are We All Pussy Riot?" 303.

542 Papacharissi, "Affective Publics," 94-95.

543 Andén-Papadopoulos, “Citizen camera-witnessing," 753.
} 
exists between the actual lived experiences of privileged onlookers and Others. ${ }^{544}$ This leads me ask what are the socio-political implications of grouping privileged bodies voices online with those who experience corporeal precarity, daily persecution, and bodily injury? In what follows, I explore the effects of the blurring of our personal and collective political practices, via collectivising hashtags.

\subsection{Are They Us? How Collectivising Hashtags Reinforce the Systemic Issues They Ostensibly Oppose}

Collectivising hashtags navigate the intersections of an individual's identity and that of Others, which in turn gives rise to discursive framing processes for articulating agency and the circulating of interpretations and observations of Others' lived experiences and identities. 545 The problem with the growing obsession for collective stories is that they can often extend beyond the communities they were initially intended for. The collectivising nature makes room for all of us to join and sometimes these precarious spaces can be appropriated. This raises an important question: when people use collectivising hashtags, whose stories are they telling and are they theirs to tell? In this section, I investigate the damaging effects of these blurring boundaries between narratives of the individual and the collective, and how they relate to broader structural inequalities in society.

The collectivising hashtags \#TheyAreUs and \#ThisIsNotUs were shared following the terrorist attack at Al Noor Mosque and Linward Islamic Centre in Ōtautahi Christchurch, in Aotearoa New Zealand, on 15 March 2019. It is worth repeating Prime Minister Jacinda Ardern's public speech after the Mosque attack, in which she stated:

It is clear that this is one of New Zealand's darkest days. Clearly, what has happened here is an extraordinary and unprecedented act of violence. Many of those who will have been directly affected by this shooting may be migrants to New Zealand, they may even be refugees here. They have chosen to make New Zealand their home, and it is their home. They are us. ${ }^{546}$

The hashtag \#TheyAreUs allowed people to form a collective 'we' and gave voice to the communal experience of grief. The hashtag \#TheyAreUs was often paired with images from memorials and vigils that were held around Aotearoa New Zealand in expression of solidarity in grief. After the shooting, there was a widely shared feeling of disbelief, grief and anger amongst the New Zealand public. The terrorist attack was live streamed and shared via Facebook and Twitter, meaning that a large number of people witnessed the shooting and experienced the horror online. Facebook claims that the video was viewed fewer than 200 times during its live broadcast and then viewed a further 4000 times before it was removed. ${ }^{547}$ Within the first 24 hours of the video's upload, there were 1.5 million attempts at resharing the video that were blocked by Facebook. The autoplay feature on Facebook and Twitter meant

\footnotetext{
544 Cole, "All of Us Are Vulnerable," 260.

545 Kuo, "Racial justice activist hashtags, " 497.

546 Ardern, "Further update from Jacinda Arden on Christchurch mass shooting."

547 Chris Sonderby, "Update on New Zealand," Facebook, 18 March, 2018,

https://about.fb.com/news/2019/03/update-on-new-zealand/
} 
that people inadvertently witnessed the disturbing content without actively choosing to do so by clicking on the video. ${ }^{548}$ Information about the shooting was unfolding live on social media platforms and many people witnessed it there before learning about it on traditional media channels. People took to Twitter and Facebook to get information, to find solace with others, and to express their feelings of confusion and fear. Tweets that were used with the hashtag \#TheyAreUs and \#ThisIsNotUs often referred to emotions associated with grief and vulnerability; some of the most common expressions included feelings of: 'helpless,' 'tears,' 'heart broken,' 'sorry,' and 'darkest day.'549 These performative acts of emotion via collectivising hashtag practices illustrate how traumatic events can help secure a shared sense of self. Åhäll and Gregory suggest that by analysing what emotions do, we can move beyond emotions as feelings and focus on how they produce discernible affects. ${ }^{550}$ Performances of self and emotion can be complicit in "normalising acts of violence, justifying oppression and masking forms of economic and political subordination." ${ }^{551}$

Emotions act to create a particular version of self whilst cultivating an adversarial perception of Others. One interviewee explained it's the well-meaning intention to include the Muslim community that simultaneously acts to highlight the divide:

It is hard to explain, you go through a period where you (I am sure you have been in the same position) you desperately want to affirm your belonging and to that suggesting that there is a divide although important is also deeply painful. I think the \#TheyAreUs was that was affirming that they [the Muslim community] are us... but by being so bold in labeling that divide it was like further othering-that sense of belonging. 552

The emotional outpouring of solidarity was intended to make Muslim communities feel that they belong. However, in doing so the emotional sentiments of empathy, pity, and affinity emphasised the divide between the 'helpless immigrants' and the 'welcoming Western subjects'.

Several critical race and feminist scholars have advised caution when experiencing the emotional pull of empathy and solidarity. Rodino-Colocino claims that passive empathy can be counterproductive in that "it enables oppressors and even oppressed people to project feelings of commonality, understanding, as well as fear and guilt rather than do the work of being selfreflexive."553 At the same time, pity can also function to mask past injustices and ignore responsibility for the suffering of others. Emotion can act to reinforce hierarchical relationships between 'us' and 'them' by locating agency with privileged bodies and simultaneously denying Others the capacity to act. ${ }^{554}$ Ahmed concludes that passive empathy

\footnotetext{
548 The New Zealand Department of Internal Affairs acknowledged the issue of auto play on social media and on the websites of traditional news outlets, in which people may see disturbing content without choosing to do so stating: "We are aware that people may have unsuspectingly viewed the video on social media platforms thinking it is a media article, so please be vigilant of images that yourself and those around you are viewing, particularly our young people." See Timberg et al., "The New Zealand shooting shows how Youtube and Facebook spread hate and violent images - yet again."

549 These are some of the most common emotional adjectives and expressions that I recorded in my discourse analysis of the \#TheyAreUs hashtag.

550 Åhäll and Gregory, "Security, Emotions, Affect," 118.

551 Åhäll and Gregory, "Security, Emotions, Affect," 118.

552 Interview with Alice Canton conducted Thursday 11 June 2020 via Zoom conference call.

553 Rodino-Colocino, "Countering Cruelty with Empathy," 96.

554 Åhäll and Gregory, "Security, Emotions, Affect,” 118.
} 
"sustains the very difference it seeks to overcome." 555 Through these comments we can observe that the use of collectivising hashtags exposes a concerning tension between wanting to provide a voice to the voiceless Other and speaking on their behalf. I maintain that this tension between narratives of the individual and the collective stems from the fact that collectivising hashtags are affecting a looped digital gaze. ${ }^{556}$ The collectivising hashtag \#TheyAreUs draws attention away from the victims of Mosque shootings and back onto Pākehā and Tauiwi New Zealanders. The shooting becomes an assault on 'us', the broader Aotearoa New Zealand public. ${ }^{557}$ This new sense of commonality is grounded in shared citizenship and a familiar sense of 'Kiwiness' that is recognisable and defendable. What privileged bodies are seeing is not really the Other but rather the familiar and known elements of ourselves within them. The use of collectivising hashtags enables audiences to raise awareness of a cause and, at the same time, display their own views through public affiliation, "possibly to reinforce one's own public view as someone who is aware and committed." 558 As a result, the life of the vulnerable subject becomes subsidiary; they become martyrs fuelling another's political narrative.

Collectivising hashtags raise concerns relating to agency, specifically the placement of Western bodies in a position of privilege and benevolence. In her analysis of \#BringBackOurGirls, Loken suggests that the 'our' in the \#BringBackOurGirls campaign speaks to a troubling discourse through which the value of the distant Other is placed in relationship to the more privileged Western agent. 559 This is to say, the subject who "bestows solidarity upon others" is coded as having agency and value, whereas marginalised bodies have none except their association with the privileged subject. 560 Social inequalities are sustained by what Hall calls "the spectacle of the Other," where one dominant community is normalised and all other communities are positioned in its periphery. ${ }^{561}$ The hashtag \#BringBackOurGirls explored by Groeneveld and \#TheyAreUs are similar in their construction in that they both rely on the ownership of their subjects to produce public sympathy and media 'spreadability.' ${ }^{62}$ By extending Groeneveld's argument on the limits of transnational solidarity to collectivising hashtags, I argue that while the \#TheyAreUs hashtags were initially created as an expression of solidarity with the victims of the Mosque attacks, they act as an admission of Muslims as 'lesser' bodies.

'Difference-blind' approaches have been critiqued for using supposedly neutral liberal principles of equal dignity and fairness. ${ }^{563}$ Emily Beausoleil suggests that difference-blind approaches continue to "reinforce entrenched inequalities and occlude them in the same gesture" by simultaneously 'welcoming' immigrants in and requiring assimilation into Pākehā

\footnotetext{
555 Ahmed, The Cultural Politics of Emotion; 30

556 Refer back to section 1.1 Collectivising Hashtags: A Growing Phenomenon for detailed discussion on the looped gaze.

557 Other hashtags that were used around the time \#TheyAreUs trended focused on New Zealand and Christchurch as a whole. For example, hashtags like \#Christchurch, \#ChristchurchStrong \#ArohaNZ made no reference to the affected Muslim Communities.

558 De Cock and Pedraza, "From expressing solidarity to mocking on Twitter," 200.

559 Loken, "The Invisability of Imperialism," 1100-1101.

560 Groeneveld, "Are We All Pussy Riot?" 303.

561 Hall, "Cultural Representations," 223.

562 The term 'spreadability' refers to the function of the hashtag in terms of its capacity to reach a wide audience. See Groeneveld, “Are We All Pussy Riot?” 299.

563 The 'difference-blind' approach emerges from classical liberalism in an effort to account for pluralism and avoid discrimination on the basis of difference and achieve equal treatment. See Beausoleil, "Gather Your People," 6.
} 
New Zealand culture. ${ }^{564}$ In the context of the \#TheyAreUs collectivising hashtag, Muslim bodies are deemed to be worthy of acceptance and deserving of protection only in their capacity to be claimed. 'They' are deserving of protection because the Aotearoa New Zealand public has decided to make them one of 'us' rather than because of the grave violation of human rights committed against them as humans. The concern here is that Muslim bodies need to be 'us' in order to be "politically legitimated." 565 Collectivising hashtags reconstitute Other bodies as valuable and therefore "less dispensable" because privileged bodies claim them as their own, not because they are valuable in and of themselves. ${ }^{566}$ As people craft online narratives about who they are, "agency is semantically and affectively accessed and claims to power performed." 567 The outsider status of Muslim lives with whom solidarity is claimed via what Groeneveld calls an "exceptionalist discourse" ensures that agency remains with the Pākehā or Tauiwi subject and is not decentred in any way. ${ }^{568}$ The \#TheyAreUs hashtag brings the lives of Muslims into the view of Pākehā and Tauiwi onlookers but has not resulted in any true form of inclusiveness.

This discourse has left privileged bodies with an impoverished form of solidarity that is only concerned for Muslim bodies insofar as their suffering impacts the majority of New Zealanders and the collective 'us.' Richard Day, in his critical discussion on the possible gift of multiculturalism, poses the question "Who is this we that gives the gift?"569 Day points out that 'we' as 'States-people' have the power to choose whether or not to bestow the gift of inclusivity upon 'them' as immigrants and minority bodies.570 This is to say, when people create a collective, a 'we' or an 'us', it inadvertently establishes a norm and positions the 'they' and 'them' in opposition. This norm functions as a political nexus and all minority bodies are forcibly situated in relation to this nexus of power. Building on Day's critique of multiculturalism, I ask how the gift of 'us' in the collectivising hashtag \#TheyAreUs paradoxically acts to reaffirm Muslim bodies as outsiders.

\section{Figure 7.}

Aotearoa New Zealand based theatre artist Alice Canton tweeted, "Yes I understand and, in fact agree in standing in unity. But also this dichotomy of acknowledging that Muslims (in this context) are a 'they' that 'we' validate by saying we accept them (which perhaps up to this point many didn't) doesn't sit well with me." ${ }^{571}$ When explaining her tweet in an interview, she stated:

Pronouns and inclusive language can be incredibly powerful, but also can be detrimental to a cause and I think that's why I said that it [\#TheyAreUs] did not sit comfortably for me. Because I wasn't prepared to denounce it [\#TheyAreUs] as a statement - because I am not Muslim - it also did not sit comfortably that I had to call

\footnotetext{
564 Beausoleil, “Gather Your People,” 6.

565 Burgess, Marwick, and Poell, The Sage Handbook of Social Media, 1101.

566 Groeneveld, "Are We All Pussy Riot?" 299.

567 Papacharissi, "Affective Publics," 94.

568 Groeneveld, "Are We All Pussy Riot?" 300-301.

${ }^{569}$ Richard Day, "Who is this we that gives the gift? Native American Political Theory and The Western Tradition,"

Critical Horizons 2, no2 (2002): 173, doi: 10.1163/156851601760001300.

570 Day, "Who is this we that gives the gift?" 195.

571 See Appendix figure 7: Alice Canton Tweet.
} 
the Muslim community a 'they' in that moment. By emphasising the 'they' and 'us' it encouraged a continuum - or a bias in which there is an inclusive and exclusive group. 572

Canton's tweet suggests that the designation of 'they' and 'us' places Pākehā and Tauiwi New Zealanders in a position of the host or owner who welcomes outsiders in. The collectivising hashtag \#TheyAreUs allows Pākehā to see themselves as charitable and altruistic, qualified to include Muslim communities in Aotearoa New Zealand society, while at the same time calling 'them' (Muslim refugees, immigrants, and citizens) to assimilate to White New Zealand culture, affirming the dominance of a particular colonised Westernised version of 'us'.

In her critique of a liberal multicultural policy, Beausoleil problematises the "presumption of a central (settler) culture that tolerates, even celebrates, 'other' group difference, but whose own group remains unmarked and whose authority to name and acknowledge the difference of others remains unquestioned." 573 She argues that we must not simply 'learn from' the experience of Others, but rather learn to listen to and from one's own group difference, "to learn to hear one's own accent, to sense and own the particular history and inheritance from which one inevitably speaks, as a member of historical and structural collective." 574 She maintains that the settler-colonial approach to encountering difference is one that remains distinctly "unmarked."575 For Beausoleil, the condition of being unmarked is a highly particular one borne of settler colonial histories that presumes a universal ground for commonality, recognition, and reconciliation can be brokered through a Western difference-blind approach. 576 Beausoleil emphasises that "the very propensity to universalise" presumes the Western drive to remain unmarked, and to centre the Western experience as the norm while simultaneously ignoring the histories of colonisation violence that led to domination. ${ }^{577}$

I argue that there is a connection between Beausoleil's notion of unmarked White identity and Kuo's previously mentioned conceptualisation of racialised digital enclaves. Kuo remarked,

As a racially unmarked and disembodied space, Twitter is perceived as White. White participation in online activities is rarely understood as constitutive of White identity; instead we are trained to understand their online activities as stuff 'people' do [italics added]. 578

By recognising Twitter as a racially marked space, embodied by real people with varying proximities to Whiteness and privilege, we can resist hegemonic settler culture that perceives White discourse and architecture as structurally even, neutral and unmarked by privilege. We

\footnotetext{
572 Interview with Alice Canton conducted 11 June 2020 via Zoom conference call.

573 Beausoleil, “Gather Your People," 7.

574 Beausoleil, "Gather Your People," 3.

575 Emily Beausoleil explains the condition of being 'unmarked' is highly particular one, borne of settler colonial histories that presume not that a universal ground for commonality, recognition, and reconciliation exists but that a Western brokering of a this peace through a difference-blind approach is objective. Beausoleil argues that "the very propensity to universalize" presumes the desire to be unmarked, to centre the Western experience as the norm as well as ignore the histories of colonisation violence and the legacies of domination that remain today. See Beausoleil, "Gather Your People," 6.

576 Beausoleil, "Gather Your People," 8.

577 Beausoleil, "Gather Your People," 10.

578 Brock, "From the Blackhand Side," 534.
} 
need to recognise hashtags as specific racial and cultural codes. Sanjay Sharma argues that digital networks are generative of race and can be grasped by an approach attentive to the operations of online platforms. ${ }^{579}$ My contention is that a move to an understanding of digital media networks that pays attention to structural inequality in these spaces opens up new possibilities for rethinking how race and privilege work online.

The collectivising hashtag \#TheyAreUs takes a difference-blind approach and in doing so blankets over "specific histories that undergird presently entrenched [settler-colonial] inequalities." 580 Although the \#TheyAreUs hashtag makes Muslims part of the collective 'us', this recent inclusion only emphasises their historic status as Other. ${ }^{581}$ Ardern's speech, with its emphasis on Muslim bodies as immigrants and refugees, ignores the fact that Muslim communities have been in New Zealand for a long time. Pakeeza Rasheed, chairperson of the Khadija Leadership Network, writes:

Let's not fool ourselves. We have never really been a part of New Zealand. We have merely been allowed to exist-never embraced, never included, never accepted. Muslims have been in New Zealand since the 1800s but we are still treated as outsiders. ${ }^{582}$

Sahar Ghumkhor points out while some Muslims have been in Aotearoa New Zealand longer than some Pākehā or Tauiwi, they are still presented as foreigners:

What struck me about Ardern's statement - and the many others like it praising diversity, the welcoming nature of Kiwis, and the provincial shire with a small tightknit community - is how dishonest it is... Although Islam has a century-long presence in the country, Muslims continue to be portrayed and treated as immigrant and refugees ie inherently 'foreign'. They are either 'welcomed' or told to 'go back' to where they came from - with both sentiments demonstrating that they are not really seen by the majority as an integral part of New Zealand's society. ${ }^{583}$

Ghumkhor concludes that the oscillation of 'they' (the outsider) and 'us' (the fully civilised human) reveals the precarious nature of Muslim lives and their place in the nation. ${ }^{584}$ The collectivising hashtag \#TheyAreUs erases the multiplicity of individuals and instead portrays all Muslim bodies as one foreign body.

In my interview with gender-based violence researcher and practitioner Hala Nasr, she explained:

When it came to Christchurch the \#TheyAreUs really wasn't about (wasn't from the perspective or didn't amplify - didn't center) Muslims at all to be honest. So what I

\footnotetext{
579 Sharma, "Black Twitter?" 47.

580 Beausoleil, "Gather Your People," 7.

581 Sahar Ghumkhor, “The Hypocrisy of New Zealand's 'this Is Not Us' Claim,” Aljazeera, 20 March, 2019, https://www.aljazeera.com/indepth/opinion/hypocrisy-zealand-claim-190319104526942.html.

582 Pakeeza Rasheed, "I am a Muslim New Zealand women and I am as angry as I am sad," The Vice, 17 March, 2019

https://www.vice.com/en_nz/article/8xy34p/i-am-a-muslim-new-zealand-woman-and-i-am-as-angry-as-i-am-sad

583 Ghumkhor, "The Hypocrisy of New Zealand's 'this Is Not Us' Claim."

584 Ghumkhor, "The Hypocrisy of New Zealand's 'this Is Not Us' Claim."
} 
would say to counter that - is to amplify voices and experiences of Muslims. To share diverse opinions - there is a whole range of diverse opinions even within the Muslim community - we are not homogenous - we are not all the same - we do not all practice our faith the same way. So making sure you amplify [Muslim voices] keeping in mind that diversity and who that serves. 585

Nasr voiced her concern about the collectivising nature of the \#TheyAreUs with its 'erasure' of cultural diversities and differences in lived experiences (figure 8). There are marked differences between experience within Muslim communities, between men and women, between women who choose to wear the hijab, burqas or niqabs (visibly indicating their religion) and those that choose not to, differences in lived experiences between practitioners of Islam who are also people of colour, and between those who are citizens and those who are refugees and immigrants. When privileged bodies include themselves in the discourse of Others via collectivising hashtagging practices, they ignore the multiplicity of cultural diversities and inadvertently reaffirm minority bodies as outsiders. This is to say, when privileged bodies hashtag \#TheyAreUs, they unwittingly downplay the lived experiences of Muslim bodies and confuse important distinctions among particular vulnerabilities. Collectivising hashtags that gain momentum on the basis of passive empathy run the risk of mis-producing emotions that are not the basis of lived experience "a feeling of being in another's shoes without the risk of actually doing so."586

The \#TheyAreUs hashtag asserts an ambiguity and ambivalence, and thus "ignores the corporeal experience of precarity." 587 Butler distinguishes between ontological and situational vulnerability-in other words, between the vulnerability that is a condition of life's 'precariousness' and the vulnerabilities that are embedded in specific structures of powerprecarity.588 According to Butler, precariousness is not simply an existential condition of the individual, but rather the social and political condition in which the "denial of the coloniser's precariousness in the name of the invulnerable self-defence seeks to deny the condition in which human animals are exposed to each other, and where precariousness is a generalised condition." 589 The assertion that Muslim communities are 'us' suggests a failure to recognise that, as a minority in Aotearoa New Zealand, these communities have experienced a long history of violence, persecution, and dispossession, the likes of which Pākehā and Tauiwi New Zealanders have not encountered. Ghumkor discusses how members of her family who are visibly Muslim experience the everyday consequences of Islamophobic attitudes, saying: "Cars have sped up towards them as they have tried to cross the street; in public spaces they have been called terrorists or have been asked to take off the veil." 590 The lived experience of precarity and vulnerability is distributed unevenly and allocated differentially across people in Aotearoa New Zealand. One interviewee explained how her own experiences growing up in Aotearoa conflict with the \#TheyAreUs sentiment stating:

\footnotetext{
585 Interview with Hala Nasr conducted 16 October 2020 via Zoom conference call. See also, Hala Nasr, "Islamophobia: A Personal Reflection." The Pantograph Punch. 23 March, 2019. https://www.pantographpunch.com/posts/islamaphobia-a-personal-reflection.

586 Megan Boler, “The Risks of Empathy: Interrogating Multiculturalism's Gaze," Cultural Studies 11, no2 (1997):

253-73, doi: 10.1080/09502389700490141

587 Butler, Frames of War, 25.

588 Butler, Frames of War, 25.

589 Butler, Frames of War, xxv.

590 Ghumkhor, "The Hypocrisy of New Zealand's 'this Is Not Us' Claim."
} 
\#Theyareus erases the kind of experiences of islamophobia that have shaped my life growing up in New Zealand where I was born and raised. You know a better hashtag would have been \#WeWillDoBetter or \#CallOutYourRacistUncle - you know what I mean. The \#TheyAreUs intent was to say that Muslims in New Zealand are welcome and I find that problematic... If we put that Muslims are welcome aside - another idea is that you know that Muslims are just as 'Kiwi' as Pākehā New Zealanders and we simply are not. My lived experiences literally attest to that - so what are you trying to achieve by saying that? And I think for me the way I read it immediately was White guilt right. It was this distancing between the extreme White supremacism that we saw with the Mosque terrorist versus the kind of everyday racism and Islamophobia that I have experienced everyday my entire life from good people who are friends, people that I love, people who are not evil or bad or would go around shooting Muslims as they pray. So I guess like that kind of sentiment for me if there was any kind of solidarity sentiment - for me it did not come from the \#TheyAreUs statement in fact it enraged me more. 591

Muslim worshipers in Al Noor Mosque and Linward Islamic Centre were corporeally vulnerable on the day of the attack and are equally so every day they practice their faith as a minority in New Zealand, an important distinction that Pākehā or Tauiwi miss when they tweet \#TheyAreUs. Dewey remarks, "you simply can't claim an identity so inextricably tied to pain and persecution, when you have suffered none of that history." ${ }^{592}$ In other words, privileged onlookers cannot claim to understand the experience of the vulnerable Other or 'be' them. Yet, under the constant pressure of shareability and virality, hashtags are subject to "disjunctures of meaning, to misrepresentation and appropriation."593 The immediate and urgent nature of social media discourse often negates the complexities and heterogeneity of the lived experience. The suggestion that 'they are us' acts to radically decontextualise the attack on Muslim worshipers in Ōtautahi.

Critical feminist theorists remain wary of the latent particularity of universalisms arguing instead for accepting rather than obscuring group differences. ${ }^{594}$ Tuana maintains that alterity is not something we should attempt to remove; our differences in lived experience are not something we can collectivise and we need to recognise that there are "modalities of being that exceed our own and cannot be fully comprehended." 595 An anonymous article written by a Muslim New Zealand woman recounted a debate within her community following the terror attack where they considered Aotearoa New Zealand's response and attempt to "make us feel like we are one of them." ${ }^{596}$ She responded - "Why 'them'? We shouldn't have to be 'them."'597 In the rush to respond to the horrific events of 15 March 2019, attempts to express solidarity and inclusivity have overlooked the corporeal reality and differences of lived experiences for

591 Ghumkhor, "The Hypocrisy of New Zealand's 'this Is Not Us' Claim."

591 Interview with Hala Nasr conducted 16 October 2020 via Zoom conference call.

592 Dewey, "\#JeSuisNarcissique."

593 Brager, "The Selfie and the Other," 1669.

${ }^{594}$ Cole, "All of Us Are Vulnerable," 276.

595 Tuana, "The Speculum of Ignorance," 15-16.

596 "Headscarves movement is cheap tokenism," Stuff, 22 March 2019,

https://www.stuff.co.nz/national/christchurch-shooting/111473440/headscarves-movement-means-well-but-it-

is-cheap-tokenism?utm_source=dlvr.it\&utm_medium=twitter

597 "Headscarves movement is cheap tokenism." 
Muslim bodies; 'they' are more vulnerable to violence and dispossession than 'us'. Privileged onlookers cannot claim to understand the experiences of vulnerable others; 'they' are not 'us' and, perhaps more importantly, 'we' are not 'them' because 'we' do not suffer from threat, discrimination, and fear that 'they' do.

\subsection{Is This Us? Interrogating Underlying Power Relations and Our Location Within Them}

This is not us.

The words ring. As though saying them over and over again etches them into the whenua. Oh we want so badly for them to be true.

Masjids. Two of them. IEDs. What's that, a bomb or something? An assault rifle, or five. A

manifesto, a live-stream, a tweet.

A shooter.

The lack of melanin in his skin has protected him... for now.

The world watches. Tick tock tick tock. Two, four, six, forty-nine.

And then. She comes up to the podium, all strength in her compassion. And she says it:

\section{Terrorist Attack. Extremist.}

A victory!

But then:

They are us.

They? Them. Those.

Other.

Said with the best of intentions. But those words betray Whiteness. We build this society as much as you do. We educate, we serve, we lead, we innovate. But we're still the other, left beyond the barricade.

When you tricked me into eating bacon.

When it was just a joke.

When you don't say my name properly.

When you confuse me with another brown person.

When you defend hate under the guise of free speech.

When you say, "we're all just New Zealanders"...

But are we?

Are you scared of going through an airport?

Instead of watching your own, you were watching me.

Five eyes are seemingly blind... to what they don't want to see.

You've been so successful; you have us blaming ourselves. We started it, my mother tells me. It breaks my heart, because I know you did. In 1415. The Great Game. We lost. Again and again.

But now, you love us. You stand with us. The flowers smell nice. You post on Facebook about the Muslim experience. But you never asked, so do you even know? A stranger, you offer to walk me home. But why the fuck would I come to you?

Enough.

Enough tokenism. Enough rhetoric. Enough naïveté.

I need to do my bit.

You need to do your bit.

To kill the monster; we can only do it together.

The number of reasons has gone up to fifty. 
This is us.

But this is not who we want to be.

Maybe one day we will finally be you. ${ }^{598}$

-Anonymous

Claims to know or represent the experiences of Muslim bodies through collectivising hashtag practices can involve forms of appropriation on the part of privileged subjects which obscure complicity in the power structures that saw escalating violence towards Muslim bodies go unchecked. I suggest that the collectivising hashtag \#ThisIsNotUs speaks to Aotearoa New Zealand's reluctance to recognise underlying racist attitudes. The White supremacist attack on Muslim worshipers in Ōtautahi came as a shock to many New Zealanders and called into question many previously held assumptions about Aotearoa New Zealand as a tolerant, accommodating, and progressive multicultural society. ${ }^{599}$ Elliott suggests that, in the wake of these attacks, two mutually exclusive stories have emerged about who 'we' are as individuals and as a nation. ${ }^{600}$ The dominant narrative following the Ōtautahi Mosque shootings was one of shock, horror, and dislocation of first world safety. This is made evident by Prime Minister Ardern's speech in which she stated:

For those of you who are watching at home tonight and are questioning how this could have happened here - we were not a target because we are a safe harbor for those who hate. We were not chosen for this act of violence because we condone racism, because we are an enclave for extremism. We were chosen for the very fact that we are none of these things. ${ }^{601}$

Prime Minister Ardern was quick to reject the shooter, insisting that Aotearoa New Zealand as a nation does not condone or foster racism and extremism. In her statement she emphasised the fact that the Aotearoa New Zealand public were a victim of this attack through no fault of their own, stating that it was the perpetrator who chose Aotearoa New Zealand because we stand for the opposite of racism and extremist behaviours. Hall of the Policy Observatory at Auckland University of Technology says: "When I hear the prime minister's words, 'This is not us', I do not hear this as literal denial. I hear it as a wish, an aspiration, a declaration of national values."602 Figure 9 illustrates that for many the collectivising hashtag \#ThisIsNotUs was intended as a progressive shift in thinking. While I agree with Hall's assessment that the Prime Minister's statement and the \#ThisIsNotUs hashtags were not meant to be read as a literal denial - I do think it misses a very crucial step in the reconciliation process: acknowledging that racism and violent extremism do exist and that privileged bodies have been silent in their presence for a long time now. I argue that before we can assert that \#ThisIsNotUs, we must acknowledge that these bodies were and continue to be 'marginalised, insignificant, peripheral' and that the journey to overcoming this is an ongoing one.

598 “They are us. They? Them? Whose?” Villanesse, 20 March, 2019, https://www.villainesse.com/no-filter/theyare-us-they-them-those

${ }^{599}$ Colleen Ward and James Liu, "Ethno-Cultural Conflict in Aotearoa/New Zealand: Balancing Indigenous Rights and Multicultural Responsibilities," in Handbook of Ethnic Conflict, eds., Dan Landis and Rosita D. Albert (MA, Boston: Springer US, 2011), 45-69, doi: 10.1007/978-1-4614-0448-4_3

600 Elliott, "After Christchurch."

601 Elliott, "After Christchurch."

602 David Hall, "We must recognise racism in NZ before we can put it right," Stuff, 24 April, 2019,

https://www.stuff.co.nz/national/christchurch-shooting/112212972/we-must-recognise-racism-in-nz-before-wecan-put-it-right 
The difference in reaction from Pākehā New Zealanders and Muslim communities demonstrates the differences in their lived experiences: Pākehā New Zealanders responded in shock because of the tragic loss of human life and the stark reminder of human precariousness, whereas Muslim communities were not surprised because they constantly experience reminders of their own precarity. While Jess Berentson-Shaw, writing for New Zealand Newsroom, commented in the days since the shooting she heard many people say, 'This is not us, this is not our New Zealand', she also heard many of her Muslim, Māori, Pacific, Iranian, Chinese friends, colleagues and acquaintances say, "This is us. We have been telling you for years."603 A number of other marginalised bodies expressed a heavy-hearted expectancy following the shooting. Australian Muslim TV host Waleed Aly gave an emotional message live on TV after the Mosque shooting in which he shared that he was not shocked by the terror attack:

Of all the things I could say, that I'm gutted and I'm scared and I feel overcome with utter hopelessness, the most dishonest thing would be to say that I'm shocked. There is nothing about Christchurch that shocks me...The attacks in Christchurch, in which an Australian man opened fire on two mosques, which he livestreamed on social media, has been coming... everything we say to try to tear people apart, demonise particular groups, set them against each other, that all has consequences, even if we're not the ones with our fingers on the trigger. ${ }^{604}$

Similarly, Anjum Rahman of the Islamic Women's Council of New Zealand has written about the lengths her group went to in order to raise concern about growing anti-Islamic and racist activity saying "we begged and pleaded, we demanded. We knocked on every door we could." 605 Elliot contends that the attack on Muslim communities has forced many New Zealanders to face this disconnect between who they want to believe they are and who they actually are, posing the question:

So which is it? Is New Zealand a country, as our Prime Minister asserted in which there is no place for the ideologies espoused by the Christchurch Mosque terrorist? Or are we a country in which Islamophobia and racist hatred has been directed towards Muslim women for years?606

These contradictory renderings of self necessitate a greater attentiveness to the grounds upon which claims to solidarity and our shared humanity are made and invite privileged bodies to question why the collectivising hashtag \#ThisIsNotUs resonated so strongly with the majority of the Aotearoa New Zealand public.

603 Jess Berentson-Shaw, “This Has Been Us. We Need to Change It,” News Room, 18 March 2019, https://www.newsroom.co.nz/this-has-been-us-we-need-to-change-it.

${ }^{604}$ Waleed Aly, "Christchurch Mosque Shootings: Australian Muslim TV Host Waleed Aly's Emotional Message - 'I'm Not Shocked."'New Zealand Herald, 16 March, 2019 https://www.nzherald.co.nz/nz/christchurch-mosqueshootings-australian-muslim-tv-host-waleed-alys-emotional-message-im-notshocked/XE7XRJTYWF64MR737J7SXCMOT4/

605 Anjum Rahman, "We Warned You. We Begged. We Pleaded. And Now We Demand Accountability," The Spinoff, 17 March, 2019, https://thespinoff.co.nz/society/17-03-2019/we-warned-you-we-begged-we-pleaded-and-nowwe-demand-accountability/ 606 Elliott, "After Christchurch." 
What the New Zealand public found most shocking about the terror attack was not the horrific violence perpetrated against Muslim bodies, but that the violence was perpetrated here in Aotearoa New Zealand (see figures 10, 11 and 12). Violent extremist attacks are a near a daily occurrence in Syria, Iraq, and Afghanistan and yet their deaths go largely unnoticed because as 'Others elsewhere', their loss can be kept at a distance. Butler suggests that Arab peoples, predominantly practitioners of Islam, have fallen outside Western concern for violence perpetrated against 'humans' as it is defined by a Western mould.607 Growing anti-Muslim sentiment and violent extremism in the West somehow did not apply to Aotearoa New Zealand with its unbridgeable sense of distance and the misplaced belief that Islamophobia and violent extremism 'is not us.' Accordingly, Aotearoa New Zealand's image as a safe, welcoming, and tolerant nation has been injured by the Mosque attacks in Ōtautahi. I argue that the collectivising hashtag \#ThisIsNotUs frames the attack on Muslim communities of Al Noor Mosque and Linward Islamic Centre as an attack on all New Zealanders and as an affront to our way of life. The 'this is not us' response suggests Aotearoa New Zealand's primary concern is defending its reputation as a safe and tolerant nation.

Following the Mosque attacks, New Zealanders were quick to point out the value of the Muslim communities 'add' to Aotearoa New Zealand, often referring to their beautiful languages, prayers and heterogenous cultural contributions. Beausoleil points out that Other cultures are not considered valuable in themselves but validated in light of their contribution of 'diversity' to the nation's culture: "while Anglo-Celtic culture merely and unquestionably exists, migrant cultures 'exist for' the latter justified as a resources through a discourse of cultural enrichment."608 While diverse communities undoubtedly do bring enrichment to our communities, it is important to know that this cultural enrichment is not in service of Pākehā and dominant groups. The collectivising hashtag \#ThisIsNotUs presumes a "central (settler) culture that tolerates, even celebrates, 'other' group difference, but whose own group difference remains unmarked and whose authority to name and acknowledge the difference of others remains unquestioned." 609 In doing so, the hashtag draws focus away from the harm caused to Muslim communities and "supplant[s] ourselves as the main object of concern." 610 The dominant feeling following the Mosque attacks was that of dislocation from first world safety and a concern that this tragedy could somehow have happened here to 'us'.

The use of the \#ThisIsNotUs hashtag by privileged bodies only acknowledges Muslim bodies insofar as their suffering concerns 'us'. This collectivity is motivated by a concern for self-that this harm, insecurity or suffering could befall me.611 Boler argues that in order to bolster public sympathy and spreadability, passive empathy is predicated on an "irreducible difference - a recognition that I am not you...empathy is possible only by virtue of this distinction that I am not you."612 \#ThisIsNotUs is framed as an affront to Aotearoa New Zealand's identity and not as an assault on the Muslim communities targeted who hold a precarious place within Aotearoa New Zealand society, which is a problematic marginalisation of the Muslim population in Aotearoa New Zealand. Tanja Dreher argues that when the Mosque attack is framed as being

607 Butler, Precarious Life, 32.

608 Beausoleil, “Gather Your People," 7.

${ }^{609}$ Beausoleil, "Gather Your People," 7.

610 Schick, "Unsettling Pedagogy," 30.

611 Schick, "Unsettling Pedagogy," 30.

612 Boler "The risks of empathy," 256. 
about 'all New Zealanders,' the persistent and enduring nature of white supremacy and Islamophobia can quickly be lost" (see figures 13 and 14 for illustrations). ${ }^{613}$ The most common media frame positions racist violence such as the Mosque attacks as "an abhorrent, regrettable event, but not one that speaks to or arises from the true nature of who we are and what our society is like." 614 This refutation arises because the vulnerability that binds us together in our humanness simultaneously stands to separate a perceived group of 'insiders' from 'outsiders' who are "objects of fear, suspicion, hatred, envy, contempt, or disgust." 615 Gilson submits that vulnerability is a condition of openness to being affected by and affecting others in both positive and negative ways.616 The Mosque shootings were a stark reminder of our precariousness and vulnerability to harm. For privileged bodies, the shootings confronted them with the realities of corporeal precarity disproportionality inflicted on Muslim communities, and were a confronting and tangible demonstration of inequality that they may have preferred to gloss over through the \#ThisIsNotUs narrative.

Being disturbed by the negative aspects of vulnerability, privileged bodies may instead choose to seek what they perceive to be invulnerability and, in doing so, become willingly ignorant of their own humanness. Willful ignorance is a deeper form of ignorance that is actively cultivated. ${ }^{617}$ In Tuana's words:

Willful ignorance is a deception that we impose upon ourselves, but it is not an isolated lie that we consciously tell ourselves, a belief we know to be false but insist on repeating. Rather, willful ignorance is a systematic process of self-deception, a willful embrace of ignorance that infects those who are in positions of privilege, an active ignoring of the oppression of other and one's role in that exploitation. ${ }^{618}$

Prime Minister Ardern's declaration that "we were not chosen for this act of violence because we condone racism... we were chosen for the very fact that we are none of these things" is a willful denial of racism, bigotry, and extremism in Aotearoa New Zealand.619 In order to avoid difficult issues of racism and White supremacy in Aotearoa New Zealand, Ardern is stating that 'we' disavow our involvement, choosing instead to project blame onto the perpetrator by saying "you may have chosen us - but we utterly reject and condemn you." 620 While the hashtag \#ThisIsNotUs can be understood as aspirational, it omits the reality that racism is prevalent in Aotearoa New Zealand. The admission of this actuality is necessary before New Zealanders can assert that 'this is not us.' Elliot remarks that, as a country, Aotearoa New Zealand failed to stop something horrific from happening because "we like to believe we are better." 621 Similarly, Ghumkhor fervently argues that the shooter is not an aberration:

613 Tanja Dreher, “Listening After Christchurch,” Listening for Media Justice, 7 May, 2019.

https://tanjadreher.net/2019/05/07/listening-after-christchurch/

614 Dreher, "Listening After Christchurch."

615 Linklater, "Grand Narratives and International Relations," 9-10.

616 Gilson, "Vulnerability, Ignorance, and Oppression," 310.

617 Gilson, "Vulnerability, Ignorance, and Oppression," 313-314.

618 Tuana, "The Speculum of Ignorance," 11.

${ }^{619}$ Ardern, "Further update from Jacinda Arden on Christchurch Mass Shooting."

${ }^{620}$ Ardern, "Further update from Jacinda Arden on Christchurch Mass Shooting."

621 Elliott, "After Christchurch." 
$[\mathrm{H}] \mathrm{e}$ 's not an exception; he is an integral part of the collective 'we' in New Zealand, Australia, and the 'West.' To argue the opposite is plain denialism and a cowardly flight into the White liberal sanctuary of the 'third way' from the discomfort of reality[.] ${ }^{622}$

The fact that people were hashtagging \#ThisIsNotUs in response to the shooting of minority bodies willfully ignores the fact that this kind of racially motivated violence has happened before in Aotearoa New Zealand (see figure 15). Ngāti Rangi leader Che Wilson remarks that the last time this happened in Aotearoa New Zealand was in Parihaka in 1881, when Crown troops invaded the Taranaki settlement and decimated a peaceful village. Wilson notes,

Nothing should be taken away from the tragedy - on helping those people...but it does cause an itch at the back with statements like 'this is the darkest day in New Zealand history', that it is a loss of innocence. ${ }^{623}$

When people in a position of privilege in Aotearoa New Zealand proclaim that 'this is not us', they deny racial violence as a part of Aotearoa New Zealand's colonial history, choosing instead to "sweep it under the carpet." 624

The difficult parts of Aotearoa New Zealand's settler-colonial history are glossed over in favor of a national belief that society is egalitarian, multi-cultural, and progressive. Avril Bell claims that the vision of Aotearoa New Zealand as a 'land of milk and honey' has played a powerful part in the mythologies generated by those involved in its colonialisation and has continued to shape ideas about what it means to live in this country and be a 'Kiwi' throughout the twentieth and twenty-first century. ${ }^{625}$ Matt Wynyard claims there is a wider shared belief that the historical experience of colonisation in Aotearoa New Zealand was 'comparatively benign' when compared to colonial legacies of America, Canada, and Australia. ${ }^{626}$ Wynyard explains that despite the widespread belief, which no doubt is comforting to many Pākehā, our country is far from unique.627 The broad experience of colonisation in Aotearoa New Zealand typifies the experience of indigenous peoples around the world as Māori were violently stripped of their land, freedoms, rights and the possibilities attached to it, and were given no option but to join the cycle of capitalism that created lasting patterns of inequality between Māori and Pākehā that continue to the present day.628 Bell states plainly "Aotearoa New Zealand never offered equal opportunity for all, despite the national mythology of egalitarian-ism." 629 The willful forgetting of Aotearoa New Zealand's colonial history, and the systemic dispossession of Māori Land by Pākehā has created lasting patterns of social and economic inequality. The

\footnotetext{
622 Ghumkhor, "The Hypocrisy of New Zealand's 'this Is Not Us' Claim.”

${ }^{623}$ Leigh-Marama McLachlan, "Christchurch Mosque Attack: Māori Leaders Say Acts of Terror Nothing New in New Zealand," radio New Zealand, 21 March, 2019, https://www.rnz.co.nz/news/national/385226/christchurchmosque-attacks-maori-leaders-say-acts-of-terror-nothing-new-in-new-zealand 624 McLachlan, "Christchurch Mosque Attack."

625 Bell et al., A land of milk and honey?: Making sense of Aotearoa New Zealand, (New Zealand, Auckland: Auckland University Press, 2017), 8.

${ }^{626}$ Matt Wynyard, "Plunder in the Promised Land" in A Land of Milk and Honey?: Making Sense of Aotearoa New Zealand, ed, Bell et al., (New Zealand, Auckland: Auckland University Press, 2017), 15.

627 Wynyard, "Plunder in the Promised Land," 15.

628 Wynyard, "Plunder in the Promised Land," 15.

629 Bell et al, A land of milk and honey? 8-9.
} 
failure to acknowledge this history and its present affect on tangata whenua is part of the Pākehā settler logic that acts to simultaneously deny and reinforce modern colonialism. 630

These national mythologies of Aotearoa New Zealand as an egalitarian, diverse and tolerant society are perpetuated through collectivising hashtags. The hashtags \#TheyAreUs and \#ThisIsNotUs illustrate a strong narrative of national pride and reinforce revisionist accounts of Aotearoa New Zealand that ignore its settler colonial history. \#TheyAreUs and \#ThisIsNotUs tweets center Aotearoa New Zealand as a nation (rather than focusing on the Muslim community affected). The tags \#NewZealand, \#Christchurch and \#KiaKaha (stay strong) were used to signal nationhood. An interviewee noted this 'Kiwi exceptionalism' when it comes to settler-colonial histories and how this denial can work against addressing racism, stating,

I feel like since the terrorist attack it has kind of become like impolite to talk about Islamophobia and racism in New Zealand. People will use Jacinda's response and you know the outpouring of flowers and people visiting Mosques and as an example of how we are different and that kind of Kiwi exceptionalism is something I have kind of battled with my entire life and I would say that our Islamophobia and racism in New Zealand is no different to that we see in the States and that we see in other settler colonial countries - it is just expressed a little differently a little less overtly but it still has the same harm. Like I said the psychological and spiritual harm for me.631

The national mythology of 'Kiwi exceptionalism' promotes an idealised version of Aotearoa New Zealand and allows Pākehā and Tauiwi to distance themselves from the histories of colonisation and the inequalities of the present. Hashtagging \#ThisIsNotUs poses no risk to privilege; it allows the preferred version of self (the kind, tolerant, and welcoming version) to remain intact and enables privileged bodies to avoid challenging questions about the 'welcoming' nature of Aotearoa New Zealand politics and society. The collectivising hashtag \#ThisIsNotUs it is not just "not caring to know;" it is a systematic rejection that anyone beyond the attacker has in any way played a part in harming minority communities. ${ }^{632}$ Consequently, \#ThisIsNotUs is grounded in a notion of invulnerability. Schick suggests that it is easier to remain focused on our own drive for invulnerability than to unpack the inconvenient and uncomfortable truth that privileged bodies may have in some way played a part in the creation or maintenance of structures under which minority bodies suffer.633 To admit complicity is to open oneself to features of one's social world and one's way of inhabiting the world that are discomfiting and thus make oneself vulnerable, so privileged bodies claim instead that 'this is not us' and "ignorance is chosen over comprehension." 634 Schick points out that this version of self conveniently denies critique because people are not required to identify with their own complicity in structures of power relations that foster "an impoverished conception of recognition that accumulates knowledge about and superficially consumes the other without reflecting critically on our own role in promoting continued misrecognition."635 Privileged

\footnotetext{
630 Beausoleil, “Gather Your People,” 1.

631 Interview with Hala Nasr conducted 16 October 2020 via Zoom conference call.

632 Tuana, "The Speculum of Ignorance," 6.

${ }^{633}$ Schick, "Unsettling Pedagogy," 30.

${ }^{634}$ Schick, "Unsettling Pedagogy," 27.

635 Schick, "Unsettling Pedagogy," 30.
} 
bodies refuse to embark on a journey towards recognition that would require attending to their own complicity in silencing and marginalising others. ${ }^{636}$

The collectivising hashtag \#TheyAreUs consumes the vulnerable other by appropriating the grief of Muslim communities without critically reflecting on how dominant hashtagging performances drown out the voices of those most affected and thus maintain the status of Muslim lives as outsiders reliant on privileged bodies lifting their voices. Collectivising hashtags make invulnerability an unacknowledged norm, the standard mode of existence, a way of being that Gilson maintains is never "contextualised, interrogated or contested."637 Hashtagging \#ThisIsNotUs not only omits deeper structural inequalities, it also hinders our ability to locate and work through our own participation within this cycle of invulnerability, ignorance, and violence. Ending this cycle will require a radical emancipation, the kind that bends back on itself and helps us to locate invulnerable narratives of self and digital inequalities in everyday online encounters.

\subsection{Emancipating 'Us': Vulnerability and the Role of the Discursively Privileged Subject}

In order to work towards emancipation, I assert that a gradual shift towards vulnerability, reflexivity, and an embodied digital praxis is needed. Privileged users have a responsibility to recognise how their online performances of self affect the corporeal realities of Other bodies. A focus on an embodied digital praxis turns people's attention inward, calling those in positions of privilege to become more vulnerable and aware of the affecting nature of their digital practices. Beausoleil suggests "it becomes vital to learn to attend to one's inheritance in terms of worldview and social position." 638 To acknowledge vulnerability, users in a position of privilege must become more aware of our own history and the affecting nature of modern online interactions and of their digital renderings of self. Gilson claims that while they might know the facts about racial discrimination and oppression, becoming epistemically vulnerable requires that privileged users allow that knowledge to truly sink in, "to sink into our bodies, into our emotional responses, into our basic interpretation of the world and ourselves." 639 Becoming vulnerable means opening ourselves to a broader spectrum of human emotion, susceptible to being "affected and affecting in relation to others." ${ }^{40}$ Vulnerability makes room for the grief, complicity and discomfort required to move through suffering. This openness is key if people are to even begin to tackle difficult questions like: how did escalating violence towards Muslim communities go unchecked?

Rather than privileged bodies closing themselves off to the difficult reality of racism and violent extremism in Aotearoa New Zealand by insisting that \#ThisIsNotUs, vulnerability acknowledges the precarity and inequalities faced by marginalised communities both on and offline. Vulnerability requires questioning one's sense of self (how one thinks about and defines oneself in relation to others) and allowing this understanding of positionality to affect

\footnotetext{
636 Schick, “Unsettling Pedagogy,” 27.

637 Gilson, "Vulnerability, Ignorance, and Oppression," 320.

638 Beausoleil, "Gather Your People," 18.

639 Gilson, "Vulnerability, Ignorance, and Oppression," 325-326.

640 Gilson, "Vulnerability, Ignorance, and Oppression," 326.
} 
everyday digital practices that shape self-identity. In order to become more vulnerable, privileged bodies must invite discomfort in; in its difficulty and in its fragility, vulnerability calls us to rethink, to reimagine and rebuild a collective conception of 'us'. In this way, vulnerability brings us into a place of reflexivity by fostering a positionality that maintains both our shared humanity and alterity.

Vulnerability demands reflexivity by asking: where is my place in all of this? Butler claims that the human experience is defined by our precariousness and dependency on others, explaining

There are others out there on whom my life depends, people I do not know and may never know. This fundamental dependency on anonymous others is not a condition that I can will away. No security measure will foreclose this dependence; no violent act of sovereignty will rid the world of this fact.641

Such a change of focus calls attention to receptivity and vulnerability and brings discursively privileged subjects into the analysis. Rahman, speaking on a NetHui internet panel, stated "If the shooting opened your eyes - it is time for some self refection." ${ }^{642}$ Rahman went on to suggest that people who found the events of 15 March shocking need to 'check their bubble', referring specifically to the creation of digital selves and ecologies. ${ }^{643}$ In the following chapter, I will explore in greater depth how our digital ecology surrounding hashtag use is linked to conceptions of self and Other.

Collectivising hashtags are key to understanding how individuals come to formulate conceptions of invulnerability and thus present an opportunity to challenge racist, sexist or xenophobic versions of self. The collectivising hashtag \#ThisIsUs (see figure 16) was a counter narrative developed in response to \#ThisIsNotUs and was tweeted as a performance of reflexivity. \#ThisIsUs demonstrates reflexivity in that it allows Pākehā and Tauiwi to acknowledge Aotearoa New Zealand's settler-colonial history and present, and to take ownership of collective complicity, of willful ignorance that saw racism and White supremacy go unchecked within Aotearoa New Zealand. In this way, the collectivising hashtag \#ThisIsUs can help people to think critically about their positionality in structures of power and challenge underlying inequalities. As discussed earlier, intersectional feminist hashtags like \#SolidarityIsForWhiteWomen, \#NotYourNarrative and \#NotYourAsianSidekick are other examples of collectivising hashtags that call into question dominant narratives and highlight Western appropriation and marginalisation of minority voices. ${ }^{644}$ \#ThisIsUs emerged in response to the \#ThisisNotUs as a means to acknowledge the complacency that lead to this attack. This counternarrative exemplifies a self-reflexive critique by calling Pākehā and Tauiwi to examine their own position by asking if 'this is us.'

\footnotetext{
641 Butler, Precarious Life, xii.

${ }^{642}$ Anjum Rahman, "The Internet After Christchurch," Net Hui Panel, 3 October 2019, https://nethui2019.sched.com/event/Scud/panel-the-internet-after-christchurch

643 Rahman, "The Internet After Christchurch."

${ }^{644}$ It is important to note that hashtags like \#ThisIsUs, \#NotYourNarrative, \#SolidarityIsForWhiteWomen and \#NotYourAsianSidekick are created and used predominantly by marginalised bodies. This kind of work and the emotional labour that comes with it, is primarily carried out by the very groups targeted by harassment, doubling the negative effect. It is therefore concerning that the work of prompting reflexivity is largely left to those marginalised bodies who are most affected by the crooked platform. The limits of White allyship are explored further in Chapter Five section c) The Rise and Risk of User Participation.
} 
These hashtags highlight the diversity within feminist cultures, their strong commitment to reflexivity, and the increasing importance of embodied feminist activism in the digital spaces. Fotopoulou argues that doing feminism and being feminist implies "enacting ourselves as activists - as embodied - and political subjects through media practices, technologies, the imaginaries linked to these new technologies and the internet." 645 It is through our everyday use of collectivising hashtags that our feelings towards Others are embodied, transferred and given meaning. The things we say and do online matter; our online performances of self affect which bodies are afforded full recognition of their humanity and which are marginalised and left unseen. The processes through which hashtags trend or go viral are reflective of sociocultural norms. They 'say something' about who qualifies as human. The technological, social, and economic underpinnings of trending hashtags are reflective of the prevailing sociopolitical underpinnings of inequality in modern society.

Collectivising hashtags exemplify the collapsing of personal, political and technological performances of self. They allow us to include ourselves in communal expressions of grief, express solidarity and acknowledge this shared precariousness. The problem with uncritical participation in collective stories is that they can often extend beyond the communities they were initially intended for and confuse important distinctions between corporeal vulnerabilities. Claims to know or represent the experiences of marginalised bodies through collectivising hashtag practices can involve forms of appropriation on the part of privileged subjects which obscure their complicity in the power structures, further entrenching social inequalities. Collectivising discourse has left privileged bodies with an impoverished form of solidarity that is only concerned for minority bodies insofar as their suffering impacts the precariousness of the majority. Collectivising hashtags pose no risk to the privileged sense of self and enable privileged bodies to avoid challenging questions about the pervasive nature of settler-colonial logics. Privileged users have a responsibility to recognise how their online performances of self affect and exacerbate the corporeal realities of Other bodies.

I argue that a focus on an embodied digital praxis can help turn people's attention inward, calling those in positions of privilege to become more vulnerable and aware of the affecting nature of their digital performances of self. Vulnerability requires questioning one's sense of self and allowing this understanding of positionality to affect everyday digital practices. It is imperative that privileged users think critically about the role privileged onlookers play in constructing digital atmospheres in which ignorance, dispossession, and power inequalities fester. This approach involves allowing ourselves to become open to difficult aspects of our existence that we might prefer to leave unchallenged.646 The affective nature of online encounter calls us to look at how exclusionary practices are characterised by power imbalances and struggles at different, social, technological and political levels. Interdisciplinary research bridging feminist, Media and International Relations studies is increasingly urgent in a landscape in which collectivising hashtags can become our primary reaction to tragedy, influencing how affected and affecting bodies' respond to social inequalities and our ability to acknowledge both our shared humanity and alterity. It is through our everyday online

645 Fotopoulou, "Feminist Activism and Digital Networks," 5.

646 Gilson, "Vulnerability, Ignorance, and Oppression," 313. 
encounters with Others that the opportunity to challenge dominant conceptions of what it means to be 'us' presents itself. 


\section{Chapter Four \\ The Crooked Platform}

In the previous chapter, I suggested that privileged users must come to embrace their own positionality and vulnerability, developing a greater understanding of the affecting and interdependent nature of social media platforms. This requires privileged users to recognise the ways in which precarity is distributed unequally in online spaces in such a way that it reaffirms privileged class, gendered and racial hegemonies. In this chapter, I focus on how technological inequalities are sustained through the affordances of hashtags. That is, how the architecture of hashtags influences their use value (and vice versa). The economic, social, and political logic of collectivising hashtags is sustained and stabilised through the kinds of practices that technology allows for or constrains. Accordingly, I take a relational and multilayered approach to affordances that 'requires an emphasis on users' own accounts of technology, where affordances become as much a part of users' experiences and perceptions of technology as the technologies themselves." 647

This chapter is divided into four sections. In the first section, I focus primarily on the folksonomy, serendipitous, and algorithmic trending functions of a hashtag. In the second section I look at the ways in which collectivising hashtags are technologically and economically co-constructed by designers and stabilised by users' practices. In the third section, algorithmic impulses, I examine how social practices and power relations influence digital environments. Then, in the fourth section, I employ Harris-Perry's concept of the crooked room as a framework to explore how collectivising hashtags act to enable or challenge systemic inequalities. I discuss how the economic and technological construction of hashtags is tilted in such a way that they make it difficult for individuals to realign themselves in online spaces.

The purpose of this chapter is to move beyond the discourse presented by the collectivising hashtags \#TheyAreUs and \#ThisIsNotUs in Chapter Three and examine the more subtle ways in which hashtag technologies themselves can foster inequalities. In essence, this is the 'critical technocultural' part of the CTDA process that focuses on architectural construction and structural forms of discrimination. An affordances lens is used to operationalise the technical as well as cultural features of hashtags which are increasingly becoming the primary point of encounter between people in online ecologies. ${ }^{648}$ In this chapter, I expose connections between hashtags as technological artifact, online encounters, inequality, power, ideology and how they manifest. Ultimately, I am interested in the architectural or algorithmic structures of hashtags that are influenced by the people who design them and reinforced by "soft and networked architectures" of the people who use them. ${ }^{649}$

\footnotetext{
647 Bucher and Helmond, "The Affordances of Social Media Platforms," 16.

648 Sweeney and Brock, "Critical Informatics," 3.

649 Papacharissi, Affective Publics, 27.
} 


\subsection{Underlying technological inequalities}

Early adopters of the internet envisioned a digital democratisation of society owing to affordable, enhanced access to information for users of all backgrounds. Paul Baker and Amanda Potts describe a multicultural and difference-blind vision of the internet saying,

At first flush the internet (the networked infrastructure which connects millions of computers together) offered the human races first true opportunity for anonymity, and with it, the promise of a utopian virtual society wherein age-, gender-, race-, sexualityand religion-based prejudice would have no tangible grounding and therefore no significant presence. 650

Technology is often presented as an objective tool, a level architectural structure that affords equal opportunity to all who use it. Social media, with its algorithmic foundations built on a series of ones and zeros, is presented as unbiased and fair, creating an egalitarian platform. Initial claims were that social media could become "the great equaliser" for marginalised groups in that it allows marginalised users equal access and capability in online spaces. ${ }^{651}$ Chen suggests "it has always been convenient to think of technology development as 'value neutral', a notion that has been adopted from scientific research." 652 Social media is conceived as a value neutral tool, what it is used for (whether good or bad) is determined by the user irrespective of the tool's design. This idea helps people justify the use of technology and assures them that agency remains with the human subject. What it ignores is the fact that all technologies, like environments, are designed in a particular way that makes them best suited for particular usages and structures of use. Cyberculture scholar Daniel Punday found that:

Quite contrary to the early belief that cyberspace offers a way to escape gender, race and class as conditions of social interaction...recent critics suggest that online discourse is woven of stereotypical cultural narratives that reinstall precisely those positions. ${ }^{653}$

The theory of affordances challenges the idea that technologies are equitable and that "we can do anything with anything." 654 Gibson originally conceived the theory of affordances as a relational property, one that "points both ways, to the environment and the observer." 655 Social media platforms are architecturally structured so that they are best suited to particular uses. 656

650 Paul Baker and Amanda Potts, “'Why Do White People Have Thin Lips?' Google and the Perpetuation of Stereotypes via Auto-Complete Search Forms," Critical Discourse Studies 10, no. 2 (2013): 187, doi: $10.1080 / 17405904.2012 .744320$.

651 Social media was believed to be 'the great equalizer' in that it had potential to transform existing patterns of social inequality by lowering the threshold for civic engagement for all people. See Michael Xenos, Adriadne Vrmen, and Brian D. Loader, "The Great Equalizer? Patters of Social Media Use and Youth Political Engagment in Three Advanced Democracies," Information, Communication \& Society 17, no.2 (2014): 151-167, doi: 10.1080/1369118X.2013.871318. See also Peter Bae Brandtzaeg “Facebook is no 'Great Equalizer’: A big data approach to gender differences in civic engagement across countries"Social Science Computer Review 35, no.1 (2017): 104, doi: 10.1177/0894439315605806.

652 David Hall "How the Christchurch Principles will Fight the Spread of Hate," The Spinoff, 19 March, 2021 https://thespinoff.co.nz/society/12-11-2019/how-the-christchurch-principles-will-fight-the-spread-of-hate/ 653 Daniel Punday, "The Narrative Construction of Cyberspace: Reading Neuromancer, Reading Cyberspace Debates," College English 63, no. 2 (2000): 199, doi: 10.2307/379040.

654 Bucher and Helmond "The Affordances of Social Media Platforms," 236.

655 Gibson, The Ecological Approach to Visual Perception, 121.

656 Bucher and Helmond, "The Affordances of Social Media Platforms,"236. 
This use value is both unique to each individual and is developed in relation to other users with whom they share their online environment. As I mentioned earlier, affordances provide researchers with a way to move beyond technological determinism and social constructivism. ${ }^{67}$ This architectural assessment of collectivising hashtags is key to uncovering the underlying technological inequalities that often go unseen by users.

In assessing the affordances of collectivising hashtags, I take into account their relational properties and how they are socially situated and architecturally constraining or enabling. My analysis focuses specifically on the relational and multi-layered affordances of collectivising hashtags. A relational and multi-layered approach to the affordances of hashtags requires that I consider the multi-directionality of hashtag users' agency and connectivity. Butcher and Helmond, in their conceptualisation of affordances, claim that the question of who affords what and to whom in the realm of social media is complex and multifaceted. ${ }^{658}$ As noted by Nagy and Neff, technologies are increasingly "adaptive, learning, responsive, and changing along with the users they share an environment with."659 The move away from traditional news feeds on platforms such as Twitter suggests a more general tendency towards a "personalised furnishing" emphasising the individualised, adaptable and malleable nature of online platforms. 660

Nagy and Neff, for instance, have introduced the notion of 'imagined affordances' as "a theory that better incorporates the architecture, the mediated, and the emotional aspects of humantechnology interaction." 661 Imagined affordances, Nagy and Neff contend, "emerge between users' perceptions, attitudes, and expectations; between the materiality and functionality of technologies; and between the intentions and perceptions of designers." ${ }^{662}$ For Nagy and Neff, 'older' notions of affordances fail to address the complexity of cognitive as well as emotional processes. Simply locating the action possibilities of a social media platform in a set of features will not do, they claim, because users' perceptions, beliefs and expectations of what the technology does or what the platform suggests it is for "shape how they approach them and what actions they think are suggested." 663 Imagined affordances may not just affect how users approach social media platforms; they may also help to shape the platforms themselves. While traditional affordances theory places emphasis on the question of what technology affords users, the socio-technical nature of social media platforms also begs the reverse question: What do users afford to platforms? In the age of so-called 'big data' fuelled by expansive data points and machine learning algorithms that respond to user input in an adaptive way, users serve quite literally as the 'action possibilities' of platforms. ${ }^{664}$ More specifically, this means looking at what hashtag users afford their digital environment.

Online environments are relational and affecting; they do not exist in a vacuum separate from the normal social, economic and political forces that act upon our physical world. Online environments are structured in particular way, that moves with and in response to users'

657 Bucher and Helmond, "The Affordances of Social Media Platforms," 238.

658 Bucher and Helmond, "The Affordances of Social Media Platforms,"249.

${ }^{659}$ Nagy and Neff, "Imagined Affordance," 5.

660 Bucher and Helmond, "The Affordances of Social Media Platforms,"248.

661 Nagy and Neff, "Imagined Affordance," 2.

662 Nagy and Neff, "Imagined Affordance," 1.

663 Nagy and Neff, "Imagined Affordance," 5.

664 Bucher and Helmond, "The Affordances of Social Media Platforms,"248. 
goals. A relational and multi-layered approach examines the architectural action capabilities and limitations of hashtags. William Lafi Youmans and Jillian York explain that "social media tools, including Twitter, are both shaped and limited by their architecture: programming codes set the range of usability and users' actions are enabled and constrained by company policies and user terms." ${ }^{665}$ Hall suggests we take a closer look at the structures of the internet when addressing online harm stating:

Online content can be enlightening enriching and empowering. But it can also be hurtful or dehumanising. It can encourage people to act with grace and decency, or contempt and cruelty. It is no different from offline speech in this respect. Except that online speech exists in a realm - the internet - that isn't bound by the same constraints, and is structured by different dynamics. Familiar harms take unfamiliar forms, which our institutions are struggling to cope with.666

The structural aspects of social media platforms, such as algorithms, afford different behaviours and potentialities for different hashtag users. The affordances of collectivising hashtags are not evenly distributed. Bucher and Helmond explain that they are specific to each individual user whose experience is grounded in a complex ecology of other users with other unique technological compositions. ${ }^{667}$ Boler and Davis argue that the "algorithmic is deeply entangled in racialised, classed and gendered logics of the political present." 668 Algorithms are a starting point for analysing how collectivising hashtags "produce and make visible particular norms of use."669 I argue that the affordances of collectivising hashtags are key to understanding how users create and maintain status quo conceptions of Otherness. I maintain that the architectures of hashtags are not equitable and can act to constrain recognition of marginalised bodies who currently fall outside dominant conceptions of what it means to be human.

Tarleton Gillespie questions people's faith in algorithms as unbiased arbitrators of information, stating:

As more and more of our online public discourse takes place on a set of private content platforms and communication networks, and these providers turn to complex algorithms to manage, curate and organise these massive collections, there is an important tension emerging between what we expect these algorithms to be, and what they in fact are. Not only must we recognise that these algorithms are not neutral, and that they encode political choices, and that they frame information in a particular way. We must also understand what it means that we are coming to rely on these algorithms, that we want them to be neutral, we want them to be reliable, we want them to be the effective ways in which we come to know what is most important. 670

\footnotetext{
665 William Lafi Youmans and Jillian C. York, "Social Media and the Activist Toolkit: User Agreements, Corporate Interests, and the Information Infrastructure of Modern Social Movements," Journal of Communication 62, no.2 (2012): 316, 325, doi: 10.1111/j.1460-2466.2012.01636.x.

666 Hall, "How the Christchurch Principles will Fight the Spread of Hate."

667 Bucher and Helmond, "The Affordances of Social Media Platforms,"241.

668 Boler and Davis, "The Affective Politics of the 'Post-Truth' Era," 83.

669 Bucher and Helmond, "The Affordances of Social Media Platforms," 243.

670 Tarleton Gillispie, "Can an Algorithms Be Wrong? Twitter Trends, the specter of censorship, and our faith in the algorithms around us," Culture Digitally, 19 October, 2011, https://culturedigitally.org/2011/10/can-an-algorithmbe-wrong/
} 
Consequently, I argue that Twitter is not a neutral platform and collectivising hashtags are encoded with political choices. In the following sections, I will examine the underlying technological makeup of a hashtag and the potentialities and limitations for action that they provide. In accordance with a CTDA approach I look specifically at the algorithmic functions of the hashtag with its folksonomic, serendipitous, and trending mechanics, to unpack the connections between form, function, belief, and meaning of collectivising hashtags. ${ }^{671}$ I explore the design interests of the hashtag's creators and how they developed hashtags to encourage and constrain specific actions for underrepresented users. Sharma states that rather than asking the question 'who speaks' it is better to ask the question: "What kind of techno cultural assemblage is put into motion when we express ourselves online?"672 I also look at how the algorithmic functions of a hashtag are co-created by users themselves, who work concurrently to determine perceived or imagined action possibilities and limitations. I pay particular attention to how designers and users stabilise structural and social usages of collectivising hashtags that impact marginalised users' ability to be heard or recognised.

\section{a) Folksonomy}

From the very beginning, hashtags were a user driven innovation. The development of the hashtag takes a 'folksonomic approach', where categories are determined by users rather than added by content creators. ${ }^{673}$ Put simply, it is the ordinary 'folk' or people who create and add the tags for categorisation. Twitter aimed to take a user driven, bottom-up (as opposed to topdown, management determined) approach to the organisation of trending hashtags. The hashtag is a user-created metadiscourse convention (\# + keyword) used to coordinate Twitter conversations by providing a topical coherence. ${ }^{674}$ Prior to the development of hashtags, it was difficult to collate and archive conversations on the same topic. Without the hashtag function, topics could easily dissipate and conversations were quickly extinguished. Jackson, Bailey, and Foucault Welles explain that "hashtags, which are discursive and user generated, have become the default method to designate collective thoughts, ideas, arguments, and experiences that might otherwise stand alone or quickly be subsumed within the fast paced pastiche of Twitter."675 The original purpose of the hashtag was simply to collate information into searchable keywords. Jackson, Bailey, and Foucault Welles record the development of the hashtag sign which was first introduced in the late 1990s in net forums, where it was used to group items together for online conversations. ${ }^{676}$ Popular usage of hashtags only emerged in 2007, when Twitter user Chris Messina asked his followers what they thought about using the hashtag sign to designate groups. Co-founder Evan Williams was originally reluctant to adopt hashtags suggesting that they were "too nerdy to go mainstream." 677 However, following their

\footnotetext{
671 Brock, “Critical Technocultural Discourse Analysis,” 1012.

672 Sharma, "Black Twitter?" 55.

${ }^{673}$ Adam Mathes, "Folksonomies-cooperative classification Cooperative Classification and communication through shared metadata."Communication Through Shared Metadata," Computer Mediated Communication, December, 2004, https://adammathes.com/academic/computer-mediated-communication/folksonomies.html

${ }^{674}$ Chris Messina, "Groups for Twitter; or a proposal for twitter tag channels," Medium, 26 August, 2007,

https://medium.com/chris-messina/groups-for-twitter-or-a-proposal-for-twitter-tag-channels-5b8eb08adff8 .

675 Jackson, Bailey, and Foucault Welles, \#Hashtag Activism, xxviii.

676 Jackson, Bailey, and Foucault Welles, \#Hashtag Activism, xxviii.

677 Messina, "Groups for Twitter."
} 
suggestion by Messina, hashtags became popular among users, compelling Twitter designers to incorporate them into the structure of the website and add a 'what's happening' section to accommodate trending hashtags. Messina's tweet was the catalyst for the ongoing evolution of hashtags "as a method to thread conversations, people, and movements together."678

The connective and immediate affordances of hashtags are well suited to referencing events as they unfold. Jackson, Bailey and Foucault Welles remarked "for those individuals and collectives unattached to elite institutions, Twitter, and the unifying code of the hashtag have allowed direct communication of raw and immediate images, emotions, and ideas and their widespread dissemination in a way previously unknown."679 For example, just six months after Twitter's creation in August 2016, a mild earthquake hit California and users turned to Twitter to talk about it. The event (and the flood of people it brought to the platform) helped Twitter's team of developers see the potential of Twitter as a way for people to contribute their own reporting of a live event, each from his or her own vantage point. Hashtags were quickly adapted to respond to events, disasters, social movements and protests. Hashtags join people together along subject lines in an act of crowd formation, particularly during times of crisis. This crowding is intensified by the instantaneous nature of online interactions, especially in comparison to more traditional forms of media. In an interview with a hashtag user, they explain how they use Twitter as a way to respond to events as they unfold, saying:

I definitely use it for a primary source for news, so not just news as in updates that come from reputable (or what I would deem reputable) new sources, but also on the ground. Activities, so if something happens, so for example I see a building burning in the distance I am $99.99 \%$ more likely to jump on Twitter and do it because of the immediacy of that collective action than I am to go to the Radio New Zealand website or whatever. 680

The narratives that emerge around Twitter hashtags evolve far more rapidly than traditional media. For this reason, Twitter has become one of the major platforms for "disseminating information to the public in the hope of spurring particular actions or outcomes."681 It is easy to see why hashtags are increasingly popular amongst social movements for their 'on the ground' and 'on the go' assembly features. Twitter developed the structural affordances of hashtags in response to user demand. Another interviewee explained:

I was in Egypt during (well, before) the 2011 revolution. I was there with my family and then my parents had flown back to New Zealand leaving my sister and I to hang out with family and then the revolution erupted. Twitter was a key player or a key mediator or tool for communication during the revolution because the government was blocking cell coverage and people couldn't call each other. So people were kind of using Twitter to get information out and share information between activists. So I got heavily involved in Twitter while I was there during the revolution. ${ }^{682}$

678 Jackson, Bailey, and Foucault Welles, \#Hashtag Activism, xxviii.

679 Jackson, Bailey, and Foucault Welles, \#Hashtag Activism, xxx.

${ }^{680}$ Interview with Alice Canton conducted 11 June 2020 via Zoom conference call.

681 Jackson, Bailey, and Foucault Welles, \#Hashtag Activism, xxix.

682 Interview with Hala Nasr conducted 16 October 2020 via Zoom conference call. 
The communicative capacity for activists became an important part of Twitter's brand identity. Activists and protestors were making use of Twitter during times of political upheaval, and as a result Twitter as a platform was tweaked to facilitate this use. For example, in 2009 Twitter rescheduled planned downtime for maintenance so as not to conflict with a large planned protest in Iran. ${ }^{683}$ This is a user generated political act that impacted the very mechanical structuring and development of Twitter; it illustrates how hashtags are vernacular and encourage a co-creating performance. A hashtag acts as a beacon, allowing all users to join in the conversation and forge both its development and implementation. One of the downsides of the rapid pace of technological development is that monitoring the usages of these hashtag technologies and practices becomes increasingly difficult.

Folksonomy is often thought of as a powerful democratising tool; it allows ordinary users to 'vote' on the trending tag with their use of it. In this way, folksonomic approaches allow the general population to have some say in how their content is structured, by selecting topics in a way that is as scalable and fast moving as popular opinion. One of the key functions of the hashtag is its ability to collate talking points, bringing individual messages together to develop a larger narrative. The problem with the folksonomic structure of hashtags is that they create networks that often reflect hegemonic views. This is not truly democratic but rather a majoritarian approach where the dominant narrative acts to silence minority perspectives. The folksonomic function of the hashtag demonstrates the power of the collective in that it allows individuals to centre themselves and their views within a broader public narrative. ${ }^{684}$ The socio-political implications of grouping privileged bodies voices online discussed in the previous chapter are exacerbated by folksonomy, because large groups representing majority views can more easily influence the development of hashtags as a tool to better support privileged narratives. In this way, the folksonomic mechanics of a hashtag can enhance the online action possibilities of already dominant users and constrains action possibilities of underrepresented users.

\section{b) Serendipity}

A concept that is often applied in online spaces is the idea of serendipity. That is, the idea that a person might 'serendipitously', without preparation or counter to expectations, encounter something of interest or value online. ${ }^{685}$ Hashtags as a medium not only afford serendipity, but were born from the concepts that serendipity represents, and it can be found in both the medium's design and genesis. ${ }^{686}$ In their initial conception, Messina claimed that, rather than creating pre-determined groups, he was interested in "contextualising, content filtering and exploratory serendipity." 687 Messina once described the aim of the hashtag, saying "I'm more

\footnotetext{
${ }^{683}$ Anita R. Gohdes, "Repression in the digital age: Communication technology and the politics of state violence," PhD Dissertation, Universität Mannheim (2014): 16.

${ }^{684}$ Counterpublics take advantage of the folksonomic architecture of hashtags by seizing opportunities for resistance in the form of hashtag hijacking. See section 5.1 Networked Acts a) Comedy, Tragedy and Performative Acts of Subversion.

685 Manuel Coelho de Melo, “On Serendipity in the Digital Medium.” PhD dissertation, Universidade do Porto, (2018): 27.

${ }^{686}$ Coelho de Melo, "On Serendipity in the Digital Medium," 27.

687 Belle Beth Cooper, "The Surprising History of Twitter's Hashtag Origin,” Buffer Blog, 24 September, 2013,

https://buffer.com/resources/a-concise-history-of-twitter-hashtags-and-how-you-should-use-them-properly/
} 
interested in simply having a better eavesdropping experience of Twitter."688 Manuel Coelho de Melo suggests that social media platforms like Twitter are designed for serendipity and surprise that enables us to go 'off the beaten track' when encountering information and other people in online spaces. ${ }^{689}$ Coelho de Melo explains the importance of serendipity saying:

We need digital systems to be designed to provide unpredictability, that allows us to discover the unsought and the unforeseeable, that challenge and surprise us, that benefit both the end user, enriching their experiences, as well as the industry itself, through expanding the reach and potential of interactive systems, increasing user engagement. In other words, we need systems designed for serendipity. 690

The serendipitous nature of hashtags allows people to make unpredictable connections, happening upon news and making an unplanned discovery that provides enrichment or excitement. This facilitates commercial demands by providing interest and keeping users on platforms for longer.

Hashtags have the ability to move us beyond our particular 'in-group' filters by providing broader visibility to a single topic of conversation. Proponents of serendipitous design claim that this allows the digital medium to optimise interaction that spans "the wide breadth of human experience." 691 Kuo explains the connective power of social media platforms, saying that "its potential power as a social platform lies in how networked clusters of people can coalescence, respond, and mobilise to amplify messages beyond individuals and specific communities." ${ }^{692}$ Serendipity can be seen as both a positive and negative for hashtag users. One positive is that hashtags have a linking ability that allows users interested in a topic to be introduced to a wider range of people and be presented with multiple (sometimes conflicting) viewpoints on a subject. Coelho de Melo suggests that "an architecture of serendipity allows us to counteract homophily in online spaces." 693 Hashtags are designed to offer linking experiences, enabling users to create their own tweet and share their own personal opinion while connecting it to the larger networked narrative through the hashtag.

The flip side of this serendipitous connection is that sometimes it exposes people to hateful and harmful views or rhetoric that they do not want to encounter. In an interview with a hashtag user they explained the 'rabbit hole' consequence of hashtags saying,

So you click on a thing, and then you click on another thing and then all of a sudden you are just in this mire of filth and it's just like-oh fuck-how do I get out of here.694

Hashtags are designed to move beyond the community groups that they were initially intended for. In Chapter Three I explained how this collectivity gives rise to ways of articulating agency and of appropriating Others' lived experiences and identities. The serendipitous function of hashtags enables people to encounter people beyond their 'in-group' (those we follow on

\footnotetext{
688 Cooper, "Twitter's Hashtag Origin."

689 Coelho de Melo, "On Serendipity in the Digital Medium," 7.

${ }^{690}$ Coelho de Melo, "On Serendipity in the Digital Medium," 30.

691 Coelho de Melo, "On Serendipity in the Digital Medium," 7.

${ }^{692}$ Kuo, "Racial Justice Activist Hashtags," 495.

693 Melo, "On Serendipity in the Digital Medium," 7.

694 Interview with Alice Canton conducted 11 June 2020 via Zoom conference call.
} 
Twitter and those who follow us) and sometimes precarious spaces can be appropriated where those spaces overlap or are invaded. The problem with a serendipitous architecture and potential for appropriation is exacerbated by the trending topic function discussed in the next section.

\section{c) Trending Topics}

Twitter filters popular topics computationally through an algorithmic process that has become known as the 'trending topic.' 695 While hashtags and trending topics are closely linked and both serve to organise Twitter conversations, they are not the same. ${ }^{696}$ Brock explains that the folksonomic function of hashtags allows users to situate their message within a wider real-time conversation, whereas trending topics are intended to capture and collate topics that see a sudden surge in popularity. ${ }^{697}$ The exact algorithmic formulation of a trending hashtag is the intellectual property of Twitter and remains largely unknown (though the policies governing them are generally made public to some degree). Twitter's own explanation of how trends work is available in its policies and help pages, in its company blog, in tweets, in response to press queries and even in comment threads. ${ }^{698}$ While Twitter refuses to reveal its own 'secret sauce' critics gather anecdotal evidence through statistical analysis, using available online tools that track what counts as "trend-ness." 699

There have been several studies into the perceived function of trending hashtags by computer science and engineering researchers. Tejaree Samakoti, Shaik Naseera and Tella Pramila suggest that the driving force of a hashtag is based on its popularity, coverage, transmission, and reputation..$^{700}$ The popularity of a hashtag designates how important the topic is based on the overall number of tweets that reproduce a particular hashtag (trending tags amplify it even further). According to Samakoti, Naseera and Pramila, popularity is the most useful metric for assessing the evolution of a trending topic and is calculated based on the number of times a specific hashtag is used to capture the topic's overarching vitality. ${ }^{701}$ Coverage and account dynamics also play an important role in topics that trend: coverage of a topic illustrates the number of people participating in the communication on a particular topic. The algorithm looks at the spread amongst unique users, and the number of accounts actively using a specific hashtag in a particular geographical area (either internationally or nationally depending on the trending topic filter) as opposed to the total number of hashtags.

Transmission of the topic is also calculated for the propagation of a trending topic; this assesses the number of mentions and retweets a hashtag gets. Transmission adds a conversational element to the assessment of the trending hashtag, showing how people are interacting with one another and the hashtag. Finally, the reputation and follower dynamic of

695 Brock, "From the Blackhand Side," 538.

696 Brock, "From the Blackhand Side," 538.

697 Brock, "From the Blackhand Side," 538.

${ }^{698}$ Gillispie, "Can an algorithm be wrong?"

699 Gillispie, "Can an algorithm be wrong?"

700 The terms 'popularity', 'coverage', 'transmission', and 'reputation' all come from Tejaree Samakoti, Shaik Naserra, and Tella Pramila, "Perception of Trend Topic in Twitter: A Case Study," Journal of Software Engeneering 11, no.4 (2017): 12-17, doi: 10.26634/jse.11.4.13816.

701 Samakoti, Naserra, and Pramila, "Perception of Trend Topic in Twitter, " 12. 
hashtag users indicates the potential coverage of a topic due to the procreation of a topic. Put more simply, the number of followers that belong to the individual users play an indicative role when assessing whether or not a hashtag will trend.

Reputation indicates how popular the Twitter users are and how likely it is that the hashtag will be picked up by their followers. The reputation function reinforces already-prominent voices online. While there are many known examples of hashtags that originate with a user without a strong following, that hashtag's rise to trending status can often be explained by its subsequent use by a person with a larger following. For example, the hashtag \#MeToo was originally used by activist Tarana Burke, but only went viral after it was used by actress Alyssa Milano. The hashtag \#BringBackOurGirls only trended internationally following a tweet from Michelle Obama, former first lady of the United States. The user of a hashtag and their following is therefore considered to be an indication of its ability to trend. The trending algorithm results in a popularity of the moment founded on a 'rich gets richer' notoriety system where popularity determines a hashtag's spread.

The folksonomic, serendipitous, and trending topic functionalities mean that hashtags are being created and dropped constantly. Gillipsie suggests the algorithm must take into account not just the number of tweets, but factors such as whether or not the term is accelerating in its use, whether it has trended before, if it is being used across diffuse networks of people, and if the tweets are personalised (as opposed to retweets of the same post). ${ }^{702}$ The trending algorithm aims to capture topics that enjoy surges in attention, "rising distinctly above the normal chatter." 703 It is the combination of the folksonomic (user driven), serendipitous individual-collective melding and trending surge functions of hashtags that make them reflective of a particular kind of narrative. Gillipsie explains that algorithms that define how hashtags operate are complex; they are carefully designed by programmers to capture something site providers need and 'weed out' the inevitable mistakes that do not fit Twitter's brand. ${ }^{704}$ The architecture and design of hashtags favours a rhetoric that reflects not just topics that are always popular, but those that are triggered by urgency, excitement and personal, impassioned response. This is the kind of mob-mentality rhetoric that moves quickly to collectivise people. Gillipsie says pointedly "while the Twitter network supports the voice of the people, Twitter the corporation of course must have allegiances firmly intertwined with the fat cats of Wall Street."705 The combination of these design elements means that not all hashtags rise to trending status equally. In the following section, I explore how Twitter as a platform is structurally inclined to foster capitalistic designs and desires, which are fed by dominant narratives.

\subsection{Capitalist designs and desires}

Social media feeds are constructed by proprietary, partial and productive algorithms that mean their sorting mechanisms are encoded with bias. Researchers point to website providers and their hiring of programme engineers who are responsible for creating websites and

702 Gillispie, "Can an algorithm be wrong?"

703 Gillispie, "Can an algorithm be wrong?"

704 Gillispie, "Can an algorithm be wrong?"

705 Gillispie, "Can an algorithm be wrong?" 
algorithms. Jackson, Bailey, and Foucault Welles maintain that "whether and how to curate content are not neutral."706 The capitalist decisions of corporate social media companies are often "mired in racism and sexism" particularly when it comes to who these influential companies choose to hire. ${ }^{707}$ The algorithms, policies, and business practices of digital platforms have come under scrutiny for what Ariadna Matamoros-Fernandez calls "platformed racism."708 Despite the disproportionate use of Twitter by Black women in 2015, Twitter had no Black women employees and, according to their 2017 Equal Employment Opportunity report, of the three per cent of people of colour, none of them held positions of senior management. ${ }^{709}$ A UNESCO report in 2019 revealed that women currently only represent six per cent of software developers, stating "Today, women and girls are twenty-five per cent less likely than men to know how to leverage digital technology for basic purposes, four times less likely to know how to programme computers and thirteen times less likely to file for a technology patent."710 Mager found through a series of interviews that engineers are considered the driving force behind online interaction as 'the people who architect code' or software developers. ${ }^{711}$ It is particularly concerning then that women and people of colour are excluded from positions at the development level in these organisations because it is at that level where the experience of users is ultimately determined. Jackson, Bailey, and Foucault Welles explain:

Although Twitter CEO Jack Dorsey and other social media CEOs vociferously deny actively coding prejudice into their platforms, not specifically coding racism, sexism, and other forms of hate into platforms is insufficient. A systemic failure to imagine various ways platforms may incubate and magnify bias, however unintentional, allows them to proliferate. ${ }^{712}$

Most social platform engineers work for privately owned, for-profit companies like Twitter, Facebook and Tik Tok. As a corporate company, the means to generate profit must be written into the structure of the code.

Code that magnifies biases extends from broader foundational capitalist, settler-colonial logics to unseen algorithmic functions. ${ }^{713}$ Twitter is a business just like many other online platforms and its computer engineers' primary focus is maintaining attention and generating advertising revenue by connecting end-users to advertisers. ${ }^{714}$ Twitter allows users to pay to promote hashtags, what is referred to as a 'promoted trend', meaning that increased visibility is

\footnotetext{
706 Jackson, Bailey, and Foucault Welles, “\#Hashtag Activism,” 191.

707 Jackson, Bailey, and Foucault Welles, “\#Hashtag Activism,” 191.

708 Adriana Matamoros-Fernández, "Platformed Racism: The Mediation and Circulation of an Australian Race-Based Controversy on Twitter, Facebook and YouTube," Information, Communication \& Society 20, no. 6 (2017): 930-46 doi: 10.1080/1369118X.2017.1293130.

709 Jackson, Bailey, and Foucault Welles, “\#Hashtag Activism,” 192.

710 UNESCO, "I'd blush- if- I- could: Closing gender divides in digital skills through education,” 20 January, 2021, https://en.unesco.org/Id-blush-if-I-could.

711 Mager, "Algorithmic Ideaology," 775.

712 Jackson, Bailey, and Foucault Welles, “\#Hashtag Activism,” 191.

713 There is rich literature from critical race studies that examines inequitable algorithmic structures including: Benjamin Ruha's, Race After Technology and Captivating Technology; Safiya Umoja Noble's, Algorithms of Oppression; Roopika Risam's New Digital Worlds: Postcolonial Digital Humanities in Theory; Douglas A. Boyd and Mary Larson's Oral History and Digital Humanities: Voice, Access and Engagement; Charlton D. McIIwain's Black Software: The Internet and Racial Justice, from the Afro Net to Black Lives Matter; and W. E. B. Du Bois's Data Portraits: Visualizing Black America.

714 Bucher and Helmond, "The Affordances of Social Media Platforms," 243.
} 
available to those who can afford it.715 One of the most prominent arguments highlighting technological bias is the corporate logics within which online narratives evolve. Dean argues that social media platforms are based on business models that favour profit, stating,

They present themselves for a democratic public in their eager offering of information, access, and opportunity. They present themselves as a democratic public when the very fact of networked communications comes to mean democratisation, when expansions in the infrastructure of the information society are assumed to be enactments of a demos. But, as is becoming increasingly clear, the expansion and intensification of communication and entertainment networks yields not democracy but something else entirely: communicative capitalism..$^{716}$

Dean contends that the programmability, popularity, connectivity and "datafication" that characterises the current media ecology means that "the occupiers contribute to the production of digital media content being partly constitutive of current capitalism." 717 Dean terms this concept "communicative capitalism", a system in which the circulation of messages and the exchange value of online interactions dominates rather than their usefulness. ${ }^{718}$

The algorithmic logics of a trending hashtag are concerned with maintaining relevance and the attention of the audience. The aim is to appeal to the largest number of people with the information that is of most interest to the majority of people. This is what Elizabeth Van Couvering, in her examination of Google search engines, called "traffic commodity." 719 In order for Twitter to succeed as an online platform, it has married the technological structure of a hashtag with a business model that fits a fast consuming and networked capitalism. ${ }^{720}$ Dean argues:

A constitutive feature of communicative capitalism is precisely this morphing of message into contribution...The message is simply part of a circulating data stream. Its particular content is irrelevant. Who sent it is irrelevant. Who receives it is irrelevant. That it need be responded to is irrelevant. The only thing that is relevant is circulation, the addition to the pool. Any particular contribution remains secondary to the fact of circulation. ${ }^{721}$

For Dean, the content or use value of our online interactions becomes secondary or even irrelevant. ${ }^{722}$ Hence, any response to them becomes irrelevant as well, and any political potential disperses into the perpetual flow of communication. ${ }^{723}$ Users compete for visibility in

715 Twitter, "What is a Promoted Trend," 19 March, 2021,

https://business.twitter.com/en/advertising/takeover/promoted-trend.html

716 Jodi Dean, "Why the Net Is Not a Public Sphere," Constellations 10, no.1 (2003): 102, doi: 10.1111/1467-

8675.00315.

717 Jodi Dean, The Communist Horizon, (UK, London: Verso, 2012), 236.

718 Dean, The Communist Horizon, 236.

719 Mager, "Algorithmic Ideaology," 774.

720 Elizabeth Van Couvering, The History of the Internet Search Engine: Navigational Media and the Traffic

Commodity, (Berlin: Springer, 2008),117-206.

721 Jodi Dean, "Communicative Capitalism: Circulation and the Foreclosure of Politics," Cultural Politics 1, no.1 (2005): 58, doi: 10.2752/174321905778054845.

722 Anne Kaun, "Regimes of Time: Media Practices of the Dispossessed," Time \& Society 24, no.2 (2015): 236, doi:

$10.1177 / 0961463 X 15577276$.

723 Kaun, "Regimes of Time," 236. 
an environment which diminishes recognition in terms of production, distribution, and consumption time. ${ }^{724}$ Dean contends that activists struggle for visibility, which is the currency of the internet. ${ }^{725}$ Here, affordances of social media are determined by the temporality that architectural aspects of social network technologies imply and correspondingly the kinds of users behaviours and practices that temporality affords.

Dean suggests that there is a tight entanglement of technology and the capitalist society in which we live, saying, "our technologies mirror our societies. They reproduce and embody the complex interplay of professional, technical, economic, and political factors." 726 Dean is concerned with the flow of information on social media sites, and particularly that what is most important to people is the torrent of and the adding to of this continuous flood of information without engaging critically with it. ${ }^{27}$ She explains,

Ideals of access, inclusion, discussion and participation come to be realised in and through expansions, intensifications and interconnections of global telecommunications. But instead of leading to more equitable distributions of wealth and influence, instead of enabling the emergence of a richer variety in modes of living and practices of freedom, the deluge of screens and spectacles undermines political opportunity and efficacy for most of the world's peoples. ${ }^{728}$

The folksonomic, serendipitous, and trending features of the hashtag discussed in the last section are aligned with capitalist logics and support the freedoms of dominant groups in online spaces. In an interview I conducted with a campaign creator, they expressed feelings along the same lines saying "Twitter is a constant stream of interesting things and nothingness at the same time."729 Dean maintains that the "fantasy of abundance' covers over the way facts and opinions, images and reactions circulate in a massive stream of content, losing their specificity and merging with and into the data flow."730 Any given message is thus a contribution to this ever-circulating content. The algorithmic design of hashtags is based on capitalist logics which Mager refers to as the "capital accumulation cycle" and Dean calls "communicative capitalism." 731 Political performances of self via collectivising hashtags play into and are influenced by the corporate, for profit nature of online platforms.

Critical feminist theorists highlight the socio-economic constraints inherent to the internet, suggesting that communication networks act to reinforce rather than challenge dominant power structures. There is a co-dependent relationship between our use of collectivising hashtags and the capitalistic structures of online spaces. Hashtags, particularly collectivising and trending hashtags, encourage user participation in the production of online content. For the platform providers this content results in more attention paid to their platforms, meaning more paid promotions and more data and more money. Dean argues that a constitutive feature

\footnotetext{
724 Kaun, “Regimes of Time," 237.

725 Jodi Dean, Democracy and Other Neoliberal Fantasies: Communicative Capitalism and Left Politics, (Durham: Duke University Press, 2009), 20.

726 Wiebe E. Bijker and John Law, Shaping Technology/Building Society: Studies in Sociotechnical Change,

(Cambridge, Mass: MIT Press, 1992), 3.

727 Dean, “Communicative Capitalism," 55.

728 Dean, "Communicative Capitalism," 55.

${ }^{729}$ Interview conducted Tuesday 3 September 2019.

730 Dean, "Communicative Capitalism," 58.

731 Mager, “Algorithmic Ideology," 770; Dean, “Communicative Capitalism," 53.
} 
of communicative capitalism is precisely this "morphing of message into contribution."732 I argue that this 'morphing' also problematises the recognition of marginalised bodies in online spaces. Counterpublics are putting in significant digital labour to have their voices heard and are competing with businesses that use paid promotions to receive greater attention. Even those campaign managers that I interviewed doing anti-racist work (like the NZHRC's \#ThatsUs campaign manager) are now turning to paid promotions to help facilitate the visibility of their work. Users believe they have no choice in the matter - they either buy into the capitalistic structure of platforms or risk going unseen.

\subsection{Algorithms and Impulses: The Co-creation of Our Online Environment}

There is a complex interplay between real world power structures, online architectures and digital practices. Mager suggests that the future of interdisciplinary research shifts its attention from the impacts of technology on a society towards the social practices and power relations that co-construct our digital environment. ${ }^{733}$ While the exact workings of Twitter's hashtag algorithm remain largely unknown, it becomes increasingly clear that this is a subsidiary question. Gillespie claims that we do not yet have a language for the unexpected associations algorithms make, beyond the intention (or even comprehension) of their designers. ${ }^{734} \mathrm{We}$ don't have a clear sense of how to frame the politics of algorithms. Gillespie suggests that,

The interesting question is, what do we think the trend list is, what it represents and how it works, what can we presume to hold it accountable when we think it is 'wrong'? What are these algorithms and what do we want them to be? 735

The more imperative question is: how does our perceived understanding of affordances influence the way we interact with them? We need to unpick the complex interplay between the architectural design of hashtags, their economic model, their imagined affordances for users, and how this perception changes their actual use. What is most important here is not simply how algorithms function. Rather, it is the meaning that we attribute to them and it is our co-creation of their significance and purpose, or "our emerging and powerful faith in them."736 Users expect hashtags to function in a particular way:

We want Trends to be about an impartial arbiter of what's relevant...and we want our pet topic, the one it seems certain that 'everyone' is (or should be) talking about, to be duly noted by this objective measure specifically designed to do so. We want Twitter to be 'right' about what is important...and sometimes we kinda want them to be wrong, deliberately wrong - because that will also fit our worldview: that when the facts are misrepresented, it's because someone did so deliberately, not because facts are in many ways the product of how they're manufactured. ${ }^{737}$

\footnotetext{
732 Dean, “Communicative Capitalism," 51.

733 Mager, "Algorithmic Ideology," 782.

734 Gillispie, "Can an algorithm be wrong?"

735 Gillispie, "Can an algorithm be wrong?"

736 Gillispie, "Can an algorithm be wrong?"

737 Gillispie, "Can an algorithm be wrong?"
} 
Gillespie finds that people want algorithms to function in a way that is consistent, reliable and objective. It is easier to believe that hashtags are just a benign scientific tool. If hashtags fail to function in the way that we think they ought to, we want to be able to place that blame primarily on the platforms and designers as the arbitrators of code. ${ }^{738}$ When trivial topics like \#JustinBeiber trend but other important hashtags like \#Ferguson, \#OccupyWallStreet and \#VictimBlaming fail, users fixate on how the architecture of social platforms is flawed.739 Gillespie explained that algorithms are not designed to take into account number of tweets. ${ }^{740}$ What trends is not a mathematical equation, nor would users want it to be; if it was the trend list would read like a popular grammar list, or be dominated with the same topics that remain consistently talked about (like K-Pop and Justin Beiber). ${ }^{74}$ The problem is that users seem to want to have it both ways; we want algorithms to be both clinical mathematical formulas that make fair decisions in which people have a democratic say in what trends and at the same time we want them to make a subjective judgment on what hashtags are socially and politically significant. Gillespie explains the contradictory expectations we have of algorithms, stating:

We may be unwilling or unable to recognise our growing dependence on these algorithmic tools, as our means of navigating the huge corpuses of data that we must, because we want so badly for these told to perform a simple, neutral calculus, without blurry edges, without human intervention, without having to be tweaked to get it 'right.' 742

Online platforms are complicated, messy, and fragile eco-systems that often play out in unexpected ways. While users are getting increasingly better at understanding how they work and how they can be used to their best advantage it is still an ongoing process. Gillespie claims "algorithms are not perfect; they are still cudgels, where one might want scalpels." 743 These algorithms are shaped by the interest of their providers, but they are also determined and repurposed by users. Users actively participate in the creation and stabilisation of the algorithmic system, a system which we do not yet fully comprehend. The results of this participation are sometimes innovative and progressive and, at other times, regressive and exclusionary. Users' expectations and beliefs around hashtag use impact the architectural structure of platforms and their functionality. Users' active participation shapes the algorithmic systems and environments in which they find themselves.

While users are able to share their own messages without hashtags, if they seek to maximise recognition and visibility then 'playing by the algorithmic rules' is necessary. In this way Twitter engages in softer forms of governance "by designing the algorithm so as to privilege some kinds of content and exclude others, and some users and not others." ${ }^{744}$ Twitter offers rules, guidelines and suggestions for proper tweeting, in hopes of gently moving users towards

\footnotetext{
738 Gillispie, "Can an algorithm be wrong?"

739 Gillispie, "Can an algorithm be wrong?"

740 Gillispie, "Can an algorithm be wrong?"

741 Over the past few years, Twitter has continued to tweak the algorithm so that it moves away from popular tweets and more actively reflects topics that spike in interest. This aligns with the socio-political interests of both users and the Twitter brand (that prides itself on presenting topical issues of political and social import.) See Twitter, "To trend or not to trend," 19 March, 2021, https://blog.twitter.com/official/en_us/a/2010/to-trend-or-not-totrend.html

742 Gillispie, "Can an algorithm be wrong?"

743 Gillispie, "Can an algorithm be wrong?"

744 Gillispie, "Can an algorithm be wrong?"
} 
the kinds of content that suit their site, "the punishment imposed on violators is that their tweets will not factor into search or trends." 745 Users play a central role in maintaining this dynamic based on popularity, coverage, transmission, and reputation. ${ }^{746}$ Technological affordances should not simply be seen as "overruling or exploiting" society but rather as enacted and stabilised by its users' need to continue engaging in the social practise of hashtagging. ${ }^{747}$ This is what Mager calls the "new spirit of capitalism," where social media users set themselves up to benefit from the marketing strategies of platforms. ${ }^{748} \mathrm{~A}$ digital campaign producer that I interviewed put it this way:

That is the way that social media works, it is just constant flow. If you want to keep your page out there, if you want to keep your followers, then being inactive is not going to do it-so I guess you have to be seen basically. Once you are in you are in-if you take yourself off how else would you communicate with people? So you know do you go back to websites? I think websites for that purpose are almost obsolete. They will find it [information] elsewhere-I think they will go elsewhere-Facebook is the thing, Twitter is the thing or Instagram yeah. ${ }^{749}$

In this quote, one of the digital campaign producers I interviewed describes the "constant flow" that they experience on social media, which inadvertently speaks to Dean's conception of communicative capitalism. ${ }^{750}$ It is all about continuing the flow of content. Online participation is not something users feel that they can opt out of, they believe it is necessary to still maintain a presence in online spaces. One digital campaign manager confessed that even though she was not convinced of the tangible value of online content, she still felt it was important to be online:

There is pressure to be putting stuff out there because otherwise the page dies... do you see what I am getting at? What are you trying to achieve the more you post? You get more followers but it is really just to be out there. Personally, I just think it is the way that the world is now-you have to have it [an online presence] because you need profile. How effective it is a different story. 751

If you simply fail to 'play by the algorithmic rules' you forfeit your ability to speak effectively in online spaces. ${ }^{752}$ Users are increasingly aware of the technological parameters of the digital environment they operate in and its affordances. Nonetheless people still choose to engage in online spaces in order to achieve their end goals. This is partly motivated by what Mager refers to as a "punishments and rewards" system: users increasingly adapt their online actions and their use of collectivising hashtags because they believe their voice is more likely to be heard if they do so. ${ }^{753}$ Gillispie, writing about users' increasing appetite for trending hashtags, writes:

\footnotetext{
745 Gillispie, "Can an algorithm be wrong?"

746 Samakoti Tejasree, Shaik Naseera and Tella Pramila, "Perception of Trend Topic in Twitter: A Case Study," Journal of Software Engineering 11, no. 14 (2017): 12-17, doi: 10.26634/jse.11.4.13816.

747 Mager, "Algorithmic Ideaology," 783.

748 Mager, "Algorithmic Ideaology," 783.

749 Interview Thursday 5 September 2019.

750 Interview Thursday 5 September 2019; Dean, “Communicative Capitalism," 51.

751 Interview Thursday 5 September 2019.

752 Mager, "Algorithmic Ideaology," 777.

753 Mager, "Algorithmic Ideaology," 777.
} 
But, many Twitter users take it to be not just a measure of visibility but a means of visibility - whether or not the appearance of a term or \#hashtag increases audience, which is not in fact clear. Trends offers to propel a topic towards greater attention, and offers proof of the attention already being paid. Or seems to [emphasis in original]. ${ }^{754}$

In order to maximise their action capabilities, users must 'play by the rules' of social media platforms and the use of hashtags exemplifies this. In order to give maximum reach to our own voice in online spaces we must stick with the status quo. So, hashtags are encouraged and reach and shareability is encouraged as a social and technological practice. It is the user's need to be 'in' and the inability or unwillingness to part with the benefits received by inherent bias that act to stabilise the technological affordances of hashtags.

Engineer-driven logic is often viewed as the most important factor underlying the construction of algorithms. ${ }^{755}$ In reality, the majority of platforms' algorithmic functions (folksonomic, serendipitous and trending) are primarily 'user driven matrixes.' Mager challenges the idea that providers and designers are solely in control of inflicting algorithmic functions on users, suggesting instead that that users "comply and stabilise" the structure of platforms. ${ }^{756}$ Mager explains this vernacular relationship, stating:

Both website providers and users should not merely be seen as victims of search engines and their new modes of exploitation. Rather, they should be conceptualised as actively stabilising the technology with their marketing, search and consumer practices - partly consciously, partly unconsciously. 757

Website providers and users stabilise the "algorithmic ideology" by "entering alliances" with platforms in order to reach their own goals.758 Mager defines algorithmic ideology as the alignment of technology as a business model that fits a 'connectionist world' and its drive towards global networked capitalism..$^{759}$ Social media platforms embody the spirit of capitalism and settler-colonial logics which users comply with and amplify in order to reach maximum utility online. ${ }^{760}$ Users strategically use algorithmic functions in order to "benefit from our marketing strategies, consumer desires, ignorance, compliance, innovation, fetish, politics of privatisation and, most of all, globalised capitalism that increasingly escapes local socio-political cultures and frameworks." 761 Hashtags have capitalism inscribed in the fabric of their algorithmic functions. Algorithmic ideology is stabilised and solidified in a socio-political context characterised by interdependent vernacular affordances and the politics of collectivism. Far from sitting in opposition to one another, capitalistic design structures, algorithmic functions and user desires work together to create an online environment that feeds off exhilarated encounters and collectivising hashtag practices. ${ }^{762}$ Therefore, over time, algorithms absorb and replicate the racial and gender bias of their programmers and users.

\footnotetext{
754 Gillispie, "Can an algorithm be wrong?"

755 Mager, "Algorithmic Ideology," 770.

756 Mager, "Algorithmic Ideology," 770.

757 Mager, "Algorithmic Ideology," 779.

758 Mager, "Algorithmic Ideology," 792.

759 Mager, "Algorithmic Ideology," 774.

760 Mager, "Algorithmic Ideology," 770.

761 Mager, "Algorithmic Ideology," 783.

762 Mager, "Algorithmic Ideology," 783
} 
This implies that hashtag users have the power to destabilise social media platforms. As Mager acknowledges, resistance needs to be facilitated by a socio-political context, which critically examines platforms and the capitalist ideologies that they embody. ${ }^{763}$ Chen claims that "understanding how the zeros and ones increasingly influence and control our lives is critical to understanding how we can reciprocate influence and control back onto those zeros and ones." 764 Chen maintains that our society and technologies are now intertwined to a point where there is no clear cause and effect: "our technologies and our values drive and affect one another." 765 This chapter highlights how political economy, algorithms, and the ideologies and biases of users and platform operators intertwine on social media platforms. From this, I synthesise that social media architectures are co-created by users, designers, and their capitalist ideologies, which acts to reaffirm systems of inequality. In the following section, I use the concept of the crooked platform to illustrate ways in which hashtags and social media platforms problematise the recognition of marginalised users in online spaces. We must shift attention away from the impacts technological architecture has on society and towards the social practices and power relations involved in their co-construction. ${ }^{766} \mathrm{I}$ argue that privileged users actively participate in the construction of online environments, stabilising and solidifying inequalities inscribed in the architectural foundations of collectivising hashtags and the crooked platform in which they are used.

\subsection{The Crooked Platform}

So the question is - have I been walking at this angle my entire life or is that angle up straight and the world is crooked? Some days it feels like you are the only thing that is at the correct angle compared to the rest of the world. So the world is crooked. And I honestly think especially in online spaces like Twitter there are moments where I like realise that I am sitting at that 30-degree angle and it is time to realign and see either myself or to see the world for what it truly is. I think that although the images are pretty horrific that being awash with videos and images while deeply triggering and really pretty horrific of African American men being brutalised by the police, there is a moment where I am like-this is me realising that. We are all sitting like this [gestures to make oneself tilted] so it is not a great way to come to a realisation of that-but it is necessary. ${ }^{767}$

The affordances of Twitter allow privileged bodies to inhabit a crooked platform in which they encounter Other non-dominant bodies. Through their encounters on Twitter, some users have come to realise that the spaces they inhabit are crooked. The technological structure of social media platforms means that people often view it as an inanimate object incapable of bias, when in reality it is deeply reflective of our current social, economic and political environment. Supposedly neutral algorithmic logics represent similar or the same biases in creating the

\footnotetext{
763 Mager, “Algorithmic Ideology," 779.

764 Chen, Shouting Zeros and Ones, 14.

765 Chen, Shouting Zeros and Ones, 14.

766 Mager, "Algorithmic Ideology," 782.

767 Interview with Alice Canton conducted 11 June 2020 via Zoom conference call. It was during this interview that she introduced me to the concept of the Crooked Room and through my discussion with Alice I began to see how see how our online platforms might also be crooked.
} 
'online' world that exists 'offline.'768 Raced, gendered, and class prejudices are 'baked into' algorithmic technologies. ${ }^{769}$ The algorithmic functions of hashtags foster kinds of affordances that do not equally benefit all users. While hashtags offer everyone the same functionality, they are tilted to favour particular capitalist usages that benefit some users and marginalise others. The algorithmic architecture of code's folksonomic, serendipitous, and trending functions means that Twitter as a platform is tilted in such a way that it supports capitalist and privileged forms of dominance. In addition, users all bring their own unique digital capacities, understandings and performances to online spaces. The folksonomic, serendipitous, and trending functions are all very dependent on other users who share that space. All our encounters both online and offline are affecting; they leave an impression upon others. Our online encounters leave others with an impression, and our positionality and unique digital privileges impact this encounter. We do not come into encounters evenly.

The underlying technological inequalities are specific to each user, encounter is grounded in a complex ecology of other users with unique technological affordances. It is increasingly necessary therefore to understand what technology affords those who use it and how it disproportionality affects marginalised users. Chen advocates for a broader consideration of "the impacts of technology, especially those that may be invisible to most users, and understanding of how might mitigate the negative impacts." 770 Social media platforms are ultimately the product of a neo-liberal policy of privatisation that enacts the same sociopolitical constraints, bias and injustices we see across our modern capitalist society. ${ }^{771}$ During his time as a computer systems engineer, Chen came to realise that "values neutral technology is a fantasy. Everything we do is laden with values, whether we acknowledge them or not."772 Critical race, gender and Media Studies scholars have found that the Internet has entrenched capitalist logics and status quo biases. ${ }^{773}$ The privileges associated with Whiteness and the disadvantages projected upon marginalised bodies have become an invisible structural feature of the online environments we co-create. I contend that it is no longer a question of whether or not social media platforms are crooked- they are-this is well established by interdisciplinary algorithmic research of scholars including Mager, Gillispie, and Chen. The question becomes: are we, as users, aligning ourselves with a crooked platform and, if so, how do we recognise our misalignment and find a way to stand up straight?

\section{a) Interviews Deconstructing the Crooked Platform}

In order for users to recognise and address their misalignment it is imperative to look at the architecture of Twitter as a platform. In his original application of CTDA Brock was interested in the affordances of Twitter's material interface as well as the platform's capacity to facilitate

\footnotetext{
768 Punday, "The Narrative Construction of Cyberspace," 199.

${ }^{769}$ Kirchner, "When Discrimination Is Baked Into Algorithms."

770 Chen, Shouting Zeros and Ones, 13.

771 Dean, "Communicative Capitalism,"

772 Chen, Shouting Zeros and Ones, 9.

773 See literature from critical race scholars that examine inequitable algorithmic structures including: Benjamin Ruha's, Race After Technology and Captivating Technology; Safiya Umoja Noble's, Algorithms of Oppression; Roopika Risam's New Digital Worlds: Postcolonial Digital Humanities in Theory; Douglas A. Boyd and Mary Larson's Oral History and Digital Humanities: Voice, Access and Engagement; Charlton D. McIlwain's Black Software: The Internet and Racial Justice, from the Afro Net to Black Lives Matter; and W. E. B. Du Bois's Data Portraits: Visualizing Black America.
} 
Black techno-cultural conventions. ${ }^{774}$ Brock considers the phenomenon of Black Twitter by exploring Twitters uptake and popularisation by young Black users. The phenomenon of Black Twitter illustrates the incredible creativity and tech literacy that Black users bring to crooked platforms. Brock observes, "it becomes remarkable that Black discourse can be employed effectively over a medium designed for a small, technologically proficient, mostly White user base." 775 According to Brock 'minimalism' and 'malleability' are two primary affordances of the Twitter platform that helped to facilitate the spread of Black Twitter. ${ }^{776}$ As a communication technology Twitter only requires an Internet-connection, screen, and input device to access and engage across the platform. 777 Twitter can be readily accessed through a mobile app, browser or from a Windows, Mac, Unix, or Linux operating system. ${ }^{778}$ Twitter is designed in such a way that it facilities mobile use and encourages quick 'on-the-go' communication and updates. Brock's analysis of Twitter's interface elements found that, "Black mobile access and Twitter usage suggest that Twitter's minimalist aesthetic and ease of material access play a role in Black adoption of the service."779 In a study of Black and Hispanic American Internet usage Aaron Smith found that $87 \%$ of Hispanic and Black Americans own a mobile phone and the majority access the Internet (and Twitter) wirelessly inferring material reasons for Twitters uptake by young Black folk. ${ }^{780}$ Smith found that Black Twitter users access Twitter nearly four times more a day than White users. ${ }^{781}$

One of the key affordances of Twitter is it's short message design and direct addressivity of messages. The 280 characters limit means that messages and connections are quickly formed and disseminated allowing people to connect intermittently throughout the day. ${ }^{782}$ Twitters “@” function and "follow" mechanism allows users to create their own informational environment through their chosen network that centres issues and experiences relevant to Black communities. ${ }^{783}$ Information is shared in real time across Twitter as well as other social media platforms and websites like Facebook, YouTube and traditional news outlets. Most third party clients (such as news websites and businesses) have the Twitter symbol on their webpage banner that allows users to directly access content to share or retweet on Twitter. Twitter minimalist interface design demands less of users in terms of access, time and is relative affordability. Contradicting mainstream expectations of Twitter demographics, discourses and utility, Black Twitter has found ways to reclaim the crooked platform, utilising its structure to recentre Black techno-cultural usages. ${ }^{784}$ Having first recognised the minimalist structure of the crooked platform and its influence on user behaviour, Black Twitter relied on hashtag's malleability to push back against the normalisation of Twitter as a White space.

\footnotetext{
774 "Black Twitter" is characterised as a networked community bounded by Black cultural specificity and lived experience. See Brock, "From the Blackhand Side," 529; and Meredith Clark, "Black Twitter: Building Connection through Cultural Conversation." in Hashtag Publics: The Power and Politics of Discursive Networks (ed., Nathan Rambujjana) Vol. 103. New York: Peter Lang AG International Academic Publishers, 2015. doi: 10.3726/978-14539-1672-8

775 Brock, "From the Blackhand Side," 534.

776 Brock, "From the Blackhand Side," 535.

777 Brock, "From the Blackhand Side," 536.

778 Brock, "From the Blackhand Side," 536.

779 Brock, "From the Blackhand Side," 536.

780 Aaron Smith, “Mobile Access 2010," Pew Internet and American Life Project. accessed 14 September, 2021 https://www.pewresearch.org/internet/2010/07/07/mobile-access-2010/; See also Aaron Smith, "Twitter Update 2011," Pew Internet and American Life Project.

781 Smith, "Mobile Access 2010."

782 Brock, "From the Blackhand Side," 535.

783 Brock, "From the Blackhand Side," 531.

784 Brock, "From the Blackhand Side," 538.
} 
For Brock, the malleability of Twitter's platform with its temporal, electronic and structural discourse mediation is a crucial affordance for Black Twitter.785 Brock maintains that the affordances of a hashtag, with its power of connectivity, is what led to the 'discovery' of Black Twitter stating, "these techno cultural displays of Black Identity would have gone unnoticed by the wider world except for the visibility offered by another signifier, the hashtag." 786 Chris Wilson identifies three elements of Black Twitter: 1) a culturally relevant hashtag (with Black discursive specificity such as \#YouOKSis or \#FastTailedGirls); 2) network participation either by a comment or a retweet by tightly linked affiliates; and 3) viral spread to reach "trending topic" status. ${ }^{787}$ Wilson's three elements of Black Twitter share a connection with the folksonomic, serendipitous, and trending affordances of a hashtag. The folksonomic hashtags with their user driven 'on the go' responses, combined with the serendipitous spread of hashtags fostered by wide-reaching networks of Black Twitter bring hashtags to the attention of the trending topic algorithm, which is how the mainstream audience became aware of the issues of concern to Black Twitter. ${ }^{788}$ In this way the affordances of Twitter have helped centre Black Twitter and facilitate its influence of the trending topics, that has "allowed outsiders to view Black discourse that was (and still is) unconcerned with the mainstream gaze."789 Importantly this shifts the gaze from White framings of Black online activity, and centres Black Twitter's impressive resilience, creativity, and tech literacy in reframing crooked platforms and reclaiming digital spaces. Brock explains, "Black Twitter's visibility via the trending topic algorithm - and the resultant othering of those conversations - led Black Twitter's framing as an intervention on 'White Public Space"790 Brock's exploration of Black Twitter demonstrates that even while using the same fixed architectures, functions and apparatus of the crooked platform, there is potential for users to realise and correct their misalignment. ${ }^{791}$ I want to build on Brock's findings, by suggesting that the affordances of collectivising hashtags, specifically their discursive malleability, can bring attention to the crooked platform and provoke users to re-orient themselves.

\section{b) The Transformative Potential of \#TheyAreUs and \#ThislsNotUs for the Crooked Platform}

One of the fundamental failings of the crooked platform is how it renders marginalised users invisible or hyper visible, particularly when encountering racially motivated violence and precarity. An affordances lens can be used to operationalise the technical as well as discursive features of \#TheyAreUs and \#ThisIsNotUs collectivising hashtags, which were the primary point of encounter between Twitter users following the Christchurch Mosque shootings. The hashtags \#TheyAreUs and \#ThisIsNotUs brought mainstream attention to the fact that the room was crooked, by bringing to light the slanted portrayal of marginalised bodies on issues of identity, difference, and citizenship. Following Prime Minister Arden's press conference the

\footnotetext{
785 Brock, "From the Blackhand Side," 531.

786 Brock, "From the Blackhand Side," 538.

787 Chris Wilson, "uknowurblack," The Root, accessed 16 September, 2021.

https://www.theroot.com/uknowurblack-1790870196.

788 Brock, "From the Blackhand Side," 541.

789 Brock, "From the Blackhand Side," 534.

790 Brock, "From the Blackhand Side," 541.

791 Brock, "From the Blackhand Side," 534.
} 
hashtag \#TheyAreUs received an acute spike in transmission which saw it reach trending topic status. The \#TheyAreUs hashtag received broad network coverage with users commenting and retweeting \#TheyAreUs, participants spanned national and international audiences. The circumstances in which the \#TheyAreUs hashtag emerged on Twitter and its particular use aligned with the folksonomic, serendipitous and trending functions of the crooked platform. While there are undoubtedly significant semantic limitations to the use of \#TheyAreUs and \#ThisIsNot hashtags (such as their appropriation by privileged users which I covered in Chapter Three). There is also evidence of marginalised users reclaiming crooked spaces and using architectural structures to their advantage.

Encounters enabled by collectivising hashtags have the capacity to create cracks and rupture the usually imperceptible architectures of crooked platform rendering it visible and opening it to critique. One of the architectural benefits of \#TheyAreUs is the folksonomies of the hashtag which can act to prioritise everyday users perspectives as a source of knowledge. The trending status of the \#TheyAreUs hashtag helped to link conversations between affected Muslim communities and the mainstream public on Twitter. Where traditional media outlets focused on stories of national grief, solidarity and 'one-ness', the folksonomies of \#TheyAreUs and \#ThisIsNotUs allowed for Muslim and other marginalised users to insert stories of their own lived experience to contradict and challenge mainstream perspectives. ${ }^{792}$ The hashtags \#TheyAreUs and \#ThisIsNotUs were often employed by marginalised users to explain the problematic nature of collectivity and point out how it fails to address pre-existing issues of racism, colonialism, and white supremacy. Importantly, this confronts privileged users with race and gender stereotypes that previously remained invisible to them. Marginalised users were able to build on the popularity and visibility of the trending \#TheyAreUs hashtag by pairing it with a culturally relevant Counterpublic hashtag like \#ThisIsUs or \#MuslimTwitter. The serendipitous affordance of the trending topic function means that users who have weak ties and may not otherwise have encountered one another are brought together in conversation by the \#TheyAreUs hashtag, calling privileged users to think critically about their positionality in structures of power and challenge underlying inequalities. Recognising the affordances of collectivising hashtags, especially those that may be invisible to most users, is thus an important step towards understanding of how we might mitigate the negative impacts of the crooked platform.

\section{c) Collectivising Hashtags As Part of a Broader Conversation}

The affordances of these collectivising hashtags becomes a vital part of broader conversations and changes in public perception and practices over time. When the \#TheyAreUs hashtag first trended, mainstream conversation was dominated with Pākehā tweets expressing shock, grief, and shared precariousness that follows the loss of first world safety. Muslim users were quick to respond using \#TheyAreUs contradicting Pākehā perspectives with their expressions of devastation and expectancy following the shooting. The stark difference between Pākehā perspectives and Muslim, Māori and other marginalised responses did not go unnoticed on Twitter as they were collated under the trending topic category. As more stories from affected

792 Frédérik Lesage and Louis Rinfret, “Shifting Media Imaginaries of the Web," First Monday 20, no. 10 (2015) doi: 10.5210/fm.v20i10.5519 
communities emerged about daily experiences of discrimination, racism, violence and exclusion that long preceded the terror attack in Ōtautahi, the narrative began to shift.

The discursive flexibility of the hashtag allows the meaning and usage of the hashtag to continue to morph as the narrative develops. An example of this is the \#TheyAreUsShutDown hashtag that trended in response to the proposed 'They Are Us' film by Director Andrew Niccol, which would dramatise the March 15 shooting. The proposed film was met with heavy criticism for fostering White Saviour narratives while disregarding the White supremacism that lead to the violence. Responding to the They Are Us film one Twitter user remarked, "You literally took a horrific act of White supremacy and turned it into a story about White people's feeling?? Nah this ain't it." The National Islamic Youth Association ("NIYA") explained that the film marginalises the affected Muslim communities choosing to focus instead on Prime Minister Jacinda Arden portrayed by lead actor Rose Byrne, NIYA state on their website, "It is also inappropriate that the film appears to centre PM Jacinda Ardern, a white woman". The NIYA circulated a petition along with the hashtag \#TheyAreUsShutDown which trended on Twitter (see figures 17 and 18). ${ }^{793}$ Interviewee Hala Nsar tweeted "Nothing about us, without us \#TheyAreUsShutdown" and encouraged Pākehā users to sign the petition and take further action to mobilise broader anti-racist work. The petition received over 75000 signatures attracting attention from traditional media outlets, and the Prime Minister's Office was approached to comment on Arden's portrayal in the film, eventually leading to the suspension of film production. Muslim community advocate, Guled Mire, said the film being put on hold was "a testament to the response and the message that New Zealand has sent as a country, as a nation, behind the Muslim community itself - which is something that needs to be applauded."794 The \#TheyAreUsShutDown hashtag illustrates the thought progression of privileged users on Twitter; as they have come encounter more survivor's stories (through social media, podcasts and traditional media) that reframe the shooting not as a one off event, but as a broader issue of systemic racism and colonialism in Aotearoa. ${ }^{795}$ It shows that over the past two years the mainstream public has (at least to some extent) come to recognise the shortfall of the original \#TheyAreUs and pay closer attention to Muslim perspectives and concerns. The hashtags \#TheyAreUs and \#TheyAreUsShutdown are placed in conversation with one another, similar to other international examples like \#NotAllMen and \#YesAllWomen, \#SayHisName and \#SayHerName. Hashtags are part of a broader conversation online about important social issues, and as social consciousness changes and develops over time hashtags are reflective of that shift.

Figures 17 and 18.

\footnotetext{
793 The National Islamic Youth Association, "Shut Down 'They Are Us' Movie, which side-lines victims of the March 15th terrorist attack." Change Org. accessed 12 October 2021. https://www.change.org/p/filmnation-entertainmentshut-down-they-are-us-movie-which-side-lines-victims-of-the-march-15th-terrorist-attack

794 Tess McClure, "They Are Us: controversial film about Christchurch attack put on hold." The Guardian. 23 July 2021. https://www.theguardian.com/film/2021/jul/23/they-are-us-controversial-film-about-christchurchattacks-put-on-hold

795 Mainstream media articles that centre victims stories: "Widows of Shuhada," Radio New Zealand. Accessed 12 October 2021, https://www.rnz.co.nz/programmes/widows-of-shuhada; "Nine Bullets: A Survivor's Story," Stuff. Accessed 12 October 2021, https://interactives.stuff.co.nz/2020/03/nine-bullets/; "They Are Us: A memorial to the victims of the 15 March 2019 Christchurch terror attacks," Radio New Zealand. Accessed 12 October 2021, https://shorthand.radionz.co.nz/they-are-us/index.html.
} 
The affordances of hashtags continue to develop over time, they are made and remade in response to existing hashtags, conversations, and encounters with Other users. Jackson, Bailey and Foucault Welles describe the development of racial violence hashtags explaining that the Black Lives Matter movement is made of a progression of hashtags from \#Ferguson to \#FalconHeights stating, "the Black Lives Matter Movement not only relies on new technological infrastructures and potentials, it was birthed in the public consciousness by them."796 They found evidence of the reanimation of hashtags including \#EricGarner and \#ICantBreathe in association with the BLM movement long after the events to which they refer took place. ${ }^{797} \mathrm{I}$ made a similarly interesting connection between my two case studies (see figure 18). I found tweets that included both the \#GiveNothingToRacism hashtag (originally launched in 2007 by the New Zealand Human Rights Commission) and the \#TheyAreUsShutDown (used in 2021 in response to proposed They Are Us film). The \#GiveNothingToRacism and \#TheyAreUs hashtags were used concurrently to highlight that the Mosque Shooting was the result of deeper socio-political issues including racism, discrimination and settler colonial logics. Addressing the proposed They Are Us Film was about more than just cancelling the film, rather it is about acknowledging ongoing issues of inequality in Aotearoa and choosing to 'Give Nothing to Racism.' Twitter conversations regarding the terrorist attack need to happen sideby-side with conversations about the elimination of everyday and systemic levels of racism in society and the use of \#GiveNothingToRacism and \#TheyAreUsShutdown helped to bridge this space. Hashtags are iterative, they are shaped and reshaped by collective imaginaries along trajectories of online publics. The hashtag's malleability makes room for a progression of critical thought and collective imaginaries as ideas develop over time and have the potential to propel a movement forward.

\section{d) Reimagining Crooked Spaces}

A hashtag's malleability and imagined affordance may affect users' reception and openness in response to racial and gender justice hashtags, helping to foster vulnerability among advantaged groups when they encounter stories of Others' lived experiences in online spaces. Privileged users not directly affected by these issues are confronted with the crooked platform through collectivising hashtags in their many iterations and in doing so become better versed in recognising and discussing issues of race and gender inequality. ${ }^{798}$ Harnessing the affordances of Twitter requires an emphasis on users' collective understanding of hashtags and the need for revision of collective imaginaries in response to racial justice hashtags. Imagined affordances may not just affect how users approach social media platforms like Twitter, they can reframe, challenge and fuel their future development. ${ }^{799}$ While Twitter's political potential may have originally been conceived as a tool to help organise, mobilise, and share information for offline participation, our social conceptions of Twitter are changing. Trending hashtags have now become movements in and of themselves, online networks have become communities of influence, and Twitter has become the social reality itself. Movements like \#MeToo, \#BlackLivesMatter and even \#TheyAreUsShutDown have fought against Twitter's conception as a White space. They have propelled our collective imaginaries and

\footnotetext{
796 Jackson, Bailey, and Foucault Welles, \#Hashtag Activism, 123.

797 Jackson, Bailey, and Foucault Welles, \#Hashtag Activism, 152

798 Jackson, Bailey, and Foucault Welles, \#Hashtag Activism, 149.

799 Bucher and Helmond, "The Affordances of Social Media Platforms," 239.
} 
restructured crooked spaces revealing their hidden inequalities. But it should also be noted that such developments do not exist in a vacuum. They are part of a difficult 'process of becoming' that is continually remediated through the hashtags' entanglement with other social, cultural, and technological developments. ${ }^{800}$ The crooked platform operates as a site for the realization of multiple potentialities, of diverse ideals and of various imaginaries that, while malleable, are still contingent on the existing architectural structures of power.

Despite this crooked platform, non-dominant bodies have found ways of challenging stereotypes, and finding their way up. In the next chapter, I explore the subversive ways in which collectivising hashtags have been used by digital counterpublics. I examine ways that hashtagged discourse and debate bring attention to the crooked platform and promote reflexivity in online performances that can help redefine the crooked platform. While the following chapter explores the ways in which collectivising hashtags and their affordances are subversively used by counterpublics, I acknowledge that these racial justice and feminist narratives continue to develop, in spite of the structural limitations on algorithmic functionalities, with their dominant corporate, cultural, and technological logics.801 In what follows, I delve deeper into the destabilising practices of digital Counterpublics, highlighting the clever, subversive and often humorous ways they bring attention to the fact that the platform is crooked. I also critically examine how collectivising hashtags foster or fail to foster vulnerability and allyship amongst advantaged groups.

${ }^{800}$ Lesage and Rinfret, "Shifting Media Imaginaries of the Web."

801 Jackson, Bailey, and Foucault Welles, \#Hashtag Activism, 190. 


\section{Chapter Five \\ From Individual to Systemic}

"It can be hard to stand up straight in a crooked room." 802

This chapter explores the clever and imaginative ways collectivising hashtag users have subverted online interactions to find a way to stand up straight within a crooked online platform. I discuss one of my case studies, the NZHRC's \#ThatsUs collectivising hashtag campaign. During the research phase of this dissertation, two key user affordances of collectivising hashtags became evident. The first is the co-construction of community via collectivising hashtags, and the second is the prevalence of performative acts that are performed by digital counterpublics to produce nondominant forms of knowledge. In the following sections, I discuss how collectivising hashtags "make visible particular relations" and explore the ways users subversively engage in collectivising hashtags practices to bring attention to the alignment of privileged users' hashtagging practices within the crooked platform. 803

This chapter is split into two main sections. The first section looks at networked acts of hashtag activism and explores the potential affordances of collectivising hashtags to challenge existing inequalities through curation, as well as networked and storytelling practices. I draw on the NZHRC's \#ThatsUs campaign to illustrate the benefits of hashtags for contemporary counterpublics by finding patterns amongst individual lived experiences and reframing them collectively to highlight underlying systems of dominance and inequality. I examine how these networked communities curate their own digital spaces and use hashtags to bring attention to the crooked platform. The second section looks at performative acts of hashtag activism and argues that that logistical use of networks and performative acts are entering a 'second act' of digital activism. ${ }^{804}$ This section is split into three parts: a) comedy, tragedy and performative acts of subversion; b) playing to game the system; c) state regulation and corporate responsibility and; d) the limits of agency in counterpublic advocacy. Counterpublics wanting to challenge the crooked platform must take into account the ways in which hashtags are structurally constraining and enabling, as well as socially constructed and situated. While I am not suggesting that it is the work of counterpublics to somehow make an uneven space even, it is important that users become aware of how their actions and inactions can reinforce a crooked space. Ultimately, what I am interested in is the unique ways collectivising hashtags can help bring our attention to the crooked platform or work towards de-stabilising it.

That's Us is a campaign by the NZHRC to combat racism in Aotearoa New Zealand. Since 2016, the campaign has been developed and reused by the NZHRC and features three distinct phases: That's Us, Give Nothing to Racism, and the Voice of Racism. The campaign was initially developed in 2016 with the slogan 'Stand up to racism \#ThatsUs'. In an interview with one of the NZHRC's communications team, they explained that one of the primary goals of the That's Us campaign is distinguishing itself as an anti-racism campaign and not simply a pro-diversity

\footnotetext{
802 Harris-Perry, Sister Citizen, 29.

803 Bucher and Helmond, "The Affordances of Social Media Platforms," 243.

${ }^{804}$ Refer to section 5.2 The Rise and Risks of User Participation for an explanation of first and second acts of social media activism. See also Hu, "The Second Act of Social-Media Activism."
} 
campaign. He explained one of the key problems they have when it comes to tackling racist attitudes, saying:

New Zealanders generally-they think racism is bad, but they don't think it is a problem here in New Zealand. So, part of the challenge is how do we show it is a problem here and show that it has an impact-in a way that the people sharing also feel like they are empowered. Telling people's stories is a way of connecting people's daily lives so that it would spark some sort of idea change. ${ }^{805}$

One of the problems faced by the NZHRC was trying to move the dialogue beyond the simplistic understanding that 'racism is bad.' The NZHRC needed to show privileged bodies that racism can take many different forms, and that more meaningful engagement is required in order to fully appreciate the prevalence and impact of racism in Aotearoa New Zealand society (see figure 19).806 What they decided to do was focus on the affects that racism has on marginalised bodies, and to communicate those affects in such a way that it encouraged privileged bodies to engage without further traumatising or marginalising vulnerable bodies.

The That's Us campaign was designed to show people that racism does exist in Aotearoa New Zealand and that people experience the harmful effects of discrimination in their everyday lives. Creating the hashtag \#ThatsUs was an important component of the campaign. When choosing the slogan, the commission knew that it would need to be a hashtag that allows people experiencing racism to take ownership of it. So, while the purpose of the campaign was to get people to stand up to racism, they chose the collectivising hashtag \#ThatsUs to encourage people to add their own stories. One of the campaign creators explained it this way:

A hashtag is sort of collectivising a story through social media. So, a hashtag felt very natural and normal to us and it felt like a way that it would move beyond us-like-it could be owned collectively rather than just us at the Human Rights Commission... We found that once we started there was like a conversation and other people would use different mechanisms like they would share on Twitter or they would message underneath a post that we posted about the story and they would tell their own story and all of that was to show the impact of racism. 807

In September 2016 \#ThatsUs spread online as more people began sharing their lived experiences of racism. The NZHRC, recognising the success of the hashtag, decided to invest further in the campaign. In 2017, the second phase of the campaign, called Give Nothing to Racism, was introduced. This broad social media-based campaign was paired with a video featuring popular New Zealand actor and director Taika Waititi. This campaign focused on New Zealand's particular problem with micro-aggressions, specifically racist jokes. The satirical style video highlights the tendency of New Zealanders to ignore 'casual' racism, stating:

805 Interview 20 June 2019 with New Zealand Human Rights Commission Digital Campaign Manager. 806 Figure 19 illustrates White defensiveness and the drive for continued dominance through re-centering of Pākehā/European culture. In instances in which issues of racism or colonisation are raised on social media, the conversation is derailed by privileged bodies allegations of 'reverse racism.'

807 Interview 20 June 2019 with New Zealand Human Rights Commission Digital Campaign Manager. 
Racism starts small. Sometimes it lives in everyday actions and comments that we laugh off, nod in agreement to, excuse, and therefore accept. But we don't have to. We can stop casual racism from growing into something more extreme. We can give it no encouragement. No respect. No place. No power. We can give it nothing. 808

Figure 20.

The Give Nothing to Racism campaign evolved into the Voice of Racism campaign in 2019. This third phase of the That's Us campaign is an interactive online experience that allows people to hear "the everyday racism felt by real people in Aotearoa New Zealand." ${ }^{809}$ The Voice of Racism campaign will be explored in detail later in this chapter.

The That's Us campaign as a case study is well suited to an exploration of the concept of the crooked platform because both the subtilties of racism and seemingly invisible nature of the crooked platform are equally difficult to discern and act in a similarly insidious way. When the That's Us campaign was initially launched in 2017, there was strong pushback from the public, particularly on Twitter. Race Relations Commissioner Dame Susan Devoy found that the majority of New Zealand citizens don't see casual racism and felt that regularly stated xenophobic jokes towards Chinese immigrants and the entrenched lower expectations of Māori students did not constitute 'real racism', demonstrating that the very real effects of these encounters for marginalised bodies is largely ignored or dismissed.810 That's Us seeks to use hashtags in order to challenge the assertion that Twitter is a racially unmarked space and draw attention to the White settler colonial systems of dominance that underly such spaces. Throughout this chapter, I explore what the \#ThatsUs hashtag afforded the NZHRC's antiracism campaign and those who participated in it. I examine the creative ways hashtags have been employed by counterpublics to challenge racism in online spaces in terms of the interplay between discursive and digital strategies. My findings detailed below not only reveal how counterpublics make strategic use of discursive, architectural and affective affordances of \#ThatsUs, but also that these hashtags are changing and challenging dominant knowledge and conceptions of self inherent to the crooked platform.

\subsection{Networked Acts}

\section{a) A collection of individual stories speaks to systemic issues}

In this section, I explore how networked acts of storytelling via \#ThatsUs help to curate communities online. Trending hashtags can bring attention to systemic issues by showing people how widespread seemingly personal or isolated experiences are through the creation of online networks. The collectivising hashtag campaign \#ThatsUs used the hashtag to encourage the sharing of stories of real people who have themselves experienced racial prejudice, providing them with an opportunity to explain in their own words what racism sounds like and

808 New Zealand Human Rights Commission, "About the Campaign."

${ }^{809}$ New Zealand Human Rights Commission, "About the Campaign."

810 New Zealand Human Rights Commission, "About the Campaign." 
feels like. The NZHRC's Campaign Manager explained the power of sharing 'real people's stories' through the practice of storytelling stating:

That's Us was a way of collectivising a voice of people who would stand up to racism. The act-people would take to stand up to racism by sharing the stories of the people who were impacted by it [racism] in their daily lives... Incorporating stories that are a pretty powerful way of bringing about behavioral change as a way its own lesson-that digital media has this real power to spread a message and how useful it was to tell real people's stories - and people read them because they are interested in them [as people] and its quite interesting. 811

In an interview, communications staff from the NZHRC explained that Māori and Pasifika communities have limited ways of sharing their stories and that they found the hashtag \#ThatsUs useful in that it allows them to call attention to issues of racism that the mainstream media fails to recognise. \#ThatsUs illustrates the power of storytelling when individuals come together to illustrate larger systemic issues across Aotearoa New Zealand. Rather than selecting the most 'extreme' or violent cases of racism that are picked up by mainstream media, the NZHRC called for people to share everyday experiences or micro-aggressions that often go unchecked.

It is not difficult for observers to imagine these kinds of racist encounters. Some of the stories told using the \#ThatsUs hashtag are not 'out of the ordinary' or even surprising to privileged users. However, they are the kind of stories that invite privileged bodies to put themselves in the shoes of the perpetrator. When privileged bodies are conversely shown the perspective of those victims who were affected by their comments, the emotional harm caused becomes clear. The strength of the \#ThatsUs hashtag is that it is situated within the Aotearoa New Zealand context and draws on everyday stories that New Zealanders can relate to. They share place names and colloquialisms that are recognisable to New Zealanders; people may have experienced or heard similar 'jokes' being told before or even told them themselves. Kingi Snelgar explained the lasting impact of racist jokes he experienced in his childhood:

I was 13 or so when a Police siren screamed past our school and then someone in my class shouted out: 'Watch out Kingi! the cops are coming for you!' At the time I tried to ignore it when other kids said things about my family, joking that we must be criminals or that our cars were stolen. I guess I kind of shrugged and thought it was just part of growing up. I'd ended up at this prestigious school after spending all my earlier years in Māori language schools so that kind of thing wasn't at all what I was used to. Even though my dad's Pākehā, I was brought up speaking te reo, all my friends were Māori so to go into a totally Pākehā environment and to encounter all these assumptions that I came from a criminal family because I was Māori. It was hard to deal with, yeah. Years later what I realise is problematic about what happened to me is that those kids' perceptions are passed down through generations. They don't just come up with them on their own, those boys were copying what they'd heard at home from their parents.

811 Interview 20 June 2019 with New Zealand Human Rights Commission Digital Campaign Manager. 
And what they'd heard was that Māori, like me, are criminals and nothing much else. But it did hurt, yeah and I've never forgotten. ${ }^{812}$

The power of sharing these 'seemingly normal' stories (as opposed to really obvious displays of violence) is that they can bring casual racism to privileged users' attention. These types of discriminatory or racist comments are often familiar to dominant groups; they can imagine laughing in response to the racist remark faced by Snelgar or simply failing to call out racism. ${ }^{813}$ Waititi, in his satirical campaign for the NZHRC, made the tongue-in-cheek comment: "You don't have to be a full on racist, just being a tiny bit racist is enough. A smile, a cheeky giggle, even a nod in agreement, it all adds up." 814 By highlighting the effects of these microaggressions on marginalised communities, collectivising hashtags can bring widespread underlying systems of dominance to light. Donna Hancox explains:

Stories used in this way do not promise widespread understanding and resolution of social issues or inequality simply because a narrative has been created and shared by those directly affected. Rather, they signal that there is more to be done and more to be understood, and these changes need to be established from within these local contexts. 815

A collection of stories provides a starting point for investigations into systemic injustices. If one of the aims of critical feminist research is to recognise and amplify the voices of marginalised groups and to present person-centric investigations of the world, then the intervention of storytelling on social media platforms can allow for more equitable power relations. ${ }^{816}$ Hancox highlights the fact that our ability to gain knowledge and insight into experiences outside our own is greater than ever before, "and with it comes a responsibility to acknowledge the experiences of others and consider how collaboration and participation are enacted." 817 Online storytelling practises are filled with transformative potential, but it is important to understand how digital architectures facilitate the potentialities and limitations of these practises, who stories are shared by and how they promote or fail to promote engagement.

The rise of digital storytelling in the early and mid-2000s in part mirrored the broad shift towards more participatory online culture that privileges user-generated content and ordinary stories of everyday lived experiences. ${ }^{818}$ Historically, storytelling has played a key role in social movements and, in particular, antiracist movements. ${ }^{819}$ Collectivising hashtags associated with the BLM movement include \#MyNYPD, \#IAmTryvornMartin, \#AmINext, and \#ICantBreathe, all

\footnotetext{
812 New Zealand Human Rights Commission, "Whenever A Siren Went Off I Remember Schoolmates Saying That The Cops Were Coming For Me Because I'm Māori: Kingi Snelgar,” 19 March, 2021, https://www.thatsus.co.nz/kingisnelgar

813 TSN research on the 'Casual Racism Mitigation Campaign' found a 10\% improvement in people understanding the detriment of "small acts of racism and casual racism (like laughing)." This information was provided to me by the Human Rights Commission Communications team.

814 New Zealand Human Rights Commission, "That's Us."

815 Hancox, "From Subject to Collaborator," 51.

816 Hancox, "From Subject to Collaborator," 59.

817 Hancox, "From Subject to Collaborator," 59.

818 Hancox, "From Subject to Collaborator," 53.

819 Jill Dimond et al., "Hollaback!: The Role of Collective Storytelling Online in a Social Movement Organization," Proceedings of the 2013 Conference on Computer Supported Cooperatice Work, (2013): 485, doi:

$10.1145 / 2441776.2441831$.
} 
of which relate to incidents of police brutality. Individual stories of racially motivated violence are recorded on street corners and shared on social media platforms to express the differences in lived experience for Black people in America. Brock explains that the visibility of Blackness can be partially attributed to "the conflation of Black folk in online spaces that are not exclusively our own: we are finally present online in ways that the mainstream is unable to disavow." 820 Collectivising hashtags enable non-dominant groups to share their experiences that are often marginalised by traditional media outlets, witnessing and affirming similar experiences with others within their community. Hashtags afford users storytelling processes by bringing individual stories together. In an interview with a NZHRC campaign manager, they explained:

It [a hashtag] is a way of keeping the message intact so that it doesn't just break up. What can happen sometimes is that messages can break up as they get further and further away from the central channel—so it is a way of tracking the hashtag flow. 821

Hashtags enable users to collate and archive their stories on the same topic. Without the hashtag function, individual stories could easily dissipate, and conversations be quickly extinguished.

The folksonomic user driven aspect discussed in Chapter Four also helps facilitate storytelling processes. In an interview with a collectivising hashtag user, they explained that storytelling can be empowering and helps them to publicly air their grievances. It allows for more transparency, where such conversations are usually held behind closed doors.

I guess where it kind of enables that embodiment of self more acutely through the ability to speak to power when there are really limited pathways to do that directly... I think I use Twitter as a strategy because it is like a public opportunity. It is an opportunity to have public alignment on something that would otherwise happen behind closed doors and I think I have been in enough situations where there is no accountability, no witnesses-so I think I strategically go to Twitter when I need to iron something out, as a way to create an audience to bear witness to an action. ${ }^{822}$

Collectivising hashtags are often tied to social justice movements, calling attention to issues that are personally felt and collectively shared, such as \#WeAreThe99\% during the Occupy movement, \#MeToo against sexual harassment and sexual abuse, and \#ICantBreathe against instances of police brutality and racially motivated violence. These are hashtags that were originally shared by people as testimonials; personal stories of injustice that are brought to light and shared through social media. One interviewee explains how a trending tag becomes more than its individual parts, saying, "Simply by the act of many people using it, it builds into something collective-this collective consciousness that I love." 823 As trending tags catch on, more and more people begin to participate in hashtag activism. Victims of sexual violence who gave voice to their lived experiences found that it was emotionally taxing both sharing and

${ }^{820}$ André L. Brock, Distributed Blackness: African American Cybercultures, New York: New York University Press, $2019,1$.

821 Interview 20 June 2019 with New Zealand Human Rights Commission Digital Campaign Manager.

822 Interview with Alice Canton conducted 11 June 2020 via Zoom conference call.

823 Interview conducted 11 June 2020 via Zoom conference call. 
listening to stories of abuse harassment, misogyny and sexism. ${ }^{824}$ In their inquiry into hashtag activism, Kaitlynn Mendes, Jessica Ringrose, and Jessalynn Keller, looked into the ways in which \#MeToo and \#BeenRapedNeverReported hashtags are used by girls and women to share personal stories of sexual violence and why they did not report them to authorities. ${ }^{825}$ They found that participating in a hashtag was both triggering and affirming to participants. Online storytelling and hashtagging was part of the complex work of doing digital feminist activism. One woman explained:

It was very emotional and it was very upsetting to me, this whole thing, being part of that hashtag, reading other women's little tweets, 140-character tweets. One resonated and it was really a tough couple of weeks. Even though it was positive, it was very, very difficult for me. There were some nights where I didn't sleep. 826

Mendes et al found that hashtags like \#MeToo and \#BeenRapedNeverReported made survivors feel heard by building meaningful and worthwhile networks of solidarity with fellow survivors.827 Importantly, this solidarity often transformed feminist consciousness. One participant in their study explained that \#MeToo allowed her to understand that her own history with sexual violence was part of a broader structural social problem, rather than an individual experience that rose from an encounter with 'one bad man.' 828

The transformative potential unlocked by the widespread use of a hashtag is important both for the individuals sharing their lived experiences and for those who witness the trending hashtag. The visibility and overwhelming response to collectivising hashtags like \#MeToo and \#WhyIStayed (amongst others) cannot be easily dispensed with. The cross-cultural resonance of these feminist hashtags demonstrates the prevalence of the issues they speaking to that remain unaddressed in society. Dimond et al. conducted research on the role of collective storytelling on the online Hollaback! website (an online storytelling collective that allows victims to share their own stories of street harassment). The Hollaback! collective provides an online forum for marginalised groups including women, people of colour and LGBTQIA+ to share their personal stories of harassment in a safe and supportive space.829 Dimond et al. found that by reading other people's stories of harassment on the site, participants felt that their own experience was validated and that they were a part of a larger epidemic that warrants change. ${ }^{830}$ The experience of online storytelling caused a shift to collective thinking; after sharing their own story and reading the stories of others, participants shifted from believing the experience was limited to 'just them' to viewing sexual harassment as part of a broader phenomenon, one that stems from inequality and targets the most vulnerable communities.831 Participants experienced a frame transformation in the way that they connected their individual experience under the umbrella of street harassment. 832 The

\footnotetext{
${ }^{824}$ Kaitlynn Mendes, Jessica Ringrose, and Jessalynn Keller, “\#MeToo and the Promise and Pitfalls of Challenging Rape Culture through Digital Feminist Activism," The European Journal of Women's Studies 25, no. 2 (2018): 239, doi:10.1177/1350506818765318.

825 Mendes, Ringrose, and Keller, “Challenging Rape Culture through Digital Feminist Activism," 25.

826 Mendes, Ringrose, and Keller, "Challenging Rape Culture through Digital Feminist Activism," 238.

827 Mendes, Ringrose, and Keller, "Challenging Rape Culture through Digital Feminist Activism," 238.

828 Mendes, Ringrose, and Keller, "Challenging Rape Culture through Digital Feminist Activism," 238.

829 Dimond et al., "Hollaback!" 477.

830 Dimond et al., "Hollaback!" 483.

831 Dimond et al., "Hollaback!" 483.

832 Dimond et al., "Hollaback!" 483.
} 
problem is at once personal and collective as marginalised bodies find themselves in a community of others who understand and affirm their lived experiences. For participants, posting these stories can be an act of reclaiming power and doing activism. ${ }^{833}$ Sharing these previously concealed stories helps to reframe sexual harassment and violence as a systemic issue which can have a significant impact on affected bodies willingness to respond to sex crimes. ${ }^{834}$ Equally as important, it creates an opening for privileged bodies to recognise how prevalent this behaviour is and their role in perpetuating systems of violence.

For practitioners of storytelling, artistry and social activism, it is possible to see an emerging intersection between the affordances of digital technologies and the recognition of the stories of marginalised people. 835 Concealed stories are stories told by non-dominant groups that counter 'stock stories' and uncover different ways of experiencing the world. ${ }^{836}$ The inclusivity of collectivising hashtags is both its strength and one of its greatest shortcomings. As I have argued in this chapter, the benefit of collectivism is the visibility that it affords to minority bodies who may not have previously had the ability to share their stories. Collectivising hashtags create a space in which lived experiences and their affects can be shared, creating communal bonds that affirm and speak to broader systemic issues.

Hashtags can serve primarily as connectors. Kuo outlines:

Because Twitter's algorithms are designed to value group amplification, the platform works well as a tool for racialised and gendered enclaves and satellites seeking to mobilise collectively as a counterpublic. As stories, experiences, and ideas resonate with actors, they play a dual role in circulating discourse on and beyond Twitter across multiple publics. ${ }^{837}$

Collectivising hashtags create a space in which lived experiences and their affects can be shared, creating communal bonds that affirm and speak to broader systemic issues. Hashtags like \#ThatsUs link together individual stories to move discourse "from the periphery into the center." 838 The significant impact of this is not simply the message content but rather the network that they form for marginalised users that moves discourse beyond insular discussion. The collective power of a hashtag like \#ThatsUs becomes more than the sum of its parts by propagating between different users across specific networks and offering a step towards systemic change by circulating discourse that supports the networked actions of counterpublics. It is important to recognise the value of these collectivising hashtags for counterpublic narratives and the value of online spaces for affected bodies. Privileged bodies should be encouraged to recognise the sanctity of spaces that are set apart for marginalised bodies, and the dangers of appropriating these spaces.

\footnotetext{
833 Dimond et al.,"Hollaback!” 486.

834 Mendes, Ringrose, and Keller, “Challenging Rape Culture through Digital Feminist Activism,” 238.

835 Hancox, "From Subject to Collaborator,"49.

836 Dimond et al., "Hollaback!" 486.

837 Kuo "Racial Justice Activist Hashtags," 511

${ }^{838}$ Sarah J. Jackson and Sonia Banaszczyk "Digital Standpoints: Debating gendered Violence and Racial Exclusions in the Feminist Counterpublic," The Journal of Communication Inquiry 40, no.4 (2016): 400, doi:

$10.1177 / 0196859916667731$.
} 


\section{b) Curated Communities}

Networked acts of community building, via collectivising hashtag practices, can help to centre intersectional frameworks and experiences. Hashtags mark people and actions as part of "moment and movement." 839 Kuo argues that racial justice activist hashtags can function as collective action framing tools for educational purposes. ${ }^{840 ~ " C o l l e c t i v e ~ a c t i o n ~ f r a m i n g " ~ i s ~ a ~}$ process through which hashtags frame and "locate, perceive, identify and label" within online spaces. ${ }^{841}$ Within this model, racial justice activist hashtags afford an understanding of a problematic social condition and mobilise through the circulation of hashtags. ${ }^{842}$ The \#ThatsUs anti-racism campaign by the NZHRC allowed people to encounter racism from the victims' perspective, showing privileged users what racism feels like. It was also designed with participants in mind, and one of the primary goals of the campaign was to provide a space for marginalised people to share personal stories and create supportive and enriching communities. Through my interviews, I found that although hashtag users did not feel that Twitter was a 'safe' space, they did feel that it was one over which they had some control. Users had agency in their decisions in terms of which hashtags and people they chose to follow. Several interviewees used the word 'curated' to describe how they carefully chose the people they engage with, organised the hashtags they follow and presented themselves in online spaces. One interviewee explained that while Twitter is a hyper-public space, she is able to set her own limits and boundaries that allow her to feel more comfortable within the space.

I don't actually know if I do find Twitter to be a safe space because it is so hyper public - so I-it feels (pause) I would almost challenge my own view on whether I find it to be a safe space. It is a space which I can curate because part of me feels that I can set the boundaries and its limits. ${ }^{843}$

A second interviewee explained how they curated their engagement strategically choosing who they follow based around shared interests, saying:

So, I really love using Twitter. I love how I can go into Twitter and I choose what I engage with. I choose my engagement basically through the people I follow and the people that I follow share things-there are shared interests there. So, I love that about Twitter in the sense that I feel that I have choice. 844

In my interviews with hashtag users, I found that they described their online community as one that reflects their offline community. Hashtag users make use of 'following' and 'blocking' functionalities to curate their Twitter feed. One of my interviewees explained that when she encounters instances of racism, homophobia or other reductive social values she does not engage with them and blocks them from her feed. ${ }^{845}$ Another interviewee said:

\footnotetext{
839 Kuo “Racial Justice Activist Hashtags," 496.

840 Kuo "Racial Justice Activist Hashtags," 496.

841 Kuo "Racial Justice Activist Hashtags," 497.

842 Kuo "Racial Justice Activist Hashtags," 497.

843 Interview with Alice Canton conducted 11 June 2020 via Zoom conference call.

844 Interview with Hala Nasr conducted 16 October 2020 via Zoom conference call.

845 Interview with Hala Nasr conducted 16 October 2020 via Zoom conference call.
} 
I would say that largely the people that I follow have a political and value alignment and actually it enables me to put words to thoughts that I have that might not be fully formed or might be formed but I don't have the words to articulate it so that is really helpful for me. Occasionally it gives me a chance to get insight into how people think differently to me but I think that sometimes that becomes really horrific and pretty triggering. So as much as I would like to think that I use it as a space to diversify my mind, if anything, it is like a place of safety where I can feel affirmed and held by a similar community to what I literally operate in, in my physical environment. ${ }^{846}$

For other users, Twitter allows them to encounter and surround themselves with a support network of people who share their values, but who they might not have the opportunity to meet offline. This was especially true for marginalised bodies who do not always have access to likeminded people or people with similar lived experiences in their local communities, such as trans-gender individuals or people with a disability who could be the only person in their locality with particular lived experiences. Twitter allows them to make connections with their preferred community.

Other hashtag users explained that the people that they chose to interact with on Twitter can provide enrichment. Sometimes the serendipitous nature of hashtags allows users to encounter the kind of people that share their values but whose different lived experiences challenge and progress their beliefs. One interviewee discussed that she preferred to follow people who share her 'Leftist' political views and values. ${ }^{847}$ She was happy to learn from people who had differing opinions on topics such as religion or sexuality. ${ }^{848}$ She also valued hearing from other indigenous people who (while sharing histories of colonisation) have very particular struggles depending on where they live. ${ }^{849}$ The many unique stories strengthened her belief that marginalised groups are not homogenous and the alterity that they provide acts to broaden her understanding of shared concerns and 'diversify her mind.' 850

An interviewee explained:

For me Twitter, like, I have a core group of people that I regularly interact with online. Essentially for these people, it is essentially for me somewhere that I learn more about different kinds of things that I am interested in, be it environmental issues, be it solidarity with different indigenous people around the world. It is also a way for me to connect with like-minded people that aren't in my circle of people that I know in real life. So, I find that helps in terms of expanding my thinking, so that is kind of what I use it for. 851

Online networks represent strategic coalitions and solidarity within or across various identities. ${ }^{852}$ Collectivising hashtags are often picked up by marginalised users to address

\footnotetext{
846 Interview with Alice Canton conducted 11 June 2020 via Zoom conference call.

847 Interview conducted 16 October 2020 via Zoom conference call

848 Interview conducted 16 October 2020 via Zoom conference call

849 Interview conducted 16 October 2020 via Zoom conference call

850 Interview conducted 16 October 2020 via Zoom conference call

851 Interview conducted 16 October 2020 via Zoom conference call.

852 Kuo, "Racial Justice Activist Hashtags," 498.
} 
shared experiences across racial, ethnic, religious, class and other social identity categories. ${ }^{853}$ What is often ignored is that marginalised bodies, specifically women of colour, often lead creative and political work on popular hashtags by leading racial and ethnic in-group conversations' about feminist issues. ${ }^{854}$ Jackson, Bailey and Foucault Welles found that these in-group hashtags provide "critical challenges to feminist and ethnic counterpublics by centering intersectional frameworks and experiences." 855 Hashtags are used very strategically by women of colour to address the issue of intersectionality within racial justice movements.

Intersectional feminists highlight the importance of networked acts of community building via collectivising hashtag practices. These intersectional hashtags help draw attention to the ways in which social media platforms are crooked. In the previous chapter, I established how the idea of the crooked platform can be seen as a failure to recognise certain bodies in online spaces. Increased visibility produced through trending algorithms has the potential to exacerbate existing inequalities. Collectivising hashtag networks function to create certain ingroups and out-groups that raise critical challenges to feminist and ethnic counterpublics by de-centring intersectional frameworks and experiences.856 Intersectional feminists are particularly cautious of hashtag activism and the trending powers and privileges of hashtags like \#MeToo and \#YesAllWomen.

Jackson and Banaszczyk use "counterpublic sphere theory" to explore how user generated tools like Twitter's hashtag function can equip feminist cultural workers with new ways to challenge mainstream narratives and elevate conversations within feminist spheres. ${ }^{857}$ Jackson and Banaszczyk look specifically at the \#YesAllWhiteWomen hashtag created in response to the \#YesAllWomen hashtag that trended following the Isla Vista massacre, where shooter Elliot Rodgers killed six people and injured fourteen others as revenge for perceived sexual rejection by women. 858 The hashtag \#YesAllWhiteWomen addressed the lack of intersectional women's experiences within conversations on gendered violence. ${ }^{859}$ It also addressed how the original hashtag \#YesAllWomen was appropriated in the service of a kind of "mainstream" or "White" feminism blind to intersectional politics of the shooting and Rodgers' racist attitudes towards Black, Hispanic, and Chinese ethnic groups outlined in his White supremacist manifesto. ${ }^{860}$ Jackson and Banaszczyk critique the role of shared and diverging experience within feminist counterpublics and the effects of "multiple marginalisation" of Black women. 861 What is particularly interesting about this case is not just the use of hashtags to propel counterpublic critique, but the strategic use of digital affordances. The tweets containing \#YesAllWhiteWomen also included \#YesAllWomen which serves two functions: firstly, it reasserts the marginalised users' voices and experiences as a part of the dominant feminist counterpublic and, secondly, it makes strategic use of the trending algorithm and visibility it provides by attaching itself to and piggy-backing the popularity of the trending \#YesAllWomen stream. Jackson and Banaszczyk argue:

\footnotetext{
853 Jackson, Bailey, and Foucualt Welles, \#Hashtag Activism, 31.

854 Jackson, Bailey, and Foucualt Welles, \#Hashtag Activism, 31.

855 Jackson, Bailey, and Foucualt Welles, \#Hashtag Activism, 31.

856 Jackson, Bailey, and Foucualt Welles, \#Hashtag Activism, 31.

857 Jackson and Banaszczyk, "Digital Standpoints," 391.

858 Jackson and Banaszczyk, "Digital Standpoints,", 392.

859 Jackson and Banaszczyk, "Digital Standpoints," 392.

860 Jackson, Bailey, and Foucualt Welles, \#Hashtag Activism, 31-32.

861 Jackson and Banaszczyk, "Digital Standpoints," 394.
} 
It is clear that even Twitter works as a space where historically marginalised standpoints of women can be elevated through virality and collective advocacy, the technological architecture of the platform's trending, retweeting, and mentioning functions, along with the ways mainstream and elite individuals and outlets legitimate the 'popular.' 862

The central issue behind \#YesAllWomen was not just its attempt to universalise individual women's experiences, but in the way that individualism is drowned out by the "obscuring of issues specific to groups that lay claim to the category women." 863 One of the primary purposes of the hashtag \#YesAllWhiteWomen was to create a separate networked sphere that centres the intersectional experience. In this way, the hashtag affords a purposefully curated intersectional community. Subsequent curated community hashtags include \#FastTailedGirls, \#YouOKSis, and \#SayHerName, all of which were used to illustrate the power of Black feminism politics online that challenge dominant narratives. ${ }^{864}$ In choosing the hashtags they follow and use, people can curate their online communities to produce and importantly progress feminist frames by engaging in community debates about race and privlidge.

Feminist counterpublics must negotiate the framing and resonance of mainstream feminist movements and question who is included and excluded along "intersectional axis of oppression." 865 Successful network structures are composed of large networks with weak bridging ties that link multiple spheres together. Kuo explains the networked capacity of Twitter, stating:

Twitter allows for discursive interaction with similarly identified people. With all of its algorithms constantly tracking and weighing trend, Twitter provides a digital place for people to congregate around interests and issues; it can be a place for racial flocking resulting in racial enclaves. ${ }^{866}$

Kuo found that culturally coded hashtags emerged when pursuing in-community conversations. ${ }^{867}$ In this way, identity salience can be reinforced through organisational and individual strategic use of collectivising hashtags. Jackson, Bailey, and Foucault Welles suggest that Black women use Twitter as a 'town forum' to discuss intracommunity topics and form networked acts of self to challenge structural biases of the crooked room. ${ }^{868}$ Sharma emphasises the importance of racialised hashtags or what she refers to as 'Blacktags' in terms of their transmission of meaning and affects in creating "digital race assemblages." 869 Sharma argues that Blacktags reveal the contagious effects of antiracist humour and networked

862 It is important to note that while engaging with more popular mainstream hashtags (by piggy-backing them) resulted in more visibility it also subjected marginalised users to attacks from members of the wider gender ingroup. See Jackson and Banaszczyk, "Digital Standpoints,” 403-404.

863 Jackson and Banaszczyk, "Digital Standpoints," 404.

864 Jackson, Bailey, and Foucualt Welles, \#Hashtag Activism, 32-33.

865 Jackson and Banaszczyk, "Digital Standpoints," 393.

866 Kuo, "Racial Justice Activist Hashtags," 499.

867 Kuo, "Racial Justice Activist Hashtags," 499.

868 According to a 2018 study by the Pew Research Centre, Black Americans use Twitter more than any other racial demographic in the United States. Black women are especially instrumental to the success of Twitter and online activism. See Pew Research Centre, "Demographics of Social Media Users and adoption in the United States," cited in Jackson, Bailey, and Foucualt Welles, \#Hashtag Activism, 32-33.

869 Sharma, "Black Twitter?” 48. 
relations in producing emergent racial assemblages online. ${ }^{870}$ For example, the hashtag \#FastTailedGirls was created by Mikki Kendall and Jamie Nesbitt Golden following the American Music Awards in 2013 in which a performance by singer R. Kelly displayed predatory sexual behaviour towards Black women. ${ }^{871}$ The term 'fast tailed' in Black vernacular is used to describe young Black women who are supposedly overly eager and sexually curious or promiscuous.872 The hashtag \#FastTailedGirls has a fascinating conceptual parallel to Harris-Perry's archetype of the hypersexual 'Jezebel.'873 Harris-Perry presents three stereotyped identities of Black women, explaining "Jezebel, Mammy, and Sapphire are the angles in the crooked room where Black Women live. ${ }^{874}$ They do not reflect the complexities of Black women's lived experience; instead, "they limit African American women to prescribed roles that serve the interest of Others." 875 Nesbitt Golden explained that the myth of Black women as 'fast tailed girls' misplaces blame and diverts conversations about rape and sexual assault at the expense of the victims. She further explains that the myth of 'fast-tailed' Black women "spanned not only generations, but cultures", which prompted her to use the tag on Twitter following R. Kelly's performance in hopes of dispelling the myth. ${ }^{876}$ She remarked her surprise at the online reaction to the tag, saying:

We watched as this conversation evolved from a few uncomfortable anecdotes to a place of absolution and healing. We also watched as people attempted to derail and shut down the conversation. It was shocking even to us, that so many folks were so unwilling to hear stories or examine their own complicity in rape culture. 877

The hashtag is a subversive way to address the damaging spread of a stereotypical and limiting archetype of Jezebel as an identity forced upon Black women. For Nesbitt Golden, the blowback she received (even from within Black communities) illustrated the necessity of the conversation. ${ }^{878}$ Jackson, Bailey, and Foucault Welles found that the \#FastTailedGirls hashtag is an "enactment of a politics of intersectionality and insists on the political legitimacy of Black women's experiences and critiques."879 Their networked examination of intersectional hashtags revealed that the hashtags \#FastTailedGirls, \#YesAllWhiteWomen, and \#YouOKsis were routinely tweeted together as a co-occurrence. Kuo found that hashtags help feminists of counterpublics of colour be seen:

By circulating by retweeting and/or contributing a new tweet while also repeating usage of the hashtag help make it trend, thus also pushing discussions about racial injustice into the spotlight, where it can be noticed by individuals outside of the counterpublic who are checking their social media feeds. ${ }^{880}$

\footnotetext{
870 Sharma, "Black Twitter?" 48.

871 Kendall, "Hoodfeminism."

872 Kendall, "Hoodfeminism."

${ }^{873}$ Harris-Perry, Sister Citizen Shame, 33.

874 Harris-Perry, Sister Citizen Shame, 33.

875 Harris-Perry, Sister Citizen Shame, 96.

876 Jackson, Bailey, and Foucualt Welles, \#Hashtag Activism, 36.

877 Jackson, Bailey, and Foucualt Welles, \#Hashtag Activism, 37.

878 Jackson, Bailey, and Foucualt Welles, \#Hashtag Activism, 37

879 Jackson, Bailey, and Foucualt Welles, \#Hashtag Activism, 40.

880 Kuo, “Racial Justice Activist Hashtags," 502.
} 
This strategic use of hashtags suggests that members of these networks "understand their hashtag use and creation as activism as they self-reflexively position their hashtag in relation to other on and offline activist causes." 881 It illustrates an understanding of the networked power or affordances of hashtags for community building to challenge the monolithic narratives. Brock argues that although Whiteness is assumed to be the default internet identity, Black people are remaking the internet a "Black space" by becoming increasingly visible through sociality and distributed practices. ${ }^{882}$ I submit, these intersectional hashtags also work against privileged desires to ignore race and ethnicity in virtual worlds. The phenomena of Black Twitter and Blacktags are not simply social representations or racialised categories; they are networked acts that enable curated communities to enact their 'real' and 'embodied' racial identities and cultures. Counterpublics have adapted the architecture of a hashtag to establish their own positionality, challenging the normative view of Twitter as a White space, and reasserting a sense of self.

Community building is an important aspect of hashtag usage that is not always related to or dependent on the trending feature of hashtags. For example, the hashtag \#GirlsLikeUs is used by trans-feminist advocacy groups for closed community building. Women use \#GirlsLikeUs in unconventional ways, such as including it in their profile descriptions or even setting their profile locations to \#GirlsLikeUs (which attaches the hashtag to every tweet they write and returns their tweets in searches of the hashtag, regardless of whether or not the hashtag appears in the content of their tweets). The purpose of this use is to include the hashtag as a personal and community identifier so that every tweet acts as a performance of self. Jackson, Bailey, and Foucault Welles noticed that "\#GirlsLikeUs is predominantly a bounded community, "centred on trans women with progressive politics and sustained by a consistent, if not especially large, stream of daily trans-positive tweets." 883 The close rapport between members of the network does important discursive community building and provides important emotional and psychological support for a specific group. ${ }^{884}$ The purpose of hashtags, in this instance, is not to create broad visibility but instead to create small publics that affirm one another in positive and supportive ways (a subversive and countercultural use of hashtags).

As a platform, Twitter is conceived of as a "risky and chaotic space" but an understanding of the filtering functions helps reassert control and give the feeling of an environment that is cocreated. ${ }^{885}$ As I have argued throughout this section, an understanding of digital affordances helps users create their own online eco-system that is reflective of their offline positionality. In some cases, feminists have chosen to reframe hegemonic messages, demonstrating their injustice and recasting identity and interests, setting themselves apart from the dominant public sphere on Twitter. ${ }^{886}$ It is through in-group interactions that people seek a sense of participation that Stephen Coleman has termed a "feeling of being counted," and goes on to say that it is "the affective character of an experience that renders it fulfilling for individuals." 887 The circulation of embodied energies is generative of an atmosphere that creates a shared

\footnotetext{
881 Jackson, Bailey, and Foucualt Welles, \#Hashtag Activism, 40.

882 Brock, Distributed Blackness, 5.

883 Jackson, Bailey, and Foucualt Welles, \#Hashtag Activism, 75-76.

884 Jackson, Bailey, and Foucualt Welles, \#Hashtag Activism, 78.

885 Interview with Alice Canton conducted 11 June 2020.

886 Kuo, "Racial Justice Activist Hashtags," 498.

887 Coleman, How Voters Feel, 126.
} 
sense of belonging. ${ }^{888}$ So, while online engagement on social media does not necessarily result in the formation of community, it does affect feelings of community and solidarity. ${ }^{889}$ In the case of \#ThatsUs, it affirms the values of individual stories and legitimises their experiences by appealing to the collective in-group identity while seeking to directly interrogate racist narratives outside of the counterpublic. In this way collectivising hashtags move from "from periphery to centre," calling into question dominant narratives and highlighting Western appropriation and marginalisation of minority voices. 890 Other times, racial activists use networking to create separate spheres that centre and celebrate those who are often made invisible in mainstream spaces. \#YesAllWhiteWomen, \#FastTailedGirls, \#NotYourNarrative, \#YouOKSis, \#SayHerName, and \#GirlsLikeUs are some of the many examples of collectivising hashtags that centre intersectional experiences and create in-group networks to support and highlight issues specific to groups who often fall to the periphery, obscured by the collectivising categories of 'us' 'your' 'her' and 'women.'

The examples above demonstrate how hashtags can be self-referential performances of self; we use them to act out, construct and explore different aspects of our identities. Papachrissi finds that,

self-reflexivity, irony, and play are central themes in performing the sel(ves) in realities that are relational...Play is the result of increased reflexivity, awareness of self and its surroundings. ${ }^{891}$

Networked acts and curated communities enable marginalised users to cultivate their identity and reframe discourses, retaining power by privileging their own discourse and decentring Whiteness. By cleverly making subversive use of both visibility and invisibility, "members of a racialised digital counter-public who have been perceived as 'invisible' within the dominant public utilise hashtags to make their presence and message more visible to publics dominated by Whiteness." 892 By challenging the difference-blindness of online spaces and highlighting precarity in this way, privileged users are forced to encounter their own positionality in online spaces, offering them the chance to become aware of the affecting nature of online spaces and their own vulnerability. As affected and affecting bodies, we are invited to embrace the transformative potential of vulnerability. The concept of affect establishes a conceptual connection between bodies by drawing attention to the fact that we all have the capacity to become vulnerable, and that we all participate in the creation of power structures that influence how we interact with each other. Networked acts of community building, via collectivising hashtag practices, have enabled marginalised users to call attention to the crooked platform and re-assert their own identity outside of dominant hegemonic groups, while simultaneously offering users the opportunity of making and unmaking their conceptions of self and Other by becoming vulnerable.

\footnotetext{
888 Papailias, "Witnessing in the Age of the Database," 444.

889 Papacharissi, Affective Publics, 25.

${ }^{890}$ Kuo, "Racial Justice Activist Hashtags," 505.

891 Papacharissi, Affective Publics, 108.

892 Kuo, "Racial Justice Activist Hashtags," 500.
} 


\subsection{Performances of Self}

a) Comedy, Tragedy and Performative Acts of Subversion

"I basically only ever use hashtags ironically until I am using them strategically." 893

The strategic use of collectivising hashtags demonstrates an increasing awareness and understanding of technological affordances. The logistical use of networks and performative acts suggest that "digital activism has entered a second act" in which users take increasingly embodied and relational approaches to social media. ${ }^{894}$ Counterpublics use the architecture of Twitter and the functions of a hashtag to share in-group knowledge of inequality and racism. Through the strategic use of hashtags and by making everyday lived experiences of racism accessible to both in-group and out-group users through affective appeals (such as the use of humour), these counterpublics bring attention to the crooked platform. ${ }^{895}$ \#ThatsUs combines the technical affordances of collectivising hashtags with narrative strengths of comedy and tragedy. Humour and irony are key elements in the NZHRC's Give Nothing To Racism: That's Us campaign. As part of the second phase of their anti-racism campaign, the NZHRC launched an online video featuring Waititi's unique brand of sarcastic and dry comedy. The satirical video in black and white is stylised to sound like a charity campaign in which they seek donations to "give to racism" as a cause. 896 The dialogue of the video is as follows:

As New Zealander of the year I am calling on every one of my fellow kiwis to help support a very important cause.

Racism. Needs your help to survive.

You may not be in a position to give much to racism but whatever you feel comfortable giving will make a huge difference.

You don't have to be a full on racist, just being a tiny bit racist is enough. A smile, a cheeky giggle, even a simple nod in agreement it all adds up and it gives others the message that it's okay.

[Narrator] Frequently asked questions about racism: But I'm not a real racist can I still help?

Of course, if you don't come from a racist background that's okay, being a bit racist is super easy.

[Narrator] How do I spread the word?

You don't actually have to talk people into it, just be a bit racist and they will feel the social pressure to follow along.

[Narrator] My mum says being a bit racist is bad?

Oh - shut up mum.

[Narrator] What's in it for me?

Ah nothing. There is no benefit what so ever to being racist - but ask yourself what if everyone stopped giving to racism? What kind of future would that be for our children? [Narrator] If I only give a little bit will that even make a difference?

\footnotetext{
893 Interview with Alice Canton conducted 11 June 2020 via Zoom conference call.

${ }^{894} \mathrm{Hu}$, "The Second Act of Social- Media Activism."

895 Jackson, Bailey, and Foucault Welles, "Hijacking \#myNYPD," 942.

896 New Zealand Human Rights Commission, "That's Us."
} 
Not to you, no. But to the people receiving the racism they will be getting hundreds of small bits everyday so it will add up, it will be noticed.

[Narrator] How do I show my support?

You might not want to wear a t-shirt that says how much of a racist you are. No thanks, I'm racist on the inside. But you can laugh at racist comments, it does the same thing. Remember the only thing that can keep racism alive and help it grow is feeding it, nurturing it and that is where you come in.

Will you help it flourish?

What will you give to racism? 897

The video was viewed more than 3 million times on the NZHRC's and Waititi's social media platforms, including Facebook and Twitter, and is tagged with the hashtags \#GiveNothingToRacism and \#ThatsUs. ${ }^{898}$ The video was well received by New Zealand audiences because of Waititi's ability to broach such a serious and discomforting topic such as racism in a humorous way. In an interview with the Campaign Manager at NZHRC, they found that the style of humour was key to its success stating "Kiwis want to be in on the joke and 'get it' which is why the Taika video worked well." 899 The humour and sarcasm allows the viewer to insert the serious nature of the topic themselves and fill in their own problematic racist discourse. One of the potential problems with the sheer amount of information we encounter on platforms such as Twitter is that it can be overwhelming and difficult to deal with. Tragic events unfold all across the world in real time which has the adverse effect of hardening us to humanitarian and social justice plights. Humour helps to break this indifference, and hashtags that are both funny and poignant grab our attention. Their humour speaks to a deeper truth that resonates in a way that users can relate to and engage with. The sarcasm of hashtags used in the second phase of the \#ThatsUs campaign speak to the reality of racism in Aotearoa New Zealand that is both comical and tragic. Sharma, in his exploration of networked propagation of Blacktags, found that they propagate an ambivalent social humour in which "lurks the spectre of tragic reality", recentring the experience of Black lives. ${ }^{900}$ Similarly, the Give Nothing To Racism campaign uses dark humour to provoke discomfort and serious thought about the reality of racism for those who experience it. The humour of the video palpably shifts when Waititi states sternly, "There is no benefit what so ever to being racist... But to the people receiving the racism they will be getting hundreds of small bits everyday so it will add up, it will be noticed." 901 In this way humour and discomfort are used to draw the viewer's attention to the precarity forced upon marginalised bodies.

The discursive strategies of satire and outrage have long been used by marginalised communities to critique racist structures. Jackson and Foucault Welles, in their critical examination of \#MyNYPD, found that two primary discursive strategies, satire and outrage, were used in order to use "comedy as a cure for brutality." 902 The \#MyNYPD hashtag was

\footnotetext{
897 New Zealand Human Rights Commission, "That's Us."

898 These statistics were provided to me by the Human Rights Commission communications team.

899 Interview 20 June 2019 with New Zealand Human Rights Commission Digital Campaign Manager.

900 Sharma defines "Blacktags" as racialised hashtags that use idiosyncrasies familiar only to in-group Black

American communities creating networks associated with Black Twitter. Blacktags are distinctive because they curate and virally propagate racially charged messages expressing social critique through a particular acerbic style of humour which has been associated with elements of Black-American culture. See Sharma, "Black Twitter?" 63. 901 Human Rights Commission, "That's Us."

902 Jackson, Bailey, and Foucault Welles, “Hijacking \#myNYPD,” 942.
} 
devised by the New York Police department's ("NYPD") public relations. The original purpose of the hashtag was for users to share positive stories and images of their encounters with the NYPD. ${ }^{903}$ However, it was swiftly hijacked by activists to tweet about seemingly endless stream of stories about police brutality. ${ }^{904}$ Jackson and Foucault Welles noted:

In tweets dripping with irony and sarcasm, these users constructed NYPD not only as violent, dangerous force terrorising New York's less privileged citizens, but also as an absurdity deserving of public humiliation. ${ }^{905}$

\section{Figures 21 and 22.}

Individuals sharing 'comedic truths' resonates with in-group marginalised bodies and the mass outrage that encouraged others to share their experiences of systemic injustice through trending Twitter networks. Jackson and Foucault Welles found that "\#MyNYPD trended without the help of mainstream, pro-establishment narratives, making the \#MyNYPD network an inversion of the typical power balance in mainstream counterpublics."906 They explain:

[T] he collective hijacking and trending of \#MyNYPD reveals an intentional and nearly spontaneous strategic effort; an effort that exemplifies how counterpublics strategies meant to infiltrate mainstream narratives have adapted to the technological architecture of Twitter. These efforts can be successful, in large part because Twitter's architecture allows conceptually related but otherwise disconnected messages to be stitched together in a networked narrative that become newsworthy, even by mainstream standards. ${ }^{907}$

Hashtag hijacking is evidence of a vernacular understanding of algorithmic logics by counterpublics who create subversive online networks and leverage their power for virality and visibility. There is a complex interplay here between the relational power of humour, legitimised by the lived experiences of brutality, and a networked response that sparked outrage. Jackson and Foucault Welles found that what is significant about counterpublics, beyond the role they play in legitimising and sustaining marginalised communities, is that they "explicitly and specifically seek to challenge the 'dominant knowledge' inherent to the mainstream public sphere."908 Counterpublics are playing with the architectures of hashtags in humorous and iterative ways in order to bring attention to the distortions of dominant narratives within the crooked platform.

The power of humour is increasingly being employed by counterpublics and combined with an understanding of the algorithmic functions of a hashtag to produce playful and provoking outcomes. In her analysis of \#MuslimRage, Liz Sills argues that the hashtag trended because of its unique form of argumentation and humour that could only happen through the algorithmic

\footnotetext{
903 Jackson, Bailey, and Foucault Welles, “Hijacking \#myNYPD," 942.

904 Jackson, Bailey, and Foucault Welles, \#Hashtag Activism, xxix.

905 Jackson, and Foucault Welles, "Hijacking \#myNYPD," 944.

906 Jackson, and Foucault Welles, "Hijacking \#myNYPD," 939.

907 Jackson, and Foucault Welles, "Hijacking \#myNYPD," 948.

908 Jackson, and Foucault Welles, "Hijacking \#myNYPD," 934.
} 
functions of Twitter.909 The \#MuslimRage hashtag was created in response to a Newsweek article Muslim Rage and the Last Gasp of Islamic Hate that spouts racist and stereotypical perspectives about Muslim culture.910 In a similar fashion to the collectivising hashtag \#ThatsUs, the hashtag \#MuslimRage allowed for individuals to respond (often sarcastically) with their own lived experiences that negate and challenge stereotypes. Sills found that the memetic and dialectic nature of the \#MuslimRage hashtag meant that it allowed for individuals to add their own perspective while elevating the massively resonant counternarrative of the collective towards trending status, saying:

They have a function that makes them salient and memorable, but also bridges their ostensibly simple reference function to create referent burgeoning with its own semiotic significance. That is, the tweet starts to look like an artefact rather than a text unfolding dynamically over the Twitter stream. ${ }^{911}$

Sill suggests that the use of 'operationalised comedy' is crucial in mass mediated social networking platforms like Twitter, where the serendipitous nature means that audiences come together based on the hashtag. ${ }^{912}$ Sill explains how tagging is a powerful act of subversion, stating:

A simple joke published as a tweet within a limited microblogging community might seem to have little power to combat such an immense amount of cultural angst, but its simplicity is deceptive, and actually lies at the root of its power. ${ }^{913}$

The comedy and painful truths of inequality articulated by \#ThatsUs, \#MyNYPD and \#MuslimRage hashtags resonate with in-groups and spark outrage. This strong resonance and ability for them to add their own perspective to the narrative means that there is a strong cluster of in-group counterpublics tweeting, making strategic use of a hashtag's trending functions. As more and more individuals share their experiences with racism, a strong folksonomic in-group network is brought about by mass outrage.914 The hashtag's serendipitous and trending functions mean that the collection of tweets created and spread by a networked counterpublic using humour and outrage allow these narratives to temporarily trend on Twitter. ${ }^{915}$ Counterpublics make strategic use of emotionality and the relational and structural elements of collectivising hashtags. Damon Centola and Michael Macy's analysis of hashtags from a networked perspective suggests:

The 'strength of weak ties' suggest that within a highly clustered network - a 'small world' with strong in-group ties - information may rapidly spread to other parts of the

${ }^{909}$ Liz Sills, "Hashtag Comedy: From Muslim Rage to \#MuslimRage," ReOrient 2, no. 2 (2017): 160, doi: 10.13169/reorient.2.2.0160.

910 Sills, "Hashtag Comedy," 164.

911 Sills, "Hashtag Comedy," 164.

912 Sills, "Hashtag Comedy," 168.

913 Sills, "Hashtag Comedy," 168.

914 Counterpublics take advantage of the folksonomic structures of hashtags (discussed in section 5.2 The Rise and

Risks of User Participation) seeing opportunities for resistance in the form of hijacking.

915 Jackson, and Foucault Welles, “Hijacking \#myNYPD," 948. 
network, because only a few 'long' ties are needed to make distant (bridging) connections and create larger network effects. ${ }^{916}$

In this way, hashtags have the potential to "interrupt the Whiteness of the Twitter network," drawing attention to the crooked platform. ${ }^{917}$ It is only by exploring the ways that online performances of self, humour, tragedy and personal experience are combined with hashtag architecture that we can even begin to grasp the significance of collectivising hashtags.

\section{b) Playing to Game the System}

At a cursory glance, the success of collectivising hashtags as a subversive political tool is linked to their ability to be used to 'game the system', that is, the possible manipulation of trending topics by counterpublics making strategic use of folksonomic, serendipitous, and trending functions of a hashtag. This effort relies on the digital labour, knowledge and agency of users to manipulate their digital environment, which requires further unpacking. ${ }^{918}$ This vernacular perspective affirms affordances' multi-layered composition, where users themselves build up and break down the different aspects of performance and action possibilities of a hashtag. Papacharissi refers to wordplay on Twitter as performances of connection and contestation, where an inventive use of a tag is considered 'play.'919 In her examination of the Occupy Movement hashtag, Papachrissi found that reordering and word play tended to be the preferred method of online expression. ${ }^{920}$ An example of the creativity used in hashtag word play is the adaption of \#MeToo by Chinese feminists. The \#MeToo movement received international attention and feminists worldwide have employed creative and funny approaches to including their message under the \#MeToo banner. Leta Hong Fincher has documented how the \#MeToo movement spread amongst Chinese feminists under the technological limitations of the governing communist People's Republic of China. ${ }^{921}$ Fincher found the hashtag \#RiceBunny was used by Chinese feminists to get around the national censoring of the \#MeToo hashtag. Innovative Chinese users began employing the emojis for a bowl of rice (phonetically pronounced "mi") and a rabbit (phonetically pronounced "tu") on the popular media platform Weibo to refer to the \#MeToo movement.922 This subversion shows a key understanding of algorithmic limitations of censorship and a willingness to work around them in clever and comical ways. It also emphasises the perceived power and capacity of hashtags between and beyond platforms.

An example of a collectivising hashtag that demonstrates a deeper understanding of algorithmic affordances and trending logics of hashtags is the use of the \#AllLivesMatter hashtag by K-pop fans to drown out racist narratives. Following the killing of George Floyd in May of 2020, the \#BlackLivesMatter hashtag was met with resistance from the

\footnotetext{
916 Damon Centola and Michael Macy, "Complex Contagions and the Weakness of Long Ties," The American Journal of Sociology 113, no. 3 (2007): 702-734, doi: 10.1086/521848.

917 Sharma, "Black Twitter?" 63.

918 Sharma, "Black Twitter?" 56.

919 Papacharissi, Affective Publics, 105.

920 Papacharissi, Affective Publics, 105.

921 Margret Anderson, "How Feminist in China Are Using Emoji to Avoid Censorship: There are other ways to write \#MeToo," Wired, 3 March 2018, http://www.wired.com/story/china-feminism-emoji-censorship/; See also Leta Hong Fincher, Betraying Big Brother: the Feminist Awakening in China, (UK, London: Verso, 2018).

922 Anderson, "How Feminist in China Are Using Emoji to Avoid Censorship."
} 
\#BlueLivesMatter and \#AllLivesMatter hashtags. After these hashtags began to trend in Canada, K-Pop fans took action to undermine \#AllLivesMatter by hijacking the hashtag and delegitimising the conversation by capitalising on their virality, employing the collective power of their popularity to use the \#AllLivesMatter hashtag with totally off-topic posts about Korean pop music.923 A Huffington Post reporter remarked on the adept digital literacy of teenage KPop fans, saying, "Followers of bands like BTS and BLACKPINK have mobilised to use their online literacy as a means of defusing the hashtag, rendering it functionally useless." 924 There is a clear political element included in the playful act, with teenagers taking to Twitter to actively engage in political protest. K-Pop fans have hijacked other hashtags including \#MAGA, \#Trump2020 and \#BuildTheWall. Their subversive digital acts have not just been limited to hashtags. MIT Technology Review recorded an instance where the Dallas police called for the public to send in videos of illegal activity during the BLM protest.925 K-pop fans responded by downloading the police department's app en masse and flooded it with short fan produced videos of K-pop, effectively crashing the app. ${ }^{926} \mathrm{~K}$-pop fans have also been involved in other forms of online activism including getting K-pop group BTS to pledge a million dollars for the BLM movement and collectively matching the donation themselves. They have also been involved in sabotaging political rallies by reserving tickets without the intention of actually going, essentially 'pranking' political parties. Republican campaign strategist Steve Schmidt (see figure 23) tweeted about the pranking of a Trump rally saying "my 16-year-old daughter and her friends in Park City, Utah, have hundreds of tickets. You have been rolled by America's teens." 927

Abby Ohlheiser explains that these acts of play and pranking, while humorous, are very much intentional and the result of thoughtful and strategic collective action, stating:

This narrative has found traction partly because it plays against stereotypes: K-pop fandom is often dismissed as a monolithic swarm of annoying, shallow screaming tweens who manipulate Twitter's trending algorithms in order to establish which group or performer is most worthy. Suddenly being shown evidence that stans are more complex, thoughtful, or socially aware than the stereotype is a surprise only for those who weren't paying attention..$^{928}$

The light-hearted tongue-in-cheek act of play demonstrated by K-Pop fans supports Papacharissi's premise for the convergence of private fantasy and public disclosure that may make individuals more comfortable expressing political thoughts they would otherwise withhold. ${ }^{929}$

\#ProudBoys is another example of hashtag hijacking with a keen political tilt. The hashtag \#ProudBoys headlined following a speech by former President Donald Trump when he failed

\footnotetext{
923 Connor Garel “How K-Pop Fans Are Drowning Out \#AllLivesMatterhashtags,” Huffington Post, 3 September, 2020 https://www.huffingtonpost.ca/entry/k-pop-fans-all-lives-matter_ca_5f47e722c5b6cf66b2b4aef5

924 Garel "How K-Pop Fans Are Drowning Out \#AllLivesMatterhashtags."

925 Abby Ohlheiser, “How K-pop fan became celebrated online vigilantes," MIT Technology Review, 5 June, 2020, https://www.technologyreview.com/2020/06/05/1002781/kpop-fans-and-black-lives-matter/

926 Ohlheiser, "How K-pop fan became celebrated online vigilantes."

927 Garel "Drowning Out \#AllLivesMatterhashtags."

928 Ohlheiser, "How K-Pop fans because vigilantes."

929 Papacharissi, Affective Publics, 107.
} 
to condemn the White supremacy group 'Proud Boys', who often spout White nationalist, antiMuslim, and misogynistic rhetoric. The hashtag \#ProudBoys was soon hijacked by gay and queer men with pictures of their partners and families. One user explained that he felt the reclaiming replaced a rhetoric of hate with one of love and joy. In figure 24, he said "reclaiming of \#ProudBoys is wonderful. Here's me and my husband. Together for 20 years and married for 3. Both very proud boys." 930 This is a brilliant example of how users employ strategic use of hashtags with performances of self in a way that is both playful and political. Members of the LGBTQIA+ community rallied behind this hashtag, drowning out messages of hate and replacing them with uplifting and supportive messages that still had political potency. Papacharissi explains that "the act of referencing the tag renders the personal political, civic, and social in that it allows it to leave the private sphere and enter the public realm, through a path that typically involves play." 931 Play allows people to reclaim or reframe their online performances of self. The key in the case of hashtag hijacking is that the act of play is used as a strategy for framing conversations collectively and getting others to put their own 'spin' on the trending topic through an understanding of the algorithmic logics of the hashtag.

Although hashtags have been repurposed and used by activists and marginalised groups to challenge status quo socio-political hierarchies, these subversive strategies are not without fault. Ohleiser notes that internet culture has a long history of relying on marginalised communities, specifically young Black people, to drive trends. ${ }^{932}$ The collectivising and fastpaced nature of online actions still present significant limitations for subversive movements. A Black K-pop fan remarked that the collective actions of K-Pop fans using digital tactics to support BLM groups seemed to be sincere and genuinely helped when \#AllLivesMatter trended. ${ }^{933}$ However, just one week later she remarked:

The stans, while actively targeting hashtags, are moving on, with references to \#BlackLivesMatter slowing down. The attention shifted from the cause to the fans themselves, who were mythologised in near real time. But once the attention moves elsewhere, not all fans have the option to shift to the next trend.934

It is Black people who are left to keep speaking out and organising BLM long after its trending power dissipates. For Black Americans, the BLM movement is not just a passing phase; it is a constant ongoing battle against police brutality and racially motivated violence that is part of their everyday lived experience. It is important to acknowledge the difficult and ongoing digital labour that often falls to minority bodies to keep these movements going.

Beth Berila argues that the urgency with which many White people are now calling for racial justice online in the wake of the BLM movement presents a critical paradox: on the one hand, ending racial injustice is urgent.935 Berila maintains that inequality dates back to colonisation

930 New Zealand Herald, “Gay couples reclaim far-right group 'Proud Boys' Hashtag,” 4 October, 2020, https://www.nzherald.co.nz/lifestyle/gay-couples-reclaim-far-right-group-proud-boyshashtag/RSJORAAIJXANW36K4SC2ZGVN3I/

931 Papacharissi, Affective Publics, 107.

932 Ohlheiser, "How K-Pop fans became vigilantes."

933 Ohlheiser, "How K-Pop fans became vigilantes."

934 Ohlheiser, "How K-Pop fans became vigilantes."

935 Beth Berila, "White Urgency To End Racism: why now?” Open Democracy, 23 June, 2020,

https://www.opendemocracy.net/en/transformation/white-urgency-end-racism-why-

now/?fbclid=IwAR3i8PLIbFiPrDUlRFW8drpaHVPpq3dC4RdGOeS37QlylbBhe6wRibJlm4A 
and all of us (but particularly those in close proximity to Whiteness) need to be active in processes of decolonisation and dismantling systemic racism.936 On the other hand, decolonisation is demanding and ongoing work and "this transformational energy needs to be sustained over what will be a long journey of racial transformation." 937 Institutional racism has existed for decades and it will not be undone overnight by a hashtag movement. Working towards the end of structural racism needs a creative, sustainable and long-term approach. For feminist counterpublics, this means, in part, dismantling all the ways in which privileged users interact both on and offline and rethinking 'urgency' is a big part of this. Encounters on social media affect users in corporeal ways and it is important that privileged bodies reflect on what their emotions are trying to tell them. Berila suggests that we look at the way this emotion arises in our embodied selves, stating:

Reflect on that urgent energy. Where is it showing up in your body? Is there a temperature, an impulse or movement? How is it manifesting? Is there an urge to do, and do you engage that impulse immediately - or can you create space to reflect on it first?

Now go deeper. What's underneath that urgent energy?

Is it actually deep pain at the pervasive violence of racism?

Is it because you didn't realise or acknowledge systemic racism until now?

Is it a pain that you contributed to it in some ways, even if you didn't mean to?

Is it a confusion that you don't know what to do or how to help?

Is it a righteous rage that this has to end now? If so, I invite you to go deeper still: what's underneath that righteous rage?

Is it, at heart, a longing to be a good person? For people to know you are a good person?"938

Privileged users need to think very carefully about how they employ their digital privilege, even if the intention is to support or better understand anti-racist movements. For Berila, the impulse to 'do something' can be another way to centre Whiteness, explaining "Whites are doers. We have been taught that we are the movers and shakers in the Western world... how much of our need to do is a way to avoid feeling?" 939 Berila suggests we all have a unique role to play in ending systemic racism, people of colour need room to heal from the trauma of oppression, dismantling internalised racism, building coalitions across racial identities and indigenous communities. ${ }^{940}$ Privileged bodies have a different role to play in ending racism, one that involves examining our performances of self and Other. All too often, marginalised bodies are placed in the position of having to defend themselves in online spaces and 'teach' privileged users about the experience of being 'Othered.' Fotopoulou points to the increased expectation for women of colour, and trans and queer youth, to use their digital platform to "fight for visibility" and are expected to claim a voice in a culture where they risk being the target of racist attacks, misogynistic trolling, or gay cyberbullying. ${ }^{941}$ In social media, women, queer groups and people of colour contribute most significantly to what Boler describes as

\footnotetext{
936 Berila, "White Urgency To End Racism."

937 Berila, "White Urgency To End Racism."

938 Berila, "White Urgency To End Racism."

939 Berila, "White Urgency To End Racism."

940 Berila, "White Urgency To End Racism."

941 Fotopoulou, Feminist Activism and Digital Networks, 19.
} 
"connective labour" in order to sustain movements. ${ }^{942}$ The invisibility of embodied and affective labour is specifically experienced by marginalised bodies in relation to networked acts of social media activism. Fotopoulou argues that we need to account for bodies and practices when thinking about feminist and queer politics in online spaces because it is a site of immaterial and affective "free" labour that is traditionally assigned to women. ${ }^{943}$ Anti-racism and anti-oppression work should not fall solely to marginalised bodies; it is of utmost importance that privileged users engage in their own race work in online spaces.

The burden of this digital labour should not fall to minority bodies, and yet the question of how dominant bodies should (or should not) go about using their digital privileges to support marginalised bodies is heavily contested. Jackson, Bailey and Foucault Welles state that the question of how members of dominant groups show up to support this labour is ever present

How do White allies to racial justice struggles and male allies to feminist projects engage digitally? Focusing only on people of colour when one is considering solutions to racial inequality or only women when considering gender opposition risks perpetuating the myth that the struggle for justice is a minority struggle alone, that majority White and male citizens bear no responsibility for grappling with and dismantling the systems of White male supremacy. 944

The discursive, architectural, and affecting affordances of hashtags can help counterpublics bring attention to important issues. In spite of the structural limitations of platforms that favour dominant corporate, cultural, and technological logics, racial justice and feminist counterpublics still evolve and thrive within these crooked spaces. While there is potential for hashtags to facilitate creative and subversive performances of self, it is increasingly clear that the majority of the digital labour falls to marginalised users, resulting in the reproduction of status quo social hierarchies. ${ }^{945}$ Hashtag counterpublics are created and constituted between users with differing access to power and privilege. ${ }^{946}$ It is important that we look at the usages of collectivising hashtags beyond their networked capacity that allows them to 'crossover' into mainstream discourse. I suggest a return to the relational and situated understanding of hashtag processes that are never experienced or created in isolation to historic hegemonic systems of power and dominance. I subscribe to the critical feminist ethic that scholars must do a better job of integrating questions of race and other identity matrices in studies of social media "if we are to avoid replicating the conditions that force women of colour to the margins of both academic and activist feminism." ${ }^{947}$ All too often, the ever present work required within crooked spaces is left to those who feel its effects most keenly, with privileged users relying on marginalised users to bring our attention to inequalities, to spark outrage and to teach them how to do better. Peoples use of collectivising hashtags, their algorithmic functions, digital networks and their affects are all constitutive of online racialised identities. ${ }^{948}$

\footnotetext{
942 Megan Boler et al., "Connective labour and social media: Women's roles in the 'leaderless' occupy movement," Convergence 20, no. 4 (2014): 438, doi:10.1177/1354856514541353

943 Fotopoulou, Feminist Activism and Digital Networks, 8.

944 Jackson, Bailey, and Foucault Welles, \#Hashtag Activism, 153.

945 Jackson and Banaszczyk, "Digital Standpoints," 393.

946 Jackson and Banaszczyk, "Digital Standpoints," 393.

947 Jackson and Banaszczyk, "Digital Standpoints," 396.

948 Sharma, "Black Twitter?” 46.
} 


\section{c) State Regulation and Corporate Responsibility}

The crooked platform in which users find themselves is not entirely of their own construction. As I have argued throughout this dissertation, there are corporate and governing bodies that co-construct online spaces. Given that the crooked platform is a shared space, questions around responsibility and moderation become entangled and fraught with complex debates including freedom of expression, anti-discrimination, equality, political participation, and privacy concerns. Serena Chen found that all parties involved are quick to absolve themselves of responsibility, particularly when the problematic nature of online racism turns into offline violence (like in the case of the Christchurch mosques shooter). ${ }^{949}$ She explains, "When real world violence is tied to online causes, websites, companies and governments all like to point fingers at each other to declare who should be responsible."950 When faced with the scale of racism and violent extremism it is easy for individuals to resign themselves and conclude that change is not within their power. However, I argue that users still have an important role to play in dismantling the racism and violent extremism of the crooked platform. In this section, I will highlight the potential and limitations of user agency and touch on the role of State regulation and corporate responsibility. ${ }^{951}$ I maintain that micro-political acts of users and Counterpublics are the best way to begin the work of re-aligning our crooked platforms.

Recognising and working towards rectifying the crooked nature of our online platforms requires both affected and affecting bodies to rethink the digital architecture and legal frameworks that structure the crooked platforms. Users from privileged backgrounds, Counterpublics, online corporations and governing bodies all have a unique role to play in antiracism work in online spaces. Chen suggests that instead of thinking of regulation, moderation, censorship, and banning as the sole responsibility of governments, or corporations, or users, we ought to see each of these actors as different points on the line of defense against online harm. ${ }^{952}$ The power of governments to change digital law or infrastructure through regulation is the most broad sweeping tool at our disposal and therefore ought to be considered our last line of defense. ${ }^{953}$ Governments perform a particularly difficult balancing act; they must consider different forms of freedoms or risk only promoting the freedoms of dominant groups (for example freedom of expression must be balanced with freedom from discrimination). ${ }^{954}$ However, these freedoms are not mutually exclusive and governments have many tools at their disposal other than hate speech regulation. Kathrine Errington argues that States ought to monitor company behavior, by reinforcing the need for transparency for all parties, as well as protecting freedom of expression by investing in the infrastructure necessary to protect users

\footnotetext{
949 Serena Chen, "A Framework for Response He Anga Urupare" in Andrew Chen (Ed.), Shouting Zeros and Ones: Digital Technology Ethics and Policy in New Zealand: Bridget Williams Books, 2020. doi: 10.7810/978198858. 950 Chen, “A Framework for Response He Anga Urupare,"184.

951 While covering all the complex debates surrounding State regulation and corporate responsibility is beyond the scope of this dissertation Chen's Shouting Zeros and Ones: Digital Technology Ethics and Policy in New Zealand provides an in-depth examination of policy following the Mosque attacks.

952 Chen, “A Framework for Response He Anga Urupare," 184.

953 Chen, "A Framework for Response He Anga Urupare," 184.

954 Katherine Errington in conversation with Anjum Raham "Reducing Online Harm" in Andrew Chen (Ed.), Shouting Zeros and Ones: Digital Technology Ethics and Policy in New Zealand: Bridget Williams Books, (2020) 47, doi: $10.7810 / 978198858$.
} 
from harm. 955 For example, the purpose of the Christchurch Call is an action plan that commits governments and tech companies to a range of measures, including developing tools to prevent the upload of terrorist and violent extremist content; countering the roots of violent extremism by increasing transparency around the removal and detection of content, and reviewing how companies' algorithms direct users to violent extremist content.956 On 15 May 2019 Aotearoa New Zealand Prime Minister Jacinda Ardern and French President Emmanuel Macron brought together Heads of State and Government and leaders from the tech sector to the Christchurch Call to Action Summit in Paris to discuss the elimination of terrorist and violent extremist content online. ${ }^{957}$ The Call was adopted by France, Aotearoa New Zealand, Canada, Indonesia, Ireland, Jordan, Norway, Senegal, the United Kingdom, the European Commission, Australia, Germany, India, Italy, Japan, the Netherlands, Spain and Sweden. Importantly, it was included a number of major digital corporations including Amazon, Facebook, Dailymotion, Google, Microsoft, Qwant, Twitter, and YouTube.958 While the Christchurch Call has been criticised for its lack of specificity and actionable outcomes, it is important to acknowledge the co-operation between State and corporate entities and their willingness to work together in response to the Christchurch shooting. The Christchurch Call, is intended to be a starting point for governments, online service providers and civil society to work together to curb online extremism.

The Christchurch Call is limited in that focuses exclusively on violent extremist content and fails to address a broader range of harmful online content. At the 2019 Paris Peace Forum David Hall from Auckland University of Technology and Wellington think-tank The Workshop presented a set of principles called the Christchurch Principles that aim to do for the digital economy what the United Nations Guiding Principles for Business and Human Rights did for the global economy. Essentially, the Christchurch Principles recommend a set of roles and responsibilities for digital technology companies, states, and civil society organisations to not only protect and respect human rights, but also to defend those democratic norms, practices and institutions that enable rights to flourish. ${ }^{959}$ The Christchurch Principles work on the assumption that non-criminal remedies have an essential and neglected role to play. There is a need to look more closely at the structure of social media platforms and users' online practices. David Kaye, the United Nations Special Rapporteur for Freedom of Expression, notes that States have a wide range of tools that don't endanger freedom of expression in the same way as moderation or censorship laws. ${ }^{960}$ These include greater transparency requirements, education programmes, counter-speech and counter-narratives, de-amplification and demonetisation of problematic speech, creating friction for sharing, and improving the capabilities of civil society and online corporations that can engage with fellow citizens in ways that States can't.961 These more nuanced approaches stress the role of corporate responsibility and the design intent for user interactions that amplify harmful online content.

\footnotetext{
955 Errington, "Reducing Online Harm," 43.

956 Ardern, Rt Hon Jacinda, “Christchurch Call to Eliminate Terrorist and Violent Extremist Online Content," Official Website of the New Zealand Government. 16 May 2019, https://www.beehive.govt.nz/release/christchurch-calleliminate-terrorist-and-violent-extremist-online-content-adopted

957 "Christchurch Call to eliminate terrorist \& Violent extremist content." The Ministry of Foreign Affairs and Trade. Accessed 15, October 2021, Christchurchcall.com

958 Ardern, "Christchurch Call to Eliminate Terrorist and Violent Extremist Online Content."

959 Hall, David, "How the Christchurch Principles Will Fight the Spread of Hate."

960 "United Nations Special Rapporteur for Freedom of Expression," United Nations General Assembly Report, 9

October 2019 https://www.ohchr.org/Documents/Issues/Opinion/A_74_486.pdf

961 Hall, "How the Christchurch Principles Will Fight the Spread of Hate."
} 
Large scale internet infrastructural providers and social media platforms such as Facebook, Twitter and YouTube with their monopolies on our attention mean that any changes to the services provided by these companies will have widespread implications and must be employed with care and consideration. Ben Thompson creates a framework for moderation by placing companies on a scale from those who control access to the internet (infrastructure companies such as Cloudflare) to those who control people facing aspects of the internet (websites like Facebook and Twitter). ${ }^{962}$ The people facing ones, Thompson argues, should have more discretion and responsibility, while those who control access and infrastructure should be more concerned with legality. It is often suggested that social media companies like Facebook and Twitter should move more quickly to de-platform users by removing, banning, de-ranking or hiding inflammatory narratives that spread racism, disinformation or conspiracy theories that lead to offline acts of terror or violence. 963 However, as much as we might want them to, algorithms cannot simply be 'tweaked' to remove all evidence of violence, racism, or white supremacy rhetoric.

Algorithms are complex and changes to their structure do not always have the intended effect or play out the way users think they ought to. For example, following the Christchurch shooting Youtube attempted to remove videos depicting gun violence from their platforms. An unintended consequence of this, was the removal of videos that were evidence of crimes, such as harassment of young Black Americans by police and violence against women by extremist regimes. These videos were to act as evidence in court cases, so simply removing all violent content had devastating consequences for those suffering abuse. ${ }^{964}$ Similarly, decisions to deplatform racist or sexist users or constrict abusive language played out in unpredictable ways. Twitter attempted to remove the term 'queer' which has been deliberately reclaimed by LGBTQIA+ communities. This resulted in the de-platforming of LGBTQIA+ users, sex workers and further marginalized these groups. ${ }^{965}$ I want to reiterate Gillespie's analogy that algorithms are "cudgels, where one might want scalpels." ${ }^{266}$ These entities have blunt tools and changes to infrastructure, algorithms, and site regulation will always risk overreach, so they need to be employed with caution. Chen maintains that large corporate entities should only enact their power in the most dangerous and extreme circumstances. ${ }^{967}$ But equally they need to be brave enough to use these tools when necessary, for example internet service providers in Aotearoa removed both 4chan and 8chan, white supremacist extremist sites that featured the shooter's manifesto following the mosque shootings. ${ }^{968}$ While users may feel frustrated that these companies shy away from making major changes to their platforms, decisions when applied unilaterally without consulting Counterpublics lead to further marginalisation. In my interview with Assistante auprès de l'Ambassadeur pour le Numérique in association with the Christchurch Call, he emphasised the need for continued political pressure for transparency and reform:

\footnotetext{
962 Ben Thompson, “A Framework for Moderation," Stratechery. 7 August, 2019, https://stratechery.com/2019/aframework-for-moderation/; See also Chen, "A Framework for Response He Anga Urupare," 182.

963 Chen, "A Framework for Response He Anga Urupare," 172.

964 Errington, "Reducing Online Harm," 48.

965 Jess Glass, "Is queer a slur? Twitter seems to think so," PinkNews, 19 March, 2018.

https://www.pinknews.co.uk/2018/03/19/is-queer-a-slur-twitter-thinks-so/

966 Gillispie, "Can an algorithm be wrong?"

967 Chen, “A Framework for Response He Anga Urupare," 187.

968 Chen, "A Framework for Response He Anga Urupare," 186.
} 
To move the tech firms with these reforms, I think that the political momentum was very important. So as much as I say the firms have been very cooperative and have been very helpful in the last couple of weeks I do believe that they want, need, very strong political pressure for them to move.969

While the underlying capitalist tilt of digital corporations can be problematic, reinforcing the misalignment of the crooked platform, the long-term business model of social media platforms depends on maintaining the wellbeing and trust of the communities they host. 970 The challenge for us as users is to tip the scales so that community wellbeing and their business models align against the crooked platform.

Users' capacities for change, while seemingly less than governments and corporates, can be just as impactful. Users' powers are more nuanced and targeted, there is room to interpret language, to understand a person's meaning and intent and develop a situated response. According to Chen, the individuals closest to the offending content's user account form the first line of defense against online harm, racism or extremism. Chen argues that not only do they have more responsibility for what goes on in their spheres, they have more influence within those communities to encourage the desired behavior and enforce community rules. ${ }^{971}$ Stating plainly, "This means you. When you see problematic behavior crop up in your friend group, family, communities - you are the first line of defense." 972 To this, I feel I must add, that it is those people who are positioned in proximity to privilege that must be the first to respond. For privileged users and those proximate to Whiteness this responsibility is a key part of doing their own race work. For example, that Pākehā or Tauiwi New Zealanders have a responsibility to respond to displays of racism or white supremacy in online spaces. In some cases, this might look like blocking or reporting a user. In other cases, there is an opportunity to recognize vulnerability and treat online conversations as an opening for critical discussion. When racism is displayed by people you have a preestablished relationship within offline spaces, such friends or family, privileged users might wish to consider inviting them into a private conversation in which you can safely work through issues. These are often referred to as 'holding spaces' where people are invited in to have vulnerable, open and critical conversations about white privilege and dominance. Participation in holding spaces is difficult work that must be moderated by experienced parties and should not be done on open platforms. ${ }^{973}$ These are trusted and carefully surveyed spaces where White users can do their own race work and feel their way through some difficult and challenging areas in their fragility and imperfection. Chen explains that "It is natural for everyone to go through awkward and embarrassing periods of growth - and potentially hold some pretty toxic views during these periods. Working these feelings out in the wild west of public internet platforms is not going to be the best place to do so - especially when you are trying to prove that you belong to a group." ${ }^{774}$ Anti-racism is something that privileged bodies can take part in, it takes ongoing

\footnotetext{
969 Interview with Assistante auprès de l'Ambassadeur pour le Numérique in association with the Christchurch Call conducted 27 August 2019.

970 Chen, "A Framework for Response He Anga Urupare," 188.

971 Chen, "A Framework for Response He Anga Urupare," 185.

972 Chen, "A Framework for Response He Anga Urupare," 185.

973 Chen, "A Framework for Response He Anga Urupare," 176.

974 Chen, "A Framework for Response He Anga Urupare," 175.
} 
work to create safer online spaces for everyone to participate in. 975 Within crooked platforms it is likely that privileged users will relapse, and fall short and that's okay as long as they are able to recognize it, surround themselves with people who can hold them accountable and remain committed to building more equitable online spaces.

Crooked platforms are the result of existing inequitable social, political, and economic structures. Pre-existing issues of racism, colonialism and white supremacy affect the atmosphere of the crooked platform. Accordingly, it will require movement from governments, corporations or civil society to change it. Chen explains that we aren't looking for just one responsibility or response, rather change requires "a comprehensive set of actions will necessarily be as varied and dynamic as the thing we are defending ourselves from."976 Assistante auprès de l'Ambassadeur pour le Numérique talked about the primary purpose of the Christchurch Call as a bringing together of the key stakeholders, not to place blame or responsibility with one party, but to understand how together we might be able to enact real change:

Ultimately the Christchurch Call was a real-life event. It was not an exclusively online event it had real consequences. So, what we need to do is we need to ensure that we protect our citizens, and we enable a social and economic management to minimize the potential of racialization within society. Through the Christchurch Call we have managed to understand that we - all three of us - need to come together governments, civil society, and the private sector...we (each of us) have individual roles and responsibilities. 977

Importantly, addressing online hate means addressing hate in offline spaces. It means changing public perceptions and practices, addressing micro and under the radar experiences of racism and hate as well as obvious displays of violent extremism that can be eliminated by legal or technical measures. Anjum Raham explains "putting in regulation without also dealing with power and the way society is structured will not achieve anything." 978 Raham found that we must work at the international, national and local community level, using a mix of persuasion, regulation and education." 979 The Royal Commission of New Zealand conducted an inquiry into the terrorist attack on the Christchurch mosques, subsequently entitled Kō tō tātou kāinga tēnei meaning "This is our home." The Commission interviewed affected whanau, survivors and witnesses as well as members of the Muslim Community Reference Group who offered material insights and lessons for the future. Kō tō tātou kāinga tēnei discussed 'what communities told us about the broader context in which the terrorist attack occurred' and stressed that addressing both grassroots and systemic levels of racism was key to eradicating violent extremism. The Muslim Community Reference Group reiterated that the support and participation of tangata whenua, te Ao Māori perspectives, and a Tiriti o Waitangi framework are all essential parts of anti-racist work in Aotearoa, particularly given shared experiences of discrimination and

\footnotetext{
975 Chen, “A Framework for Response He Anga Urupare,", 176.

976 Chen, “A Framework for Response He Anga Urupare," 194.

977 Interview with Assistante auprès de l'Ambassadeur pour le Numérique in association with the Christchurch Call conducted 27 August 2019.

978 Errington, "Reducing Online Harm," 47.

979 Errington, "Reducing Online Harm," 47.
} 
institutional racism. ${ }^{980}$ Kō tō tātou kāinga tēnei also offered a list of proposed 'Solutions' to address racism hate and discrimination. Interestingly, the Muslim Community Reference Group mentioned the Human Rights Commission \#ThatsUs campaign stating, "We were also told that the Public sector needed to put more resources into campaigns like Stand up to racism: That's us, which is run by the Human Rights Commission." 981 In the following section, I will explore how the Human Rights Commission used \#GiveNothingToRacism, \#ThatsUs, and \#VoiceofRacism campaigns as an educational tool to progress anti-racist work. I use these hashtags to examine key dilemmas and dynamics of allyship as hashtags play out in online spaces, given the unequal conditions of the crooked platform. Anti-racist work takes shape in a myriad of different spaces, through State regulation, changes to corporate structures and everyday practices of users. Sometimes the scale of racism and violent extremism in online spaces can seem overwhelming and beyond the reach of individual users - but we are not working alone on these issues. Chen reminds us, "Do not worry too much about the 'perfect' most effective action for you to take. Some of these responses will ride on incredible global movement, while others may feel like they're working against the tide. They all have a role to play. Commit to something and start from there." 982 In the following sections I will explore the potential of micro-political acts of hashtag activists and digital Counterpublics, as well as the responsibilities and limitations of White allyship in online spaces.

\section{d) The Limits of Agency and Counterpublic Advocacy}

Collectivising hashtag practices bring attention to the crooked platform and highlight stereotypes, differences in lived experiences, and systemic issues of precarity for those people who exist outside of 'mainstream' narratives. Social media platforms and hashtags are a manifold set of sociotechnical practices "generative of digital privileges and racial ordering."983 Jackson, Bailey and Foucault Welles suggest that digital allyship is a relatively new practice that is still going through growing pains, saying, "Hashtags claim to move privileged members of society towards solidarity with those less so are often regarded with scepticism as a kind of faux allyship that recentres privileged groups." 984 They examine four failed cases of male feminist allyship that followed the \#MeToo movement, including \#AllMenCan, \#IWillChange, \#IveDoneThat and \#CrimingWhileWhite in response to the BLM movement.985 They found that these hashtags served more as a catharsis exercise for the men, which ultimately failed to benefit women who were forced to witness men openly expressing their worst sexist exploits and without fear of retribution. 986 The hashtag \#IveDoneThat allowed men to find solace in the collective. While the tone of the hashtags did not necessarily signify justification of sexism, it did allow men to feel that acts of sexism were the norm. These collectivising hashtags allow

\footnotetext{
980 New Zealand Human Rights Commission, "Reflections on the Report of the Royal Commission of Inquiry into the terrorist attack on Christchurch Masjidain on 15

https://www.hrc.co.nz/files/3716/1588/7040/HRC_Reflections_on_the_report_of_the_RCI_on_terrorist_attacks_on_ Christchurch_Masjidain_FINAL.pdf

981 Royal Commission of New Zealand, "Inquiry into the Terrorist Attack on Christchurch Mosques on 15 March 2019: What communities told us about the boarder context in which the terrorist attack occurred." Accessed 7 November 2021. https://christchurchattack.royalcommission.nz/the-report/voices-of-the-community/whatcommunities-told-us-about-the-broader-context-in-which-the-terrorist-attack-occurred/

982 Chen, “A Framework for Response He Anga Urupare," 194.

983 Sharma, "Black Twitter?" 47.

984 Jackson, Bailey, and Foucault Welles, \#Hashtag Activism, 156, 164.

985 Jackson, Bailey, and Foucault Welles, \#Hashtag Activism, 153

986 Jackson, Bailey, and Foucault Welles, \#Hashtag Activism,157.
} 
users to "acknowledge and confess to benefit from White privilege without clearly engaging systemic battles with White supremacy."987 Jason Ross, who first used the \#CrimingWhileWhite hashtag, stated:

I had hoped to prompt the creation of a noticeable body of evidence of White peoples' invisible criminality. That hope was exceeded many times over. But it came at a significant cost. This tsunami of unharmed White people dominating a discussion about the perils of being Black led many to express annoyance and emotional pain. But it's a paradox: How can White people deploy our numbers and our privilege to help others without becoming - if only briefly- the protagonists? And if we don't use those assets, then what? I couldn't answer that then, and I can't answer it now. ${ }^{988}$

How we go about best using our digital affordances to challenge online inequalities is still in its early days of development. Privileged users need to be very careful that their digital affordances are not used to recentre Whiteness; \#CrimingWhileWhite had the effect of redirecting peoples focus from the continued violence against Black people and back to the experience of White people. ${ }^{989}$ Privileged bodies sharing content without thinking critically about the weight of their digital affordances can have a negative impact on marginalised bodies. A recent example of this is the \#BlackOutTuesday action which encouraged users to share a black image on their Instagram, Twitter and Facebook feeds on 2 June 2020 as an act of resistance. \#BlackOutTuesday was launched by the music industry as an act of passive resistance against racism and police brutality that aims to silence or suspend online interactions in remembrance of George Floyd, Ahmaud Arbery and Breonna Taylor. In addition to the black square image online posts often included the hashtag \#BlackLivesMatter which had the unintended side effect of drowning out critical information and updates from the BLM movement. However, almost immediately, social media users who used the \#BlackLivesMatter hashtag in addition to the \#BlackOutTuesday hashtag were inundated with user responses explaining why using that hashtag drowned out crucial information about events and resources with a sea of black boxes. ${ }^{990}$ For Meredith Clark, the response to \#BlackOutTuesday illustrated how the BLM movement had honed its ability to stick to a program, and to correct those who deployed that program naïvely. ${ }^{991}$ People are beginning to understand that our digital affordances have material consequences.

Jackson, Bailey and Foucault Welles found that one of the best ways to ensure hashtags foster change is by following a model that allows for actionable and systemic change. ${ }^{992}$ They give the example of the \#HeForShe hashtag which was launched by the United Nations Women in 2014 and provided a robust plan of action and solidarity beyond using tweets. ${ }^{993}$ The \#HeForShe campaign was started by a powerful institution suggesting that "allyship hashtags may be most successful when they are grounded in allyship theory and practical expertise from the start and supported offline." ${ }^{994}$ Similarly, Kuo stressed that it was this back end work (i.e., an

\footnotetext{
987 Jackson, Bailey, and Foucault Welles, \#Hashtag Activism, 177.

988 Jackson, Bailey, and Foucault Welles, \#Hashtag Activism,168.

989 Jackson, Bailey, and Foucault Welles, \#Hashtag Activism,168.

$990 \mathrm{Hu}$, "The Second Act of Social- Media Activism."

$991 \mathrm{Hu}$, "The Second Act of Social- Media Activism."

992 Jackson, Bailey, and Foucault Welles, \#Hashtag Activism, 182

993 Jackson, Bailey, and Foucault Welles, \#Hashtag Activism, 182-183.

994 Jackson, Bailey, and Foucault Welles, \#Hashtag Activism, 182.
} 
inventory of knowledge, and a stronger sense of alliance) that has allowed digital activism to "reflect broader concerns and visions around community safety, accessibility, and accountability." $995 \mathrm{Hu}$ found that while the uprisings might have been led by the people, what sustained them is precisely what many prior networked protests like \#WeAreThe99\% lacked, namely, pre-existing organisations with specific demands and "action plans for a better world." 996 Listening for cues and calls to action is crucial to ensuring that online activism not become an end point but rather a necessary process for broader transformative politics. In order to be successful in their hashtag use, counterpublics are forced to address deep rooted systemic issues grounded not only in our digital structures but in our everyday practices and conceptions of self.

The third phase of the NZHRC's \#ThatsUs digital campaign, The Voice Of Racism, exemplifies the power of a robust and actionable plan that encourages conversations prompted by collectivising hashtags and addresses the hierarchies and "epistemic privileges" inherent in digital practises. ${ }^{997}$ The NZHRC has iterated the \#ThatsUs campaign over the years. Following the Christchurch Mosque attacks on 15 March 2019, they once again shifted their anti-racism approach to tackle the intensification of racism and violent extremism towards Muslims and other migrant communities. The New Zealand Government specifically allocated the NZHRC $\$ 1.3$ million to address ongoing concerns in society about racism, including research, strategic advice, and the development of the Voice of Racism website in 2019. The website is an interactive audio tool that allows listeners to hear a stream of racist comments as if they were directed at the listener. The racist remarks are presented alongside the inner thoughts and feelings of people experiencing those remarks. It is also paired with a learning tool that allows the user to question and learn why the remarks are damaging and provide actionable responses. ${ }^{998}$ Race relations Commissioner Meng Foon explained the purpose of the campaign, saying:

The Commission encourages all people in Aotearoa to experience the Voice of Racism for themselves so they can understand the impact of racism and reflect on how their own words and actions may be contributing - even unintentionally, to racism. People may think one joke, one comment, one assumption, one stereotype doesn't matter, that they are trivial, but they do matter - and the cumulative effect on people experiencing these is huge. It's time we all asked ourselves; Am I contributing to racism in this country? What can I do to stop racism in Aotearoa New Zealand?999

What is particularly unique about this campaign is the audible aspect. The video begins with the question: "Are you willing to listen?" The audio recording requires users to listen to marginalised people sharing stories of their experiences of racism and encourages the listener to absorb that information and simply sit with the discomfort that they feel. Interestingly, the audio recording does not play automatically; rather, it requires the listener to 'press hold to listen' as an active, intentional undertaking, listening requires your full attention (which is countercultural in online spaces). The attentive action required of users counters the passive listening or mindless scrolling often associated with online platforms. In addition to the audio

$995 \mathrm{Hu}$, "The Second Act of Social- Media Activism."

$996 \mathrm{Hu}$, "The Second Act of Social- Media Activism."

997 Jackson and Banaszczyk, "Digital Standpoints," 401.

998 New Zealand Human Rights Commission, "New Campaign says Give No Voice To Racism."

999 New Zealand Human Rights Commission, "New Campaign says Give No Voice To Racism." 
recording, there is a learning tool provided that explains to the listener 'why is this racist.' If selected, this learning tool that takes the listener to the NZHRC resource page that explains why the comment they were listening to is racist, explaining the emotional impact of the comments as well explaining broader implications of unconscious bias and systemic violence. The Voice of Racism website also suggests 'what can you do instead', providing an alternative way of responding to online and offline situations in which you encounter racism and how a person might "resolve to act in a way that addresses them."1000 The campaign also encourages people to take action and provides links to Facebook and Twitter suggesting that you 'share what you learned.' The purpose of the Voice of Racism campaign is not to facilitate privileged bodies' ability to 'walk a mile someone else's shoes.' Rather, the Voice of Racism campaign addresses the problem of self-recognition. The campaign calls privileged bodies to recognise themselves as 'the voice of racism,' to sit with discomfort and consider their own bias, privileges and its affects. The campaign addresses issues of systemic racism and the role that structural discrimination plays beyond the individual in perpetuating inequalities: how these inequalities play out in education, justice and health systems. By listening to a condensed vocalisation of racist discourses, privileged users can reflect on their own discourses (whether internally present or externally expressed), realise their affects and become more attuned to the invisibility of the crooked room. ${ }^{1001}$ The Voice of Racism campaign brings to light the invisibility of the crooked room and how privileged bodies mis-recognise and misrepresent the experiences of marginalised bodies in order to normalise a dominant Pākehā or Tauiwi culture in Aotearoa New Zealand. Privileged users need to rethink collectivity, solidarity and allyship in online spaces. As collectivising hashtags grow in scale and popularity, they still risk being monopolised by dominant users. The question then becomes: how do privileged users apply their digital knowledge and strategically use digital affordances in a way that acknowledges their own particularity and complicity without recentring Whiteness and dominance?

Privileged bodies need to learn to pay attention to the way that the spaces they inhabit are crooked and structurally facilitate dominance. Dreher claims that we need to listen for histories of colonial violence and structures of White supremacy. ${ }^{1002}$ Listening requires an openness to our own precariousness and complicity in the unequal distribution of the precarity of Others in online spaces. Dreher suggests that we become attuned to "listening for history and structure."1003 This is to say, users need to attune themselves to understanding "White supremacy as foundational and enduring," and that the systems of dominance developed in colonial projects manifest themselves in everyday contemporary encounters both on and offline. ${ }^{1004}$ Privileged users also need to listen for implication and complicity, opening themselves to learning the ways in which they are implicated in oppressive norms and structures of Whiteness.1005 Listening requires a "critical distance from false victimhood, the celebration of White saviours and the desire for reassurance", the kind that is often displayed in collectivising hashtags. ${ }^{1006}$ We need to listen to cues of cultural difference in online spaces. Sharma explains that "race itself has become a digital medium" suggesting:

\footnotetext{
1000 New Zealand Human Rights Commission, "New Campaign says Give No Voice To Racism.” 1001 Ratcliffe, Rhetorical Listening, 28.

1002 Dreher, "Listening After Christchurch." 1003 Dreher, "Listening After Christchurch." 1004 Dreher, "Listening After Christchurch."

1005 Dreher, "Listening After Christchurch."

1006 Dreher, "Listening After Christchurch."
} 
How 'techno cultural assemblages' digital networks, communication platforms, software processes- are constitutive of online racialised subjectivity and activity. Pursuing a materialist approach also leads to re-conceiving race as an 'assemblage': encountering race as an emergent force in digital media vis-à-vis its networked connections, informatic flows and affects. ${ }^{1007}$

Privileged users need to find ways to acknowledge positionality in online spaces. This could be as simple as taking a closer look at the profile of the user or users they are engaging with online. On Twitter, certain communities use identity indicators as permanent parts of their profile. For example, use of the rainbow flag for queer communities, or \#GirlsLikeUs for trans women or the use of Blacktags in Black communities. Privileged users need to attune themselves to these indicators and recognise what these digital assemblages mean for marginalised users. Privileged users can work against the unmarked nature of dominance by explicitly sharing their situatedness. A local example of this is Aotearoa New Zealand Twitter users including Pākehā or Tauiwi in their profile as a way of acknowledging their lineage or whakapapa.

Privileged users also need to listen and centre those who are most impacted by systemic inequality, this includes listening to indigenous voices like those given voice in \#ThatsUs. Practically, this means understanding Twitter as a racialised space. For privileged users, this means thinking critically about the people they follow and the hashtags they use that help facilitate a crooked platform. It requires a responsive approach that sometimes looks like supporting marginalised networks by promoting hashtags like \#ThatsUs or \#TheVoiceOfRacism to increase their visibility, and other times it could mean recognising that certain hashtags are meant for marginalised bodies only and consciously giving them the space to self determine and celebrate their in-group networks like \#ProudBoys and \#GirlsLikeUs. Listening in online spaces requires privileged users to understand their own positionality in relation to Others, their situatedness and their proximity to Whiteness.

Rather than centring their own voices, privileged users can use their digital privilege and collectivising affordances to move narratives away from individual and towards systemic issues. Listening in online spaces helps users to understand the context and what is at stake in order to better understand when to listen and which voices to privilege. ${ }^{1008}$ Following Dreher, I assert that those situated in similar proximity to Whiteness must learn to listen for structures of White supremacy, particularly in crooked online spaces that are dominated by White voices.

A key part of the digital labour of raced and gendered counterpublics of privileged bodies is reflexivity. Reflexivity "shifts some of the focus and responsibility for change from marginalised voices and on to the conventions, institutions, and privileges which shape who and what can be heard in the media." 1009 For privileged users, this means being critical of majority discourses and trending tags, listening to them carefully with a view of how they might affect Others (and those currently out of view), and responding proactively. Reflexivity

1007 Sharma, "Black Twitter?" 48.

1008 Dreher, "Listening After Christchurch."

1009 Tanja Dreher, "Listening across Difference: Media and Multiculturalism beyond the Politics of Voice," Continuum 23, no.4 (2009): 445, doi: 10.1080/10304310903015712. 
calls those in close proximity to privilege to consciously and consistently unlearn racism. Reid explains that being an anti-racist ally means being able to recognise the following:

To me, an ally is a person who advocates and works alongside the Black community, who uplifts communities for a shared common goal driven solely by the cause - not so that they can look good. It is a person who wants to learn how to recognise what everyday racism looks like - from pay inequity to social persecution - and address it. A person who learns to hold the tension between being asked to speak up while, at the same time, also being asked not to speak up on behalf of Black folk and people of colour and just listen. To hold the fear of saying the wrong thing, while having a strong desire to say and do something. It is a person who learns to actively listen - to respond rather than react - and take considered and thoughtful actions and welcome feedback on inherent racism without spiralling out of control. It is a person who accepts that there is no certificate or completion date. To accept they will get it wrong and do it anyway. But it is mostly a person who accepts that there is no magic formula, or a one-size-fitsall approach to this work. The only way to be truly anti-racist is go on a journey to unlearn your own inherent racism, because it is on that journey that you will find your unique path to becoming actively anti-racist. 1010

Anti-racist and decolonisation work is not a straightforward path, privileged bodies cannot simply embark on a journey of self-discover and reach an end destination of enlightenment. Reid found that each of her anti-racist tutorials saw students go down a path of healing by confronting parts of themselves that they would rather hide or ignore.1011 Ultimately, antiracist work is about remaining open and vulnerable, "trying to do anti-racism work while remaining comfortable, to actively avoid confronting feelings, is just not possible." 1012 Such a change of focus can also turn our attention to receptivity and vulnerability and brings discursively privileged subjects into the analysis. ${ }^{1013}$ Reflexivity can begin with feeling, a growing awareness of the affecting nature of our online encounters and performances. Beausoleil explores the conditions of ethical encounter which she terms a "dispositional ethics" that construes 'responsibility-as-responsiveness.'1014 She defines responsibility-asresponsiveness as: "ethics borne of situated response, ethics enacted in the pulse and pause of attentiveness." 1015 Beausoleil frames "dispositional ethics as a means to hear what is yet White noise and care for-be affected by-who is currently out of view."1016 By sharing and listening to stories of vulnerability, we can collaboratively and incrementally work towards a fuller understanding of our digital practices and privileges. By learning to "stand under" the discourse of Others and recognise how our online performances of self affect Others, there is "potential to transpose a desire for mastery into a self-conscious desire for receptivity."1017 Ratcliff explains that standing under discourses means:

\footnotetext{
1010 Reid, "No More White Saviours Thanks."

1011 Reid, "No More White Saviours Thanks."

1012 Reid, "No More White Saviours Thanks."

1013 Ratcliffe, Rhetorical Listening, 28.

1014 Emily Beausoleil, “Responsibility as Responsiveness: Enacting a Dispositional Ethics of Encounter," Political Theory 45, no. 3 (2017): 291, doi: 10.1177/0090591716651109.

1015 Beausoleil, "Responsibility as Responsiveness," 293.

1016 Beausoleil, "Responsibility as Responsiveness," 297.

1017 Tanja Dreher, "Eavesdropping with Permission: The Politics of Listening for Safer Speaking Spaces," Borderlands 8 no. 1 (2009): 10. Krista Ratcliffe inverts the term 'understanding' to 'standing under' redefining it as a practice where those in a position of privilege consciously listen to the discourse that surrounds us and others while
} 
[L]etting discourses wash over, through, and around us and then letting them lie there to inform our politics and ethics. Standing under our own discourse means identifying the various discourses embodied within each of us and then listening to hear and imagine how these discourses might affect not only ourselves but others. ${ }^{1018}$

An understanding of the affordances of social media and the application of the concept of listening presents privileged bodies with the opportunity to use collectivising hashtags to stand under their own discourse. For privileged bodies, standing under the voices of marginalised bodies could look like sharing or retweeting their messages. It could also look like choosing to remain silent. For example, during the days following the Mosque attacks, Pākehā and Tauiwi users could have chosen to remain silent on social media in order to give Muslim voices the platform to speak if they chose to do so. During the BLM protests in the United States, the use of \#BlackLivesMatter hashtags could have been reserved for Black communities and those sharing organisational and educational information about protests. Digital labour for White people could look like doing their own race work by addressing privilege and educating those similarly situated to whiteness and privilege.1019 People are beginning to understand what it means to use a hashtag: "they use their own social media in a certain way to essentially quiet background noise and allow those voices that need to connect with each other the space to do so."1020 The work of privileged users in online spaces is complex and delicate. Privileged bodies will undoubtedly fall short and make many mistakes as they learn how to stand under. This is why listening, reflexivity and an iterative approach are necessary to enable privileged bodies to slowly learn what standing under the discourse of others looks like for them.

I argue that to stand under marginalised voices in online spaces is to firstly acknowledge claims to know or represent the experiences of marginalised bodies through collectivising hashtag practices can involve forms of appropriation on the part of privileged subjects which obscure their complicity in power structures, further entrenching social inequalities. Secondly, it involves looking for the invisible ways that inequality and dominance are architecturally built into the crooked spaces we inhabit and understand that this has become so normalised that privileged subjects no longer see it.1021 Thirdly, it means consciously integrating this information into online performances, by listening and feeling through self-reflexive practices, ways in which privileged renderings of self elicit invulnerability. Lastly, standing under marginalised voices requires an ongoing commitment to vulnerability, an openness to failing with a sense of humility, and a sense of wonder, listening and learning as a part of an evolving self-reflexive praxis. By listening and standing under their own narratives privileged bodies

consciously acknowledging the particular and very fluid standpoints from which it comes. See Ratcliffe,

Rhetorical Listening, 28.

1018 Ratcliffe, Rhetorical Listening, 28.

1019 A local example of this is the Tauiwi Tautoko project where non- Māori volunteers partake in a 10 week project that weaves together online training and in person hui (gatherings) to provide activists with the tools, community and digital strategies to engage in online conversations about race with evidence-based listening and messaging techniques. See Action Station Aotearoa, "Become a Tauiwi Tautoko Volunteer," 2 April, 2019,

https://actionstation.medium.com/tauiwi-tautoko-88510ebdb0c6; See also Julia Craig "Love Thy Trolls: What Pākehā can do about online racism," The Pantograph Punch, 13 April, 2020, https://www.pantographpunch.com/posts/love-thy-trolls

$1020 \mathrm{Hu}$, "The Second Act of Social- Media Activism."

1021 Ratcliffe, Rhetorical Listening, 28. 
introduce the "possibility for hearing that which we cannot see."1022 Privileged bodies can then challenge underlying inequalities by enacting themselves as embodied and situated subjects in online and offline spaces.

This chapter explores the clever and imaginative ways that collectivising hashtag users have subverted online interactions and digital performances of self. The That's Us campaign demonstrates how trending hashtags can bring attention to systemic issues by showing people how widespread these seemingly personal experiences are by creating online networks. Networked acts of community building via collectivising hashtag practices can help to centre intersectional frameworks and experiences. Counterpublics use the architecture of Twitter and functions of a hashtag to share in-group knowledge of inequality and racism. Through the strategic use of hashtags, and the incorporation of humour, hijacking, and play, counterpublics make everyday lived experiences of racism visible to both in-group and out-group users and bring attention to the crooked platform. The strategic use of collectivising hashtags demonstrates an increasing awareness and understanding of technological affordances. Digital practices and performances of self are used by marginalised bodies to reimagine what online spaces can be, both in terms of momentous social movements and in mundane everyday expressions of "the joys and pains of everyday life."1023 The logistical use of networks and performative acts suggest that "digital activism has entered a second act" in which increasingly embodied and relational approaches to social media are taken.1024 However, many privileged users are completely unaware that they are inhabiting a crooked platform because they aren't subject to the negative experiences that plague marginalised groups. The issue with these subversive approaches is that while effective, they are still in their infancy, and cannot on their own change the power relations in online spaces. As collectivising hashtags grow in scale and popularity, the digital labour increasingly falls to marginalised, in-group assemblages, and still risks being monopolised by privileged users. Race, sexuality, gender and other marginalised identity groups are being exploited for their networked affordances and performances, racialised subjectivity and activity. Pursuing a vernacular approach also leads to re-conceiving race as an 'assemblage': "encountering race as an emergent force in digital media vis-à-vis its networked connections, informatic flows and affects." 1025

What we can see with the collectivising hashtag phenomena is a lack of understanding of digital race privileges and their stabilising presence in crooked spaces. The capitalist structures of Twitter, the algorithmic functions of a hashtag, the networked communities users participate in, the tongue-in-cheek style of humour, hijacking and play associated with experiences of marginalised users all play a critical role in the transmission of collectivising hashtags' meaning and affects. A multi-layered and vernacular analysis of hashtag affordances emphasises the importance of digital architecture, labour, visibility, and invisibility when addressing Twitter and other social media platforms as crooked and racialised spaces. Collectivising hashtag practices are consecutive of online racialised identities. I assert it is possible for privileged users to employ hashtags productively, like in the case of the Voice of Racism campaign; however, they cannot do this without first recognising Twitter as a racially

1022 Ratcliffe, Rhetorical Listening, 29.

1023 Brock, Distributed Blackness, 6.

$1024 \mathrm{Hu}$, "The Second Act of Social- Media Activism."

1025 Sharma, "Black Twitter?" 48. 
marked space, their role in the online marginalisation of Others, and beginning self-reflexive processes of digital reconstitution. For those in positions of privilege, this requires that they develop new practices of digital reconstitution in which an embodied online praxis is conceived in affective terms, where the primary function of reflexivity is to remain open and responsive within online encounter. 


\section{Conclusion}

Collectivising hashtags have changed the way people engage with one another and are redefining the way people collectively think about visibility, death, mourning and precariousness. Hashtags are no longer considered 'tools' used for personal expression, but rather communal and evolving processes of digital constitution that reconfigure modern modes of encounter, relationality, and politics in fundamental ways. My research on the affectual and architectural nature of collectivising hashtags helps us to better understand how online practices can act to reinforce dominant conceptions of humanity. I have found that by invoking the concept of self when addressing issues of injustice, violence or crisis, collectivising hashtags can foster feelings of solidarity and belonging while simultaneously magnifying exclusivity and conceptions of Otherness. The "interpretative flexibility" of collectivising hashtags "allows whiteness to operate paradoxically as the individual and as humanity."1026 Users enact themselves as embodied, social and political subjects through social media practices, technologies, and the imageries linked to online performances of self. ${ }^{1027}$ As relational and situated subjects, people are continuously shaping conceptions of self and Other, moving in response to our digital environment and to one another. ${ }^{1028}$ The affective nature of online encounter is linked to a need to revert to micro-politics examining functional and relational affordances of power, specifically looking at how exclusionary practices are characterised by power imbalances and struggles at architectural, political and personal levels. The things people say and do online matter, online performances of self affect which bodies are afforded full recognition of their humanity and which are marginalised and left unseen. The messages people like and share via social media promote a particular understanding of the value of human life.

The vernacular nature of online spaces means that there is no longer a clear subject and object when it comes our use of hashtags. As I have argued throughout this dissertation, there exists an interdependent relationship between users and architectural and ideological structures. The vernacular architecture of social media platforms combined with the folksonomic, serendipitous, and trending functionalities of hashtags means that our performances of self are never expressed or experienced in isolation. Online renderings of self, including collectivising hashtags, act to stabilise the crooked architecture in which users encounter invulnerable conceptions of self and Otherness. No one can 'sit it out' in an online space; to see what happens is to shape what happens. To witness the crooked platform is to affect it, this is as true of our actions as it is of our inactions. Privileged bodies must think critically about the role they play in constructing digital atmospheres in which ignorance, dispossession, and power inequalities fester. As they come to understand privileged conceptions of an invulnerable self and unpeel the layers of complicity, it becomes clear that the systems of inequality run deep, infiltrating all aspects of human encounter both on and offline. Appreciating the emotional and architectural affects of collectivising hashtags is an important step towards understanding the new fluid and pluralistic state of world politics.

1026 Brock, Distributed Blackness, 7.

1027 Fotopoulou, Feminist Activism and Digital Networks, 22.

1028 Beausoleil, "Responsibility as Responsiveness," 312. 
Online encounter continues to be shaped and reshaped by our online rendering of self and their impacts on our online environments. The concept of vulnerability is central to my thesis; our use of collectivising hashtags can problematise recognition of precarious bodies who fall outside dominant conceptions of what it means to be human, both in a discursive and material sense. However, the potential to transform modern conceptions of self and Other lies in the unfinished and affecting nature of emotional and felt experiences. By focusing on vulnerability as an "enabling rather than limiting element for politics", there is potential for privileged users to reconstitute themselves as situated and relational beings through embodied digital practices, reflexivity and by becoming vulnerable. ${ }^{1029}$ Gilson maintains that invulnerability is dissipated most forcefully through an "awareness of the processes of constitution because such awareness is an avowal of vulnerability itself and an avowal of the self as a vulnerable one."1030 In comprehending oneself as a relational person who has come into being and is continually evolving, one positions oneself as one who has been and will continue to be, affected by others; one conceives of oneself as vulnerable.1031 By extending Gilson's idea of an 'awareness of the process of constitution' to our digital selves, I emphasise the importance of becoming aware of the affecting nature of our digital practices and privileges: as embodied digital selves whose digital potentialities are constituted in relation to Other bodies with unique digital affordances. This awareness of what I call 'processes of digital constitution', is in and of itself a realisation of a vulnerable self as someone who has been and continues to affect and be affected by others.

Our everyday online encounters with collectivising hashtags present an opportunity to challenge dominant conceptions of self through imagination, appreciation, and recognition, and more specifically, the invulnerability exposed by collectivising hashtags practices presents the opportunity to work towards a fuller conception of self. An appreciation of precariousness helps connect us to the benefits of the affecting nature of online atmospheres. Affect is released through interaction; "it marks forces and non-forces of encounter, belonging, and nonbelonging, in-between-ness and accumulative beside-ness." 1032 Butler discusses the transformative potential of mourning and concludes that one only truly mourns when they accept that, by that loss, one will be changed. ${ }^{1033}$ Thus, mourning has to do with undergoing a transformation of self. When encountering collectivising hashtags online there is transformative potential in understanding our proximity to precarity and in recognising the systemic frames and architectures of racism, extremism and White supremacy that led to the tragic deaths in Ōtautahi, Christchurch. An understanding of how privileged bodies are connected to that loss, not as a body appropriated but as a rending of self rearticulated in situated response to another, is where privileged users encounter transformative potential. A 'closeness' facilitated by hashtagging practices and algorithmic functionalities characterises our lives and modes of encountering this potential.

\footnotetext{
1029 Fotopoulou, Feminist Activism and Digital Networks, 13.

1030 Gilson, "Vulnerability, Ignorance, and Oppression," 326.

1031 Gilson, "Vulnerability, Ignorance, and Oppression," 326.

1032 Papacharissi, Affective Publics, 14.

1033 Butler, Precarious Life, 22-23.
} 
Butler reminds us that grief and the experience of precariousness offers privileged bodies a chance to start to imagine how violence might be minimised.1034 By extending Butler's analysis to online spaces, I show how collectivising hashtags speak to convoluted human conditions of precarity and precariousness. As such, collectivising hashtags present the opportunity for privileged bodies to consider how precarity is unequally distributed and how violence can be minimised, if they realise relationality and listen to difference instead of falling into the habit of speaking for marginalised bodies. The emotional experiences of mourning, anxiety and fear can lead to reflection on how others have suffered corporeal vulnerability and violence, generating a desire to produce a different online environment in which suffering unexpected violence, loss and racial aggression are not accepted as the norm. ${ }^{1035}$ Emotionality, grief, and anger in response to seeing the suffering of Others, expressed via collectivising hashtags, can help us challenge our conceptions of self as constituted in relation to others. Privileged bodies unmake themselves when they say ' $I$ ' and 'us' in the context of collectivising hashtags and open marginalised bodies up to the affects of the crooked platform. Collectivising hashtags ought to prompt the questions: What do I bring into this space? How are my performances of self, positionality, and privilege set at an angle? What is the affecting nature of this online encounter? ${ }^{1036}$ Butler remarked "Let's face it. We're undone by each other. And if we're not, we're missing something." 1037 When privileged users open themselves to an embodied online conception of self, and acknowledge the affecting, relational, and situated nature of online encounter, something deeper about who they are is revealed: something that delineates their positionality and privilege in relation to Others, shows them the ties and histories that constitute who they are today. This deeper conception of self can reconcile the shared precariousness of being corporally human and alterity of precarity in relation to marginalisation. Through unknowing and feeling, privileged users can work towards vulnerability and a fuller conception of what it means to be 'us.'

Processes of digital constitution have an affinity with anti-racist struggles, particularly given the racial differential that undergirds "culturally viable notions of the human" that we see acted out in dramatic and terrifying ways at the present time. ${ }^{1038}$ Privileged users must actively participate in the creation and revision of our evolving digital selves or risk becoming invulnerable and obscuring our own complicity in broader systems of inequality. This participation requires that we address the affecting and emotional ways the crooked platform and digital logics play upon our bodies. In online spaces, this approach looks like recognising social media platforms as racialised spaces that are marked by inequalities and corporeal difference. For privileged bodies this could look like finding ways in which Whiteness is marked and not invisibly centred as the norm. Butler explains, "I tell a story about the relations I choose, only to expose somewhere along the way, the way I am gripped and undone by these very relations. My narrative falters, as it must."1039 The narrative of dominant bodies must falter, to give way to a fuller conception of humanity, of precariousness that does not elide the precarity of Other bodies. Privileged bodies have a responsibility to do this work and they also have a stake in it. What can be gained here is not just an acknowledgment of the crooked

\footnotetext{
1034 Butler, Precarious Life, xiv.

1035 Butler, Precarious Life, xiv.

1036 See figure 23 for an example of self reflexive questions prompted by collectivising hashtags that can create an opening and deeper understanding of self.

1037 Butler, Precarious Life, 23.

1038 Butler, Precarious Life, 33.

1039 Butler, Precarious Life, 23.
} 
platform, a de-centring of self and the recognition of marginalised bodies, but perhaps more importantly a challenge to a normative notion of what it means to be human. The construct of Whiteness has cut many off not only from the humanity of marginalised bodies, as they have come to be Othered and dehumanised; it has also cut privileged bodies off from their own humanity. In making themselves invulnerable, privileged bodies have unmade their own humanity. There is exciting research to be done in relation to processes of digital constitution and the importance of this is tied to the fact that the shape of critical feminist praxis is transforming. As boundaries between online and offline lives have blurred, we need to re-think who and what define 'our' political spaces and practices.

\section{Contribution}

International Relations scholars are increasingly paying attention to online interactions in order to understand modern global politics. ${ }^{1040}$ The majority of interdisciplinary work in the areas of Media Studies and International Relations is pre-occupied with the value of social media as a pre-political instrument, qualified by its ability to bring about change through civic engagement. ${ }^{1041}$ There has been strikingly little research produced on the role of social media's architecture and its affects in International Relations. This oversight is likely due to the methodological challenges identified earlier in my research design chapter. Bleiker and Hutchison suggest a need to move beyond traditional International Relations methodological approaches, advancing three propositions to supplement social scientific methods: 1) the need to accept that research can be insightful and valid even if it engages an unobservable phenomena, and even if the results of such enquiries can neither be measured nor validated empirically; 2) the importance of examining processes of representation and the manner in which they shape political perception dynamics; 3) a willingness to consider alternative forms of insight that capture emotions. ${ }^{1042}$ Some of the most insightful inquiries into the political role of encounter are interdisciplinary; examples include excellent work on trauma, war, and social movements. ${ }^{1043}$ While attempts to embrace CTDA as a methodology in Media Studies and International Relations are to date quite limited (this is in part due to CTDA being a recent methodological design), the need for further interdisciplinary research that integrates technological architectures and user discourse framed by critical theory is crucial.1044 My dissertation contributes to burgeoning interdisciplinary approaches, feminist, Media Studies, and International Relations methodological approaches by finding connections between form, function and belief. 1045 What my work adds to this conversation is feminist knowledge on the embodied and affectual workings of vulnerability, ignorance, and precariousness of digital atmospheres. Boler and Davis remark that "social media could benefit from (feminist) scholarship that emphasises the social and relational nature of emotions." 1046 By presenting a

1040 Åhäll, "Affect as Methodology"; Bleiker and Hutchison, "Fear No More”; Clara Eroukhmanoff, "Responding to terrorism with peace, love and solidarity: 'Je suis Charlie', 'Peace' and 'I heart MCR'," Journal of International Political Theory 15, no.2 (2019): 167-187, doi: 10.1177/1755088219829884.

1041 One notable exception is Zizi Papacharissi's book Affective Publics: Sentiment, Technology, and Politics which looks at affect studies in digital and political communications.

1042 Bleiker and Hutchison, "Fear No More," 115.

1043 Bleiker and Hutchison, "Fear No More," 127.

1044 Boler and Davis, "The Affective Politics of the 'Post-Truth,"' 82.

1045 Brock, "Critical Technocultural Discourse Analysis," 1012.

1046 Boler and Davis, "The Affective Politics of the 'Post-Truth,'” 81. 
feminist methodological approach to the role of affective-encounter via social media, my thesis is an attempt to address this gap in the politics of online encounter.

Unlike existing theorisations on the emotional resonance of encounter, my thesis brings collectivising hashtags to the forefront. As I explained at the outset of my dissertation, few, if any, insights connect collectivising hashtags to normative conceptions of self. The hashtags that we use reinforce dominant conceptions of self, where Whiteness is unmarked and centred, both in terms of discourse and in terms of digital architecture, and consequently marginalised users' status as Other is maintained. The use of \#ThatsUs, \#TheyAreUs and \#ThisIsNotUs case studies provide a concrete basis for the application of ideas and extension of emancipatory methods. To this end, what my research contributes is twofold: first, a way to identify the political in the affective practices of everyday performances of self and Other via collectivising hashtags. The study of digital media and its influence on the precariousness of life is key to understanding the prevailing political, economic, and social underpinnings of inequality in modern society. The messages we like and share via social media are used to promote a particular understanding of the value of human life. An inquiry into affectual encounter helps us to understand how online practices act to reinforce status-quo conceptions of humanity, which recognises the lives of men above women, the lives of citizen over foreigner, and the lives of White persons over persons of colour. Second, by feeling differently, a feminist analysis opens up space for "thinking, acting and knowing differently."1047 I maintain that we can challenge underlying inequalities through processes of digital constitution, embracing vulnerability, and by recognising the architecture and affects of our online performances of self. My thesis investigates the real world applications of this through \#TheyAreUs, \#ThisIsNotUs and \#ThatsUs case studies to demonstrate the conditions of ethical encounter and to explore the potential and limitations for affective transformation to emancipate the prevailing politics of humanism.

My thesis has broad practical applications that move beyond purely academic interest. Insights gained from my research (particularly from analysing my case studies) contribute towards ongoing human rights-based policy development and implementation, particularly in areas of equality, social inclusion, and reconciliation. A primary goal of my research is to counter the drivers of racism and extremism online by building digital media literacy to help challenge prevailing technological inequalities in Aotearoa New Zealand. Insights gained from my research contribute to the NZHRC's on-going human rights-based policy development and implementation, particularly in areas of equality, social inclusion, and reconciliation. This reconciliation may include strategic use of hashtags and algorithmic affordances to challenge prevailing digital inequalities and replace them with positive alternatives and counternarratives. The preliminary findings of my research have been requested by the NZHRC and will contribute to the development of their anti-racism behaviour change digital campaign. The NZHRC has called for improved data collection on hate-motivated crimes in online spaces. Dr Mustafa Farouk, the President of the Federation of Islamic Associations of New Zealand, strongly believes that by collecting the data, public agencies can identify how widespread hatemotivated crimes are. ${ }^{1048}$ At present the NZHRC is looking for further research into online

1047 Åhäll, “Affect as Methodology,” 50.

1048 Jamie Ensor, "Hate-motivated crime data collection being strengthened as Muslim leaders demand action," Newshub, 19 March, 2021, www.newshub.co.nz/home/new-zealand/2020/03/hate-motivated-crime-datacollection-being-strengthened-as-muslim-leaders-demand-action.html 
crimes that occur because of a person's religion, colour, race or ethnicity, or other important personal characteristics such as sexual orientation, gender identity or disability. Greater public and governmental understanding of why certain narratives circulate and how their architectural structure fosters racist or extremist discourse will help identify possible intervention points and develop peaceful reconciliation processes. My thesis offers a starting point for further inquiries into what digital strategies best attune to the architectural design of platforms and their affects on marginalised communities. Further research in this area is needed before we can design, implement and evaluate an effective response that accounts for the structural and ideological foundations of inequality. Social media platforms and collectivising hashtags create unprecedented opportunities in peace and reconciliation education for an academic audience, government agencies, and the Aotearoa New Zealand public.

\section{Significance}

The global environment during the three years of my dissertation has been marked by uncertainty and political upheaval. For me, it has helped to reaffirm the timeliness and significance of my research into collectivising practices. I began seeing collectivising practices everywhere, both online and offline. Collectivity has marked some of the most difficult and precarious moments of global politics in recent years. The horrific terror attack on Muslim communities in Ōtautahi, Christchurch, called into question many previously held assumptions about the digitalisation of Aotearoa New Zealand politics and society and the ways privileged bodies think about security, necessitating a greater attentiveness to digital platforms and practices. Following the events of 15 March 2019, it has become painfully clear that racism and extremism left to fester in online spaces do not remain online; they affect people and spread hate. Our online actions have real world implications, and when left unexamined they can have horrific corporeal consequences for society. Given the rapid expansion of collectivising hashtags and the profound influence they have on the way we perceive one another, the need to understand affective conditions of ethical encounter are more significant than ever before. Bleiker and Hutchison stress "that the real battles today are being fought precisely within these visual and seemingly imaginary fields of media representations... shape our understanding of political phenomena more so than the actual phenomena themselves." ${ }^{1049}$ By recognising social media's role in the dehumanisation of minority bodies, we can begin reconstructing online spaces where racist and violent extremism is confronted and digital inequalities are worked through collaboratively.1050

Acknowledging the emotional resonance of collectivising hashtags is an important step towards understanding the new fluid and pluralistic state of world politics as it develops in both online and offline spaces. The BLM protests of June 2020, following the death of George Floyd, saw tens of thousands take to the streets to protest acts of violence inflicted on Black communities and to advocate for eradicating White supremacy. ${ }^{1051}$ There has been a marked

1049 Bleiker and Hutchison, "Fear No More," 131.

1050 For example, see the Tauiwi Tautoko project where non-Maori develop digital strategies to engage in online conversations about race with evidence-based listening and messaging techniques. See Action Station Aotearoa, "Become a Tauiwi Tautoko Volunteer," and Craig "Love Thy Trolls: What Pākehā can do about online racism." 1051 Black Lives Matter, “About," 19 March, 2021, https://blacklivesmatter.com/about. 
change in online spaces, Brock maintains that Black cyberculture is thriving and that young Black folk are re-making the internet as a "Black space" by sharing everyday lived experiences of imagination, creativity, innovation, and joy.1052 Through my own online encounters, I have witnessed the incredible displays of love, generosity, and resilience within counterpublics who fight to affirm and centre the lives and humanity of women, queer, trans, undocumented, and disabled folks. It has been devastating to see the expansiveness of these liberation and antiracist movements met with violent and aggressive acts of White supremacy. The anger, privilege and invulnerability of White supremacy came to a head at the 6 January 2021 storming of the United States Capitol following the defeat of Donald Trump in the 2020 presidential election. The violent attack by right-wing extremist groups unfolded in real time on Twitter, with people inside the building live streaming rioters' occupation and vandalism of the Capitol building. Former president Donald Trump took to Twitter to speak directly to the mob and, in an unprecedented act, Twitter suspended the @realDonaldTrump account for incitement to violence, determining that the Tweets were in violation of their Glorification of Violence Policy. Twitter boss Jack Dorsey tweeted, "[W]e made a decision with the best information we had based on threats to physical safety both on and off Twitter." 1053 While there will undoubtedly be much more research done in the future to unpick the global conversation around censorship and online expressions of violence, these events demonstrate that collectivity, vulnerability, ignorance, and precariousness are not just limited to hashtags, reinforcing the relationship between offline and online dynamics. I emphasise that the prevailing socio-political underpinnings of inequality are inextricably tied to social media, and online renderings of self and Other. Politics happens at all levels, in all spaces, at the same time. As we spend more and more of our time in online spaces, a holistic understanding of the interplay between socio-political influences and technology, and how the two act to reinforce or disrupt each other becomes essential to a modern understanding of politics.

The outbreak of Covid19 has been a stark reminder of the precarious and interdependent nature of corporeal lives and the interconnected nature of our global politics. It has shown the precarious nature of our embodied selves and our reliance on not only our own bodies, but those of distant others. Our dependency on essential workers has become clearer than ever: people rely on these under recognised and rewarded people; nurses, food and agricultural manufacturers, public transit, grocery store and postal workers, and all others who ensure the continuity of our survival by providing life's basic needs. We all live with this corporeal vulnerability, a vulnerability to other bodies that is intrinsically part of bodily life - it is what characterises us as humans. The interdependence of modern global relations highlights our reliance on unknown others despite our geographical distance. The dangers of our corporealness, connectedness and the justified fears of transmission and deaths seen across the globe has left Aotearoa New Zealand largely isolated, with never before experienced limitations on traveling internationally and domestically, transforming human connectedness. Covid19 has changed the way we encounter and communicate with people. New Zealanders have had to adapt both our work and social lives, that are now increasingly taking place in online spaces. The boundaries of our online and offline lives are becoming increasingly blurred. While it is impossible to look at all aspects of our personal and technological lives and how these interrelate, my research suggests that hashtags are a particularly rich site for

1052 Brock, Distributed Blackness, 5. 
encounter filled with political potential. Nowhere is the complicated mess of lived experience more evident that on social media platforms. During 2020 our social media feeds were dominated with information about Covid19, the resurgence of the BLM movement, climate change protests, and the United States election, intermixed with sourdough recipes, toilet paper shortages and Tik-Tok dances. Social media encompasses all of it: from the extraordinary to the mundane. Social media platforms illustrate the mix of technological aspects of our lives with the emotional, embodied performative and political elements of human experience. In a world where our interconnectedness and our reliance on technology has been brought into stark relief, understanding the changing nature of modern modes of encounter and political expression in online spaces is more important than ever. 


\section{Appendix}

Figure 1. New Zealand Represents Diversity, Kindness, Compassion.

Figure 2. Example of NZHRC \#ThatsUs Tweet.

Figure 3. Tweet Just Be Human. 
Figure 4. Tweet New Zealand Will Not Change.

Figure 5. Tweet Mosque Memorial.

Figure 6. Tweet Mosque Shooting Remembrance. 
Figure 7: Tweet Alice Canton.

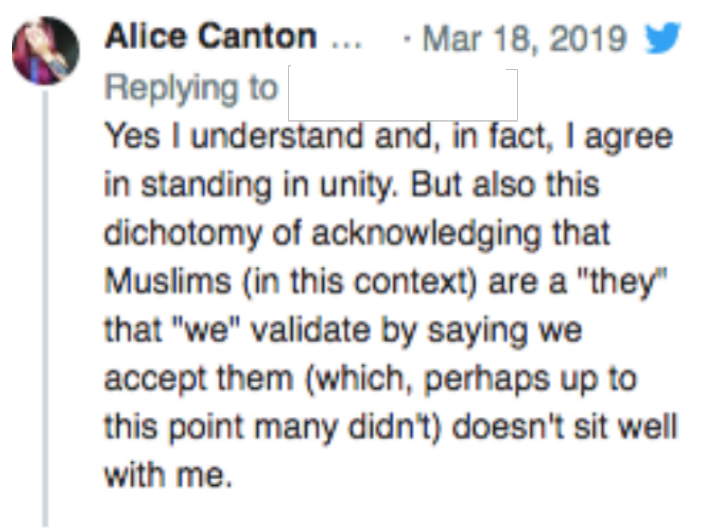

Figure 8. Hala Nasr Tweet .

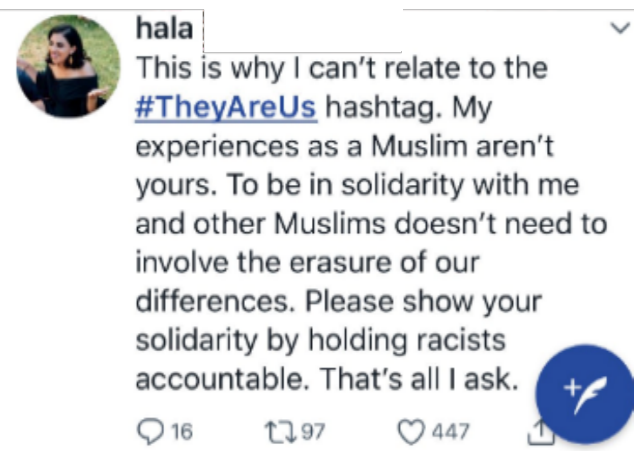

Figure 9. Tweet Questioning \#TheyAreUs Intentions. 
Figure 10. Tweet Feeling Broken

Figure 11. Tweet Keep Terrorism Out Of Our Country

Figure 12. Tweet In My Country

Figure 13. Tweet We Are Not Different

Figure 14. Tweet No Us and Them 
Figure 15. Tweet \#ThisIsNotUs Is So Bitter

Figure 16. Tweet Hala Nasr Reflecting About Collective Complicity

$$
\text { hala } \quad \text { Mar } 16
$$

Someone just told me about the \#ThislsUs hashtag which I think is about reflecting about collective complicity in white supremacy and racism... check it out and see if that makes sense for you $\mathrm{O}$
Q 1
† 2
08
- Mar 16

Replying to

This is why I'm going with the "This Is Us" because we need to own the fact that our complacency has lead to this attack

As much as we are not all white supremacists, too many of us have been more comfortable in not confronting it than having tough conversations
Q 4
Ł๖ 1
( 4

hala

- Mar 16

Yeah that hashtag makes sense to me too $(8)$

Q 七】 05 
Figure 17. From \#TheyAreUs to \#TheyAreUsShutDown
Hala
- Jun 11
You are not us, our experiences are not yours. Solidarity is about actions, but you didnt listen then, and are you even going to listen now? \#TheyAreUsShutdown

Hala Mar 16, 2019
This is why I can't relate to the \#TheyAreUs hashtag. My experiences
as a Muslim aren't yours. To be in solidarity with me and other
Muslims doesn't need to involve the erasure of our differences. Please
show your solidarity by holding racists accountable. That's all I ask.
Show this thread
$\begin{array}{ll}\text { 七】 } 16 & \text { ○ } 57\end{array}$

Figure 18. Combining \#TheyAreUsShutDown and \#GiveNothingToRacism 
Figure 19. Tweet NZHRC White Defensiveness.

Figure 20. Give Nothing To Racism Taika Waititi Video. 
Figure 21. NYPD Tweet and Tag \#myNYPD.

Figure 22. Tweet Hashtag Hijacking \#myNYPD. 
Figure 23. Tweet Playing and Pranking Acts of Subversion

Figure 24. Tweet Reclaiming \#ProudBoys

Figure 25. A Deeper Self 


\section{Interviewee Table}

\begin{tabular}{|c|c|c|c|c|c|c|}
\hline $\begin{array}{l}\text { Interviewee } \\
\text { Number }\end{array}$ & $\begin{array}{l}\text { Interview } \\
\text { Role } \\
\text { Interviewee } \\
\end{array}$ & $\begin{array}{l}\text { Summary of } \\
\text { Position }\end{array}$ & $\begin{array}{l}\text { Date of } \\
\text { Interview }\end{array}$ & $\begin{array}{l}\text { Location of } \\
\text { Interview }\end{array}$ & $\begin{array}{l}\text { Follow } \\
\text { Up } \\
\text { Date } \\
\end{array}$ & $\begin{array}{l}\text { Hashtag(s) } \\
\text { Used }\end{array}$ \\
\hline 1 & Hashtag User & $\begin{array}{l}\text { Alice Canton } \\
\text { Aotearoa New } \\
\text { Zealand based } \\
\text { theatre artist }\end{array}$ & $\begin{array}{l}11 \text { June } \\
2020\end{array}$ & $\begin{array}{l}\text { Conducted } \\
\text { via Zoom }\end{array}$ & $\begin{array}{l}5 \text { May } \\
2021\end{array}$ & $\begin{array}{l}\text { \#TheyAreUs } \\
\text { \#ThisIsNotUs } \\
\text { \#ThisIsUs }\end{array}$ \\
\hline 2 & Hashtag User & $\begin{array}{l}\text { Hala Nasr } \\
\text { gender-based } \\
\text { violence researcher } \\
\text { and practitioner }\end{array}$ & $\begin{array}{l}16 \text { October } \\
2020\end{array}$ & $\begin{array}{l}\text { Conducted } \\
\text { via Zoom }\end{array}$ & $\begin{array}{l}10 \\
\text { Novemb } \\
\text { er } 2020\end{array}$ & $\begin{array}{l}\text { \#TheyAreUs } \\
\text { \#ThisIsNotUs } \\
\text { \#ThisIsUs }\end{array}$ \\
\hline 3 & $\begin{array}{l}\text { Hashtag User } \\
\text { and } \\
\text { Campaign } \\
\text { Designer }\end{array}$ & $\begin{array}{l}\text { Ryan Mearns } \\
\text { Senior Advisor } \\
\text { Human Rights } \\
\text { Commission Digital } \\
\text { Campaign Manager }\end{array}$ & $\begin{array}{l}20 \text { June } \\
2019\end{array}$ & $\begin{array}{l}\text { Victoria } \\
\text { University } \\
\text { of } \\
\text { Wellington }\end{array}$ & $\begin{array}{l}\text { 17 April } \\
2021\end{array}$ & $\begin{array}{l}\text { \#ThatsUs } \\
\text { \#GiveNothing } \\
\text { ToRacism } \\
\text { \#VoiceOfRaci } \\
\text { sm }\end{array}$ \\
\hline 4 & $\begin{array}{l}\text { Hashtag } \\
\text { Campaign } \\
\text { Designer }\end{array}$ & $\begin{array}{l}\text { New Zealand Human } \\
\text { Rights Commission } \\
\text { Digital Campaign } \\
\text { Manager }\end{array}$ & $\begin{array}{l}20 \text { June } \\
2019\end{array}$ & $\begin{array}{l}\text { Victoria } \\
\text { University } \\
\text { of } \\
\text { Wellington }\end{array}$ & NA & $\begin{array}{l}\text { \#ThatsUs } \\
\text { \#GiveNothing } \\
\text { ToRacism } \\
\text { \#VoiceOfRaci } \\
\text { sm }\end{array}$ \\
\hline 5 & $\begin{array}{l}\text { Hashtag } \\
\text { Campaign } \\
\text { Designer }\end{array}$ & $\begin{array}{l}\text { Media and Public } \\
\text { Affairs Officer at the } \\
\text { New Zealand } \\
\text { Embassy in Paris }\end{array}$ & $\begin{array}{l}5 \text { September } \\
2019\end{array}$ & $\begin{array}{l}\text { New } \\
\text { Zealand } \\
\text { Embassy in } \\
\text { Paris }\end{array}$ & NA & \#TheyAreUs \\
\hline 6 & $\begin{array}{l}\text { Hashtag } \\
\text { Campaign } \\
\text { Designer }\end{array}$ & $\begin{array}{l}\text { Assistante auprès de } \\
\text { l'Ambassadeur pour } \\
\text { le Numérique } \\
\text { Associated with the } \\
\text { Christchurch Call }\end{array}$ & $\begin{array}{l}27 \text { August } \\
2019\end{array}$ & $\begin{array}{l}\text { Minister Dw } \\
\text { L'Europe Et } \\
\text { Des Affaires } \\
\text { Eangeres } \\
130 \text { rue de } \\
\text { l'Université } \\
\text { - } 75007 \\
\text { Paris } \\
\end{array}$ & NA & \#TheyAreUs \\
\hline 7 & $\begin{array}{l}\text { Hashtag } \\
\text { Campaign } \\
\text { Designer }\end{array}$ & $\begin{array}{l}\text { Tim Francis } \\
\text { Media Services } \\
\text { UNESCO }\end{array}$ & $\begin{array}{l}\text { 4 September } \\
2019\end{array}$ & $\begin{array}{l}\text { UNESCO } \\
\text { Headquarte } \\
\text { rs Paris }\end{array}$ & NA & $\begin{array}{l}\text { \#ThatsUs } \\
\text { Associated } \\
\text { with NZHRC }\end{array}$ \\
\hline 8 & $\begin{array}{l}\text { Hashtag } \\
\text { Campaign } \\
\text { Designer }\end{array}$ & $\begin{array}{l}\text { Alfredo Trujillo } \\
\text { Fernandez } \\
\text { Chief Media Services } \\
\text { UNESCO }\end{array}$ & $\begin{array}{l}5 \text { September } \\
2019\end{array}$ & $\begin{array}{l}\text { UNESCO } \\
\text { Headquarte } \\
\text { rs Paris }\end{array}$ & NA & $\begin{array}{l}\text { \#ThatsUs } \\
\text { Associated } \\
\text { with NZHRC }\end{array}$ \\
\hline
\end{tabular}




\section{Glossary}

affordances: a combination of the various underlying social and structural influences that are found in any given environment. See section 1.3 The Affordances of Collectivising Hashtags for a full discussion of the development of the term affordances.

algorithms: algorithms are code that specify the rules for how a group of data behaves. On social media platforms, algorithms are designed to fulfil certain functions, such as to maintain, organise and rank on platform information.

Aotearoa: is the indigenous name in te reo Māori for the country of New Zealand (translates to: land of the long white cloud).

architecture: I refer to the 'architecture' of hashtags as the soft structures of digital networks, social media platforms and processes, and hashtag functionalities and their affects. The term 'architecture' is used in connection with the field of Information Architecture to address the design of information spaces as a process, in which platform owners, software engineers, and hashtag users all contribute to the creation of online spaces as its 'architects.'

collectivising hashtags: my term for hashtags which are characterised by their use of pronouns to inclusively identify oneself with another or Others. See section 1.1 Collectivising Hashtags: A Growing Phenomenon.

counterpublics: Jackson and Foucault Welles use the term 'counterpublics' to describe the unique sites and methods used by marginalised groups to produce nondominant forms of knowledge. See section 1.4 Combining Feminist, Media Studies and International Relations Theory for a full discussion of the experiences of counterpublics.

crooked platform: I argue social media platforms are the modern, digital equivalent of the crooked room (defined below). Building on Harris-Perrys' arguments of misrecognition, I assert that the affordances of collectivising hashtags allow privileged bodies to create a 'crooked platform' in which they encounter and Other non-dominant bodies. The concept of the crooked platform is discussed in-depth in section 4.4 The Crooked Platform.

crooked room: Melissa Harris-Perry uses the concept of the 'crooked room' in her book Sister Citizen: Shame, Stereotypes and Black Women in America to illustrate how Black women are confronted with race and gender stereotypes and are standing in a 'crooked' room in which they have to navigate their way up. The concept of the crooked room is discussed in-depth in section 4.4 The Crooked Platform.

CTDA: Critical Technocultural Discourse Analysis is a multimodal analytic technique developed by André Brock for the investigation of internet and digital phenomena, artefacts and culture.

embodied digital praxis: An embodied digital praxis breaks down the cartesian divide between online and offline renderings of self, arguing it is impossible to dissociate from our bodies even in online spaces. It emphasises the felt experiences within the physical body 
immersed in online atmospheres and the affecting nature of online performances on our own bodies and on others. An embodied digital praxis turns people's attention inward, calling those in positions of privilege to become more vulnerable and aware of the affecting nature of their digital practices. See section 3.4 Emancipating 'Us' Vulnerability and the Role of the Discursively Privileged Subject.

folksonomy: folksonomy refers to a non-hierarchical categorisation or sorting of information on social media platforms. Mathes refers to the 'folksonomic approach' where trending hashtags are determined by users rather than added by content creators. See section 4.1 Underlying Technological Inequalities (a) Folksonomy.

hashtag hijacking: hijacking happens when a hashtag is used for a different purpose than the one originally intended. Hashtag hijacking is discussed in section 5.2 The Rise and Risk of User Participation or see Jackson, Bailey and Foucault Welles, "Hijacking \#myNYPD: Social Media Dissent and Networked Counterpublics."

Jacinda Ardern: is an Aotearoa New Zealand politician who has been serving as the $40^{\text {th }}$ Prime Minister of New Zealand and the leader of the Labour Party since 2017.

looped gaze: the looped gaze occurs when a privileged person encounters a minority body and only recognises the known and familiar aspects of themselves within the Other body. The looped gaze is discussed in section 1.1 Collectivising Hashtags: A Growing Phenomenon.

Māori: the indigenous Polynesian people of Aotearoa New Zealand.

marginalised bodies: bodies that experience systemic oppression that impacts their corporeal livelihood. Marginalised bodies experience a level of precarity that dominant individuals with differing proximity to Whiteness, heterosexuality, ableness, and other normative conceptions of self do not experience.

mana: in te reo Māori the term means prestige, authority, control, power, or influence (mana is used more colloquially to refer to a person's charisma, spirit or persisting force). The more prestigious the event, person or object, the more it is surrounded by mana. There is also an element of jurisdiction, mandate or stewardship associated with the term when used in relation to natural resources.

manaakitanga: in te reo Māori the term comprises hospitality, kindness, generosity, support and is the process of showing respect, generosity and care for others.

Other(ing/ness): I use critical feminist constructs of 'Other' or 'Othering' to describe the act of marginalisation where certain individuals or groups are labelled as not fitting within the norms of the dominant patriarchal society. Where Man is constructed as subject, Woman is constructed as Other. As such, the concept of Other tells us far more about patriarchal and dominant systems of marginalisation (see Davis, Embracing Alterity). More recently, intersectional studies have shown how generalised conceptions of subject and Other are present in specific intersecting forms that reflect dominant gender, race, ethnicity, religion, age, sexual orientation, and other structural positions (see Mari Tripp, "Retheorizing Human Security through a gender lens.") 
Pākehā: in te reo Māori the term refers to a New Zealander of European descent, originally applied to English-speaking Europeans living in Aotearoa, New Zealand.

precarity: precarity is a politically induced condition in which certain populations suffer from failing social and economic networks of support and become differentially exposed to injury, violence and death. See section 1.2 Critical Feminist Framework, see also Butler, Frames of War, 25.

precariousness: precariousness is a shared human condition, where all lives are dependent on circumstances beyond one's control (in that life's persistence is not guaranteed and can be ended at any moment). See section 1.2 Critical Feminist Framework, see also Butler, Frames of War, 25.

privileged bodies: privilege is about ones proximity to power, opportunity, and patterns of thinking associated with White people. Rather than being conceived as the additional benefits, advantages and immunity that come from having a white body - privileged is better conceived as the blind spots, unknowing, and willful ignorance that stem from settler-colonial histories and that remain invisible to all but non-white people.

serendipity: social media platforms like Twitter are designed for surprising and chance occurrence or 'stumbling upon' information. Algorithm's functionality allows for serendipity that enables users to go 'off the beaten track' when encountering information and other people in online spaces. See section 4.1 Underlying Technological Inequalities (b) Serendipity.

standing under: Krista Ratcliffe inverts the term 'understanding' to 'standing under' redefining it as a practice where those in a position of privilege consciously listen to the discourse that surrounds us and others while acknowledging the particular and very fluid standpoints from which it comes. Standing under is discussed in-depth in section 5.2 The Rise and Risks of User Participation (c) The Limits of Agency and Counterpublic Advocacy, see also Ratcliffe, Rhetorical Listening : Identification, Gender, Whiteness.

spreadability: the term 'spreadability' refers to the function of the hashtag in terms of its capacity to reach a wide audience. See section 3.2 Are They 'Us'? How Collectivising Hashtags Reinforce the Systemic Issues They Ostensibly Oppose. See also, Groeneveld, "Are We All Pussy Riot? On Narratives of Feminist Return and the Limits of Transnational Solidarity."

Tauiwi: In te reo Māori the term refers to a foreigner or non-Māori immigrant to Aotearoa New Zealand. This term can refer to first generation immigrants, refugees and other non-Māori people who have come from afar.

Te Tiriti o Waitangi: is an agreement drawn up between representatives of the British Crown and representatives of Māori iwi and hapū. It was named after the place in the Bay of Islands where it was first signed on $6^{\text {th }}$ February 1840 . The principles of Te Tiriti o Waitangi, as articulated by the Courts and the Waitangi Tribunal, provide the framework for how Pākehā can work towards meeting their obligations under Te Tiriti. 
trending: trending hashtags are intended to capture and collate topics that see a sudden surge in popularity. See section 4.1 Underlying Technological Inequalities (c) Trending Topics.

unmarked: unmarked refers to the historical creation of racial identities and the privileges of racial invisibility of the dominant (White) culture. The dominant culture is consequently 'unmarked' and unraced because all other cultures are understood (i.e. marked) relative to their differences to Whiteness. Beausoleil explains the condition of being 'unmarked' as a highly particular one, borne of settler colonial histories that presume not only that a universal ground for commonality, recognition, and reconciliation exists, but that a Western brokering of this peace through a difference-blind approach is objective. See section 3.2 Are They 'Us'? How Collectivising Hashtags Reinforce Systemic Issues They Ostensibly Oppose. See also, Beausoleil, "'Gather Your People': Learning to Listen Intergenerationally in Settler-Indigenous Politics."

vulnerable subjects: vulnerable subjects refers specifically to bodies who suffer the corporeal consequences of vulnerability, as opposed to our universal capacity for vulnerability, in order to highlight the inequality that inherently exists between the actual lived experiences of privileged onlookers and Others.

whakapapa: in te reo Māori the term comprises genealogy, genealogical table, lineage, and descent. Reciting whakapapa was, and is, an important skill and reflects the importance of genealogies in Māori society in terms of leadership, land and fishing rights, kinship and status. It is central to all Māori institutions.

willful ignorance: Tuana describes 'willful ignorance' as a deception that we impose upon ourselves. Willful ignorance is actively cultivated and must be continually maintained because it appears to be in privileged bodies' best interest to remain ignorant. See section 1.2 Feminist Conceptual Framework, see also Tuana, "The Speculum of Ignorance: The Women's Health Movement and Epistemologies of Ignorance."

White(ness): refers to the structures associated with a person's proximity to 'Whiteness' and privilege. The study of Whiteness negates colour or difference blind approaches to International Relations by looking at the particularities of white identity, the historical and current processes of colonisation that produce White privilege, as well as the dominant nature of White culture, and possible processes for social change that affect white identity and systemic racism.

Hashtag Glossary:

\#AllLivesMatter and \#BlueLivesMatter: the \#AllLivesMatter hashtag first emerged in 2016 and has since come to be associated with resistance to and criticism of the Black Lives Matter movement. Similar to \#AllLivesMatter, the \#BlueLivesMatter hashtag is used to resist the Black Lives Matter movement and to reassert the value of state police. Following the killing of George Floyd in May of 2020, the \#BlackLivesMatter hashtag was met with resistance from the \#AllLivesMatter and \#BlueLivesMatter hashtags. 
\#AllMenCan, \#IveDoneThat, and \#IWillChange: are male allyship hashtags that emerged following the \#MeToo movement in 2017. They encouraged men to share stories of sexism and admit to problematic behavior. These hashtags are discussed in section 5.2 The Rise and Risks of Audience Participation, (c) The Limits of Agency and Counterpublics Advocacy.

\#AmINext: was a hashtag created by indigenous Canadian women Holly Jarrett to call attention to the high rate of missing and murdered Indigenous women in Canada and trended in September 2014.

\#BlackLivesMatter: the Black Lives Matter hashtag movement began in 2013 after the racially motivated killing of Black teenager Trayvon Martin. At the time the hashtag \#BlackLivesMatter was created to share the protest on social media, it has since become a global movement.

\#BlackOutTuesday: \#BlackOutTuesday was launched by the music industry as an act of passive resistance against racism and police brutality that aims to silence or suspend online interactions in remembrance of George Floyd, Ahmaud Arbery and Breonna Taylor. \#BlackOutTuesday encouraged users to share a black image on their Instagram, Twitter and Facebook feeds on $2^{\text {nd }}$ June 2020 as an act of resistance. See section 5.2 Performances of Self, (c) The Limits of Agency and Counterpublic Advocacy.

\#BringBack0urGirls: a hashtag started in 2014 by Nigerians and adopted globally in response to the kidnapping of 276 schoolgirls by terrorist group Boko Haram.

\#CrimingWhileWhite: trended following the sentencing of Eric Garner's killer where White people detailed the crimes they committed without legal redress.

\#Ferguson: the hashtag campaign \#Ferguson which trended locally (following the shooting of Michael Brown, a Black teenager in Ferguson, Missouri) yet failed to trend in the United States.

\#GirlsLikeUs: the hashtag \#GirlsLikeUs has been used for trans-feminist advocacy and closed community building. See section 5.1 Networked Acts (b) Curated communities

\#HandsUpDontShoot: the slogan 'hands up, don't shoot' was coined in Ferguson in reference to witnesses who explained Michael Brown's hands were raised at the time of his shooting by police in 2014. The hashtags' popularity led to a discriminatory mutation by right-wing groups who began sharing the hashtag \#PantsUpDontLoot in attempt to counter the narrative of state racism that emerged in the wake of Brown's killing.

\#HeadscarvesForHumanity and \#ScarvesInSolidarity: these hashtags called women to wear headscarves in a display of solidarity with the Muslim community on the one week anniversary of the terrorist attacks on the Muslim community of Ōtautahi, Christchurch. It took place 22nd March 2019. These hashtags are discussed in section 3.2 Are They Us? How Collectivising Hashtags Reinforce the Systemic Issues They Ostensibly Oppose.

\#HeForShe: the \#HeForShe hashtag was launched by the United Nations Women (the United Nations entity for Gender Equality and the Empowerment of Women) in 2014. It is a male allyship hashtag that works towards gender equality. See section 5.2 The Rise and Risks of User Participation, (c) The Limits of Agency and Counterpublic Advocacy. 
\#IAmMalala: trended in 2012 in response to the attempted killing of Pakistani education activist Malala Yousafzai by Taliban gunmen.

\#IAmJewish: the hashtag \#IAmJewish trended following a series of attacks against Jewish Communities in France in 2015. The statement 'I am Jewish' was based on the final words of American Jewish man Daniel Pearl a journalist for the Wall Street Journal who was kidnapped and beheaded by terrorists in Pakistan in 1963.

\#IAmRefugee and \#KiyiyaVuranInsanlik: are hashtags that trended in 2016 in relation to the human rights abuses against Syrians civilians, the hashtag \#IAmRefugee trended following the bombings in Aleppo. The most widely circulated photograph of a Syrian toddler lying face down on the beach in the Turkish resort town of Budrum lead to the hashtag \#KiyiyaVuranInsanlik which literally translates to 'humanity washed ashore' bringing international attention to the refugee crisis.

\#ICantBreathe: this hashtag was created in 2014 in response to the death of Eric Garner after police officers threw him to the ground and put him in a chokehold. Garner's last words, as recorded on a cell phone video, were: 'I can't breathe.'

\#IfTheyGunnedMeDown: the hashtag was a response to how Black teenager Michael Brown was portrayed in the media following his unarmed shooting by police. The hashtag aimed to address a rhetorical question among the Black community: 'If they gunned me down,' what picture would the media use to represent me? And how do those negative stereotypes portray and affect Black communities.

\#JeSuisCharlie: the '\#JeSuis' (translates to: I am) hashtag trended following the 2015 terrorist attack on the Paris office of satirical newspaper Charlie Hebdo.

\#MeToo: the Me Too movement was initially voiced by Tarana Burke in 2006. The hashtag denoting the political campaign to both express solidarity amongst women who have been sexually assaulted and/or harassed, as well as hold alleged perpetrators accountable. It trended on Twitter in 2017 following widespread sexual-abuse allegations against director Harvey Weinstein.

\#MuslimRage: the \#MuslimRage hashtag was created in response to a 2012 Newsweek article, Muslim Rage and the Last Gasp of Islamic Hate, that spouts racist and stereotypical perspectives about Muslim culture. \#MuslimRage allowed for individuals to respond (often sarcastically) with their own lived experiences that negate and challenge stereotypes.

\#MyNYPD: the \#MyNYPD hashtag was devised by the New York Police department's ("NYPD") public relations team. The original purpose of the hashtag was for users to share positive stories and images of their encounters with the NYPD. However, it was swiftly hijacked by activists to tweet about seemingly endless stories of police brutality. See section 5.2 The Rise and Risks of User Participation, (a) Comedy, Tragedy and Performative Acts of Subversion. 
\#NotYourAsianSidekick: activist and graduate student Suey Park launched \#NotYourAsianSidekick in 2014 in attempt to dismantle White, hetero, patriarchal, corporate America.

\#NotYourNarrative: \#NotYourNarrative was started by Roqayah Chamseddine in 2014 to challenge Western media's portrayal of Muslim women.

\#ProudBoys: the hashtag \#ProudBoys headlined following a speech by former President Donald Trump when he failed to condemn a White supremacy group 'Proud Boys' who often spout White nationalism, anti-Muslim, and misogynistic rhetoric. The hashtag \#ProudBoys was soon hijacked by gay and queer men with pictures of their partners and families.

\#SayHerName: the \#SayHerName hashtag is a social movement that began in 2015 to address the invisibility of Black Women in mainstream new media (and within the Black Lives Matter movement). It seeks to raise awareness for Black female victims of police brutality and antiBlack violence in the United States.

\#SolidarityIsForWhiteWomen: hood feminism blogger Mikki Kendall started the \#SolidarityIsForWhiteWomen hashtag in 2014 to vent her frustration over the reaction to gender studies professor Hugo Schwyzer's admission that he had slept with former students and used his position to silence women of colour bloggers.

\#ThatsUs and \#GiveNothingToRacism: a digital storytelling campaign launched in 2016 by the New Zealand Human Rights Commission ("NZHRC") to combat racism in Aotearoa, New Zealand. See section 2.4 Case Studies (b) \#ThatUs.

\#ThisIsNotUs and \#TheyAreUs: trended following the terrorist attacks on the Muslim community of Ōtautahi, Christchurch on Friday 15th March 2019. See section 2.4 Case Studies (a) \#TheyAreUs and \#ThisIsNotUs.

\#VictimBlaming and \#SafetyTipsForLadies: were hashtags used as sarcastic takedowns of victim blaming culture by feminists on Twitter in 2013.

\#WeAreAllPussyRiot: the hashtag \#WeAreAllPussyRiot trended in response to the incarceration of feminist punk rock group Pussy Riot members following a protest at a Russian Orthodox church in 2012.

\#WeAreThe99\% and \#0ccupyWallSteet: 'We are the 99\%' is a political slogan widely used in 2011 during the Occupy Wall Street and broader Occupy movements. This hashtag was used concurrently with \#OccupyWallStreet.

\#WeAreTrayvonMartin: a hashtag that trended in 2012 following following the racially motivated shooting of 17 year old Trayvon Benjamin Martin, a Black American from Miami Gardens, Florida, who was fatally shot in Sanford, Florida by George Zimmerman.

\#WhyIStayed and \#BeenRapedNeverReported: the \#WhylStayed hashtag trended in November 2014, following a domestic abuse case with Baltimore Ravens running back and his then fiancé Janay Rice, which sparked a conversation about why abuse victims 'choose' to stay 
in abusive relationships. In 2018 the hashtag \#BeenRapedNeverReported was added to the conversation about why women chose not to report instances of sexual harassment and violence to police.

\#YesAllWomen and \#YesAllWhiteWomen: the \#YesAllWhiteWomen hashtag was created in response to the \#YesAllWomen hashtag that trended following the Isla Vista massacre, where shooter Elliot Rodgers killed 6 people and injured 14 others as revenge for perceived sexual rejection by women. The hashtag \#YesAllWhiteWomen addressed the lack of intersectional women's experiences within conversations on gendered violence. See section 5.1 Networked Acts (b) Curated Communities.

\#FastTailedGirls: \#FastTailedGirls was created by Mikki Kendall and Jamie Nesbitt Golden following the American Music Awards in 2013 in which a performance by singer R. Kelly displayed predatory sexual behaviour towards Black women. See section 5.1 Networked Acts, (b) Curated Communities.

\#YouOKSis: Is part of an intersectional 'hashtag feminist' movement that challenges street harassment. The aim is to highlight the power of Black feminism politics online that challenges the exclusivity of white feminism. See section 5.1 Networked Acts (b) Curated Communities. 


\section{Bibliography}

Action Station Aotearoa, “Become a Tauiwi Tautoko Volunteer," 2 April, 2019.

https://actionstation.medium.com/tauiwi-tautoko-8851ebdb0c6

Åhäll, Linda. "Affect as Methodology: Feminism and the Politics of Emotion1." International Political Sociology 12, no. 1 (2018): 36-52. doi: 10.1093/ips/olx024.

Åhäll, Linda and Thomas A. Gregory. "Security, Emotions, Affect." Critical studies on security 1, no. 1 (2013): 117-120. doi: 10.1080/21624887.2013.790217

Ahmed, Sara. The Cultural Politics of Emotion. Second Ed. Edinburgh: Edinburgh University Press, 2014.

Aly, Waleed. “Christchurch Mosque Shootings: Australian Muslim TV Host Waleed Aly's Emotional Message - 'I'm Not Shocked.'” New Zealand Herald, 16 March, 2019 https://www.nzherald.co.nz/nz/christchurch-mosque-shootings-australian-muslim-tvhost-waleed-alys-emotional-message-im-notshocked/XE7XRJTYWF64MR737J7SXCMOT4/

Andén-Papadopoulos, Kari. "Citizen Camera-Witnessing: Embodied Political Dissent in the Age of 'Mediated Mass Self-Communication.'” New Media \& Society 16, no. 5 (2014): 753-69, doi: $10.1177 / 1461444813489863$.

Anderson, Ben. "Affective Atmospheres." Emotion, Space and Society 2, no. 2 (2009): 77-81. doi: 10.1016/j.emospa.2009.08.005

Anderson, Margret. "How Feminist in China Are Using Emoji to Avoid Censorship: There are other ways to write \#MeToo," Wired, 3 March, 2018, http://www.wired.com/story/china-feminism-emoji-censorship/

Ardern, Rt Hon Jacinda. "Further update from Jacinda Arden on Christchurch mass shooting." Official Website of the New Zealand Government. 15 March, 2019. https://www.beehive.govt.nz/release/further-update-jacinda-ardern-christchurchmass-shooting

- - - "Ministerial Statements - Mosque Terror Attacks Christchurch." Official Website of the New Zealand Government. 19 March, 2019.

https://www.parliament.nz/en/pb/hansarddebates/rhr/combined/HansDeb_2019031 9_20190319_08

- - - "Christchurch Call to Eliminate Terrorist and Violent Extremist Online Content," Official Website of the New Zealand Government. 16 May 2019, https://www.beehive.govt.nz/release/christchurch-call-eliminate-terrorist-and-violentextremist-online-content-adopted

Aziz, Omid and Manohar Paluri. "Engineering for nostalgia: Building a personalized 'On This Day' experience." Facebook Code. 17 March, 2021. https://code.facebook.com/posts/1748968875380127/engineering-for-nostalgia- 
building-a-personalized-on-this-day-experience/

Baker, Paul and Amanda Potts. "Why Do White People Have Thin Lips?' Google and the Perpetuation of Stereotypes via Auto-Complete Search Forms." Critical Discourse Studies 10, no. 2 (2013): 187-204. doi: 10.1080/17405904.2012.744320

Bandyopadhyay, Ranjan and Patil Vrushali. "The white woman's burden' - the racialized, gendered politics of volunteer tourism." Tourism Geographies. 19 no. 4 2017, doi:10.1080/14616688.2017.1298150.

Barry, Brian. Culture and Equality: an Egalitarian Critique of Multiculturalism. England, Cambridge: Polity Press, 2011.

Bauman, Zygmunt. Living on Borrowed Time: Conversations with Citali Rovirosa-Madrazo. UK, Cambridge: Polity 2013.

Beausoleil, Emily. "Embodying an Ethics of Response-Ability." Borderlands 14, no. 2 (2015)" 116.

- - - "Responsibility as Responsiveness: Enacting a Dispositional Ethics of Encounter." Political Theory 45, no. 3 (2017): 291-318. doi: 10.1177/0090591716651109.

_-_.'“Gather Your People': Learning to Listen Intergenerationally in Settler-Indigenous Politics." Political Theory 48, no. 6 (2020): 665-691. doi: 10.1177/0090591720919392.

Beauvoir, Simone de. The Second Sex . Edited by Constance. Borde and Sheila. MalovanyChevallier. London: Vintage, 2010.

Beer, David. "The Social Power of Algorithms." Information, Communication \& Society 20, no. 1 (2017): 1-13. doi:10.1080/1369118X.2016.1216147.

Bell, Avril, Vivienne Elizabeth, Tracey McIntosh, and Matt Wynyard. A Land of Milk and Honey?: Making Sense of Aotearoa New Zealand. New Zealand, Auckland: Auckland University Press, 2017.

Berents, Helen. "Hashtagging Girlhood: \#IAmMalala, \#BringBackOurGirls and Gendering Representations of Global Politics." International Feminist Journal of Politics 18, no. 4 (2016): 513-27. doi: 10.1080/14616742.2016.1207463.

Berentson-Shaw, Jess. “This Has Been Us. We Need to Change It.” Newsroom. 19 March, 2019. https://www.newsroom.co.nz/this-has-been-us-we-need-to-change-it.

Berila, Beth. "White Urgency To End Racism: why now?" Open Democracy. 23 June, 2020 https://www.opendemocracy.net/en/transformation/white-urgency-end-racism-whynow/?fbclid=IwAR3i8PLIbFiPrDUlRFW8drpaHVPpq3dC4RdGOeS37QlylbBhe6wRibJlm4 A.

Bijker, Wiebe E. and John Law. Shaping Technology/building Society Studies in Sociotechnical Change. Cambridge, Mass: MIT Press, 1992. 
Black Lives Matter. “About.” (accessed 19 March 2021) https://blacklivesmatter.com/about.

Bleiker, Roland, and Emma Hutchison. "Fear No More: Emotions and World Politics." Review of International Studies 34, (2008): 115-35. doi: 10.1017/S0260210508007821.

Bliddal, Henrik, Casper Sylvest, and Peter Wilson. Classics of International Relations Essays in Criticism and Appreciation England, Oxfordshire: Routledge, 2013.

Blommaert, Jan, and Chris Bulcaen. "Critical Discourse Analysis." Annual Review of Anthropology 29, no. 1 (2000): 447-466. doi: 10.1146/annurev.anthro.29.1.447

Boler, Megan. “The Risks of Empathy: Interrogating Multiculturalism's Gaze.” Cultural Studies 11, no. 2 (1997): 253-73. doi: 10.1080/09502389700490141.

Boler, Megan, Averie Macdonald, Christina Nitsou and Anne Harris. "Connective labour and social media: Women's roles in the 'leaderless' occupy movement," Convergence 20, no. 4 (2014): 438-460, doi:10.1177/1354856514541353

Boler, Megan, and Elizabeth Davis. "The Affective Politics of the 'Post-Truth' Era: Feeling Rules and Networked Subjectivity." Emotion, Space and Society 27 (2018): 75-85.

doi: 10.1016/j.emospa.2018.03.002.

Boltanski, Luc. Distant Suffering: Morality, Media and Politics. Cambridge: Cambridge, 1999. doi: 10.1017/CB09780511489402

Bonilla, Yarimar and Jonathan Rosa."\#Ferguson: Digital Protest, Hashtag Ethnography, and the Racial Politics of Social Media in the United States." American Ethnologist 42, no.1 (2015): 4-17. doi: 10.1111/amet.12112.

Boyatzis, Richard E. Transforming Qualitative Information: Thematic Analysis and Code Development. Thousand Oaks, CA: Sage Publications, 1998.

Boyd, Douglas A and Mary A. Larson. Oral History and Digital Humanities: Voice, Access, and Engagement. New York: Palgrave Macmillan, 2014. doi: 10.1057/9781137322029

Brager, Jenna. "The Selfie and the Other: Consuming Viral Tragedy and Social Media (after)Lives." International Journal of Communication 9, no. 1 (2015): 1660-71.

Brandtzaeg, Petter Bae. "Facebook Is No 'Great Equalizer': A Big Data Approach to Gender Differences in Civic Engagement Across Countries." Social Science Computer Review 35, no. 1 (2017): 103-125. Doi: 10.1177/0894439315605806

British Psychological Society. Ethics Guidelines for Internet-mediated Research. April 2017. www.bps.org.uk/publications/policy-and-guidelines/ research-guidelines-policydocuments/research- guidelines-policy 
Brock, André. "Critical Technocultural Discourse Analysis." New Media \& Society 20, no. 3 (2018): 1012-30. doi: 10.1177/1461444816677532.

- - - .From the Blackhand Side: Twitter as a Cultural Conversation." Journal of Broadcasting \& Electronic Media 56, no. 4 (2012): 529-49. doi: 10.1080/08838151.2012.732147.

-_-Distributed Blackness: African American Cybercultures, New York: New York University Press, 2019.

Burgess, Jean, Alice Marwick, and Thomas Poell. The SAGE Handbook of Social Media. London: SAGE Publications Ltd, 2018. doi: 10.4135/9781473984066.

Butcher, Taina and Anne Helmond. "The Affordance of Social Media Platforms" in The SAGE Handbook of Social Media. eds., Jean Burgess, Alice Marwick, and Thomas Poell, SAGE Publications Ltd., 2018: 233-250, doi: 10.413/9781473984066.n14

Butler, Judith. Frames of War: When Is Life Grievable? London: Verso, 2009.

- - Gender Trouble Feminism and the Subversion of Identity. New York: Routledge, 1999.

- - - Precarious Life: The Powers of Mourning and Violence. London: Verso, 2006.

Callahan, John F. Ralph Ellison's Invisible Man: A Casebook. New York: Oxford University Press, 2004.

Centola, Damon, and Michael Macy. "Complex Contagions and the Weakness of Long Ties." The American journal of sociology 113, no. 3 (2007): 702-734. doi: 10.1086/521848

Charmaz, Kathy. "Teaching Theory Construction With Initial Grounded Theory Tools: A Reflection on Lessons and Learning." Qualitative health research 25, no. 12 (2015): 1610-1622. doi: 10.1177/1049732315613982

Chen, Andrew. Shouting Zeros and Ones: Digital Technology, Ethics and Policy in New Zealand Wellington: Bridget Williams Books, 2020. doi: 10.7810/978198858

Chen, Serena, "A Framework for Response He Anga Urupare" in Andrew Chen (Ed.), Shouting Zeros and Ones: Digital Technology Ethics and Policy in New Zealand: Bridget Williams Books, 2020. doi: 10.7810/978198858

Christensen, Henrik Serup. "Political Activities on the Internet: Slacktivism or Political Participation by Other Means?” First Monday (2011). doi: 10.5210/fm.v16i2.3336

Christensen, Miyase, André Jansson, and Christian Christensen. Online Territories: Globalization, Mediated Practice, and Social Space. New York: Peter Lang, 2011.

Clark, Meredith. "Black Twitter: Building Connection through Cultural Conversation." in Hashtag Publics: The Power and Politics of Discursive Networks (ed., Nathan Rambujjana) Vol. 103. New York: Peter Lang AG International Academic Publishers, 2015. Doi: 10.3726/978-1-4539-1672-8 
Clément, Maéva, and Eric Sangar. Researching Emotions in International Relations: Methodological Perspectives on the Emotional Turn. Cham: Springer International Publishing AG, 2017.

Cock, Barbara De, and Andrea Pizarro Pedraza. "From Expressing Solidarity to Mocking on Twitter: Pragmatic Functions of Hashtags Starting with \# Jesuis across Languages" 47, no. 2 (2018): 197-217. https://doi.org/10.1017/S0047404518000052.

Cole, Alyson. "All of Us Are Vulnerable, But Some Are More Vulnerable than Others: The Political Ambiguity of Vulnerability Studies, an Ambivalent Critique." Critical Horizons 17, no. 2 (2016): 260-77. doi: 10.1080/14409917.2016.1153896.

Cole, Teju. "The White-Savior Industrial Complex." The Atlantic, 22 March, 2012. https://www.theatlantic.com/international/archive/2012/03/the-white-saviorindustrial-complex/254843/

Coleman, Stephen. How Voters Feel .ambridge, New York: Cambridge University Press, 2013. Cooper, Belle Beth. "The surprising history of Twitter's hashtag origin." Buffer Blog, 24 September, 2013. https://buffer.com/resources/a-concise-history-of-twitter-hashtagsand-how-you-should-use-them-properly/

Craig, Julia, "Love they Troll: What Pākehā Can Do About Online Racism. " Social Equity and Wellbeing Network, 2 April, 2021. https://www.pantograph-punch.com/posts/love-thytrolls

Dahlberg, Lincoln. "Rethinking the Fragmentation of the Cyberpublic: From Consensus to Contestation." New Media \& Society 9, no. 5 (2007): 827-47. doi: $10.1177 / 1461444807081228$.

Day, Richard. "Who Is This We That Gives the Gift? Native American Political Theory and The Western Tradition." Critical Horizons 2, no. 2 (2001): 173-201. doi: 10.1163/156851601760001300.

Dean, Jodi. Blog Theory: Feedback and Capture in the Circuits of Drive. Cambridge, UK: Polity, 2010.

_——. "Claiming Division, Naming a Wrong." Theory \& Event 14, no. 4 (2011), doi: 10.1353/tae.2011.0069.

- _- "Communicative Capitalism: Circulation and the Foreclosure of Politics." Cultural Politics 1, no. 1 (2005): 51-73. doi: 10.2752/174321905778054845.

- - Democracy and Other Neoliberal Fantasies: Communicative Capitalism and Left Politics. Durham: Duke University Press, 2009.

- - - The Communist Horizon. London; New York: Verso, 2012.

- ——."Why the Net is not a Public Sphere.” Constellations, 10, no.1 (2003): 95-112. doi: $10.1111 / 1467-8675.00315$

De Cock, Barbara, and Andrea Pizarro Pedraza. "From Expressing Solidarity to Mocking on Twitter: Pragmatic Functions of Hashtags Starting with \# Jesuis across Languages." Language in Society 47, no. 2 (2018): 197-217. doi: 10.1017/S0047404518000052. 
Dewey, Caitlin. “\#JeSuisNarcissique: Why Do 'solidarity' Hashtags Only Go Viral When They're Actually about Us?” The Washington Post, 13 January, 2015.

https://www.washingtonpost.com/news/the-

intersect/wp/2015/01/12/jesuisnarcissique-why-do-solidarity-hashtags-only-go-viralwhen-theyre-actually-about-us/?noredirect=on\&utm_term=.ce890a7fa855.

Dijck, José van. "After Connectivity: The Era of Connectication." Social Media + Society 1, no. 1 (2015): 1-2. doi: 10.1177/2056305115578873.

- - - The Culture of Connectivity: A Critical History of Social Media. New York: Oxford University Press, 2013.

Dimond et al "Hollaback!: the role of storytelling online in a social movement organisation." Conference on Computer Supported Cooperative Network. February, 2013 doi: $10.1145 / 2441776.2441831$

Dreher, Tanja. "Eavesdropping with Permission: The Politics of Listening for Safer Speaking Spaces." Borderlands 8, no. 1 (2009): 1-21.

- - - "Listening across Difference: Media and Multiculturalism beyond the Politics of Voice." Continuum 23, no. 4 (2009): 445-58. doi: 10.1080/10304310903015712.

_—_. "Listening After Christchurch." Listening for Media Justice. 7 May, 2019. https://tanjadreher.net/2019/05/07/listening-after-christchurch/

Elliott, Marianne. "After Christchurch: A Tale of Two New Zealands." The Conversationalist. 29 March, 2019. https://conversationalist.org/2019/03/29/a-tale-of-two-new-zealandsand-the-journey-toward-reconciliation/

Enloe, Cynthia. “The Mundane Matters." International Political Sociology 5, no. 4 (2011): 44750. doi: 10.1111/j.1749-5687.2011.00145_2.x.

Ensor, Jamie. "Hate-motivated crime data collection being strengthened as Muslim leaders demand action." Newshub. 19 March, 2021. https://www.newshub.co.nz/home/newzealand/2020/03/hate-motivated-crime-data-collection-being-strengthened-as-muslimleaders-demand-action.html

Eroukmanof, Clara "Responding to terrorism with peace, love and solidarity: 'Je suis Charlie', 'Peace' and 'I heart MCR'. Journal of International Political Theory 15, no.2 (2019): 167187, doi: $10.1177 / 1755088219829884$.

Errington, Katherine in conversation with Anjum Raham "Reducing Online Harm" in Andrew Chen (Ed.), Shouting Zeros and Ones: Digital Technology Ethics and Policy in New Zealand: Bridget Williams Books, 2020. doi: 10.7810/978198858

Fenton, Natalie. “ Digital, Political, Radical." Journal of Communication Inquiry 42, no. 3 (2018): 275-277. doi: 10.1177/0196859918757528.

Fiesler, Casey, and Nicholas Proferes. "Participant' Perceptions of Twitter Research Ethics." Social Media + Society 4, no. 1 (2018): 1-14. doi: 10.1177/2056305118763366 
Leta Hong Fincher. Betraying Big Brother: the Feminist Awakening in China. UK, London: Verso, 2018.

Florini, Sarah. 2019. Beyond Hashtags : Racial Politics and Black Digital Networks. Critical Cultural Communication. New York: New York University Press.

- - Tweets, Tweeps, and Signifyin': Communication and Cultural Performance on Black Twitter. Television \& New Media 15 no. 3 (2014): 223-237. doi: $10.1177 / 1527476413480247$

Fotopoulou, Aristea. Feminist Activism and Digital Networks Between Empowerment and Vulnerability." London: Palgrave Macmillan, 2016.

Garel, Connor. "How K-Pop Fans Are Drowing Out \#AllLivesMatterhashtags." Huffington Post. 3 September, 2020. https://www.huffingtonpost.ca/entry/k-pop-fans-all-livesmatter_ca_5f47e722c5b6cf66b2b4aef5

Gaver, William. "Situating Action II: Affordances for Interaction: The Social Is Material for Design." Ecological psychology 8, no. 2 (1996): 111-129. doi: 10.1207/s15326969eco0802_2

Gerbaudo, Paolo. "The Persistence of Collectivity in Digital Protest." Information, Communication \& Society 17, no. 2 (2014): 264-268.

doi: 10.1080/1369118X.2013.868504

Gerbaudo, Paolo, and Emiliano Treré. "In Search of the 'We' of Social Media Activism: Introduction to the Special Issue on Social Media and Protest Identities." Information, Communication \& Society 18, no. 8 (2015): 865-871. doi: 10.1080/1369118X.2015.1043319.

Ghumkor, Sahar. "The Hypocrisy of New Zealand's 'this Is Not Us' Claim." Aljazeera. 20 March, 2019. https://www.aljazeera.com/indepth/opinion/hypocrisy-zealand-claim190319104526942.html.

Gibson, James J. The Ecological Approach to Visual Perception. Classic ed. London: Routledge, 2015. doi: $10.4324 / 9781315740218$

Gillespie, Tarleton. "The Politics of 'Platforms."” New Media and Society 12, no. 3 (2010): 34764. doi: 10.1177/1461444809342738.

- - - .Can an Algorithms Be Wrong? Twitter Trends, the specter of censorship, and our faith in the algorithms around us." Culture Digitally. 19 October, 2011. https://culturedigitally.org/2011/10/can-an-algorithm-be-wrong/

Gilson, Erinn. "Vulnerability, Ignorance, and Oppression." Hypatia 26, no. 2 (2011): 308-32. doi: 10.1111/j.1527-2001.2010.01158.x.

Glass, Jess, “Is queer a slur? Twitter seems to think so," PinkNews, 19 March, 2018. https://www.pinknews.co.uk/2018/03/19/is-queer-a-slur-twitter-thinks-so/ 
Gleeson, Jessamy and Breanan Turner. "Online Feminist Activism as Performative Consciousness-Raising: A \#MeToo Case Study." in MeToo and the Politics of Social Change. ed. Fileborn, Bianca., and Rachel Loney-Howes. Cham: Springer International Publishing, 2019. Web.

Gluhovic, Milija, Silvija Jestrovic, Shirin Rai, and Michael Saward, The Oxford handbook of Politics and Performance, Oxford University Press 2018: doi: 10.1093/oxfordhb/9780190863456.013.100

Gohdes, Anita R. "Repression in the digital age: Communication technology and the politics of state violence." PhD Dissertation, Universität Mannheim, 2014.

Groeneveld, Elizabeth. "Are We All Pussy Riot? On Narratives of Feminist Return and the Limits of Transnational Solidarity." Feminist Theory 16, no. 3 (2015): 289-307. doi: $10.1177 / 1464700115604134$.

Gross, Terry. “'I Can't Breathe' Examines Modern Policing And The Life And Death Of Eric Garner." Fresh Air. Philadelphia: NPR, 2017. https://search-proquestcom.helicon.vuw.ac.nz/other-sources/i-cant-breathe-examines-modern-policinglife/docview/1954001696/se-2?accountid=14782

Guha, Pallavi. "Hash Tagging But Not Trending: The Success and Failure of The News Media to Engage with Online Feminist Activism in India." Feminist Media Studies 15, no. 1 (2014): 155-157. doi: 10.1080/14680777.2015.987424.

Hall, Stuart. Representation: Cultural Representations and Signifying Practices. London, Thousand Oaks: Sage in Association with Open University, 1997.

Hall, David. "We must recognise racism in NZ before we can put it right." Stuff. 24 April, 2019. https://www.stuff.co.nz/national/christchurch-shooting/112212972/we-mustrecognise-racism-in-nz-before-we-can-put-it-right . "How the Christchurch Principles will fight the spread of hate." The Spinoff. 19 March, 2021. https://thespinoff.co.nz/society/12-11-2019/how-the-christchurch-principleswill-fight-the-spread-of-hate/.

Hancox, Donna. "From Subject to Collaborator: Transmedia Storytelling and Social Research." Convergence 23, no. 1 (2017): 49-60. doi: 10.1177/1354856516675252

Hanisch, Carol. "The Personal Is Political," in Notes From the Second Year: Women's Liberation, eds. Firestone and Koedt. US, New York: Published by Editors, 1970.

Harris-DeBerry, Kelly, Denese Shervington and Rashida Govan "Crooked Room: Stories from New Orleans.” Institute of Women and Ethnic Studies. 13 April, 2021. https://static1.squarespace.com/static/59f78bfbf43b558afe23e48a/t/5a84ac1be4966b 15dd8840b8/1518644264742/crooked-room_final_web.pdf

Harris-Perry, Melissa V. Sister Citizen: Shame, Stereotypes, and Black Women in America. New Haven: Yale University Press, 2011. 
Hayes, Kecia, Shirley R. Steinberg, and Tobin Kenneth. Key Works in Critical Pedagogy. 1st ed. Rotterdam: Sense Publishers, 2011.

Hawkesworth, Mary. "Knowers, Knowing, Known: Feminist Theory and Claims of Truth." Signs: Journal of Women in Culture and Society 14, no. 3 (1989): 533-557. doi: 10.1086/494523

_- - "Truth and Truths in Feminist Knowledge Production: Positivist and Feminist Conceptions of Objectivity" in Handbook of Feminist Research: theory and praxis, ed, Sharlene Nagy Hesse-Biber Thousand Oaks, California: SAGE publications, 2012.

"Headscarves Movement Means Well but It Is 'cheap tokenism."' Stuff, 22 March 2019. https://www.stuff.co.nz/national/christchurch-shooting/111473440/headscarvesmovement-means-well-but-it-is-cheaptokenism?utm_source=dlvr.it\&utm_medium=twitter

Hemmings, Clare. "Affective Solidarity: Feminist Reflexivity and Political Transformation." Feminist Theory 13, no. 2 (2012): 147-61. doi: 10.1177/1464700112442643.

Hennell, Kath, Mark Limmer, and Maria Piacentini. "Ethical Dilemmas Using Social Media in Qualitative Social Research: A Case Study of Online Participant Observation." Sociological research online 25, no. 3 (2020): 473-489. doi: 10.1177/1360780419888933

Herr, Kathryn G, and Gary L Anderson. Action Research Dissertation: A Guide for Students and Faculty. Los Angeles: SAGE Publications, 2005. doi: 10.4135/9781452226644

Hess, Amanda. “\#IAm.” Slate. 9 January, 2015. http://www.slate.com/articles/news_and_politics/politics/2015/01/_jesuischarlie_the_d efault_mode_of_showing_solidarity_in_the_hashtag_age.html.

Hesse-Biber, Sharlene Nagy. Handbook of feminist research: Theory and praxis. 2nd ed. Thousand Oaks, California: SAGE publications, 2012. doi: 10.4135/9781483384740

hooks, bell. Ain't I a Woman: Black Women and Feminism. London: Routledge, 2015. doi: 10.4324/9781315743264

- - B Black Looks: Race and Representation. New York: Routledge, 2015.

-_- Talking Back: Thinking Feminist, Thinking Black Boston. MA: South End Press, 1989.

Hu, Jane. "The Second Act of Social-Media Activism." The New Yorker. 3 August, 2020. https://www.newyorker.com/culture/cultural-comment/the-second-act-of-socialmedia-activism

Hunt, Paul. "Tackling racism, islamophobia and hate in New Zealand.” New Zealand Human Rights Commission. 18 March, 2021. https://www.hrc.co.nz/news/tackling-racismislamophobia-and-hate-new-zealand/

Hutchby, Ian. “Technologies, Texts and Affordances." Sociology (Oxford) 35, no. 2 (2001): 441456. doi: $10.1177 /$ S0038038501000219 
Hutchison, Emma. Affective Communities in World Politics: Collective Emotions after Trauma. New York: Cambridge University Press, 2016.

Hutchison, Emma, and Roland Bleiker. "Theorizing Emotions in World Politics." International theory 6, no. 3 (2014): 491-514. doi: 10.1017/S1752971914000232

International Telecommunications Union, "ITU Facts and Figures 2020.” 31 July 2020, https://www.itu.int/en/ITU-D/Statistics/Documents/facts/FactsFigures2020.pdf

Iosifidis, Petros, and Mark Wheeler. Public Spheres and Mediated Social Networks in the Western Context and Beyond. London: Palgrave Macmillan UK, 2016. doi: 10.1057/978-1-13741030-6.

Jackson, Sarah J., Moya Bailey, and Brooke Foucault Welles. \#HashtagActivism: Networks of Race and Gender Justice. Cambridge, MA: The MIT Press, 2020.

Jackson, Sarah J., and Brooke Foucault Welles. "Hijacking \#myNYPD: Social Media Dissent and Networked Counterpublics." Journal of Communication 65, no. 6 (2015): 932-952. doi: 10.1111/jcom.12185

Jackson Sarah J., and Sonia Banaszczyk, "Digital Standpoints: Debating Gendered Violence and Racial Exclusions in the Feminist Counterpublic." Journal of Communication Inquiry 40, no. 4 (2016): 391-407. doi: 10.1177/0196859916667731

Jenkins, Henry, Sam Ford, and Joshua Green. Spreadable Media - Creating Value and Meaning in a Networked Culture. New York: New York University Press 2013.

Jones, Alison. "The Limits of Cross-Cultural Dialogue: Pedagogy, Desire, and Absolution in the Classroom." Educational Theory 49, no. 3 (1999): 299-316. doi: 10.1111/j.17415446.1999.00299.x.

Jones, Steve, Doing Internet Research: Critical Issues and Methods for Examining the Net. Thousand Oaks, California: Sage Publications, 1999.

Kaun, Anne. "Regimes of Time: Media Practices of the Dispossessed." Time \& Society 24, no. 2 (2015): 221-43. doi: 10.1177/0961463X15577276.

Kendall, Mikki, Hoodfeminism: Notes from the women that a movement forgot. New York: Penguin Books, 2020.

Khazraee, Emad, and Alison N. Novak. "Digitally Mediated Protest: Social Media Affordances for Collective Identity Construction." Social Media \& Society 4 no.1 (2018): 1-14. doi: $10.1177 / 2056305118765740$.

Kirchner, Lauren. "When Discrimination Is Baked Into Algorithms." The Atlantic. 7 September, 2015. https://www.theatlantic.com/business/archive/2015/09/discriminationalgorithms-disparate-impact/403969/ . 
Kincheloe, Joe, L. and Peter McLaren. "Reflecting on Critical Theory and Qualitative Research," in The Landscape of Qualitative Research, eds. N. Denzin and Y Lincoln CA, California: Sage, 2003.

King, Dewitt. "Black Software: The Internet and Racial Justice, from the AfroNet to Black Lives Matter by Charlton D. Mcllwain, and: Distributed Blackness: African American Cybercultures by André Brock Jr. (review)." The Velvet Light Trap 86, no.1 (2020): 69-71.

Kuntsman, Adi. "Digital Archives of Feelings and Their Haunted Futures." Borderlands 10, no. 2 (2011).

Kuo, Rachel. "Racial Justice Activist Hashtags: Counterpublics and Discourse Circulation." New Media \& Society 20, no. 2 (2018): 495-514. doi: 10.1177/1461444816663485.

Lesage, Frédérik and Louis Rinfret, "Shifting Media Imaginaries of the Web," First Monday 20, no. 10 (2015) doi: 10.5210/fm.v20i10.5519

Linklater, Andrew. "Grand Narratives and International Relations." Global Change, Peace \& Security 21, no. 1 (2009): 3-17. doi.10.1080/14781150802659234.

_-_. "Distant Suffering and Cosmopolitan Obligations." International Politics 44, no.1 (2007): 19-36. doi: 10.1057/palgrave.ip.8800156

Loken, Meredith. "\#Bringbackourgirls and the Invisibility of Imperialism." Feminist Media Studies 14, no. 6 (2014): 1100-1101. doi: 10.1080/14680777.2014.975442

Longhofer, Jeffrey, Jerry Floersch, and Eric Hartmann, "A Case for the Case Study: How and Why They Matter," Clinical Social Work Journal 45, no. 3 (2017): 189-200, doi: 10.1007/s10615-017-0631-8

Maddison Sarah and Frances Shaw, "Feminist Perspectives on Social Movement Research." in Handbook of Feminist Research: theory and praxis, ed, Sharlene Nagy Hesse-Biber. Thousand Oaks: SAGE Publications Inc, 2012. doi: 10.4135/9781483384740.n19

Mager, Astrid. "Algorithmic Ideology: How Capitalist Society Shapes Search Engines." Information, Communication \& Society: 15, no. 5 (2012): 769-87. doi: 10.1080/1369118X.2012.676056.

Maragh, Raven S. “Authenticity on 'Black Twitter': Reading Racial Performance and Social Networking." Television \& New Media 19, no. 7 (2018): 591-609. doi: $10.1177 / 1527476417738569$.

Matamoros-Fernández, Ariadna. "Platformed Racism: The Mediation and Circulation of an Australian Race-Based Controversy on Twitter, Facebook and YouTube," Information, Communication \& Society 20, no. 6 (2017): 930-46, doi: 10.1080/1369118X.2017.1293130.

Mathes, Adam. "Folksonomies- Cooperative Classification and Communication Through Shared 
Metadata." Computer Mediated Communication. December 2004.

https://adammathes.com/academic/computer-mediated-

communication/folksonomies.html

Maxfield, Mary. "History Retweeting Itself: Imperial Feminist Appropriations of 'Bring Back Our Girls."' Feminist Media Studies 16, no. 5 (2016): 886-900.

doi: 10.1080/14680777.2015.1116018.

Tess McClure, "They Are Us: controversial film about Christchurch attack put on hold." The Guardian. 23 July 2021. https://www.theguardian.com/film/2021/jul/23/they-are-uscontroversial-film-about-christchurch-attacks-put-on-hold

McLachlan, Leigh-Marama. "Christchurch Mosque Attack: Māori Leaders Say Acts of Terror Nothing New in New Zealand." Radio New Zealand. 21 March, 2019. https://www.rnz.co.nz/news/national/385226/christchurch-mosque-attacks-maorileaders-say-acts-of-terror-nothing-new-in-new-zealand

McVeigh-Schultz, Joshua, and Nancy Baym. "Thinking of you: Vernacular affordance in the context of the microsocial relationship app, couple. " Social Media + Society, 1 no. 2 (2015): $1-13$. doi: $10.1177 / 2056305115604649$.

McVey, James Alexander, and Heather Suzanne Woods, "Anti-racist Activism and the Transformational Principles of Hashtag Publics: From \#HandsUpDontShoot to \#PantsUpDonetLoot." Present Tense. 2 March, 2016. https://www.presenttensejournal.org/volume-5/anti-racist-activism-and-thetransformational-principles-of-hashtag-publics-from-handsupdontshoot-topantsupdontloot/

Mead, Sidney M. Tikanga Mãori: Living by Māori Values. Wellington, Aotearoa, New Zealand: Huia Publishers, 2016.

Mendes, Kaitlynn, Jessica Ringrose, and Jessalynn Keller. \#MeToo and the promise and pitfalls of challenging rape culture through digital feminist activism. European Journal of Women's Studies 25 no. 2 (2018):236-246. doi: 10.1177/1350506818765318

Messina, Chris. "Groups for Twitter; or A Proposal for Twitter Tag Channels. " Medium. 26 August 2007. https://medium.com/chris-messina/groups-for-twitter-or-a-proposal-fortwitter-tag-channels-5b8eb08adff8.

Melo, Manuel Coelho de. "On Serendipity in the Digital Medium: Towards a Framework for Valuable Unpredictability in Interaction Design." PhD dissertation, Universidade do Porto, (2018).

Morozov, Evgeny. The Net Delusion : The Dark Side of Internet Freedom. US, New York: Public Affairs, 2011.

Naaman, Mor, Jeffrey Boase, and Chih-Hui Lai. "Is It Really about Me?: Message Content in 
Social Awareness Streams," In Proceedings of the 2010 ACM Conference on Computer Supported Cooperative Work (2010): 189-192, doi: 10.1145/1718918.1718953.

Nagy, Peter, and Gina Neff. "Imagined Affordance: Reconstructing a Keyword for Communication Theory." Social Media + Society 1, no.2 (2015): 1-9. doi: $10.1177 / 2056305115603385$.

Nasr, Hala. "Islamophobia: A Personal Reflection." The Pantograph Punch. 23 March, 2019. https://www.pantograph-punch.com/posts/islamaphobia-a-personal-reflection.

Ohlheiser, Abby. "How K-Pop fans because celebrated online vigilantes." MIT Technology Review. 5 June, 2020 https://www.technologyreview.com/2020/06/05/1002781/kpopfans-and-black-lives-matter/

New Zealand Herald. "Gay couples reclaim far-right group 'Proud Boys' Hashtag." 4 October, 2020. https://www.nzherald.co.nz/lifestyle/gay-couples-reclaim-far-right-group-proudboys-hashtag/RSJORAAIJXANW36K4SC2ZGVN3I/

New Zealand Human Rights Commission, "About The Campaign: That's Us is a campaign by the Human Rights Commission to combat racism." 18 March, 2021.

https://www.thatsus.co.nz/about

-_—."That Us." 18 March, 2021. http://www.thatsus.co.nz/

———. “New Campaign says 'Give No Voice To Racism.” 18 March, 2021. https://www.hrc.co.nz/news/new-campaign-says-give-no-voice-racism/ ."Reflections on the Report of the Royal Commission of Inquiry into the terrorist attack on Christchurch Masjidain on 15th March 2019," accessed 21 October 2021. https://www.hrc.co.nz/files/3716/1588/7040/HRC_Reflections_on_the_report_of_the_ RCI_on_terrorist_attacks_on_Christchurch_Masjidain_FINAL.pdf

. "Whenever A Siren Went Off I Remember Schoolmates Saying That The Cops Were Coming For Me Because I'm Māori: Kingi Snelgar.” 19 March, 2021. https://www.thatsus.co.nz/kingi-snelgar

"Nine Bullets: A Survivor's Story," Stuff. Accessed 12 October 2021, https://interactives.stuff.co.nz/2020/03/nine-bullets/

Noble, Safiya Umoja. Algorithms of Oppression: How Search Engines Reinforce Racism, New York University Press, 2018.

Papacharissi, Zizi. Affective Publics: Sentiment, Technology, and Politics. New York: Oxford University Press, 2014.

- _- "Without You, I'm Nothing: Performances of the Self on Twitter." International journal of communication (Online) 16 July, 2012: 1-12.

Papailias, Penelope. “(Un)Seeing Dead Refugee Bodies: Mourning Memes, Spectropolitics, and the Haunting of Europe." Media, Culture \& Society 41 no.8 (2018): 1048-1068. doi: $10.1177 / 0163443718756178$.

- - - "Witnessing in the Age of the Database: Viral Memorials, Affective Publics, and the Assemblage of Mourning." Memory Studies 9, no. 4 (2016): 437-54. 
doi: $10.1177 / 1750698015622058$.

Pettiford-Wates, Tawnya. “The Crooked Room. Not Just a Theory."Urban Views, 19 March, 2021. https://urbanviewsrva.com/2016/11/29/the-crooked-room-not-just-a-theory/

Punday Daniel. "The Narrative Construction of Cyberspace: Reading Neuromancer, Reading Cyberspace Debates." College English 63, no. 2 (2000): 194-213. doi: 10.2307/379040

Rahman, Anjum. "We Warned You. We Begged. We Pleaded. And Now We Demand Accountability." The Spinoff. 17 March, 2019. https://thespinoff.co.nz/society/17-032019/we-warned-you-we-begged-we-pleaded-and-now-we-demand-accountability/.

_-_. .The Internet After Christchurch" Panel Net Hui NZ. 3 October, 2019. https://nethui2019.sched.com/event/Scud/panel-the-internet-after-christchurch

Rasheed, Pakeeza "I am a Muslim New Zealand women and I am as angry as I am sad." Vice. 17 March, 2019. https://www.vice.com/en_nz/article/8xy34p/i-am-a-muslim-new-zealandwoman-and-i-am-as-angry-as-i-am-sad

Ratcliffe, Krista. Rhetorical Listening: Identification, Gender, Whiteness. Carbondale: Southern Illinois University Press, 2005.

Reid, Nova. "No More White Saviours Thanks: how to be a true anti-racist ally." The Guardian. 19 September, 2021. https://www.theguardian.com/world/2021/sep/19/no-morewhite-saviours-thanks-how-to-be-a-true-anti-racist-ally

Reinharz, Shulamit, and Lynn Davidman. Feminist Methods in Social Research. New York: Oxford University Press, 1992.

Reiser, Stanley. “The Culture of Technology." Social Science and Medicine 21, no. 5 (1985): 597. doi: 10.1016/0277-9536(85)90048-6.

Reynolds, Ann, Janet Staiger, and Ann Cvetkovich. Political Emotions. New York: Routledge, Taylor and Francis, 2010. doi: 10.4324/9780203849538.

Resmini, Andrea and Luca Rosati. "A Brief history of Information Architecture." Journal of Information Architecture 3, no. 2 (2011): 33-45.

Risam, Roopika. New Digital Worlds Postcolonial Digital Humanities in Theory, Praxis, and Pedagogy. Evanston, Illinois: Northwestern University Press, 2019.

Rodino-Colocino, Michelle. "Me Too, \#MeToo: Countering Cruelty with Empathy." Communication and Critical/Cultural Studies 15, no. 1 (2018): 96-100. doi: 10.1080/14791420.2018.1435083.

Royal Commission of New Zealand. "Inquiry into the Terrorist Attack on Christchurch Mosques on 15 March 2019: What communities told us about the boarder context in which the terrorist attack occurred." Accessed 7 November 2021. https://christchurchattack.royalcommission.nz/the-report/voices-of-the- 
community/what-communities-told-us-about-the-broader-context-in-which-theterrorist-attack-occurred/

Rubin, Herbert, and Irene Rubin. Qualitative Interviewing: the Art of Hearing Data. Thousand Oaks, Calif: Sage Publications, 2005. 19-38, doi: 10.4135/9781452226651.n2.

Ruha, Race after Technology: Abolitionist Tools for the New Jim Code. Polity, 2019.

Rusert, Britt, and Whitney Battle-Baptiste. W. E. B. Du Bois's Data Portraits: Visualizing Black America. New York: Princeton Architectural Press, 2018.

Samakoti, Tejaree, Shaik Naserra, and Tella Pramila. "Perception of Trend Topic in Twitter: A Case Study," I-Manager's Journal on Software Engineering 11, no. 4 (2017): 12-17. doi: 10.26634/jse.11.4.13816.

Santhanam, Laura, Vanessa Dennis and Travis Daub. "What Do the Newly Released Witness Statements Tell Us about the Michael Brown Shooting." PBS. 16 March, 2021. https://www.pbs.org/newshour/nation/newly-released-witness-testimony-tell-us-michaelbrown-shooting.

Schick, Kate. "Unsettling Pedagogy: Recognition, Vulnerability, and the International." in Recognition and Global Politics: Critical Encounters Between State and World. ed. Patrick Hayden and Kate Schick Manchester: Manchester University Press, 2016.

Seib, Philip. The Future of \#Diplomacy. Cambridge: Polity, 2016.

Sharma, Sanjay. "Black Twitter? Racial Hashtags, Networks and Contagion." New formations 78, no. 78 (2013): 46-64. doi: 10.3898/NEWF.78.02.2013

Sills, Liz. "Hashtag Comedy: From Muslim Rage to \#Muslimrage." ReOrient 2, no. 2 (2017): 160174. doi: 10.13169/reorient.2.2.0160.

Smith, Aaron. "Mobile Access 2010," Pew Internet and American Life Project. accessed 14 September, 2021 https://www.pewresearch.org/internet/2010/07/07/mobile-access2010/

Solomon, Ty and Brent J. Steele, "Micro-moves in International Relations theory," European Journal of International Relations 23 no. 2 (2017): 277, doi: $10.1177 / 13540661166344442$.

Sonderby, Chris. "Update on New Zealand." Facebook. 18 March, 2019. https://about.fb.com/news/2019/03/update-on-new-zealand/

Spelman, Elizabeth. "Managing Ignorance." in Race and Epistemologies of Ignorance, ed. Shannon Sullivan and Nancy Tuana. Ithaca: State University of New York Press, 2007. 119131. 
Stanfill, Mel. "The Interface as Discourse: The Production of Norms through Web Design." New media \& society 17, no. 7 (2015): 1059-1074. doi: 10.1177/1461444814520873.

Snow, David, and Danny Trom. "The case study and the study of social movements." in Methods of social movement research, ed, B. Klandermans and S. Staggenborg. Minneapolis: University of Minnesota Press, 2002.

Strauss, Anselm L., and Juliet M. Corbin. Basics of Qualitative Research: Grounded Theory Procedures and Techniques. Newbury Park, California: Sage Publications, 1990.

Sweeney, Miriam. "Not Just a Pretty (Inter)Face: A Critical Analysis of Microsoft's 'Ms. Dewey.'” PhD Dissertation, University of Illinois, 2013.

Sweeney, Miriam, and André Brock. "Critical Informatics: New Methods and Practices." Proceedings of the American Society for Information Science and Technology 51, no. 1 (2014): 1-8.

doi: 10.1002/meet.2014.14505101032.

Tejasree, Samakoti, Shaik Naseera, and Tella Pramila. Perception of a trend topic of Twitter: A case study i-Manager's Journal on Software Engineering 11, no. 4 (2017) 12-17. doi: $10.26634 /$ jse.11.4.13816

Timberg, Craig, Drew Harwell, Hamza Shaban, Andrew Ba Tran, and Brian Fung. "The New Zealand shooting shows how Youtube and Facebook spread hate and violent images - yet again." The Washington Post. 16 March, 2019. https://www.washingtonpost.com/technology/2019/03/15/facebook-youtube-twitteramplified-video-christchurch-mosque-shooting/

The National Islamic Youth Association, "Shut Down 'They Are Us' Movie, which side-lines victims of the March 15th terrorist attack." Change Org. accessed 12 October 2021. https://www.change.org/p/filmnation-entertainment-shut-down-they-are-us-moviewhich-side-lines-victims-of-the-march-15th-terrorist-attack

"They Are Us: A memorial to the victims of the 15 March 2019 Christchurch terror attacks," Radio New Zealand. Accessed 12 October 2021, https://shorthand.radionz.co.nz/they-areus/index.html.

“They are us. They? Them? Those?” Villainesse. 20 March, 2019. https://www.villainesse.com/no-filter/they-are-us-they-them-those

Thompson, Ben. “A Framework for Moderation," Stratechery. 7 August, 2019, https://stratechery.com/2019/a-framework-for-moderation/

Thurman Neil. "Making 'The Daily Me': Technology, economics and habit in the mainstream assimilation of personalized news." Journalism 12, no. 4 (2011): 395-415. doi:10.1177/1464884910388228

Tripp, Aili. "Retheorizing Human Security through a gender lens." in Gender Violence, and Human Security: Critical Feminist Perspectives, ed. Ali Tripp, Myra Marx Ferree, and Christina Ewig. New York: NYU Press, 2013. 
Tuana, Nancy. “The Speculum of Ignorance: The Women's Health Movement and Epistemologies of Ignorance." Hypatia 21, no. 3 (2006): 1-19. doi: 10.1111/j.15272001.2006.tb01110.x.

Townsend, Leanne, and Claire Wallace. "The Ethics of Using Social Media Data in Research: A New Framework." In The Ethics of Online Research, 2 (2017): 189-207. doi: 10.1108/S2398-601820180000002008

Tufekci, Zeynep. Twitter and Tear Gas: the power and fragility of networked protest. New Haven, Yale University Press, 2017.

- - - "What Happens to \#Ferguson Affects Ferguson: Net Neutrality, Algorithmic Filtering and Ferguson." Medium. 16 March, 2021. https://medium.com/message/ferguson-isalso-a-net-neutrality-issue-6d2f3db51eb0\#.rj1vniwdq.

_-_."New Media and the People-Powered Uprisings." MIT Technology Review, 30 August, 2011 https://www.technologyreview.com/2011/08/30/191614/new-media-and-thepeople-powered-uprisings/

Twitter. "To trend or not to trend." 19 March, 2021. https://blog.twitter.com/official/en_us/a/2010/to-trend-or-not-to-trend.html

_-_. "What is a Promoted Trend."19 March, 2021. https://business.twitter.com/en/advertising/takeover/promoted-trend.html

UNESCO, "I'd blush if I could: Closing gender divides in digital skills through education." United National Scientific and Cultural Organisation. 20 January, 2021. https://en.unesco.org/Id-blush-if-I-could

Union, International Telecommunications. "ITU Facts and Figures 2017.” 27 August, 2018. https://www.google.com/url?q=https://www.itu.int/en/ITUD/Statistics/Pages/facts/default.aspx\&sa=D\&ust=1535323845185000\&usg=AFQjCNGfT 1SpQM-I1yJ9_8PEgYS_f3vmdA.

“United Nations Special Rapporteur for Freedom of Expression," United Nations General Assembly Report, 9 October 2019 https://www.ohchr.org/Documents/Issues/Opinion/A_74_486.pdf

Van Couvering, Elizabeth. The History of the Internet Search Engine: Navigational Media and the Traffic Commodity. Information Science and Knowledge Management. Berlin: Springer, 2008.

Vitak, Jessica, Nicholas Proferes, Katie Shilton, Zahra Ashktorab. Ethics Regulation in Social Computing Research: Examining the Role of Institutional Review Boards. Journal of Empirical Research on Human Research Ethics. 2017;12(5): 372-382. doi: $10.1177 / 1556264617725200$.

Ward, Colleen, and James Liu. "Ethno-Cultural Conflict in Aotearoa/New Zealand: Balancing Indigenous Rights and Multicultural Responsibilities." in Handbook of Ethnic Conflict, eds., Dan Landis and Rosita D. Albert. MA, Boston: Springer US, 2011. 45-69. doi: 10.1007/978- 
1-4614-0448-4_3.

Watson, Janell. “Butler's Biopolitics: Precarious Community.” Theory \& Event 15, no. 2 (2012).

Wellman, Barry. “Computer Networks as Social Networks.” Science 293, no. 5537 (2001): 2031-34. doi: 10.1126/science.1065547.

Wellman, Barry, Anabel Quan-Haase, Jeffrey Boase, Wenhong Chen, Keith Hampton, Isabel Díaz, and Kakuko Miyata. "The Social Affordances of the Internet for Networked Individualism." Journal of Computer-Mediated Communication 8, no. 3 (2003). doi: 10.1111/j.1083-6101.2003.tb00216.x

Wendell, Susan. "Toward a Feminist Theory of Disability." Hypatia 4, no. 2 (1989): 104-24. doi: 10.1111/j.1527-2001.1989.tb00576.x.

"Widows of Shuhada," Radio New Zealand. Accessed 12 October 2021, https://www.rnz.co.nz/programmes/widows-of-shuhada

William, Lafi Youmans, and Jillian C .York, "Social Media and the Activist Toolkit: User Agreements, Corporate Interests, and the Information Infrastructure of Modern Social Movements," Journal of Communication 62, no. 2 (2012): 316-325. doi: 10.1111/j.14602466.2012.01636.x.

Williams, Matthew L., Pete Burnap, and Luke Sloan. "Towards an Ethical Framework for Publishing Twitter Data in Social Research: Taking into Account Users' Views, Online Context and Algorithmic Estimation." Sociology (Oxford) 51, no. 6 (2017): 1149-1168. doi: $10.1177 / 0038038517708140$

Wilson. Chris. "uknowurblack," The Root, accessed 16 September, 2021. https://www.theroot.com/uknowurblack-1790870196.

Woods, Heather, and James A. McVey. "\#BlackLivesMatter as A Case Study in the Politics of Digital Media: Algorithms, Hashtag Publics, and Organizing Protest Online." Teaching Media Quarterly 4, no. 1 (2016).

Wynyard, Matt. "Plunder in the Promised Land A Land of Milk and Honey?: Making Sense of Aotearoa New Zealand." edited by Avril Bell, et al., Auckland University Press, 2017.

Xenos, Michael, Ariadne Vromen, and Brian D. Loader. "The Great Equalizer? Patterns of Social Media Use and Youth Political Engagement in Three Advanced Democracies." Information, communication \& society 17, no. 2 (2014): 151-167. doi: 10.1080/1369118X.2013.871318

Youmans, William Lafi, and Jillian C. York. "Social Media and the Activist Toolkit: User Agreements, Corporate Interests, and the Information Infrastructure of Modern Social Movements." Journal of communication 62, no. 2 (2012): 315-329. doi: 10.1111/j.14602466.2012.01636.x 
Zehfuss, Maja. Wounds of Memory: The Politics of War in Germany. UK Cambridge: Cambridge University Press, 2009. doi:10.1017/CBO9780511551109. 
